Universidad deValladolid

PROGRAMA DE DOCTORADO EN INGENIERÍA INDUSTRIAL

\author{
TESIS DOCTORAL:
}

\title{
CONTROL SYSTEMS OF OFFSHORE HYDROGEN PRODUCTION BY RENEWABLE ENERGIES
}

Presentada por Álvaro Serna Cantero para optar al grado de

Doctor por la Universidad de Valladolid

Dirigida por:

Fernando Juan Tadeo Rico 

Álvaro Serna Cantero

\section{CONTROL SYSTEMS OF OFFSHORE HYDROGEN PRODUCTION BY RENEWABLE ENERGIES}

Tese de doutorado submetida ao Programa de Pós-Graduação em Engenharia de Automação e Sistemas para a obtenção do Grau de doutor em Engenharia de Automação e Sistemas pela Universidade Federal de Santa Catarina (UFSC) e em Engenharia Industrial pela Universidad de Valladolid (UVA) em regime de cotutela.

Orientadores:

Prof. Fernando Juan Tadeo Rico (UVA).

Prof. Julio Elías Normey-Rico (UFSC)

Florianópolis

2018 
Ficha de identificação da obra elaborada pelo autor, através do Programa de Geração Automática da Biblioteca Universitária da UFSC.

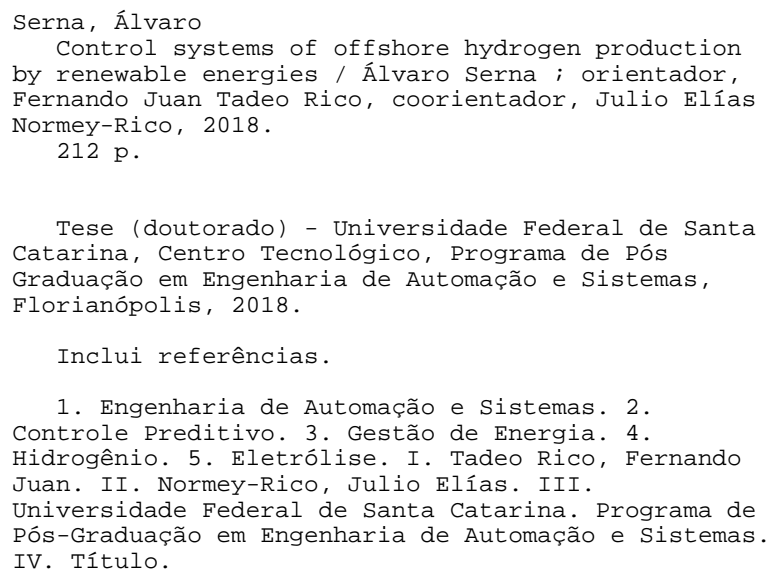




\section{CONTROL SYSTEMS OF OFFSHORE HYDROGEN PRODUCTION BY RENEWABLE ENERGIES}

Esta Tese foi julgada adequada para obtenção do Título de "Doutor em Engenharia de Automação e Sistemas", e aprovada em sua forma final pelo Programa de Pós-Graduação em Engenharia de Automação e Sistemas da Universidade Federal de Santa Catarina e pelo Programa de Ingeniería Industrial da Universidad de Valladolid (Espanha).

Florianópolis, 26 de Fevereiro de 2018.

Prof. Daniel Coutinho

Coordenador do Curso

Universidade Federal de Santa Catarina

\section{Banca Examinadora}

Prof. Daniel Coutinho

Universidade Federal de

Santa Catarina
Prof. Carlos Bordons Alba

Universidad de Sevilla

Prof. Jorge O. Trierweiler

Universidade Federal do Río

Grande do Sul 

Este trabajo está dedicado a mi familia y a todos los que me han apoyado durante los años de tesis. 



\section{AGRADECIMIENTOS}

In these lines I want to remember and thank all the people that have contributed to this thesis in some way.

This thesis would not have been possible without the help of my advisors, Fernando Tadeo and Julio E. Normey Rico. I want to thank them for their tremendous dedication, their motivational skills and their effort spent in helping me with valuable comments and advice, and for guiding me during these four years. I also want to thank my partners of the 'Departamento de Ingeniería de Sistemas y Automática' of the 'Universidad de Valladolid', and especially my colleagues José Luis, Carlos, Tania, Cristian, Pedro, María, Jacobo, Imene and Johanna for the good times in meetings and conferences. I wish them all the best.

I address my special thanks to the staff of the 'Departamento de Automação e Sistemas' of the 'Universidade Federal de Santa Catarina', particularly Vítor Mateus and André Tahim for always being nice and helpful.

I also want to remember and give thanks to José Gabriel García Clúa from the National University of La Plata, for the advices about hydrogen he suggested me.

I would also like to express my deepest gratitude to Félix García-Torres, for his advice and valuable contributions during my research stay in the $\mathrm{CNH} 2$, and also for his hospitality during my stay in Puertollano.

I also gratefully acknowledge the research grants program from the 'Universidad de Valladolid' and the 'Junta de Castilla y León' and the European Commission (7th Framework Programme, grant agreement 288145, Ocean of Tomorrow Joint Call 2011).

Y gracias a mi familia: a mi madre, a mi padre y a mi hermana por vuestro gran apoyo y ayuda incondicional.

Thank you,

Álvaro 

"The Stone Age did not end for lack of stone, and the Oil Age will end long before the world runs out of oil".

(William McDonough) 



\section{RESUMO ESTENDIDO}

Esta tese trata do projeto de um Sistema de Gestão de Energia (SGE), utilizando Controle Preditivo (Model Predictive Control - MPC) que busca equilibrar o consumo de energía renovável de um conjunto de unidades de eletrólise. A energia gerada na plataforma é equilibrada regulando o ponto de operação de cada unidade de eletrólise e suas conexões ou desconexões, usando um MPC baseado em um algoritmo de Programação Múltipla Inteira-Quadrática. Este algoritmo de Controle Preditivo permite levar em conta previsões de potência e consumo de energia disponível, melhorar o equilíbrio e reduzir o número de ligações e desconexões dos dispositivos. Diferentes estudos de caso são realizados em instalações compostas por unidades de geração de energia elétrica a partir da energía das ondas e do vento. Osmose reversa é considerada como um passo intermediário para a produção de agua que alimenta um conjunto de eletrolizadores. A validação utilizando dados medidos no local de destino das plataformas mostra o funcionamento adequado do SGE proposto. Além disso, a tese também apresenta o projeto de um sistema de controle a curto prazo (segundos) acoplado ao SGE em uma microgrid baseada no hidrogênio. Finalmente, é desenvolvido um estudo econômico dos componentes desta microgrid.

Palavras-chave: Energia Eólica. Energia das Ondas. Osmose Inversa. Hidrogênio. Eletrólise. Eletrolisador Alcalino. Modelo de Controle Preditivo. Sistema de Gestão de Energia. 



\section{RESUMEN}

Esta tesis trata sobre un proyecto de diseño de un Sistema de Gestión de Energía (SGE), utilizando Control Predictivo (Model Predictive Control - MPC) que busca equilibrar el consumo de energía renovable con un conjunto de unidades de electrólisis productoras de hidrógeno. La energía generada en la plataforma es equilibrada regulando el punto de operación de cada unidad de electrólisis y sus conexiones o desconexiones, usando un MPC basado en un algoritmo de Programación Mixta-Entera Cuadrática. Este algoritmo de Control Predictivo permite tomar en cuenta previsiones de potencia y consumo de energía disponible, mejorar el equilibrio y reducir el número de encendidos y apagados de los equipos. Diferentes casos de estudio son realizados en instalaciones compuestas por unidades de generación de energía eléctrica a partir de la energía de las olas y del viento. Se considera la técnica de ósmosis inversa como paso intermedio para la producción de agua que alimenta el conjunto de electrolizadores. La validación se realiza utilizando datos meteorológicos medidos en el lugar propuesto para el sistema, mostrando el funcionamiento adecuado del SGE propuesto. Además, la tesis también presenta el estudio de un sistema de control a corto plazo (segundos) acoplado al SGE en una micro red basada en hidrógeno. Finalmente, se desarrolla un estudio económico de los componentes de la micro red propuesta.

Palabras clave: Energía Eólica. Energía de las Olas. Ósmosis Inversa. Hidrógeno. Electrólisis. Electrolizador Alcalino. Modelo de Control Predictivo. Sistema de Gestión de Energía. 



\begin{abstract}
This thesis deals with the design of an Energy Management Systems (EMS), based on Model Predictive Control (MPC) to balance the consumption of renewable energy by a set of electrolysis units. The energy generated at the installation is balanced by regulating the operating point of each electrolysis unit and its connections or disconnections, using an MPC based on a Mixed-Integer-QuadraticProgramming algorithm. This Predictive Control algorithm makes it possible to take into account predictions of available power and power consumption, to improve the balance and reduce the number of connections and disconnections of the devices. For this, different case studies are carried out on installations composed of wave and wind energies. Reverse osmosis is considered as an intermediate step for water production which feeds a set of electrolyzers. Validation using measured data at the target location of the installations shows the adequate operation of the proposed EMS. In addition, the thesis also presents the design of a short term system control system (seconds) coupled to the EMS for the hydrogen-based microgrid. Finally an economic study of the components of this microgrid is developed.
\end{abstract}

Keywords: Wind Energy. Wave Energy. Reverse Osmosis. Hydrogen. Electrolysis. Alkaline Electrolyzer. Model Predictive Control. Energy Management System. 



\section{LIST OF FIGURES}

Figure 1.1 - H2OCEAN platform [http://www.h2ocean-project.eu/] .........29

Figure 1.2 - Participants in H2OCEAN project ..........................................30

Figure 2.1 - Share of US primary energy demand, 1780-2100...................36

Figure 2.2 - World map of wave energy flux in $\mathrm{kW}$ per meter wave

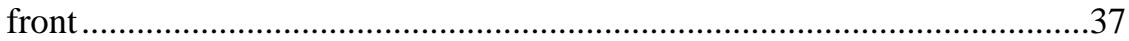

Figure 2.3 - Wave period in January in North Atlantic Ocean .....................37

Figure 2.4 - Wave height in January in North Atlantic Ocean .....................37

Figure 2.5 - Example of a WEC coupled with a VAWT (H2OCEAN) ........38

Figure 2.6 - Scheme of the WEC proposed in H2OCEAN...........................39

Figure 2.7 - Energy profile given by a 1.6 MW WEC using data of Fig.

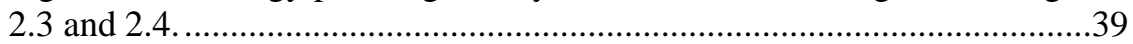

Figure 2.8 - Example of a WEC Power Matrix in 3D ...............................40

Figure 2.9 - Example of a 30-100kW Vertical Axes Wind Turbine in

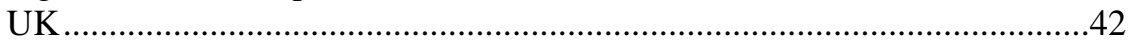

Figure 2.10 - Wind speed in January in North Atlantic Ocean....................42

Figure 2.11 - Energy profile given by a 5 MW VAWT using the data of

Figure 2.10

Figure 2.12 - Energy profile given by the VAWT developed in the H2OCEAN project. .............................................................................43

Figure 2.13 - Industrial Reverse Osmosis system.....................................44

Figure 2.14 - Transport of water through an RO membrane ......................45

Figure 2.15 - Hydrogen-based car (Toyota Mirai). ....................................47

Figure 2.16 - Steam reforming of natural gas ........................................48

Figure 2.17 - Partial oxidation process scheme ........................................49

Figure 2.18 - Coal gasification process scheme ......................................50

Figure 2.19 - Scheme of the electrolysis reaction......................................52

Figure 2.20 - Alkaline electrolyzer stack ...............................................53

Figure 2.21 - PEM electrolyzer module …...........................................55

Figure 2.22 - PEM stack module .........................................................55

Figure 2.23 - Model Predictive Control (MPC) scheme..............................57

Figure 2.24 - Receding horizon scheme …...........................................58

Figure 3.1 - Structure of the proposed desalination installation ..................68

Figure 3.2 - Structure of the first case study ...........................................69

Figure 3.3 - Proposed $\mathrm{EMS}_{\mathrm{W}}$ for the first case study .................................71

Figure 3.4 - Sequential Function Chart of the Control Logic of the RO .....72

Figure 3.5 - Detail of the Sequential Function Chart (Stage A) ..................73

Figure 3.6 - Scheme of the sizing for the first case study...........................75

Figure 3.7 - Effect of battery capacity $\left(\mathrm{C}_{\mathrm{P}}\right)$ on system performance $\left(\mathrm{V}_{\mathrm{S}}\right.$ $5500 \mathrm{~m}^{3}$ ). 
Figure 3.8 - Effect of seawater tank volume $\left(\mathrm{V}_{\mathrm{S}}\right)$ on system

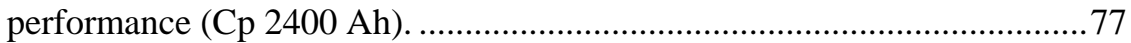

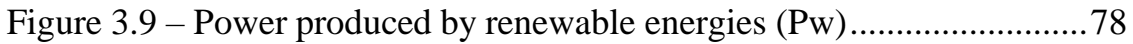

Figure 3.10 - Fresh water produced $\left(\mathrm{Q}_{\mathrm{F}}\right)$ in each RO section .....................79

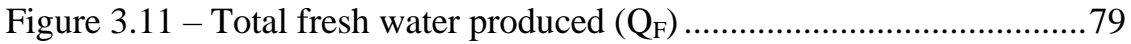

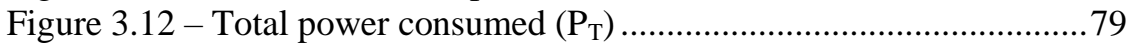

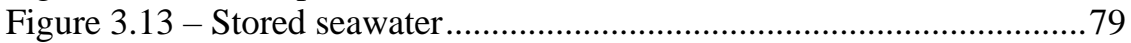

Figure 3.14 - \% Battery charge 100\%(1-DOD)............................................ 80

Figure 3.15 - Structure of the second case study ..................................... 81

Figure 3.16 - Scheme of the proposed $\mathrm{EMS}_{\mathrm{W}}$ for the second case study ....82 Figure 3.17 - Power available $\left(\mathrm{P}_{\mathrm{W}}\right)$ and consumed $\left(\mathrm{P}_{\mathrm{T}}\right)$ by the

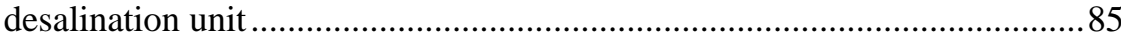

Figure 3.18 -Evaluation of the seawater tank level $\left(\mathrm{V}_{\mathrm{S}}\right)$............................85

Figure 3.19 - Evaluation of the fresh water tank level (BT1) .....................86

Figure 3.20 - Evaluation of the DEMI water tank level (BT2) ..................86

Figure 3.21 - Operation of the seawater pump (SWP) ............................. 86

Figure 3.22 - Operation of the first stage of the desalination unit

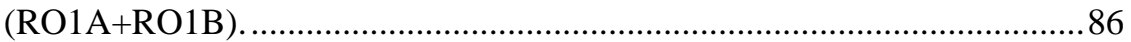

Figure 3.23 - Operation of the second stage of the desalination unit

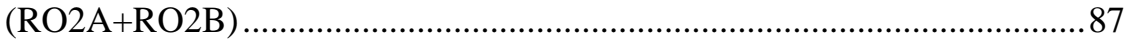

Figure 3.24 - Process diagram of the hydrogen plant............................... 88

Figure 3.25 - Converted power along time.............................................95

Figure 3.26 - Power consumed by the different sections in the

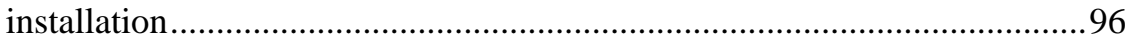

Figure 3.27 - Power balance (converted - consumed) ..............................96

Figure 3.28 - \% Batteries charge: 100\% (1 - DOD) ...............................96

Figure 3.29 - Hydrogen production in the installation ...............................96

Figure 3.30 - DEMI water tank level.......................................................97

Figure 4.1 - Block structure of the renewable hydrogen plant .................... 103

Figure 4.2 - Scheme of the controlled and manipulated variables .............. 104

Figure 4.3 - Ratio $\mathrm{H}_{2}$ produced/Power consumed at different $\alpha$............... 105

Figure 4.4 - Proposed $\mathrm{EMS}_{\mathrm{H}}$ based on MPC ideas.................................... 106

Figure 4.5 - Structure of the $\mathrm{EMS}_{\mathrm{H}}$ control algorithm...............................119

Figure 4.6 - A co-located hybrid VAWT-WEC device ............................... 120

Figure 4.7 - Meteorological predictions of wave period ............................. 121

Figure 4.8 - Meteorological predictions of wave height ........................... 121

Figure 4.9 - Meteorological predictions of wind speed..............................122

Figure 4.10 - Power available and consumed for the first case study .........123

Figure 4.11 - Operation of electrolyzer $i=1$ for the first case study. .........123

Figure 4.12 - Operation of electrolyzer $i=2$ for the first case study .......... 124

Figure 4.13 - Operation of electrolyzer $i=3$ for the first case study .......... 124 
Figure 4.14 - Hydrogen production for the first case study .......................125

Figure 4.15 - Power available and consumed for the second case study .....127

Figure 4.16 - Operation of electrolyzer $i=1$ for the second case study ......127

Figure 4.17 - Operation of electrolyzer $\mathrm{i}=2$ for the second case study ......127

Figure 4.18 - Operation of electrolyzer $i=3$ for the second case study ......128

Figure 4.19 - Operation of electrolyzer $i=4$ for the second case study ......128

Figure 4.20 - Operation of electrolyzer $i=5$ for the second case study ......128

Figure 4.21 - Operation of electrolyzer $i=6$ for the second case study ......129

Figure 4.22 - Hydrogen production for the second case study ....................129

Figure 5.1 - Coupling of the Long Term System with the Short Term

System for the hydrogen-based microgrid ...............................................135

Figure 5.2 - Components of the hydrogen-based microgrid ........................138

Figure 5.3 - Activation time $(\varphi)$ between the on/off state $(\delta)$ and the

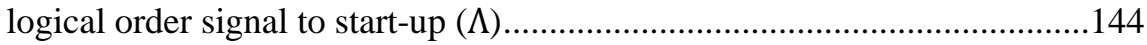

Figure 5.4 - Block diagram coupling the LTS and the STS........................146

Figure 5.5 - Hydrogen-based microgrid proposed in this case study ..........150

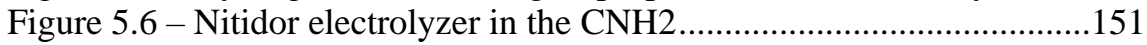

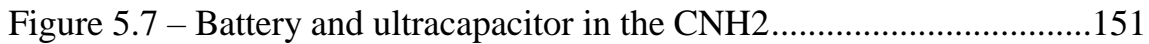

Figure 5.8 - Available renewable power profile ........................................152

Figure 5.9 - Operation of the electrolyzers (Elz $1=4 \mathrm{kWp}$, Elz $2=$

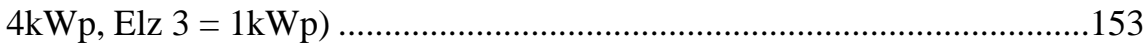

Figure 5.10 - Power exchange of the battery and ultracapacitor .................153

Figure 5.11 - Battery and ultracapacitor SOC .........................................154

Figure A.1 - Example of a hydrogen-based microgrid ..............................190

Figure A.2 - Smart house powered by renewable energies and a hydrogen-based microgrid in the $\mathrm{CNH} 2$, Spain .........................................191

Figure A.3 - Example of a Siemens PLC controller .....................................191

Figure A.4 - Possible customers of HyRenCon..........................................192

Figure A.5 - Scheme of a hydrogen-based microgrid for the case of the Phi Suea House in Thailand ....................................................................198

Figure A.6 - Benefits in the environment of a hydrogen-based microgrid for the case of the Phi Suea House in Thailand

Figure A.7 - Scheme of the components of the hydrogen-based

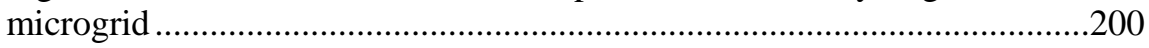

Figure A.8 - Investment for the HyRenCon company for the first five

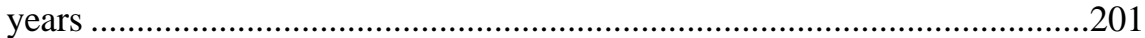

Figure A.9 - Financing for the HyRenCon company for the first five

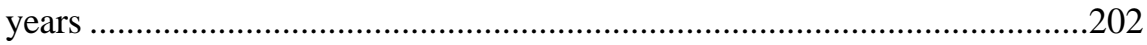

Figure A.10 - Sales for the HyRenCon company for the first five years.....202 
Figure A.11 - Purchases for the HyRenCon company for the first five years

Figure A.12 - Staff costs for the HyRenCon company for the first five

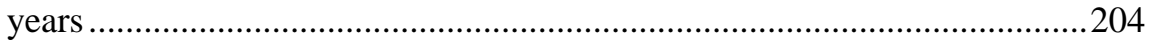

Figure A.13 - Gains and losses over the first five years.............................204 Figure A.14 - Gain and losses for the HyRenCon company for the first

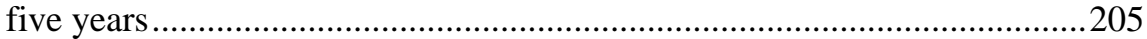




\section{LIST OF TABLES}

Table 1.1 - Conversion of logic relations into Mixed Integer Inequalities ..59

Table 3.1 - Selected operating point for the first case study ........................78

Table 3.2 - Parameters and consumptions of the second case study............87

Table 4.1 - MLD Inequalities transformed for this approximation...............114

Table 4.2 - Operation indices and consumptions of scenario 1 ...................129

Table 4.3 - Operation indices and consumptions of scenario 2 ..................134

Table 5.1 - List of the future predictions ...............................................146

Table 5.2 - List of the hydrogen microgrid measurements .........................146

Table 5.3 - List of the LTS variables........................................................147

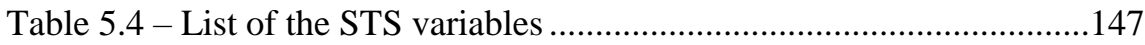

Table 5.5 - List of the model predictions..................................................147

Table 5.6 - List of the future predictions …….............................................154 


\section{LIST OF ABBREVIATIONS AND ACRONYMS}

AEMET - Agencia Estatal de Meteorología AeH2 - Asociación Española de Hidrógeno

BMC - Business Model Canvas

$\mathrm{CNH} 2$ - Centro Nacional del Hidrógeno

DC - Direct Current

DEMI - Demineralized

DOD - Depth of Discharge

ELMS - Electrolyzer Management System

EMS - Energy Management System

EUR- Euros

F-HBA - Floating Heave-buoy Array

FCEV- Fuel Cell Electric Vehicle

FWP - Fresh water pump

ICT - Information Technology and Communication

LTS - Long Term System

MIQP - Mixed Integer Quadratic Programming

MLD - Mixed Logical Dynamical System

NLMIQP - Non Linear Mixed Integer Quadratic Programming

PEM - Proton Exchange Membrane

PID - Proportional-Integral-Derivative controller

PLC - Programmable Logic Controller

PNMPC - Practical Non-Linear Model Predictive Control

PTO - Power Take Off

RO - Reverse Osmosis

SETA - Sociedad Española de Tratamiento de Agua

SME - Small and Medium-sized Enterprise

SMR - Steam Methane Reforming

SOC - State Of Charge

SOEC - Solid Oxide Electrolyzer Cell

STS - Short Term System

SWP - Seawater Pump

VAWT -Vertical Axes Wind Turbine

WEC - Wave Energy Converter

WGSR - Water-Gas Shift Reaction

WP - Work Package 


\section{LIST OF SYMBOLS}

$\mathrm{H}_{\mathrm{S}}-$ Significant wave height (m)

$\mathrm{T}_{\mathrm{P}}-$ Mean wave period (s)

$\mathrm{W}_{\mathbf{S}}$ - Mean wind speed $(\mathrm{m} / \mathrm{s})$

$\mathrm{u}-$ Control action of the sequence

$\mathrm{Q}_{\mathrm{F}}-$ Fresh water flow $\left(\mathrm{m}^{3} / \mathrm{h}\right)$

$\mathrm{Q}_{\mathrm{S}}$ - Seawater flow $\left(\mathrm{m}^{3} / \mathrm{h}\right)$

$\mathrm{V}_{\mathrm{S}}$ - Seawater tank $\left(\mathrm{m}^{3}\right)$

BT1 - Fresh water tank $\left(\mathrm{m}^{3}\right)$

$\mathrm{L}_{\mathrm{T}}$ - Tank level of the seawater tank $(\mathrm{m})$

$\mathrm{L}_{\mathrm{Tmax}}$ - Maximum tank level of the seawater tank (m)

$\mathrm{L}_{\text {Tmin }}$ - Minimum tank level of the seawater tank (m)

I - Amperage of the battery (A)

V - Voltage of the battery (V)

$\mathrm{P}_{\mathrm{W}}$ - Power supplied by the renewable energies $(\mathrm{kW})$

$\mathrm{P}_{\mathrm{T}}$ - Total power consumed $(\mathrm{kW})$

$\mathrm{C}_{\mathrm{R}}$ - Rated capacity at that discharge rate $(\mathrm{A} \cdot \mathrm{h})$

$\mathrm{C}_{\mathrm{P}}-$ Peukert's capacity of the battery $(\mathrm{A} \cdot \mathrm{h})$

$\mathrm{t}$ - Time

$\mathrm{k}_{\mathrm{P}}-$ Peukert's coefficient

$\boldsymbol{\psi}$ - Efficiency of the battery

$\mathrm{W}_{\mathrm{a}}-$ Hours of autonomy (h)

$\mathrm{Q}_{\mathrm{DE}}$ - Demineralized water flow $\left(\mathrm{m}^{3} / \mathrm{h}\right)$

BT2 - Demineralized water tank $\left(\mathrm{m}^{3}\right)$

$\mathrm{i}$ - Subscript of each device

$\mathrm{U}_{\mathrm{i}}$ - Prioritized units in the reverse osmosis

$\mathrm{E}_{\mathrm{i}}$ - List of predicted energy demands

$\mathrm{O}_{\mathrm{i}}-$ List of operating units

$\mathrm{D}_{\mathrm{i}}-$ List of disconnected units

$\mathrm{n}$ - Number of devices

$\overline{\mathrm{P}}_{\mathrm{EL}}$ - Rated power consumption of the electrolyzers $(\mathrm{kW})$

$\mathrm{P}_{\mathrm{OS}}$ - Power consumed by the reverse osmosis $(\mathrm{kW})$

$\mathrm{P}_{\mathrm{CO}}$ - Power consumed by the compression $(\mathrm{kW})$

$\mathrm{U}_{\text {rev }}-$ reversible voltage or open circuit voltage at the cell (V)

$\eta$ - Over potential (V)

$\Delta \mathrm{Gi}-$ Gibbs free energy $(\mathrm{J})$

$\mathrm{F}$ - Faraday constant $(\mathrm{C} / \mathrm{mol})$

$\mathrm{V}_{0}$ - Initial specific volume $\left(\mathrm{m}^{3} / \mathrm{kg}\right)$

$\mathrm{p}$ - Pressure (bar) 
$\mathrm{R}$ - Gas constant ( $\mathrm{J} / \mathrm{mol})$

$\gamma$ - Ratio of specific heats

$\mathrm{T}$ - Temperature $(\mathrm{K})$

$\mathrm{E}_{\text {pro }}$ - Activation energy for proton transport in the membrane $(\mathrm{J} / \mathrm{mol})$

$\mathrm{E}_{\mathrm{exc}}-$ Activation energy for the electrode reaction $(\mathrm{J} / \mathrm{mol})$

$\pi$ - Conductivity of the membrane $(\mathrm{S} / \mathrm{m})$

RE - Resistive loss $(\Omega)$

$\mathrm{t}_{\mathrm{m}}$ - Thickness of the membrane (m)

ac - Activity coefficient

$\mathrm{i}_{0}-$ Exchange current density $\left(\mathrm{A} / \mathrm{m}^{2}\right)$

$\lambda$ - Charge transfer coefficients

$\mathrm{N}$ - Prediction horizon

$\mathrm{N}_{\mathrm{u}}$ - Control horizon

$\mathrm{i}$ - Subscript of each device

$\delta_{\mathrm{i}}(\mathrm{k})$ - Binary variable: ON/OFF electrolysis unit $\mathrm{i}$ at instant $\mathrm{k}$

$\widehat{\delta}_{\mathrm{i}}(\mathrm{k})$ - Prediction of the binary variable of unit $\mathrm{i}$ at instant $\mathrm{k}$

$\alpha_{i}(k)$ - Capacity factor of electrolysis unit $i$ at instant $k$

$\widehat{\alpha}_{i}(k)$ - Prediction of the capacity factor of unit $i$ at instant $k$

$z_{i}(k)$ - Auxiliary variable of electrolysis unit $i$ at instant $k$

$\Delta \mathrm{z}_{\mathrm{i}}(\mathrm{k})$ - Increase of the auxiliary variable of unit $\mathrm{i}$ at instant $\mathrm{k}$

$\widehat{\Delta \mathrm{z}}_{\mathrm{i}}(\mathrm{k})$ - Prediction of the increase of the auxiliary variable

$\mathrm{H}_{\mathrm{i}}(\mathrm{k})$ - Hydrogen production of electrolysis unit $\mathrm{i}$ at instant $\mathrm{k}\left(\mathrm{Nm}^{3} / \mathrm{h}\right)$

$\widehat{\mathrm{H}}_{\mathrm{i}}(\mathrm{k})$ - Prediction of the hydrogen production of unit $\mathrm{i}$ at instant $\mathrm{k}$

$\overline{\mathrm{H}}_{\mathrm{i}}-$ Maximum $\mathrm{H}_{2}$ production $\left(\mathrm{Nm}^{3} / \mathrm{h}\right)$ of electrolysis unit $\mathrm{i}$

$\mathrm{a}_{\mathrm{i}}$ - Slope of power model of electrolysis unit $\mathrm{i}\left(\mathrm{kWh} / \mathrm{Nm}^{3}\right)$

$b_{i}-$ Offset of power model of electrolysis unit $\mathrm{i}\left(\mathrm{kWh} / \mathrm{Nm}^{3}\right)$

$\underline{\alpha}_{\mathrm{i}} \quad \bar{\alpha}_{\mathrm{i}}-$ Minimum and maximum capacity factor of unit $\mathrm{i}$

$\mathrm{P}_{\mathrm{i}}(\mathrm{k})$ - Power consumption of electrolysis unit $\mathrm{i}$ at instant $\mathrm{k}(\mathrm{kW})$

$\widehat{\mathrm{P}}_{\mathrm{avai}}$ able $(\mathrm{k})$ - Prediction of power available at instant $\mathrm{k}(\mathrm{kW})$

$\mathrm{w}_{\mathrm{H}}$ - Weighting factor of the error

$\mathrm{w}_{\delta}-$ Weighting factor of the control variable

$\mathrm{J}-$ Quadratic cost function $\left(\mathrm{Nm}^{3} / \mathrm{h}\right)$

$\mathrm{T}$ - Triangular matrix

$g_{i}(k)$ - Optimization model of electrolysis unit $\mathrm{i}$ at instant $\mathrm{k}$

Q - Quadratic part of the cost function

$\mathrm{L}$ - Linear part of the cost function

A, B - Constraints matrices

$\mathrm{f}-$ Free response vector

$\mathrm{G}$ - System's dynamic matrix

$\Delta \mathrm{u}-$ Vector of control increments 
$\mathrm{k}$ - Time index

$\mathrm{T}_{\mathrm{s}}$ - Sample time

$\mathrm{P}_{\mathrm{i}}^{\text {dis }}$ - Discharge power of the device $\mathrm{i}(\mathrm{kW})$

$\mathrm{P}_{\mathrm{i}}^{\mathrm{ch}}$ - Charge power of the device $\mathrm{i}(\mathrm{kW})$

$\mathrm{C}_{\mathrm{i}}^{\mathrm{max}}$ - Maximum capacity of the device I $(\mathrm{A} \cdot \mathrm{h})$

$\psi_{i}^{\text {dis }}$ - Discharge efficiency of the device $i$

$\psi_{i}^{\text {ch }}$ - Charge efficiency of the device $i$

$\mathrm{z}_{\text {ele }}^{\mathrm{LTS}}$ - Power formulated as MLD variable for the Long Term System

$\mathrm{z}_{\text {ele }}^{\mathrm{STS}}$ - Power formulated as MLD variable for the Short Term System

$\varphi_{\mathrm{i}}$ - Activation time to start up the electrolyzer $\mathrm{i}$

$\Lambda_{\mathrm{i}}-$ Logical order signal to start up the electrolyzer i

$\mathrm{m}$ - Lower bound of the system

$\mathrm{M}$ - Upper bound of the system

$\varepsilon$-Smaller tolerance of the device

$\sigma_{i}^{\text {on }}$ - Start-up state of the electrolyzer

$\sigma_{\dot{i}}^{\text {off }}$ - Shut-down state of the electrolyzer

$\vartheta_{\mathrm{i}}-$ MLD power variation in degradation state

SOC $_{i}-$ State of Charge of the device $i$ 



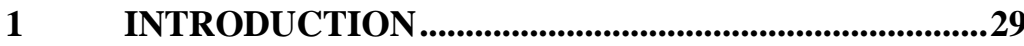

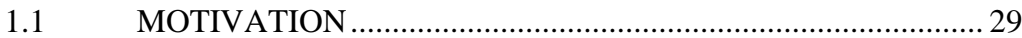

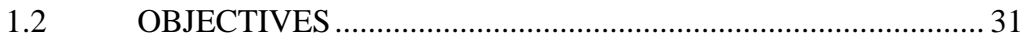

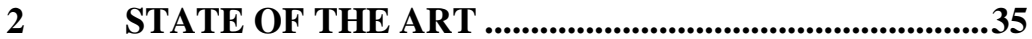

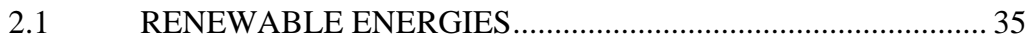

2.1.1 Wave Energy .................................................................................... 36

2.1.2 Wind Energy ........................................................................................... 41

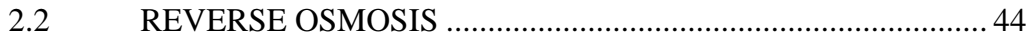

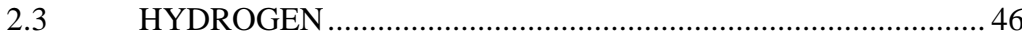

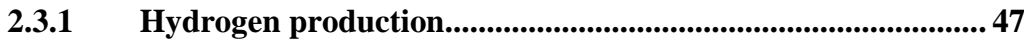

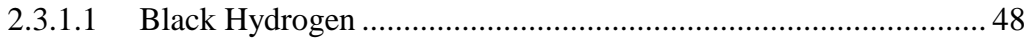

2.3.1.2 Green Hydrogen...................................................................... 51

2.3.1.3 Blue Hydrogen .................................................................................. 51

2.4 MODEL PREDICTIVE CONTROL …........................................56

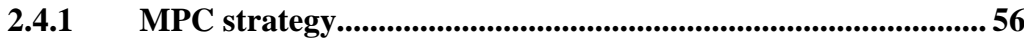

2.4.2 Receding horizon..................................................................................58

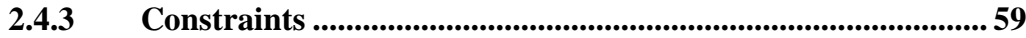

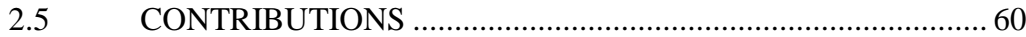

2.5.1 Journal papers..........................................................................................6 60

2.5.2 Conference papers ........................................................................ 60

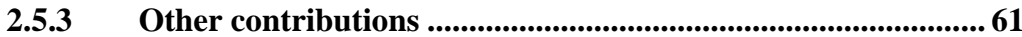

2.5.4 Patent and intellectual property registration ............................. 62

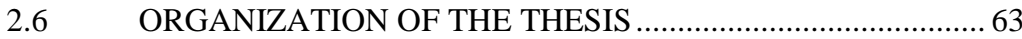

2.7 SUMMARY AND CONCLUSIONS ........................................... 64

3 CONTROL OF THE H2OCEAN PLATFORM .............67

3.1 FRESH $\mathrm{H}_{2} \mathrm{O}$ PRODUCTION IN THE H2OCEAN PLATFORM 67

3.1.1 Desalination plant operation .................................................... 68

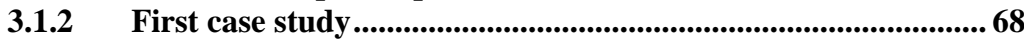

3.1.2.1 Energy Management System based on heuristic control................ 70

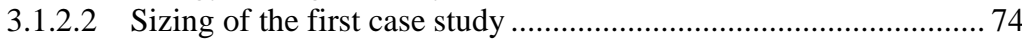

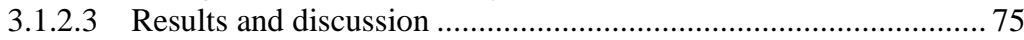

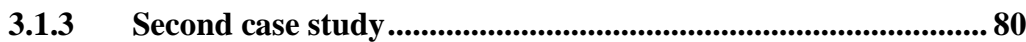

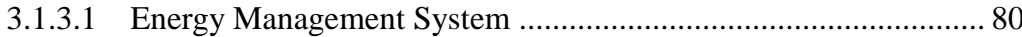

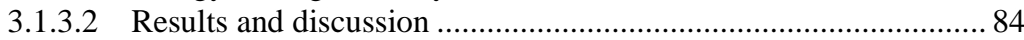

$3.2 \quad \mathrm{H}_{2}$ PRODUCTION IN THE H2OCEAN PLATFORM ................. 87

3.2.1 Hydrogen plant operation for hydrogen production ................. 88

3.2.2 Energy Management System........................................................... 89

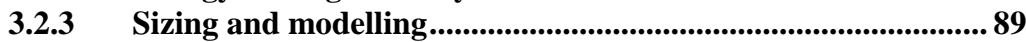

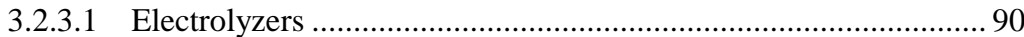

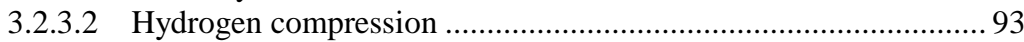

3.2.3.3 Electricity storage …………………….................................... 94 


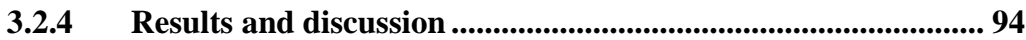

3.3 SUMMARY AND CONCLUSIONS ........................................ 97

4 ENERGY MANAGEMENT SYSTEM FOR HYDROGEN PRODUCTION BASED ON MPC .........................................101

4.1 MATERIALS AND METHOD ………................................... 102

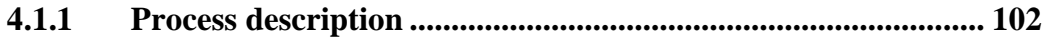

4.1.2 Manipulated variables........................................................................ 103

4.1.3 Model and controlled variables ........................................................ 104

4.1.4 Model Predictive Control for hydrogen production ................... 105

4.2 PROPOSED ENERGY MANAGEMENT SYSTEM .................. 107

4.2.1 Control objectives ........................................................................ 107

4.2.2 Cost function and optimization problem ...................................... 107

4.2.3 Approximation to an MIQP............................................................. 109

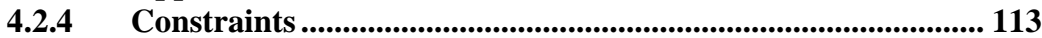

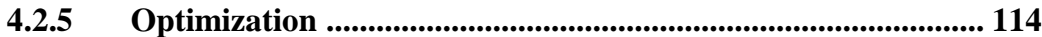

4.2.6 MPC strategy ........................................................................ 118

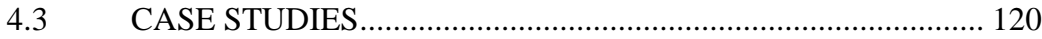

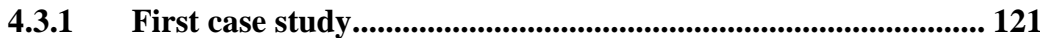

4.3.2 Second case study.................................................................................. 125

4.4 SUMMARY AND CONCLUSIONS ........................................ 130

5 COUPLING OF A LOW LEVEL SYSTEM WITH A HIGH

LEVEL SYSTEM IN A H $\mathrm{H}_{2}$ MICROGRID .................................135

5.1 HYDROGEN-BASED MICROGRIDS ...................................... 136

5.1.1 Components of the hydrogen-based microgrid .......................... 137

5.1.2 Electrolyzers........................................................................................... 138

5.1.3 Batteries and ultracapacitor .................................................. 139

5.2 LONG TERM SYSTEM ......................................................... 140

5.2.1 Long term MPC design ............................................................. 141

5.1.2 Control objectives of the LTS ................................................... 141

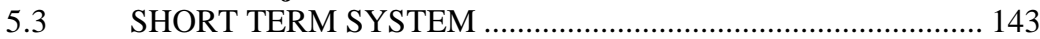

5.3.1 Short term MPC design......................................................... 145

5.3.2 Control objectives of the STS ....................................................... 147

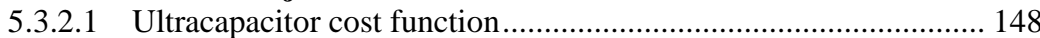

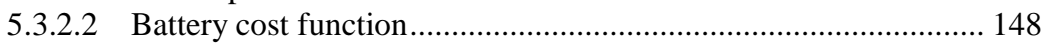

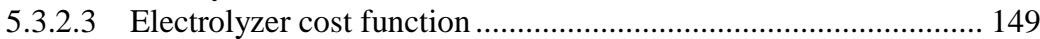

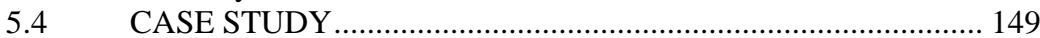

5.4.1 Controller implementation....................................................... 152

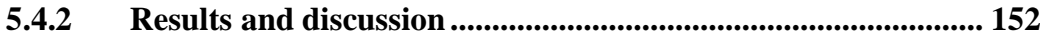

5.5 SUMMARY AND CONCLUSIONS ......................................... 154

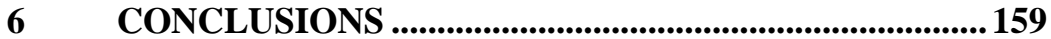

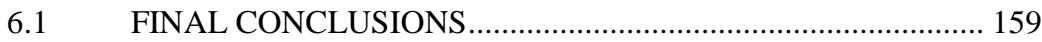




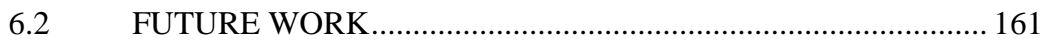

ACKNOWLEDGEMENTS ........................................163

REFERENCES..................................................................164

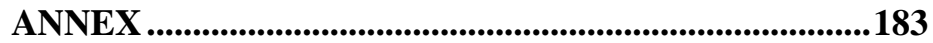



CHAPTER 1

\section{INTRODUCTION}




\section{INTRODUCTION}

\subsection{MOTIVATION}

This thesis is derived from the European Project H2OCEAN (http://www.h2ocean-project.eu/), whose aim was the development of a wind-wave power offshore platform equipped for hydrogen generation by electrolyzers (see Figure 1.1). The platform comprises a Reverse Osmosis section as an intermediate step in the production of hydrogen.

H2OCEAN started its activities on January 1st, 2012 and ended on December 31st, 2014. The European Union granted a financial contribution of 4.5 million EUR (FP7-OCEAN.2011-1 "Multi-use offshore platforms").

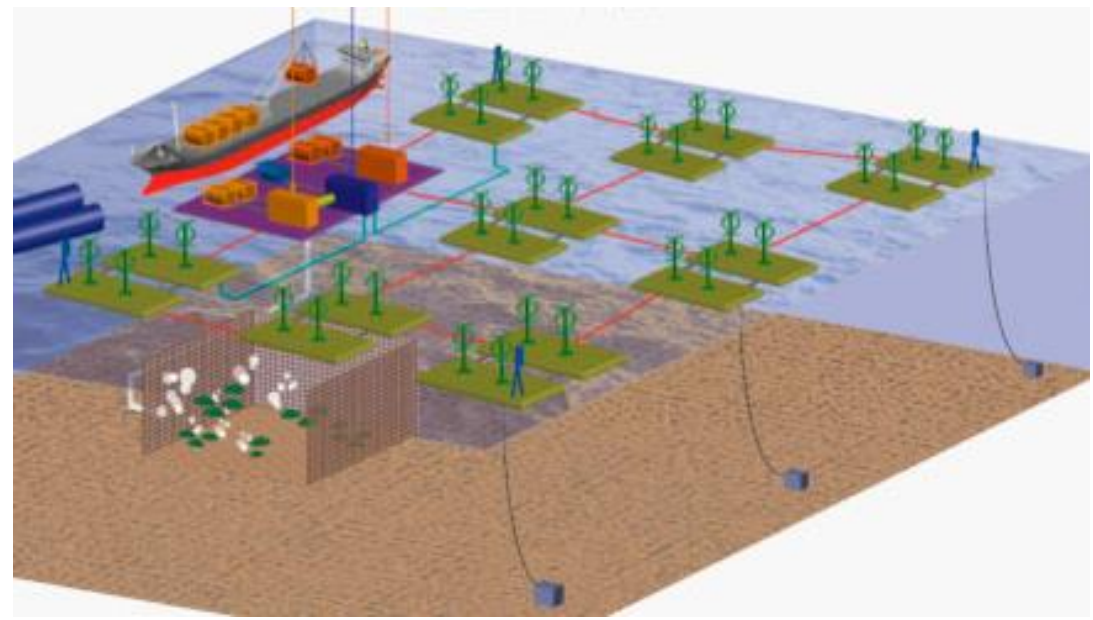

Figure 1.1- H2OCEAN platform (http://www.h2ocean-project.eu/).

The H2OCEAN Consortium was composed of 17 partners from 5 European countries (Spain, the United Kingdom, Denmark, Germany and Italy): 10 SMEs, 1 Large Enterprise, 4 Universities (among them the University of Valladolid) and 2 Research Institutes.

The team had a multi-sectorial profile, including renewable energy technologies, fluid mechanics engineering, off-shore engineering, desalination engineering, hydrogen engineering, offshore aquaculture, maritime transport and economics, logistics systems, safety and risk assessment, environmental and economic impact, and ICT. 


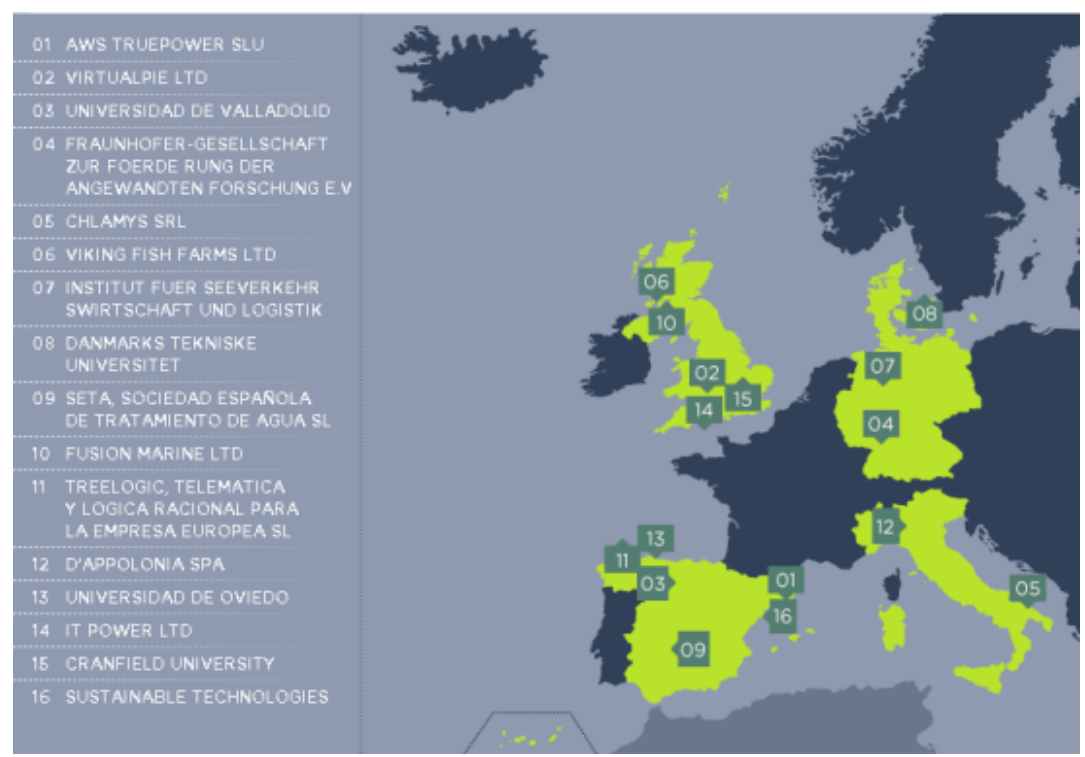

Figure 1.2- Participants in H2OCEAN Project.

The University of Valladolid was the leader of Work Package 5. The goals of this WP5 were the development and dimensioning of a hydrogen installation for offshore platforms. The work done included:

1. Evaluation of existing electrolyzing technologies for marine environments (AGERSTED, 2014).

2. Design of offshore desalination units for hydrogen generation (TORRIJOS, 2012).

3. Development of an Energy Management System (EMS) for the offshore hydrogen installation to minimize energy consumption and balance production and consumption of energy (SERNA et al. 2017).

The unique feature of the H2OCEAN concept, besides the integration of different activities into a shared multi-use installation, was the novel approach for the transmission of offshore-generated renewable electrical energy through hydrogen. This concept allows effective transport and storage of the energy, decoupling energy production and consumption, thus avoiding the grid imbalance problem inherent to current offshore renewable energy systems. Additionally, it circumvents the need for a cable transmission system which takes up a significant 
investment share for offshore energy generation infrastructures, increasing the price of energy (BAUER; LYSGAARD, 2015).

Offshore power links are known to be significantly expensive (RUDDY et al. 2016), so the system is here assumed to be fully isolated from the grid. Thus, the EMS balances power consumption with production by connecting or disconnecting sections of the electrolyzation plant (following a Smart Grid approach for the microgrid in the plant), and using temporary storage of electricity for short-term balances and increased autonomy (which is a relevant issue in offshore installations). The importance of designing a control system to balance the energy provided from renewable sources and the energy consumed by the components of the installation (reverse osmosis, hydrogen production, storage, etc.) was considered a key factor for its correct operation. Therefore, the operation of the devices using an advanced control strategy based on model predictive control ideas is very relevant for these systems (MELO; CHANG CHIEN, 2014), so it is the focus of the current thesis.

\subsection{OBJECTIVES OF THE THESIS}

The main objective of this thesis named, "Control system of offshore hydrogen production by renewable energies", is to develop an Energy Management System (EMS) based on Model Predictive Control (MPC) ideas that balances energy consumption with the renewable energy supplied in stand-alone installations, in particular for offshore installations.

For this, the modelling of the renewable energy sources (wave and wind energy), plus the design of a control proposal for water generation by reverse osmosis, and hydrogen production by electrolysis focusing on the H2OCEAN platform is first carried out (Chapter 3).

Then, an advanced control system of the electrolysis section, numerically optimizing the state-of-health of the devices, is developed in Chapter 4.

Chapter 5 evaluates the coupling of low and high level controllers of the hydrogen-based microgrids made up of electrolyzers, batteries and ultracapacitor.

Finally, an economic study and a business plan for the implantation of the controlled hydrogen-based microgrid in the market are carried out in Annex A. 


\section{CHAPTER 2}

STATE OF THE ART 


\section{STATE OF THE ART}

\subsection{RENEWABLE ENERGIES}

Worldwide primary energy demand, which mainly relies on fossil fuels, has doubled since 1971 (QUADRELLI; PETERSON, 2007). This demand is increasing following economic development and population growth (CHUNG et al. 2012). Therefore, mankind is facing unprecedented challenges for energy supplies because of the decrease in the availability of inexpensive fossil fuels (KRUYT et al. 2009) and the harmful effects of the emissions of greenhouse gases, such as carbon, sulphur and nitrogen dioxides (LEWIS et al. 2011). These emissions generate climate change and the reduction of the ozone layer (BARNES et al. 2016). These reasons should provide sufficient motivation for a decrease in the consumption of fossil fuels: providing affordable, clean, secure and adequate energy sources remains one of the world's biggest challenges (TOUATI, 2015). The need for renewable energy sources to meet world energy demand and progressively divert pollutant fossil energy sources is clear (ELLABBAN et al. 2014), so new energy resources are required (YAHYAOUI, 2015). Thus, many research efforts are concentrating on developing efficient alternative energy sources (POST et al. 2007): Renewable energies, such as photovoltaic, solar thermal, wind, hydro, waves and biomass are the best placed to fill this gap.

Figure 2.1 shows the evolution of different energy sources during the last centuries and an estimate for the next years. Nonetheless, the uneven availability of energy sources, complex logistics, or high installation costs are still preventing them from being widely used. Renewable energy has many advantages, but a central problem is to balance energy consumption with energy production in remote areas (DE MATOS et al. 2015).

In this thesis, two different energy sources are used to produce hydrogen: wave and wind energy, which are reviewed here. The purpose of this subchapter is to present an overview of the development of wave and wind energy, discussing its technology and its energy producing devices. The expected progress and the main limitations are also discussed. 


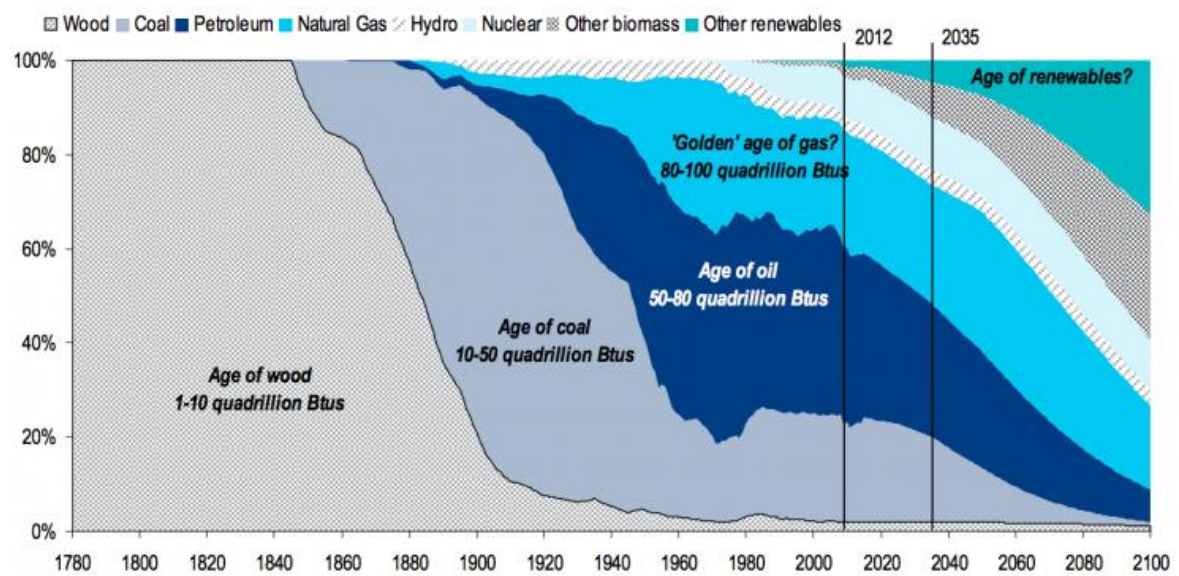

Figure 2.1- Share of US primary energy demand, 1780-2100. (ROSER, 2016)

\subsubsection{Wave energy}

Wave energy can be extracted easily from the oceans to generate renewable energy to fulfil human requirements (ZURKINDEN et al. 2014). In comparison with other energy sources, it is less developed than wind, photovoltaic and fossil fuel technologies (CLÉMENT et al. 2002). Different studies have evaluated this technology in different locations around the world, for example in the Atlantic Ocean (IGLESIAS et al. 2009), the Pacific Ocean (LENEE-BLUHM et al. 2011) or the Mediterranean Sea (LIBERTI et al. 2013). Figure 2.2 depicts the flux of wave energy in the oceans and seas worldwide. These studies indicate the potential hydrodynamic power in each location in order to get an approximation of the energy that can be absorbed by a device (converter) which transforms mechanical energy into electricity. Wave energy is an indirect form of energy (ANTONIO, 2010), as it is in fact wind that generates waves. When arriving at wave energy converters, these waves give some of their energy, which is converted into electricity. Similarly to wind energy, the main drawback of wave energy is its variability on several time-scales (GARRET; MUNK, 1975): from wave to wave, with the state of the sea, and from month to month. 


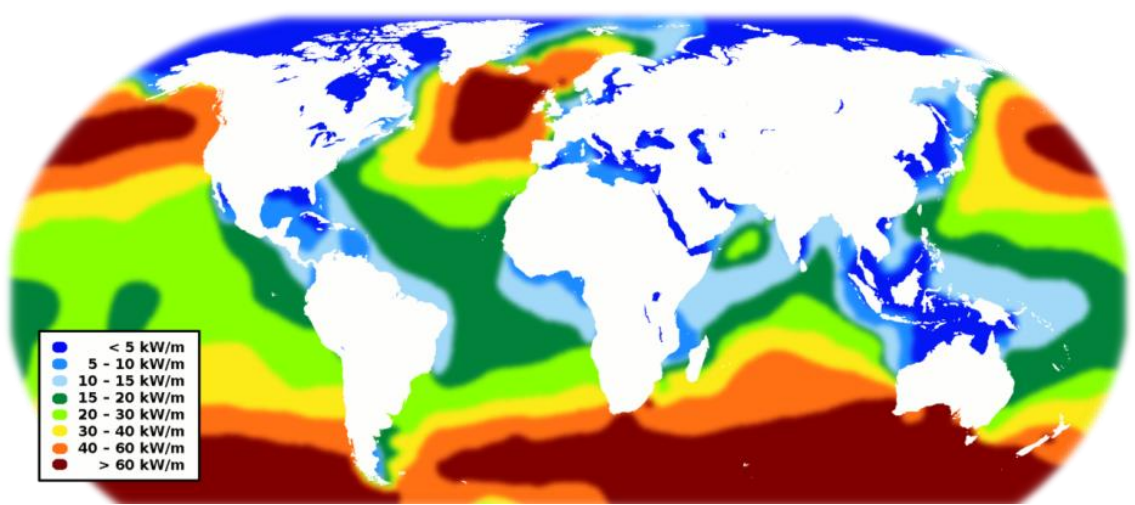

Figure 2.2- World map of wave energy flux in $\mathrm{kW}$ per meter wave front. (http://www.newslettereuropean.eu/new-way-wave-tidal-energy/).

The energy produced by waves depends on the wave period $\left(\mathrm{T}_{\mathrm{P}}\right)$ and height $\left(\mathrm{H}_{\mathrm{S}}\right)$. Figures 2.3 and 2.4 show these parameters in a certain location in the North Atlantic Ocean over 1 month in winter. It is these parameters that are used in this thesis (Chapter 3). As can be seen, they vary because of meteorological conditions:
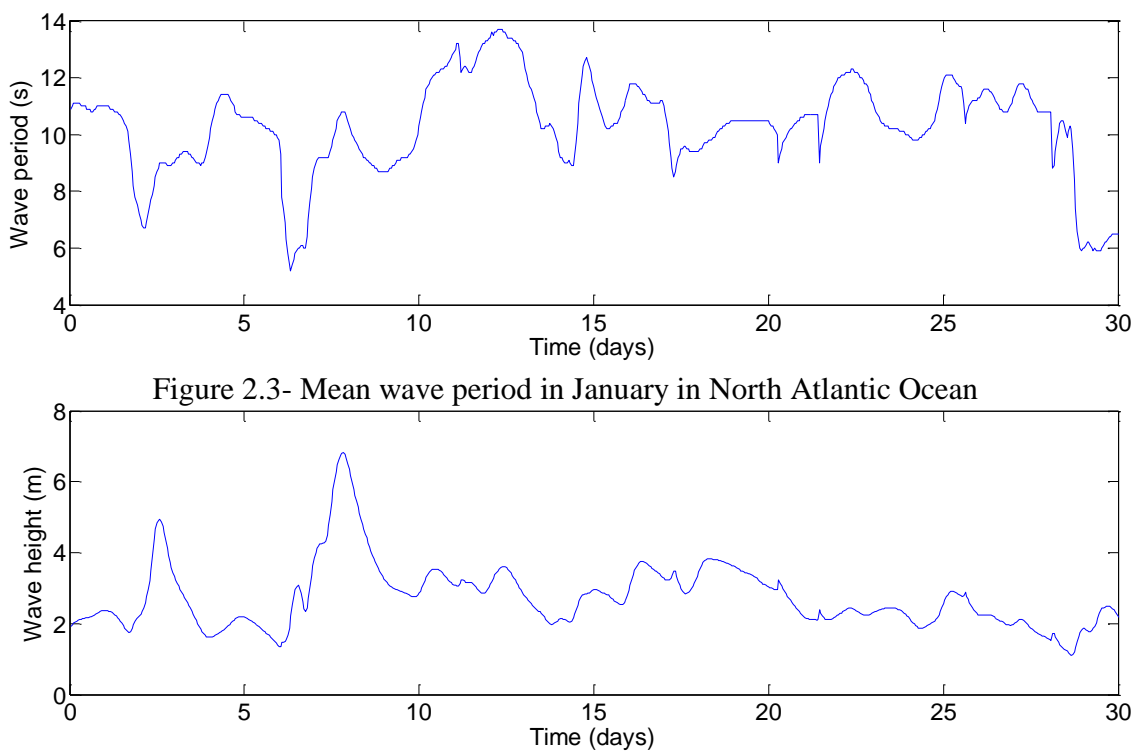

Figure 2.4- Significant wave height in January in North Atlantic Ocean (ROC, 2014) 


\section{Wave energy converters}

The number of companies that design a device capable of exploiting wave energy is increasing (FOLLEY, 2016). The output energy of a mechanism is basically determined by the system characteristics and the wave weather in the area (BABARIT et al. 2012). The most common devices are the multibody floating Wave Energy Converters, WEC (SIRNIVAS et al. 2016). Figure 2.5 shows an example of a WEC coupled with a vertical axes wind turbine (VAWT), developed in the H2OCEAN project. For offshore installations, the energy is extracted by the relative motion of different parts of the structure. The main advantage of these devices is that, in deep water (> $40 \mathrm{~m})$, there is a greater energy potential because the waves have not yet experienced losses. The device used in this thesis is a floating heavebuoy array (F-HBA), represented in Figure 2.6. It is a multibody floating WEC composed of many heaving buoys connected to a common reference structure. This structure is composed of an arrangement of a single support structure and a series of ballast baskets, connected through tension wires. The total buoyancy force from the buoys is balanced by net gravity forces of the bridge and the ballast baskets.

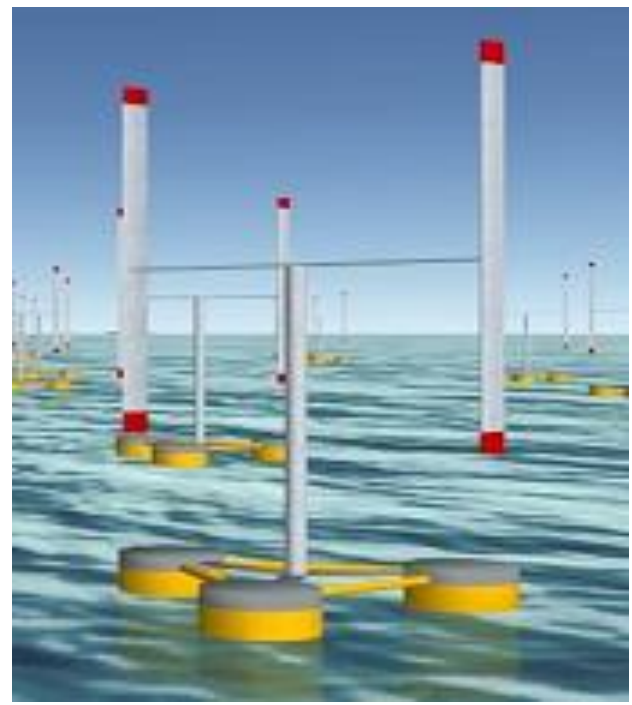

Figure 2.5- Example of a WEC coupled with a VAWT in H2OCEAN in H2OCEAN (BORG; COLLU, 2014) 


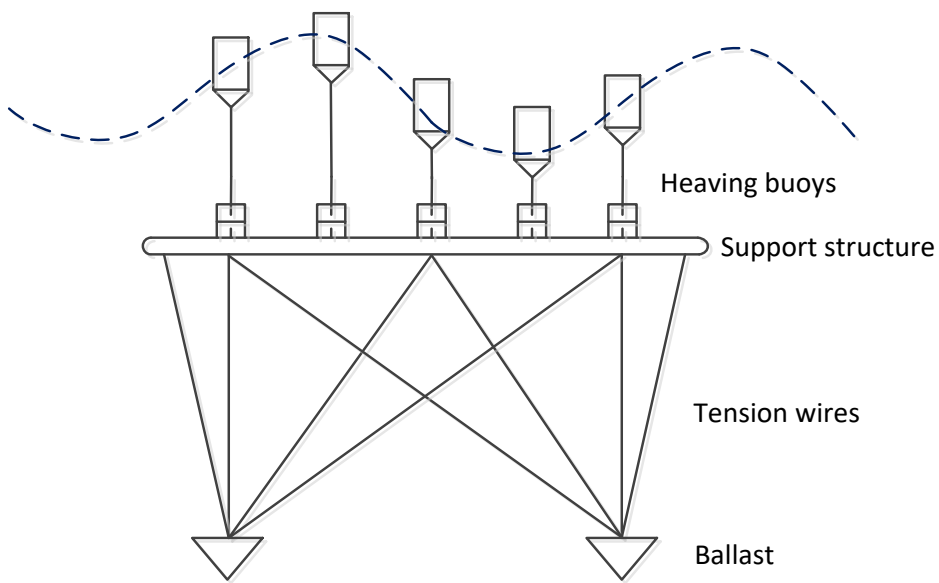

Figure 2.6- Scheme of the WEC proposed in H2OCEAN

Figure 2.7 depicts the average power output that can be absorbed by the specific wave energy converter (WEC) shown in Figure 2.5, taking into account meteorological parameters described previously of mean wave period and significant wave height.

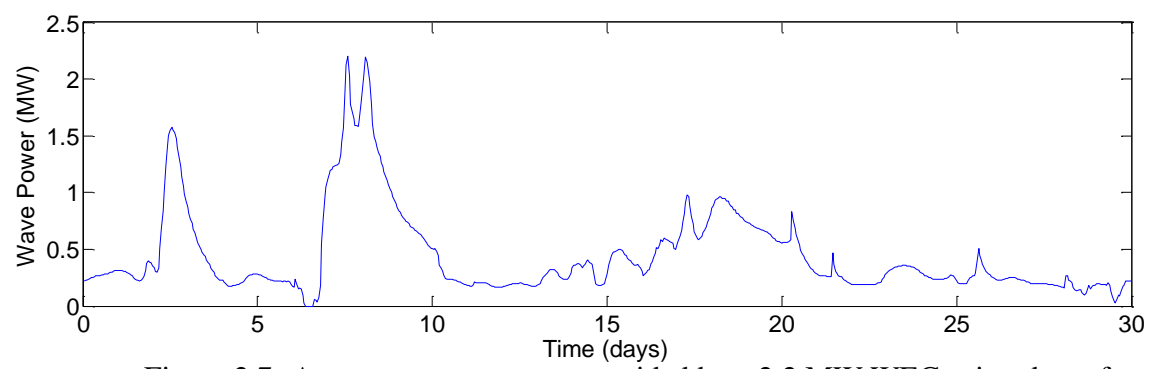

Figure 2.7- Average power output provided by a $2.2 \mathrm{MW}$ WEC using data of Figs.2.3-2.4.

The buoys are connected to the submerged structure via a hydraulic Power Take-Off (PTO) system, which converts the mechanical energy of the device into electricity. In the case of wave activated body WECs, they can be based on hydraulic components (hydraulic rams and motors) combined with an electrical generator (HENDERSON, 2006), or they can be fully electrical (ERIKSSON, 2007 and RUELLAN et al. 2010), which was assumed in this thesis due to the special conditions of offshore platforms.

One of the key points in the structural design and energy extraction capacity of the device is the response to different periods and wave 
heights (see Figure 2.8). To evaluate the energy produced by the WEC, water waves are considered to travel along the surface of the sea with an approximate sinusoidal profile, characterized in terms of the time between successive crests and the size of these crests (THORPE, 1999). Wave height and period are represented by statistical measurements, the most common being the significant wave height (around four times the root-mean square of the surface elevation during a given window), and the wave period.

The devices have a maximum range of operation. The power output that can be used by a device is limited to a maximum significant wave height and a minimum wave period. Multiplying the WEC power matrix (Figure 2.8) by the buoy-measured data of the sea location, the average absorbed power output during a specific time period of the device can be derived.

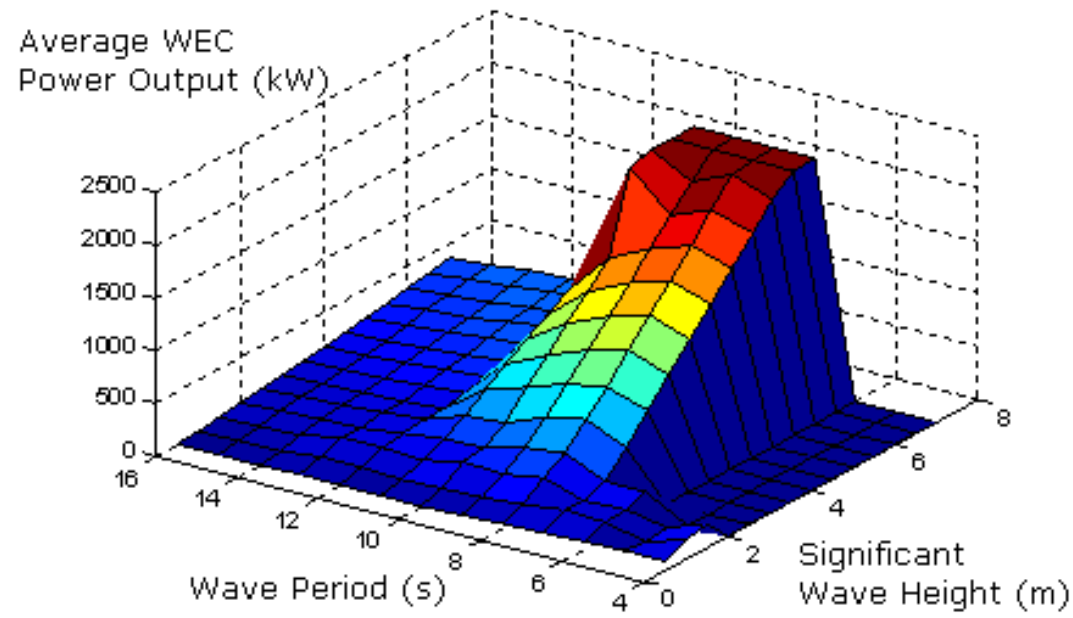

Figure 2.8- Example of a WEC Power Matrix in 3D (SERNA, TADEO 2014)

The wave energy industry is beginning to approach the deployment of wave farms, arrays of full-scale WECs (ASTARIZ; IGLESIAS, 2015). Methods to compare and evaluate the energy resource at different locations, and at different scales, are required in order to inform WEC project developers and allow them to select the most suitable sites to achieve optimal power capture and economic performance from their installations (RINGWOOD et al. 2014). 


\subsubsection{Wind energy}

Wind energy is a renewable energy source which is obtained from air masses in movement (BURTON et al. 2001). Electric power is generated by a turbine that converts a portion of the kinetic energy from the wind into mechanical energy (BIANCHI et al. 2007). This technology has matured to a level of development where it is generally accepted (GONZÁLEZ; LACAL-ARÁNTEGUI, 2016). Wind power is already playing an important role in electricity generation, especially in countries such as Germany, Denmark, Korea or Spain (PÉREZCOLLADO et al. 2015), (HOU et al. 2017), (KIM; KIM, 2017). World wind energy resources are substantial, and in many areas, such as the US and Northern Europe, could in theory supply all of the electricity demand (JACOBSON; DELUCCHI, 2011). However, the intermittent character of the wind resources and the necessity of long distances for energy transmission are considered the main drawbacks of wind energy.

Nowadays offshore farms are a promising technology (ESTEBAN et al. 2011) and there is considerable hope that offshore wind farms may be the solution (NG; RAN, 2016). Vast offshore areas are characterized by higher and more reliable wind resources in comparison with continental areas. However, offshore wind energy production is in a quite preliminary phase (BALOG et al. 2016). There have been many successes with offshore wind farms in Europe since installations began in 1991 (SUBRAMANI; JACANGELO, 2014).

\section{$\underline{\text { Vertical Axes Wind Turbine }}$}

Figure 2.9 shows an example of a Vertical Axes Wind Turbine (VAWT), which is the one used in this thesis as it was selected in H2OCEAN (BORG; COLLU, 2014) for its simple integration in floating installations. It is a type of wind turbine where the main rotor shaft is set transversal to the wind, while the main components are located at the base of the turbine. VAWTs do not need to be pointed into the wind, which removes the need for wind-sensing and orientation mechanisms. As previously depicted in Figure 2.5, there are some prototypes which couple WEC and VAWT. In this thesis, the device which produces energy for hydrogen installation is a hybrid apparatus as in this example (BORG; COLLU, 2015). 


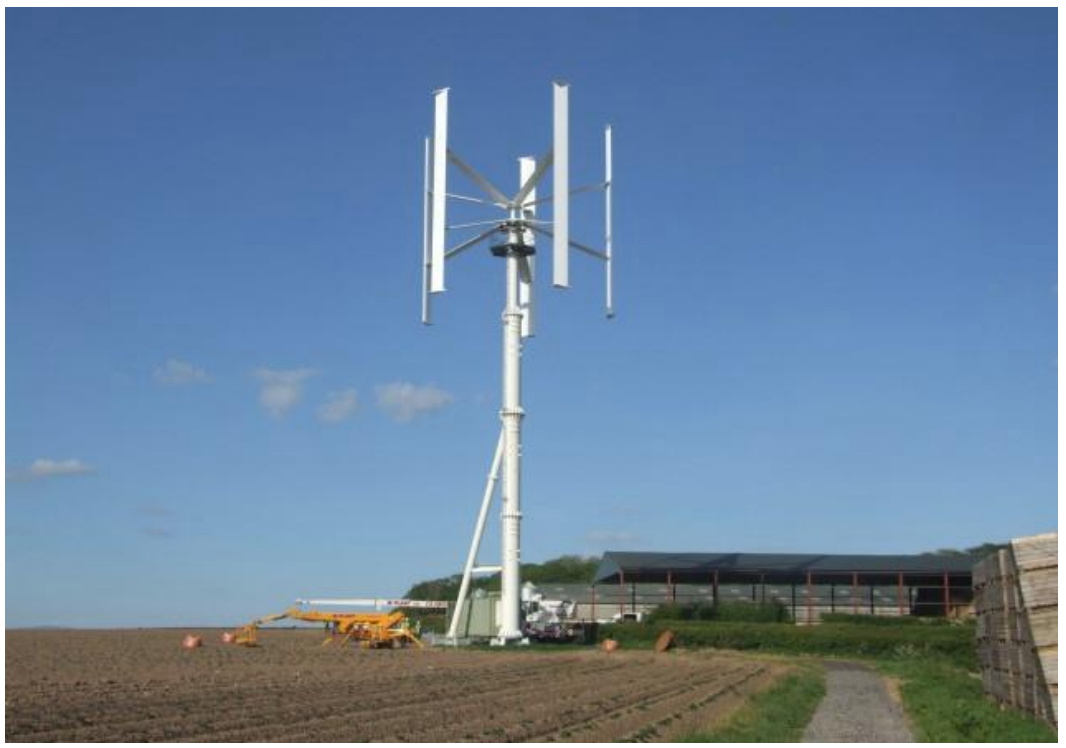

Figure 2.9- Example of a 30-100kW Vertical Axes Wind Turbine in UK (https://bobbischof.com/about/vertical-axis-wind-turbines-for-micro-generation/).

The energy produced by the wind depends mainly on its speed. Figure 2.10 shows mean wind speed $\left(\mathrm{W}_{\mathrm{S}}\right)$ in the same location and for the same period of time as in 2.1.1. There can be more variability than in the case of waves, due to differences in inertial masses of water versus air.

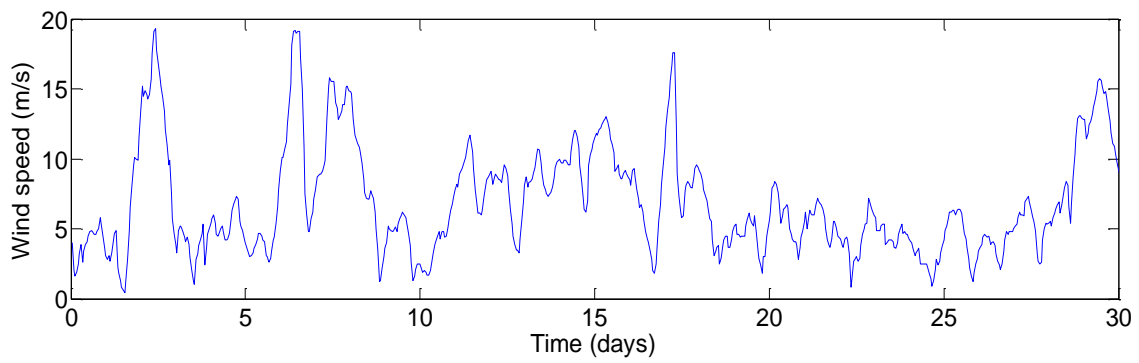

Figure 2.10- Mean wind speed in January in North Atlantic Ocean.

(ROC, 2014)

Figure 2.11 depicts the average power output that can be absorbed by the specific hybrid VAWT shown in Figure 2.5, taking into account the mean wind speed shown in Figure 2.10. As can be seen, this power 
is even more variable than wave power and depends strongly on meteorological conditions.

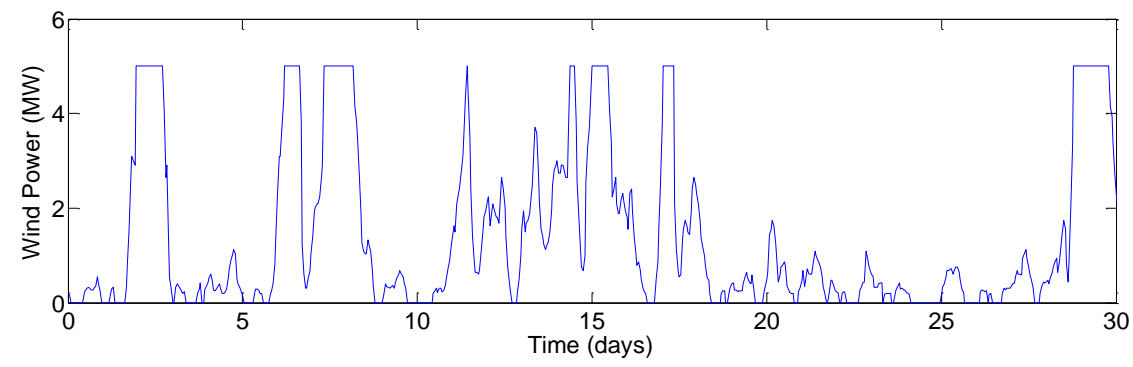

Figure 2.11- Average power output provided by a 5 MW VAWT using data of Figs.2.10

Wind turbines have a maximum range of operation. The average power output that can be used by a device is limited to a certain range of mean wind speeds. Figure 2.12 shows the relationship between power output and mean wind speed in this specific VAWT:

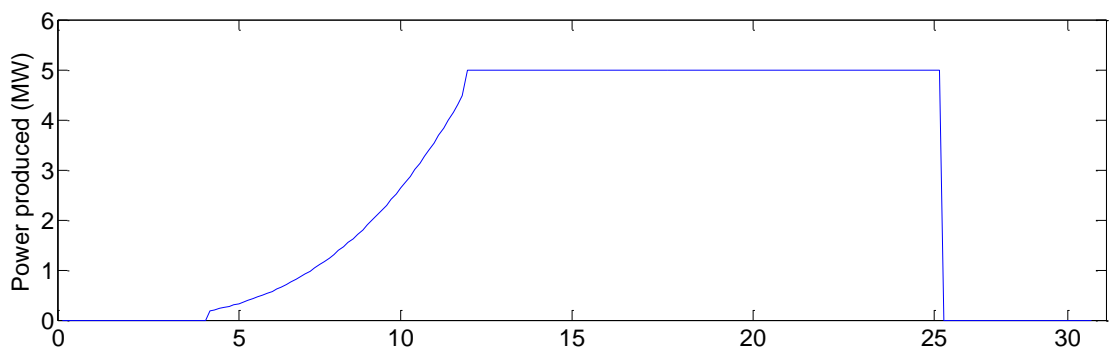

Figure 2.12- Power profile of the VAWT developed in the H2Ocean project.

Unlike in the case of wave energy, in which energy depends on two variables (wave period and height), wind energy only depends on one variable (wind speed). Moreover, each VAWT has its own power profile that depends on the wind speed and the VAWT characteristics. 


\subsection{REVERSE OSMOSIS}

Reverse Osmosis (RO) is an intermediate step which desalinates seawater to produce demineralized water, because electrolysis only operates with low conductivity water (less than a few $\mu S$ ). In the last few decades, different techniques for fresh water production have been developed. RO has become the most popular desalination technology (especially for large-scale seawater desalination plants) (GUDE, 2016). The required plant capacity, the product cost, the technology maturity and the coupling of the renewable energy and the desalination systems (GARCÍA-RODRÍGUEZ, 2003) determine RO as the best option for the case proposed in this thesis. Figure 2.13 depicts a typical industrial RO system.

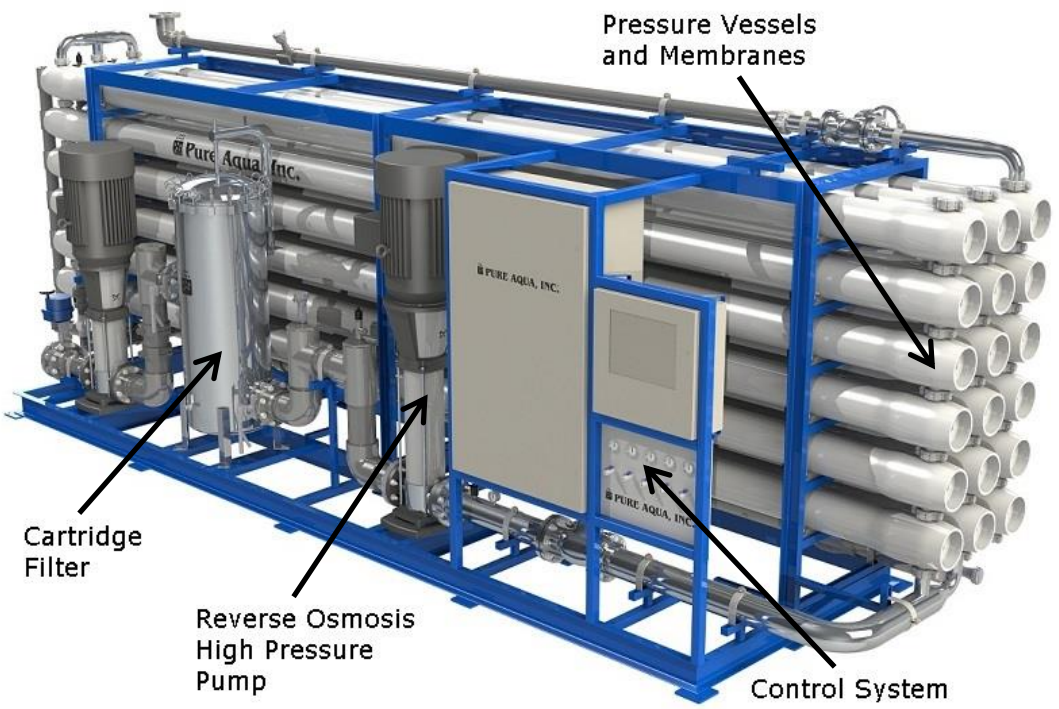

Figure 2.13- Industrial Reverse Osmosis system (http://www.pureaqua.com/what-is-reverse-osmosis-ro/).

$\mathrm{RO}$ is a technique that uses a semipermeable membrane to remove ions, molecules and large particles from seawater to produce drinkable water (see Figure 2.14). In this technology, pressure is applied to overcome the osmotic pressure, a colligative property that is driven by chemical potential differences of the solvent. The result is that the solute is retained on the pressurized side of the membrane, so pure water is allowed to pass to the other side (AMBASHTA; SILLANPÄ̈̈, 2012). 
The pressure required depends mainly on the salt concentration of the feed flow. Typical values are over 40 bars for brackish water and over 80 bars for seawater (WONG et al. 2012). This pressure is supplied by high-pressure pumps of positive-displacement or (more commonly) centrifugal type (see Fig 2.13). Flow and other characteristics of the desalted water (named "permeate") depend on many factors, such as salt concentration, operating pressure, temperature, membrane permeability, etc., (LI; WANG, 2010).

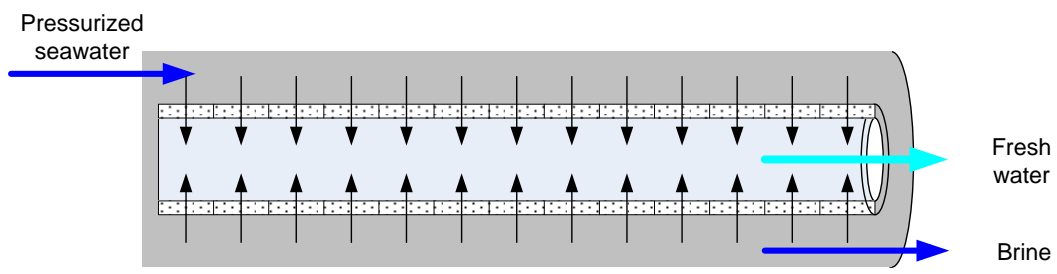

Figure 2.14- Transport of water through an RO membrane

To produce a high desalted water flow, the membranes are packed in different configurations. There are several types of RO membranes such as for seawater, brackish water, high rejection, high recovery, or low flux (GOMEZ PALACIN, 2014). An RO desalination plant has different stages or sections: the pre-treatment of the feed flow, the pumping system with the high-pressure pumps, the RO pressure vessel racks, the post-treatment of the desalted flow before being removed and, finally, the energy recovery of the reject flow before being removed (GOMEZ PALACIN, 2014).

With regard to the process selection, RO has the lowest energy consumption; nevertheless, it requires skilled workers and the availability of chemical and membrane supplies. If these requirements are not a problem at the plant location, the RO process can be considered. Besides that, distillation processes offer much better product quality and only they ensure a suitable product in the case of pollution of the raw seawater. If both RO and thermal processes are suitable for a given location, the renewable energy available and the electric/mechanic/thermal energy required by the process limit the possible selection. Finally, the required plant capacity, the annual and daily distribution of fresh water demand, the product cost, the technology maturity and any problem related to the coupling of the 
renewable energy and the desalination systems determine the selection (GARCÍA-RODRÍGUEZ, 2003).

Offshore desalination plants powered by renewable energies are being proposed as an alternative for a coastal desalination facility, for those locations where the lack of suitable land makes a land-based desalination plant inadequate (DAVIES, 2005). This is an offshore plant, which makes the implementation of distillation processes difficult. Thus, RO was selected as the desalination technique.

\subsection{HYDROGEN}

Hydrogen has been considered as an energy source since the nineteenth century (HAMACHER, 2016). Because of global climate change, carbon emissions into the atmosphere should be gradually restricted (OPPENHEIMER; ANTTILA-HUGHES, 2016). Therefore, current energy sources which feed homes, industries and transport should be gradually replaced by alternative sources (GARCÍA-CLÚA, 2013). Hydrogen is a clean energy carrier independent of energy sources (SUBRAMANI et al. 2016) and, when it is produced from renewable energies, offers significant advantages (PANWAR et al. 2011). It is still not a primary energy source such as oil or coal, although it can be considered as an excellent energy vector. One advantage of hydrogen in comparison with other energy sources is that it is everywhere. For example, in water it is bound with oxygen, which is one of the most abundant components on Earth, but it also can be linked with carbon in compounds such as natural gas, coal or biomass.

Nowadays, the most common method to produce hydrogen is the extraction of natural gas by steam reforming. However, this method generates greenhouse gases and purity is not sufficient for fuel cells which require a hydrogen purity of $99.99 \%$ (DAVIDS et al. 2016). Furthermore, it is more convenient to develop different technologies to obtain hydrogen from non-fossil fuels, such as wind and wave energy sources (ACAR; DINCER, 2014). One way to obtain hydrogen is from water separation in an apparatus called an electrolyzer. This hydrogen can then be used in the reverse process occurring in fuel cells, which releases energy that can then be used for different uses (for example in a hydrogen car, as depicted in Figure 2.15). 


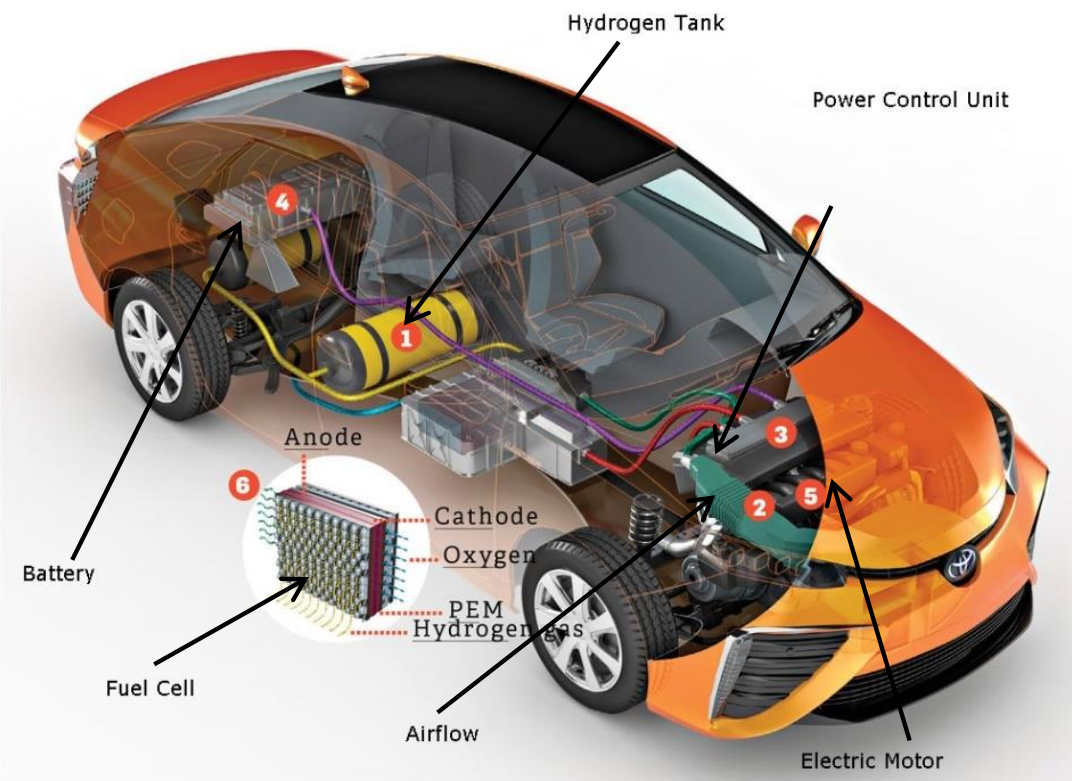

Figure 2.15- Hydrogen-based car Toyota Mirai (http://www.popsci.com/how-hydrogen-vehicles-work).

\subsubsection{Hydrogen production}

Nowadays, worldwide hydrogen production was estimated at around 50 million tons in 2013 and most of the production is obtained from natural gas reforming (KROPOSKI et. al. 2006). This production method currently prevails due to its profitability, but the sources from which hydrogen can be obtained are varied. The state of the art of the technologies associated to hydrogen production is very different; while some technologies are still in a research stage, others are already well known on a laboratory scale.

According to the origin of the extracted hydrogen, these processes can be classified into three groups (VARKARAKI et al. 2007). The first comprises the processes that extract hydrogen from fossil fuels (black hydrogen). The second group includes processes with extraction from biomass (green hydrogen). In the third group, hydrogen is obtained by water separation (blue hydrogen). These are now reviewed below: 


\subsubsection{Black $\mathrm{H}_{2}$}

\section{$\underline{\text { Steam reforming }}$}

Steam Methane Reforming, SMR, is the least expensive method and therefore the most used to produce hydrogen nowadays (GARCÍACLÚA, 2013). It is the most common technology for $\mathrm{H}_{2}$ production on a large scale in the chemical industry and refineries. SMR is the endothermic chemical reaction in which methane, the main component of natural gas, reacts with steam to deliver a mixture of $\mathrm{H}_{2}$ gas and carbon monoxide called syngas (TSUBOI et al. 2017). The heat required for the reaction is normally obtained by combustion of the methane feed gas. Reaction 2 is called WGSR (Water-Gas Shift Reaction). Figure 2.16 shows the SMR process:

$$
\begin{aligned}
& \mathrm{CH}_{4}+\mathrm{H}_{2} \mathrm{O}+\text { heat } \rightarrow \mathrm{CO}+3 \mathrm{H}_{2} \\
& \mathrm{CO}+\mathrm{H}_{2} \mathrm{O} \rightarrow \mathrm{CO}_{2}+\mathrm{H}_{2}+\text { heat }
\end{aligned}
$$

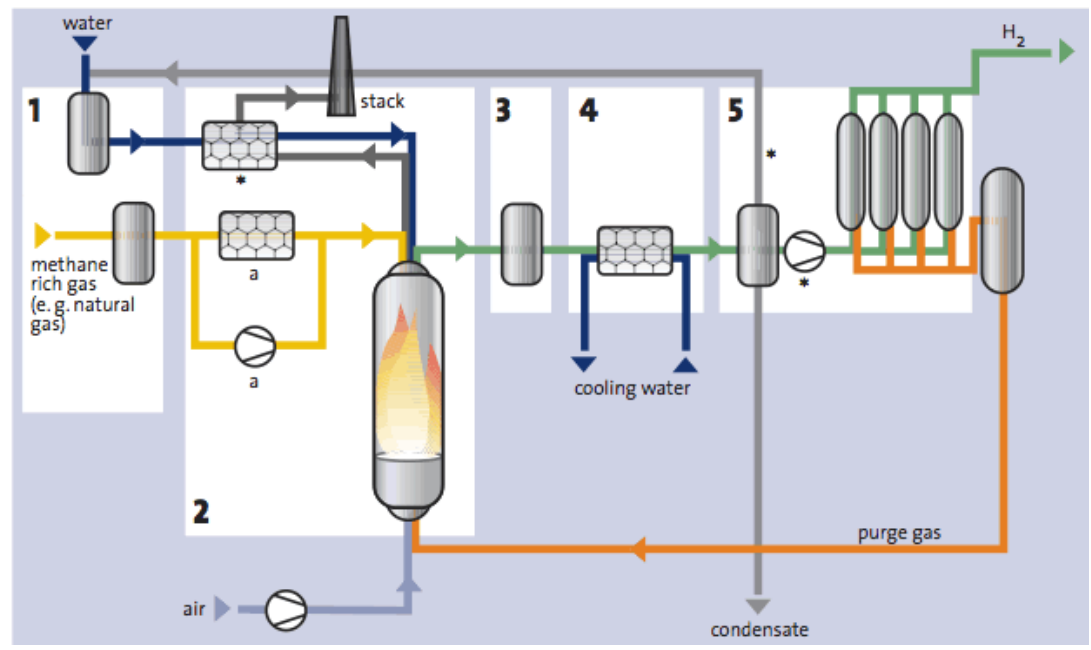

Figure 2.16- Steam reforming of natural gas process (https://wiki.uiowa.edu/display/greenergy/Steam+Reforming+of+Natural+Gas).

Steam reforming of most hydrocarbons only happens with certain catalysts (for example nickel is the most effective (KHO et al. 2017)). The natural gas reforming provides energy conversion efficiencies of up to $85 \%$ for large centralized systems (GARCÍA-CLÚA, 2013). The cost of the overall process is highly dependent on the price of natural gas. 


\section{$\underline{\text { Partial oxidation }}$}

Partial oxidation is a reforming process where the fuel is partially burned. The exothermic reaction (3) provides the heat required by the other reforming reactions, resulting in $\mathrm{CO}$ and $\mathrm{H}_{2}$. The $\mathrm{CO}$ produced is then converted into $\mathrm{H}_{2}$ according to the WGSR reaction (2).

$$
\mathrm{CH}_{4}+1 / 2 \mathrm{O}_{2} \rightarrow \mathrm{CO}+2 \mathrm{H}_{2}+\text { heat }
$$

This technique is often applied in refineries for the conversion of waste into $\mathrm{H}_{2}, \mathrm{CO}, \mathrm{CO}_{2}$ and $\mathrm{H}_{2} \mathrm{O}$. Fuel oils, gasoline and methanol can also be raw materials. Some shortcomings are its low efficiency, the requirement of pure $\mathrm{O}_{2}$ and its high level of pollution, more than SMR (GARCÍA-CLÚA, 2013).

\section{PARTIAL OXIDATION}

\section{NATURAL GAS}

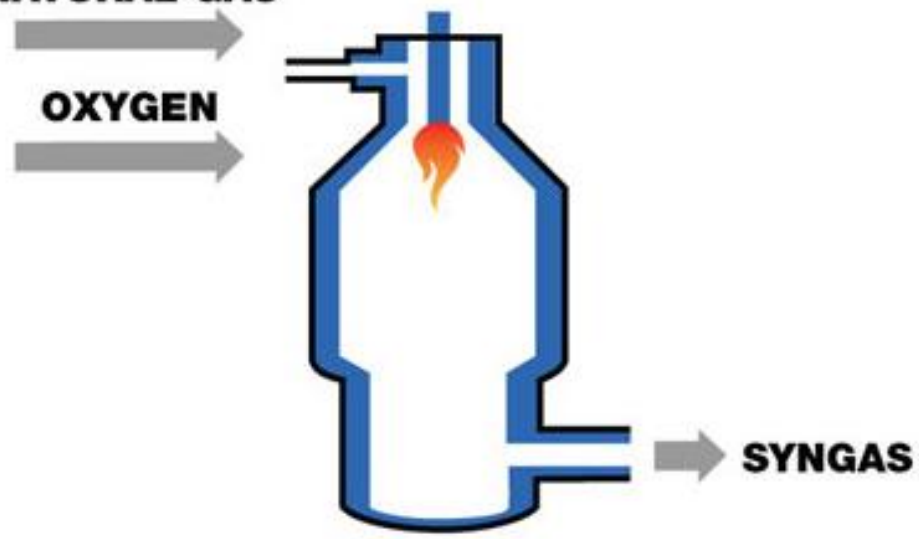

Figure 2.17- Partial oxidation process scheme (http://www.gasification-syngas.org/technology/syngas-production/).

\section{Pyrolysis}

Pyrolysis is the thermochemical decomposition of organic material at elevated temperatures in the absence of $\mathrm{O}_{2}$. It involves the simultaneous change of chemical composition and physical phase. Hydrocarbons are transformed into $\mathrm{H}_{2}$ without producing $\mathrm{CO}_{2}$ if the 
decomposition is performed without $\mathrm{O}_{2}$ at a temperature of $1600^{\circ} \mathrm{C}$ in a plasma reactor (DONG et al. 2015). The full reaction is given by equation (4).

$$
\mathrm{CH}_{4} \rightarrow \mathrm{C}+2 \mathrm{H}_{2}
$$

\section{Gasification}

Coal gasification is a process that converts solid coal into synthesis gas mainly composed of $\mathrm{H}_{2}, \mathrm{CO}, \mathrm{CO}_{2}$ and $\mathrm{CH}_{4}$. The reaction is

$$
\mathrm{C}+\mathrm{H}_{2} \mathrm{O}+\text { heat } \rightarrow \mathrm{CO}+\mathrm{H}_{2}
$$

Coal can be gasified by controlling the mix of coal, oxygen and steam into the gasifier (SHOKO et. al. 2006). Due to the fact that the reaction is endothermic, additional heat is required as in the SMR. CO produced is then converted to $\mathrm{H}_{2}$ and $\mathrm{CO}_{2}$ through the WGSR reaction (see reaction 2). In most applications, $\mathrm{H}_{2}$ needs to be purified before future applications. Despite this procedure being already commercially available, nowadays, it can only compete with SMR in countries where the cost of natural gas is very high (GARCÍA-CLÚA, 2013).

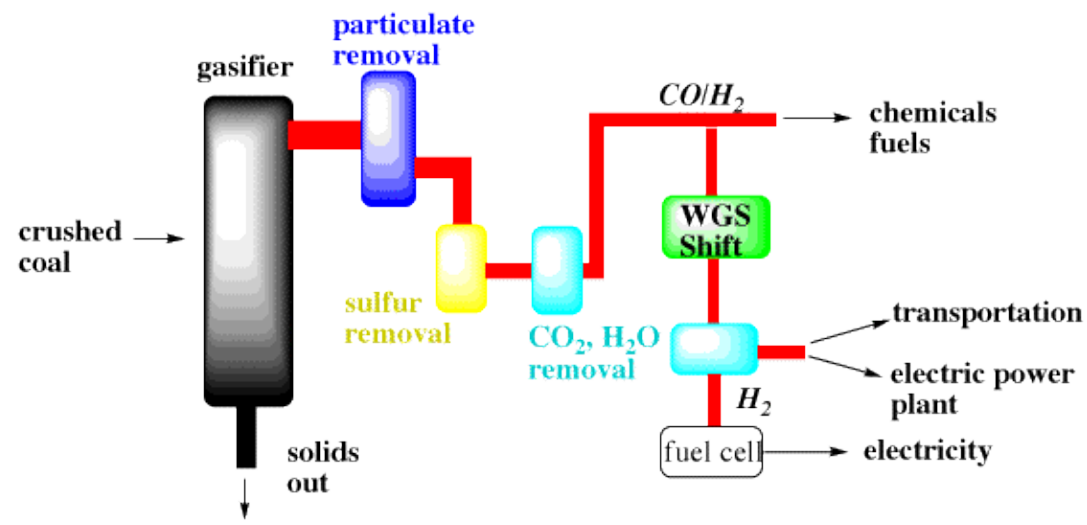

Figure 2.18- Coal gasification process scheme (http://butane.chem.uiuc.edu/pshapley/environmental/15/1.html). 


\subsubsection{Green $\mathrm{H}_{2}$}

The use of biomass as a renewable energy resource is nowadays becoming a reality. The production of $\mathrm{H}_{2}$ from biomass can be divided into three main categories (NI et al. 2006):

1. Direct production (e.g. pyrolysis/gasification, which are similar to the "black $\mathrm{H}_{2}$ " discussed in section 2.3.1.1).

2. Indirect means of production via reforming biofuels (e.g. biogas, biodiesel).

3. Metabolic processes that disintegrate water via photosynthesis to produce a WGSR reaction through photo-biological organisms.

Producing $\mathrm{H}_{2}$ by extraction from biomass can be considered better than in the case of fossil fuels, as the raw material consumes $\mathrm{CO}_{2}$ from the atmosphere during its growth, so it is considered renewable and carbon-free (GARCÍA-CLÚA, 2013).

\subsubsection{Blue $\mathrm{H}_{2}$}

Electrolyzation is a mature, market-available technique (see Figures 2.19-2.22) that can operate intermittently, producing large volumes of hydrogen without greenhouse gas emissions, as long as the electricity is provided by renewable sources (DOS SANTOS et al. 2017). Figure 2.18 depicts the simplest scheme of electrolysis reaction. The full electrolysis reaction is given by Equation (6):

$$
\mathrm{H}_{2} \mathrm{O}+\text { electricity } \rightarrow \mathrm{H}_{2} \uparrow+1 / 2 \mathrm{O}_{2} \uparrow
$$

To produce $1 \mathrm{~kg}$ of hydrogen under standard conditions for temperature and pressure, an ideal electrolyzer would require $39 \mathrm{kWh}$ and 8.9 litres of water (GARCÍA-CLÚA, 2013). The electrical power required by commercial electrolyzers to produce the same amount of hydrogen is usually, currently, between 53.4 and $70.1 \mathrm{kWh}$, which results in efficiencies of 73 to 56\% [57]. A few recent electrolyzers can achieve efficiencies above $75 \%$ of full load (see Figure 2.22). 


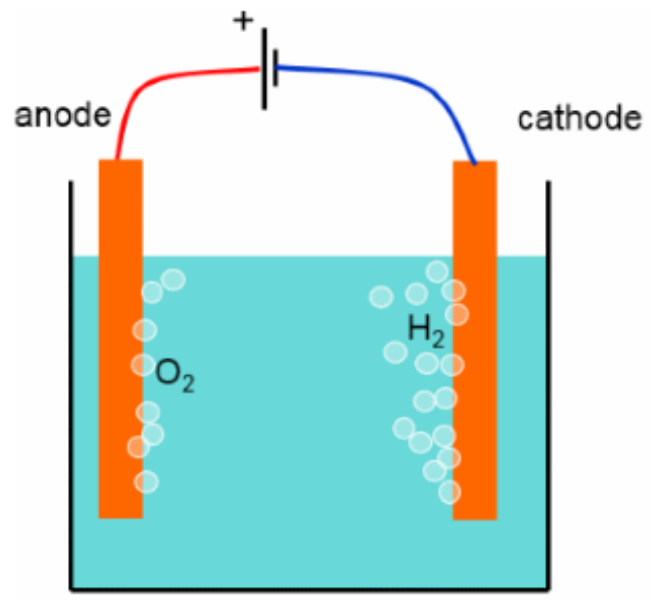

Figure 2.19- Scheme of the electrolysis reaction (http://www.diracdelta.co.uk/science/source/w/a/water\%20electrolysis/source.html\#. WJHVNH_iSyI).

There are two main types of low temperature electrolyzers: alkaline (GANLEY, 2009) and proton exchange membrane, PEM (BARBIR, 2005), which are the most frequent in the market. Furthermore, there exist high temperature electrolyzers (SOEC), but they are still only a promising technology (SCHILLER et al. 2009).

\section{$\underline{\text { Alkaline electrolysis }}$}

Alkaline electrolyzers generate $\mathrm{H}_{2}$ with a purity better than $99.97 \%$, which is the quality used in the automotive industry (PETERSEN, 2012). They are already available at the power levels (about MW) that make the technology cost-efficient (see Refs (VALVERDE et al. 2016), (RASHID et al. 2015), (MORGAN et al. 2013) and (XIANG et al. 2016) for details). An aqueous solution of 20 to $30 \%$ potassium hydroxide $(\mathrm{KOH})$ is used as the ionically conductive medium. The electrodes immersed in this electrolyte are polarized by electrochemical reactions (7) and (8), resulting in the overall reaction (6) presented before:

Cathode $2 \mathrm{H}_{2} \mathrm{O}+2 \mathrm{e}^{-} \rightarrow \mathrm{H}_{2} \uparrow+2 \mathrm{OH}^{-}$

Anode $2 \mathrm{OH}^{-} \rightarrow 1 / 2 \mathrm{O}_{2} \uparrow+\mathrm{H}_{2} \mathrm{O}+2 \mathrm{e}^{-}$ 
Each cathode-anode pair forms a basic electrolysis cell that operates at 1.9-2.5V DC. There are two types of cell design: unipolar and bipolar. Unipolar cells are interconnected in parallel by single polarity electrodes. In this way, high currents and low voltages are obtained. Unipolar cells are simpler to repair than bipolar. Bipolar cells are interconnected in series leading to higher battery voltages, thus, electrodes assume both polarities. Each of the electrodes acts as an anode on one face and as a cathode on the other, except those located at the ends. The stack is connected via alternating layers of electrodes with separation membranes and compressing the assembly with clamps. As cells are relatively thin, the entire stack can be considerably smaller than in the unipolar design. One disadvantage is that a cell cannot be repaired without removing the entire stack. The main challenges for the future of alkaline electrolysis are reducing costs and increasing energy efficiency (GARCÍA-CLÚA, 2013). Figure 2.20 presents a bipolar design of an alkaline electrolyzer stack.

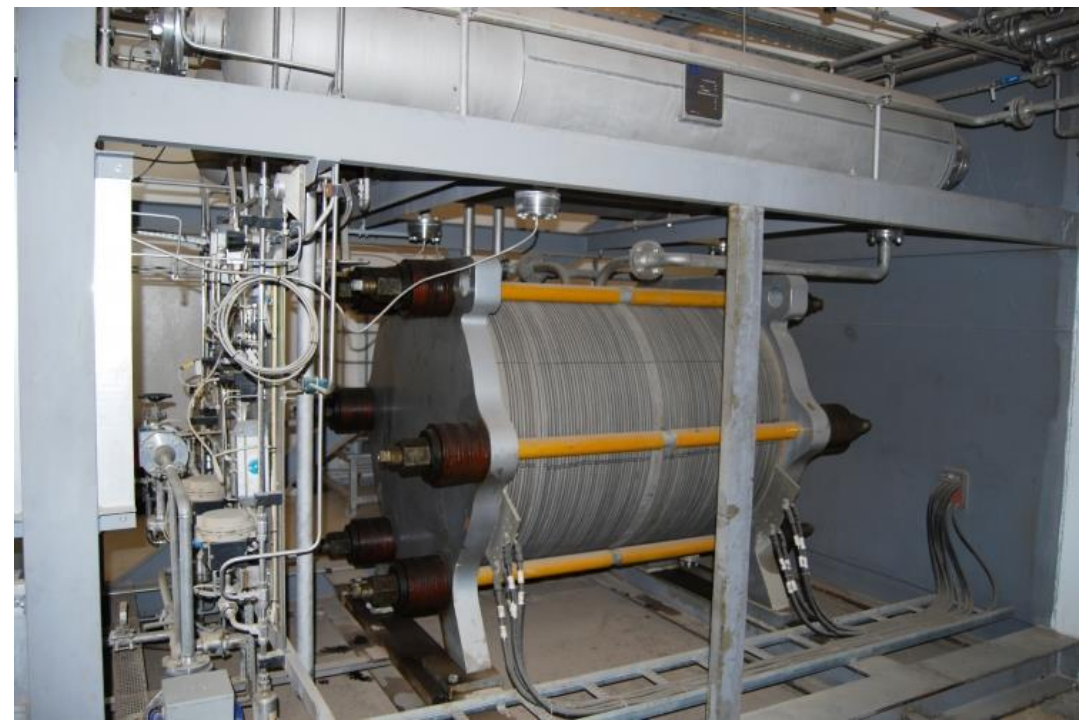

Figure 2.20-Alkaline electrolyzer stack filled with a $\mathrm{KOH}$ pure solution (http://www.alnooroils.com/en/post.php?id=26). 


\section{$\underline{\text { PEM Electrolysis }}$}

A second electrolyzer technology that is commercially available is the solid Polymer Electrolyte Membrane, or PEM. In a PEM electrolyzer, the electrolyte is in a thin, solid, ion-conducting membrane instead of the aqueous solution of alkaline electrolyzers. This allows protons to transfer from the anode to the cathode and, in this way, $\mathrm{H}_{2}$ can be separated from $\mathrm{O}_{2}$ (GARCÍA-CLÚA, 2013). PEM electrolyzers have advantages in terms of safety when compared with alternative technologies (see (MANSILLA et al. 2013) and references therein); moreover, they have already been successfully tested in marine environments (DI BLASI et al 2013). Hydrogen is produced at the cathode side and oxygen on the anode side, following reactions (9) and (10). In the case of an acidic PEM cell, it is assumed that liquid water splitting occurs according to the following half-cell reactions:

Cathode $2 \mathrm{H}^{+}+2 \mathrm{e}^{-} \rightarrow \mathrm{H}_{2} \uparrow$

Anode $\mathrm{H}_{2} \mathrm{O} \rightarrow 1 / 2 \mathrm{O}_{2} \uparrow+2 \mathrm{H}^{+}+2 \mathrm{e}^{-}$

Solvated protons formed at the oxygen-evolving anode of the PEM cell migrate through the membrane to the cathode, where they are reduced to molecular hydrogen. PEM technology is one of the most promising water electrolysis technologies for direct coupling with renewable electrical sources (ROZAIN et al: 2016, MENDES et al. 2016). Figures 2.21 and 2.22, respectively, show a PEM module and stack.

\section{$\underline{\text { High temperature electrolysis }}$}

Solid Oxide Electrolyzer Cells (SOECs) have attracted a great deal of interest because they can convert electrical energy into chemical energy, producing hydrogen with high efficiency (CARMO et al. 2013). In 1985, Dönitz and Erdle were the first to report results from a solid oxide electrolyzer (SOECs) using a supported tubular electrolyte. Nowadays, preliminary lab-scale studies are mainly focused on the development of novel, improved, low cost and highly durable materials for SOECs. 


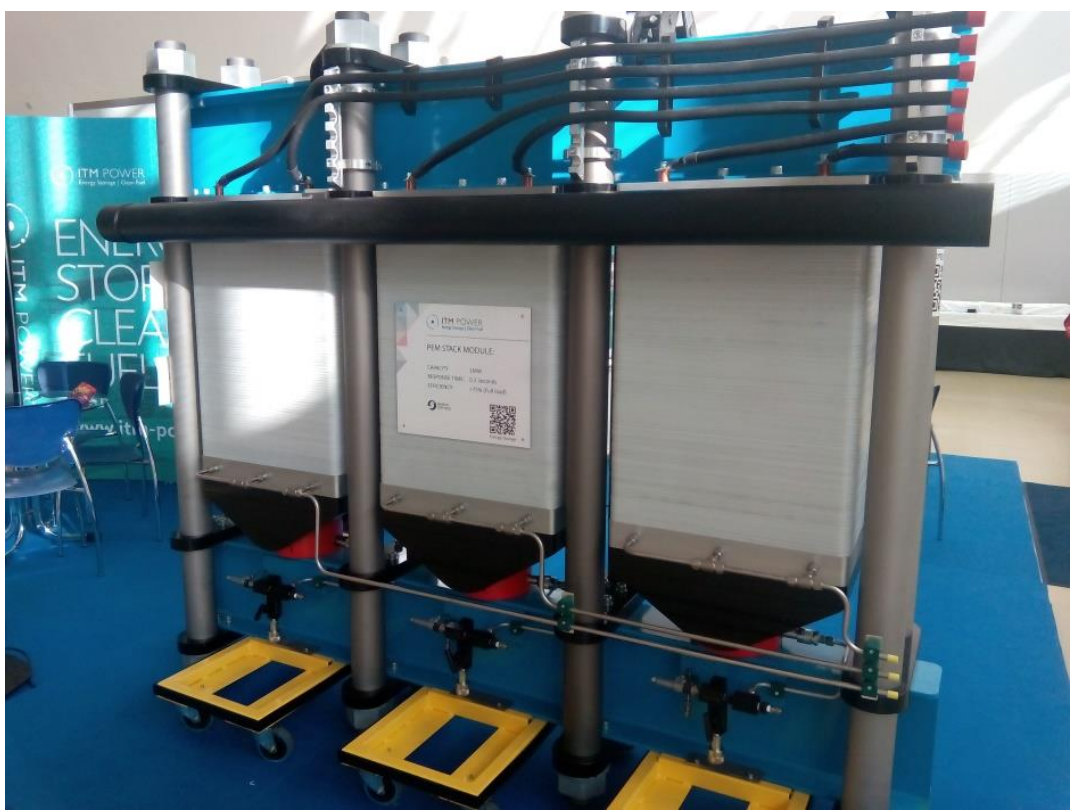

Figure 2.21- 1 MW ITM Power PEM electrolyzer stack module.

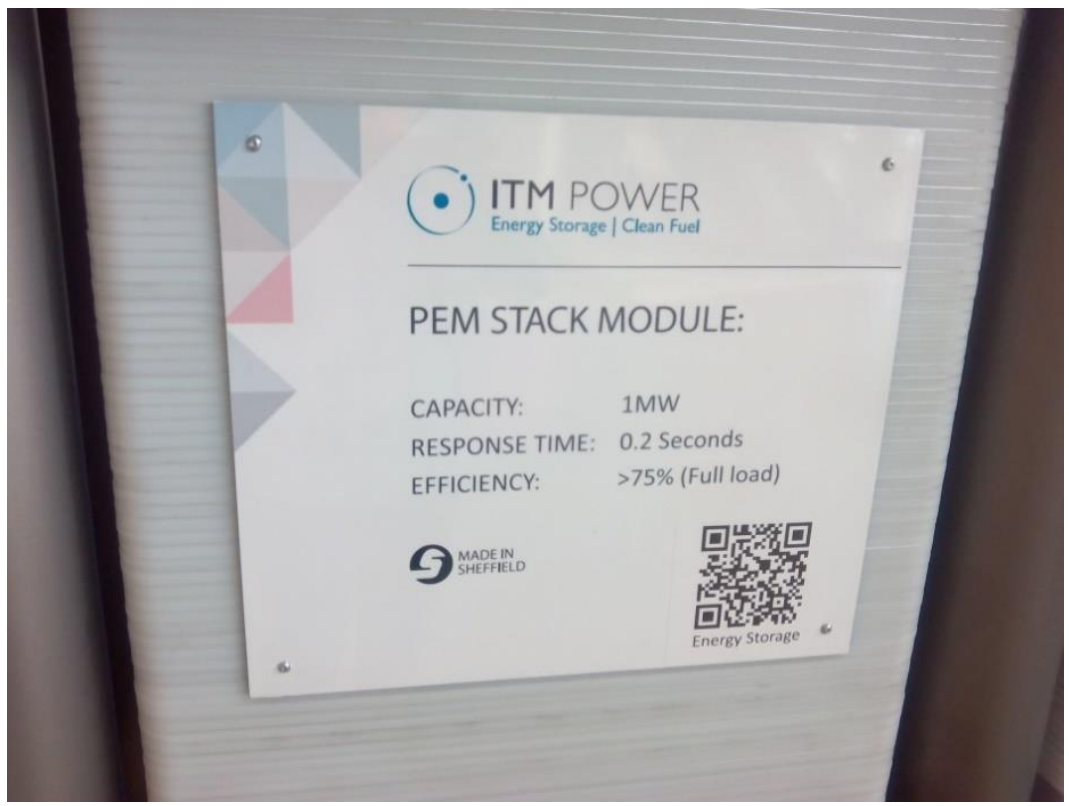

Figure 2.22-ITM Power commercial PEM modules. 
These studies focus on the development of the inherent manufacturing processes, and the integration in efficient and durable electrolyzers. Also interesting is the fact that SOECs could be used for the electrolysis of $\mathrm{CO}_{2}$ to $\mathrm{CO}$, and also for the co-electrolysis of $\mathrm{H}_{2} \mathrm{O} / \mathrm{CO}_{2}$ to $\mathrm{H}_{2} / \mathrm{CO}$ (syngas) (CARMO et al. 2013). The SOEC technology is still a promising technology, but has a huge potential for the future mass production of $\mathrm{H}_{2}$, if the issues related to operation and durability of the ceramic materials at high temperature are solved (REITER, 2016).

\subsection{MODEL PREDICTIVE CONTROL}

The term Model Predictive Control (MPC) does not designate a specific control strategy, but a very ample range of control methods which make explicit use of a model of the process to obtain the control signal by minimizing an objective function. Three decades have passed since milestone publications by several industrialists spawned a flurry of research and industrial/commercial activities on MPC (LEE, 2011). This control system has been popular in industry since the 1980s and there is steadily increasing attention from control practitioners and theoreticians (CAMACHO; BORDONS, 2013). Throughout the three decades of the development, theory and practice supported each other quite effectively, a primary reason for the fast and steady rise of the technology (LEE, 2011). MPC was originally studied and applied in the process industry, where it has been in use for decades (MORARI; LEE, 1999). Now, predictive control is being considered in other areas, such as power electronics and drives (RODRIGUEZ et al. 2013). The reason for the growing interest in the use of MPC in this field is the existence of very good mathematical models to predict the behaviour of the variables under control in electrical and mechanical systems (VAZQUEZ et al. 2014). Comparing with other methods of process control, MPC can be used to solve the most common problems in today's industrial processes, which need to be operated under tight performance specifications where many constraints need to be satisfied (CHRISTOFIDES et al. 2013).

\subsubsection{MPC strategy}

The principal elements in MPC are shown in Figure 2.23. The main characteristic is the use of the model of the system for the prediction of the future behaviour of the controlled variables (VAZQUEZ et al. 2014). This model is used to predict the future plant 
outputs, based on past and current values and on the proposed optimal future control actions. These actions are calculated by the optimizer, taking into account the cost function as well as the constraints (CAMACHO; BORDONS, 2013). All MPC controllers follow this strategy:

1- The predicted outputs for a determined horizon $\mathrm{N}$, called the prediction horizon, are predicted at each instant $k$ using the process model. These predicted outputs depend on the sequence of future control signals $u$, which are those to be sent to the system to be calculated.

2- The sequence of future control signals is calculated by optimizing a determined criterion in order to keep the process as close as possible to the future references. This criterion usually takes the form of a cost function. Constraints are also included in the optimization block.

3- MPC uses a receding horizon strategy; thus, although a set of future control moves are computed in the optimization block, only the first control action of the sequence $(u)$ is applied and the procedure is repeated at the next sampling time (LEE, 2011).

\section{Cost Function Constraints}

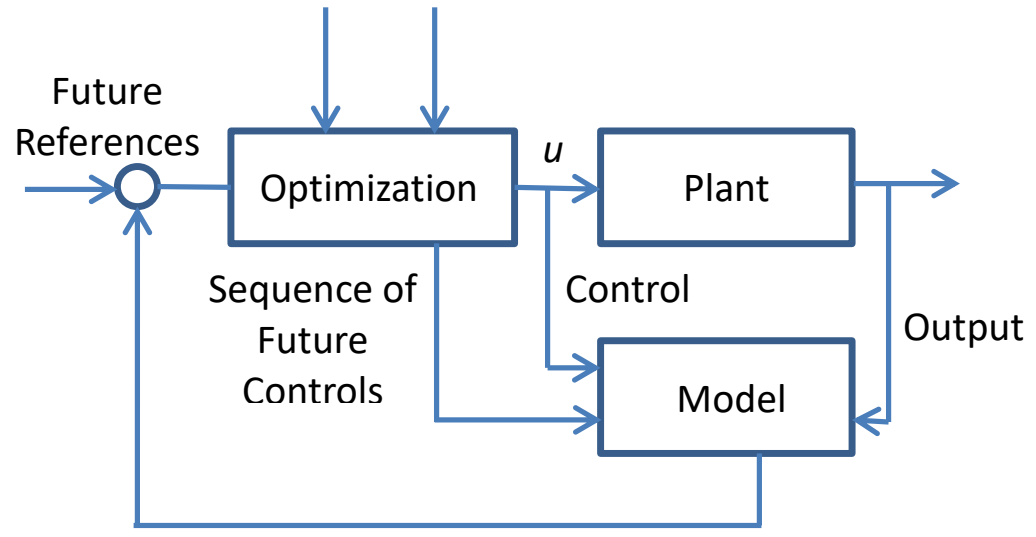

\section{Predicted Outputs}

Figure 2.23-Model Predictive Control (MPC) scheme.

A model is used to predict the future plant outputs, based on past and current values and on the proposed optimal future control actions. These actions are calculated by the optimizer, taking into account the 
cost function (where the future tracking error is considered) as well as the constraints. The process model consequently plays a decisive role in the controller. The chosen model must be capable of capturing the process dynamics so as to precisely predict the future outputs, as well as being simple to implement and to understand. The optimizer is another fundamental part of the strategy as it provides the control actions (CAMACHO; BORDONS, 2013).

\subsubsection{Receding horizon}

It is important to remark that one of the most important characteristics of the MPC is the use of the receding horizon. At each instant, the horizon is displaced towards the future, which involves the application of the sequence calculated at each step k. In this type of strategy, only the first control actions are taken at each instant and the procedure is again repeated for the next control decisions in a receding horizon fashion (unlike other classical control schemes such as PIDs, in which the control actions are taken based on past errors). In the receding-horizon strategy, only the first elements of the control variable are used, rejecting the rest and repeating the calculations at the next sampling time (CAMACHO; BORDONS, 2013).

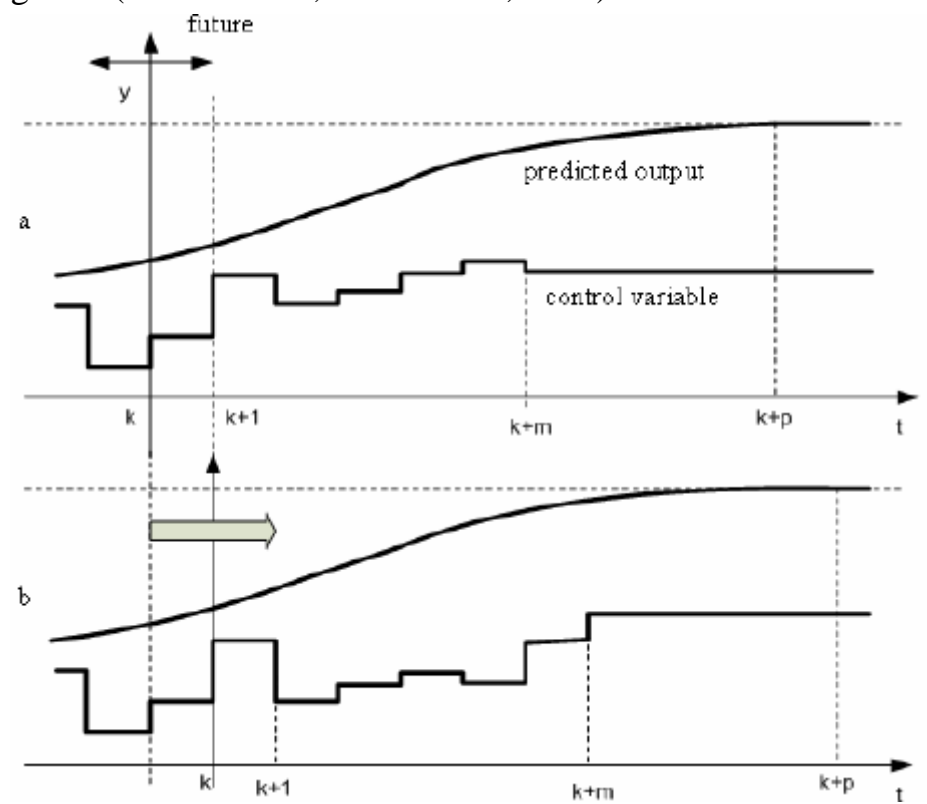

Figure 2.24-Receding horizon scheme (PARASCHIV et al. 2009). 


\subsubsection{Constraints}

To solve MPC constraints in this thesis, the Mixed Logical Dynamical System (MLD) will be used. The MLD was developed for the first time by (BEMPORAD; MORARI, 1999) to associate the performance of the system with discrete variables $\delta$ and continuous variables $\alpha$. MLD conversions make it possible to include binary and auxiliary variables, introduced in a discrete-time dynamic system to describe, in a unified model, the evolution of the continuous and logic signals of the system.

The MLD MPC results in an optimization problem with a set of linear constraints and integer (in this case Boolean) decision variables. With the introduction of a series of basic conversions, given in Table 1.1 , the non-linearity of the system, introduced by the combination of logical and dynamic variables, is transformed into constraints of the control algorithm (GARCÍA-TORRES, 2015). In Table 1.1, $\mathrm{m}$ and $\mathrm{M}$ represent the lower and upper bounds of the system and $\varepsilon>0$ is the smaller tolerance of the device (BEMPORAD; MORARI, 1999).

\begin{tabular}{|c|c|c|c|}
\hline & Relation & Logic & MLD Inequalities \\
\hline P1 & $\operatorname{AND}(\wedge)$ & $\mathrm{S}_{1} \wedge \mathrm{S}_{2}$ & $\delta_{1}=1, \delta_{2}=1$ \\
\hline P2 & & $\mathrm{S}_{3} \leftrightarrow\left(\mathrm{S}_{1} \wedge \mathrm{S}_{2}\right)$ & $\begin{array}{c}-\delta_{1}+\delta_{3} \leq 0 \\
-\delta_{2}+\delta_{3} \leq 0 \\
\delta_{1}+\delta_{2}-\delta_{3} \leq 1\end{array}$ \\
\hline P3 & OR (v) & $S_{1} \vee S_{2}$ & $\delta_{1}+\delta_{2} \geq 1$ \\
\hline P4 & $\operatorname{NOT}(\sim)$ & $\sim \mathrm{S}_{1}$ & $\delta_{1}=0$ \\
\hline P5 & $\operatorname{IMPLY}(\rightarrow)$ & $\mathrm{S}_{1} \rightarrow \mathrm{S}_{2}$ & $-\delta_{1}-\delta_{2} \leq 0$ \\
\hline P6 & $\operatorname{IF}(\leftrightarrow)$ & $\mathrm{S}_{1} \leftrightarrow \mathrm{S}_{2}$ & $-\delta_{1}-\delta_{2}=0$ \\
\hline P7 & & {$\left[\mathrm{a}^{\mathrm{T}} \mathrm{x} \leq 0\right] \rightarrow[\delta=1]$} & $\mathrm{a}^{\mathrm{T}} \mathrm{X} \geq \varepsilon+(\mathrm{m}-\varepsilon)$ \\
\hline P8 & & {$[\delta=1] \rightarrow\left[\mathrm{a}^{\mathrm{T}} \mathrm{X} \leq 0\right]$} & $\mathrm{a}^{\mathrm{T}} \leq \mathrm{M}-\mathrm{M} \delta$ \\
\hline P9 & & {$\left[\mathrm{a}^{\mathrm{T}} \mathrm{x} \leq 0\right] \leftrightarrow[\delta=1]$} & $\begin{array}{c}\mathrm{a}^{\mathrm{T}} \leq \mathrm{M}-\mathrm{M} \delta \\
\mathrm{a}^{\mathrm{T}} \geq \varepsilon+(\mathrm{m}-\varepsilon) \delta\end{array}$ \\
\hline P10 & $\begin{array}{l}\text { Mixed } \\
\text { Product }\end{array}$ & $\mathrm{z}=\delta \cdot \mathrm{a}^{\mathrm{T}} \mathrm{x}$ & $\begin{array}{c}\mathrm{z} \leq \mathrm{M} \delta \\
\mathrm{z} \geq \mathrm{m} \delta \\
\mathrm{z} \leq \mathrm{a}^{\mathrm{T}} \mathrm{x}-\mathrm{m}(1-\delta) \\
\mathrm{z} \geq \mathrm{a}^{\mathrm{T}} \mathrm{x}-\mathrm{M}(1-\delta)\end{array}$ \\
\hline
\end{tabular}

Table 1.1 - Conversion of logic relations into Mixed Integer Inequalities. 


\subsection{CONTRIBUTIONS OF THE THESIS}

\subsubsection{Journal papers}

SERNA, A.; YAHYAOUI, I.; NORMEY-RICO, J. E.; de PRADA, C.; TADEO, F. Predictive control for hydrogen production by electrolysis in an offshore platform using renewable energies. International Journal of Hydrogen Energy, 42(17) 12865-12876, 2017. IF (2016): 3.6.

SERNA, A.; TADEO, F.; NORMEY-RICO, J. E. Ruled-based control of off-grid desalination powered by renewable energies. Renewable energy and sustainable development, pp 205-213, 1, N ${ }^{\mathrm{o}} 1,2015$.

SERNA, A.; TADEO, F. Offshore hydrogen production from wave energy. International Journal of Hydrogen Energy, 39(3), 15491557, 2014. IF (2014): 3.3.

SERNA, A.; TADEO, F. Offshore desalination using wave energy. Advances in Mechanical Engineering, 5, 539857, 2013. IF (2013): 0.5 .

\subsubsection{Conference papers}

SERNA, A.; TADEO, F.; YAHYAOUI, I.; NORMEY-RICO, J. E. Business background analysis for a controlled hydrogen-based microgrid. In Proceedings of the $14^{\text {th }}$ International Workshop on Advanced Control and Diagnosis (ACD), November 2017, Bucharest, Romania.

SERNA, A.; TADEO, F.; NORMEY-RICO, J.E. Advanced control based on MPC ideas for offshore hydrogen production. In Proceedings of the $\mathbf{3 8}^{\text {th }}$ Jornadas de Automática 2017, September, Gijón, Spain.

SERNA, A.; TADEO, F.; YAHYAOUI, I.; NORMEY-RICO, J. E.; GARCIA-TORRES, F. Evaluation of a Long Term System coupled with a Short Term System of a Hydrogen-Based Microgrid. In Proceedings of the $\mathbf{8}^{\text {th }}$ International Renewable Energy Congress (IREC), March 2017, Amman, Jordan. (pp. 1-6). IEEE. 
SERNA, A.; TADEO, F.; NORMEY-RICO, J. E.; AGERSTED, K. Ruled-based control of off-grid electrolysis. In Proceedings of the $\mathbf{2 1}^{\text {st }}$ World Hydrogen Energy Congress (WHEC), June 2016, Zaragoza, Spain.

SERNA, A.; TADEO, F.; NORMEY-RICO, J. E. Mixed-IntegerQuadratic-Programming based Predictive Control for hydrogen production using renewable energy. In Proceedings of the $\mathbf{7}^{\text {th }}$ International Renewable Energy Congress (IREC), March 2016, Hammamet, Tunisia. (pp. 1-6). IEEE.

SERNA, A.; TADEO, F.; NORMEY-RICO, J. E. Control avanzado basado en ideas de control predictivo para la producción de hidrógeno mediante electrólisis. In Proceedings of the $14^{\text {th }}$ Simposio de Ingeniería de Control CEA 2016, March 2016, Logroño, Spain.

SERNA, A.; TADEO, F.; NORMEY-RICO, J.E. Producción de hidrógeno por energías renovables en una plataforma híbrida en alta mar. In Proceedings of the $\mathbf{3 6}^{\text {th }}$ Jornadas de Automática 2015, September, Bilbao, Spain.

SERNA, A.; NORMEY-RICO, J. E.; TADEO, F. Model predictive control of hydrogen production by renewable energy. In Proceedings of the $6^{\text {th }}$ International Renewable Energy Congress (IREC), March 2015, Sousse, Tunisia. (pp. 1-6). IEEE.

SERNA, A.; TADEO, F.; TORRIJOS, D. Heuristic control of multistage desalination plants under variable available power. In Proceedings of the $15^{\text {th }}$ International Conference of Sciences and Techniques of Automatic Control and Computer Engineering (STA), December 2014, Hammamet, Tunisia. (pp. 853-858). IEEE.

SERNA, A.; TORRIJOS, D.; TADEO, F., TOUATI, K. Evaluation of wave energy for a near-the-coast offshore desalination plant. In Proceedings of the International Desalination Association (IDA) World Congress, October 2013, Tianjin, China.

\subsubsection{Other contributions}

Co-author of one chapter in the book titled "Advances in Renewable Energies and Power Technologies: Volume 1: Solar and Wind Energy" 
ISBN: 9780128129593 and one chapter in the book titled: "Advances in Renewable Energies and Power Technologies: Volume 2: Geothermal and Biomass Energies, Fuel Cells and Smart Grids" ISBN: 9780128131855. Edited by Dr. Imene Yahyaoui. Elsevier, $1^{\text {st }}$ January 2018.

YAHYAOUI, I.; ATIEH, A.; SERNA, A.; TADEO, F. Sensitivity analysis for photovoltaic water pumping systems: Energetic and economic studies. Energy Conversion and Management, 135, 402415, 2017. IF (2016): 5.6.

SERNA, A.; TADEO, F.; NORMEY-RICO, J. E. Control de la producción de $\mathrm{H}_{2}$ por energías renovables en una plataforma híbrida en alta mar. In the $\mathbf{3}^{\text {rd }}$ Jornadas del Programa de Doctorandos de la Universidad de Valladolid, September 2016, Valladolid, Spain. Poster presentation.

SERNA, A.; TADEO, F.; NORMEY-RICO, J.E. (2015, March). Sistema de control en la producción de hidrógeno en alta mar mediante energías renovables. In the $\mathbf{8}^{\text {th }}$ Reunión de Jóvenes Investigadores Iberoamericanos, March 2015, Tordesillas, Spain. Poster presentation.

SERNA, A.; TADEO, F. Modelling of an offshore hydrogen production from wave energy. In Proceedings of the $4^{\text {th }}$ International Renewable Energy Congress (IREC), December 2012, Sousse, Tunisia. Oral presentation.

SERNA, A.; TADEO, F.; de PRADA, C. The H2OCEAN Project: A wind + wave power open-sea platform equipped for hydrogen generation. In Offshore Wind Turbines Workshop, University of Hull, September 2012, Hull, UK. Poster presentation.

\subsubsection{Patent and intellectual property registration}

Title: Offshore hydrogen production using wave energy

Author: ÁLVARO SERNA CANTERO

Reference number: VA-299-2013

Year: 2013

Right holder: University of Valladolid (Spain) 
Winner of the University of Valladolid "Prometeo" award 2013 whose aim is the stimulation of the application of knowledge, as well as collaboration between knowledge-generating agents and specialists in the transfer of knowledge and the promotion of a culture of innovation and creativity. For this, this award provides incentives for the development of market-oriented prototypes, achieving a set of products that can be offered to meet the needs of the market.

\subsection{ORGANIZATION OF THE THESIS}

This thesis is organized as follows:

Chapter 1: This chapter introduces the thesis content. Section 1.1 gives the motivation, while section 1.2 give details of the objectives proposed for this thesis.

Chapter 2: This chapter deals with the state of the art of the technologies developed in the thesis. Section 2.1 is dedicated to renewable energies. Section 2.2 gives a review of reverse osmosis. Section 2.3 presents information about hydrogen economy and production, followed by a summary of Model Predictive Control theory (Section 2.4). Finally, the contributions of the thesis are detailed.

Chapter 3: This chapter focuses on the design of control strategies for the production of water by Reverse Osmosis and hydrogen by electrolysis within the H2OCEAN offshore platform. Section 3.1 is dedicated to the fresh water production, whilst Section 3.2 deals with hydrogen production. Finally, this chapter ends with some conclusions.

Chapter 4: This chapter develops an Energy Management System of hydrogen production $\left(\mathrm{EMS}_{\mathrm{H}}\right)$ based on Model Predictive Control ideas optimizing the connections and disconnections of the electrolyzers. This numerical optimization solves a Mixed-Integer Quadratic Programming algorithm with constraints.

Chapter 5: This chapter comprises the coupling of a short-term control system with the long-term $\mathrm{EMS}_{\mathrm{H}}$ proposed in Chapter 4 for a hydrogen-based microgrid composed of electrolyzers, battery and an ultracapacitor. 

work.

Chapter 6: This chapter includes some conclusions and future

Annex: This annex presents an economic study and a business plan for the hydrogen-based microgrid proposed in Chapter 5.

\subsection{SUMMARY AND CONCLUSIONS}

In this chapter, an overall introduction of the technologies developed in the thesis has been detailed:

- Wind and wave energy are the energy sources chosen to produce energy, as they can be easily obtained in the H2OCEAN platform.

- Reverse Osmosis is the most adequate technology to transform seawater into fresh water. It is very well known and commercially available.

- Electrolysis has been chosen to obtain hydrogen from water due to its technological maturity and easy implementation.

- Model Predictive Control is an advanced control strategy that can be used to solve the most common problems in today's industrial processes, which need to be operated under tight performance specifications. Thus, it was chosen to design the Energy Management System for hydrogen production that is fully developed in Chapter 4.

The chapter ended with the contributions made by the author during the thesis and the organization of the different chapters. 


\section{CHAPTER 3}

\section{CONTROL OF THE H2OCEAN PLATFORM}




\section{CONTROL PROPOSAL FOR THE H2OCEAN PLATFORM}

This chapter deals with the design of control strategies for the production of water by Reverse Osmosis (RO) and hydrogen by electrolysis in the renewable energy offshore H2OCEAN platform. The purpose is to test the feasibility of these control systems in the production of drinkable water and hydrogen using renewable energy in out-of-sight installations. These tasks were defined in Section 1.1 as part of the work done by the University of Valladolid for the H2OCEAN project.

\subsection{FRESH $\mathrm{H}_{2} \mathrm{O}$ PRODUCTION IN THE H2OCEAN PLATFORM}

This section evaluates a control proposal design for water production within the H2OCEAN project (see Section 1.1), which will be evaluated for two different case studies.

First, the subsystems that compose the proposed desalination plant are described. Then, for the first case study, an Energy Management System for Water production $\left(E M S_{W}\right)$ based on heuristic control is given, as well as a proposal for sizing these subsystems. The influence of sizing on the expected performance is then studied for a specific location using buoy-measured data.

Finally a second case study proposes a rule-based $\mathrm{EMS}_{\mathrm{W}}$ to control the installation, due to its easier implementation so that low conductivity water for electrolysis can be produced. This case study is also evaluated using buoy-measured data.

The proposal presented here is based on dividing the desalination plant into a few sections, which would be switched on or shutdown, depending on the available energy (SERNA; TADEO, 2013). All of this requires an $\mathrm{EMS}_{\mathrm{W}}$ which be will discussed later. Power consumption adapts to power production by connecting or disconnecting sections of the installation (following a Smart Grid approach for the microgrid in the plant). The temporary storage of electricity in batteries for short-time balances is selected for its smooth operation and for the increase in autonomy.

A description of the different components of the desalination plant is given in 3.1.1, whilst the first case study is proposed in section 3.1.2. The second case study is presented in section 3.1.3. 


\subsubsection{Desalination plant operation}

The process diagram in Figure 3.1 presents the main blocks of the proposal: the renewable energy sources, the supply of seawater through seawater pumps (SWP) and the desalination stage. A set of batteries provide electricity for the case of there being no renewable energy available. Then, fresh water is transported (by tankers, bladders or pipes) to the hydrogen production section.

As already mentioned in Section 2.1, renewable energy production changes over time, which requires the production of water (and thus power consumption) to be adapted to the available power. This is challenging for RO plants, as they are normally designed to operate at an optimal working point. Changing the working point of the plant (thus changing the flow/pressure combination from a specific value) makes it possible to adapt the RO electrical load to the demand.

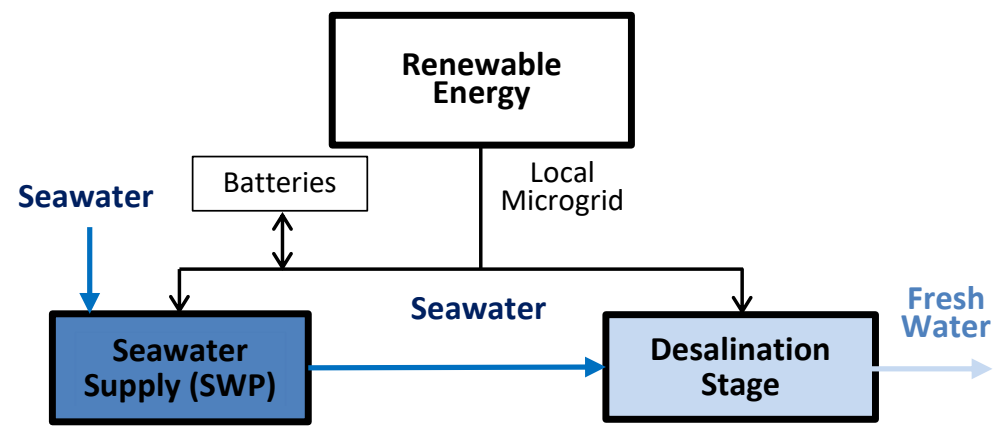

Figure 3.1 - Structure of the proposed desalination installation

A specific $\mathrm{EMS}_{\mathrm{W}}$, discussed later, would be responsible for adapting power consumption to demand, always with the aim of operating the plant at the best possible overall efficiency, while taking into account the operating constraints.

\subsubsection{First case study}

The desalination plant proposed in this section was developed as part of the H2OCEAN project (SERNA; TADEO, 2013) from previous designs by SETA (Sociedad Española de Tratamiento de Agua). It is shown in Figure 3.2.

In this first case study the first proposal of $\mathrm{EMS}_{\mathrm{W}}$ is developed. It was decided to partition the desalination stage of the RO plant into three 
sections of different sizes (A, B and C): the three sections operate as a standard RO plant (producing water with maximum efficiency, at a fixed working point). Sections can operate on an individual basis or together with other sections, depending on the available energy.

Seawater with flow $Q_{S}$ is taken from the sea by the SWPs before being stored in a single seawater tank with volume $V_{S}$, as can be seen in Figure 3.2. It is then desalinated and stored in a fresh water tank with volume BT1, in order to transport it offshore through pipes and/or water tank ships or bladders (represented by flow $\mathrm{Q}_{\mathrm{F}}$ ).

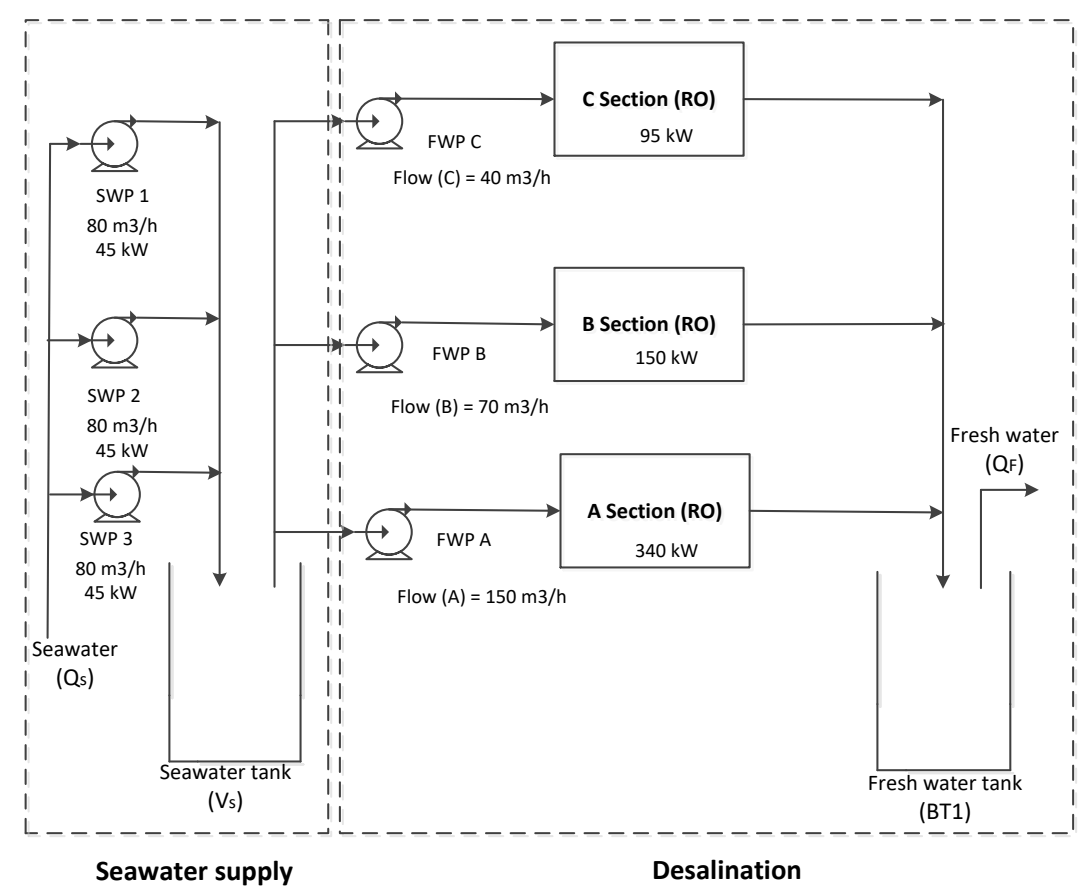

Figure 3.2 - Structure of the first case study.

The proposed system is off-grid, so energy production and demand must be balanced. Several technologies have been proposed for temporary storage (ANTONIA; SAUR, 2012). Here, we propose the following $\mathrm{EMS}_{\mathrm{W}}$ for this first case study: 


\subsubsection{Energy Management System based on heuristic control}

A central component to ensure the smooth operation of the facility is the control system, which should balance electricity production and consumption by adapting the consumed loads: the power of the seawater pumps (SWPs) and the high pressure pumps working in the different sections of the RO.

The key decision variable, the Depth of Discharge (DOD) of a battery, is the percentage of capacity to which it is discharged. Values approaching 1 correspond to the battery being almost discharged. It is assumed that the control algorithm is based on the two following ideas:

1) Main control variables are the connection/disconnection of the different sections $\mathrm{A}, \mathrm{B}$ and $\mathrm{C}$ in the RO and the SWPs (See Figure 3.3).

- When the production is higher than the consumption, the energy is stored so the DOD of the battery decreases: until the temporary storage system is nearly full, different sections of the RO and the SWP are switched on depending on the value of the DOD.

- If the DOD increases significantly because production is lower than demand, sections of the RO and the SWP are switched off (these sections are then automatically cleaned and maintenance operations are carried out).

2) Another control variable is the connection/disconnection of the three SWPs for safety conditions, as these pumps operate independently from the RO plant:

- When the level of the seawater tank $V_{S}$ is higher than a certain safety value $\left(\mathrm{L}_{\mathrm{T}} \geq \mathrm{L}_{\mathrm{Tmax}}\right)$, the three SWPs are switched off simultaneously.

- When the level of the seawater tank $V_{S}$ is lower than a certain safety value $\left(\mathrm{L} \leq \mathrm{L}_{T \text { min }}\right)$, the three SWPs are switched on simultaneously. 


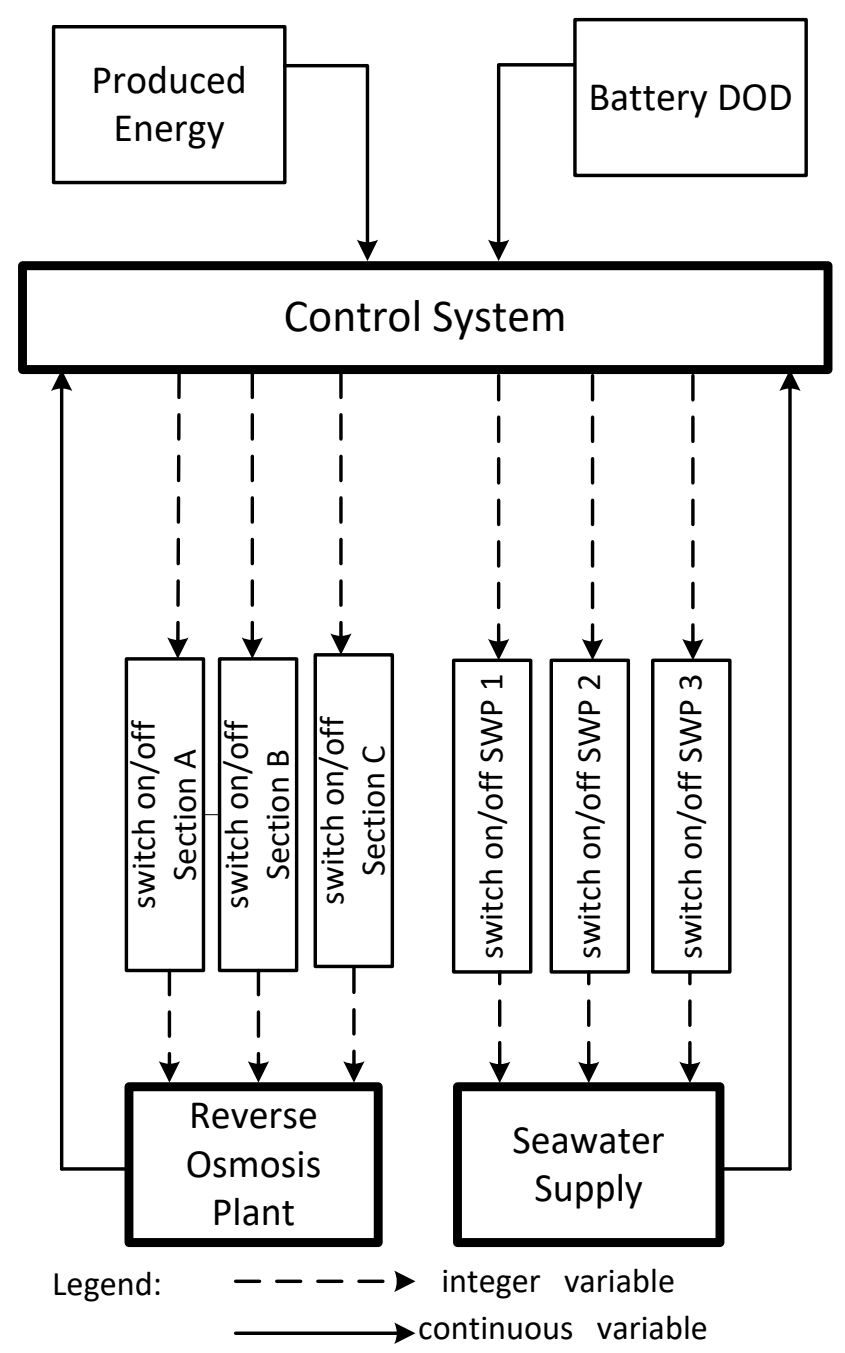

Figure 3.3- Proposed $\mathrm{EMS}_{\mathrm{W}}$ for the first case study

The control logic is summarized in the Sequential Function Chart in Figure 3.4, where different sequences of the desalination process can be seen. There is one different combination of RO sections (A, B and C) in each stage. Therefore, for each range of DOD values, there is a certain operating stage. Furthermore, in each stage, the three SWPs are switched on/off one by one depending on the value of the DOD, as can 
be seen in the detail of the Sequential Function Chart of stage A presented in Figure 3.5.

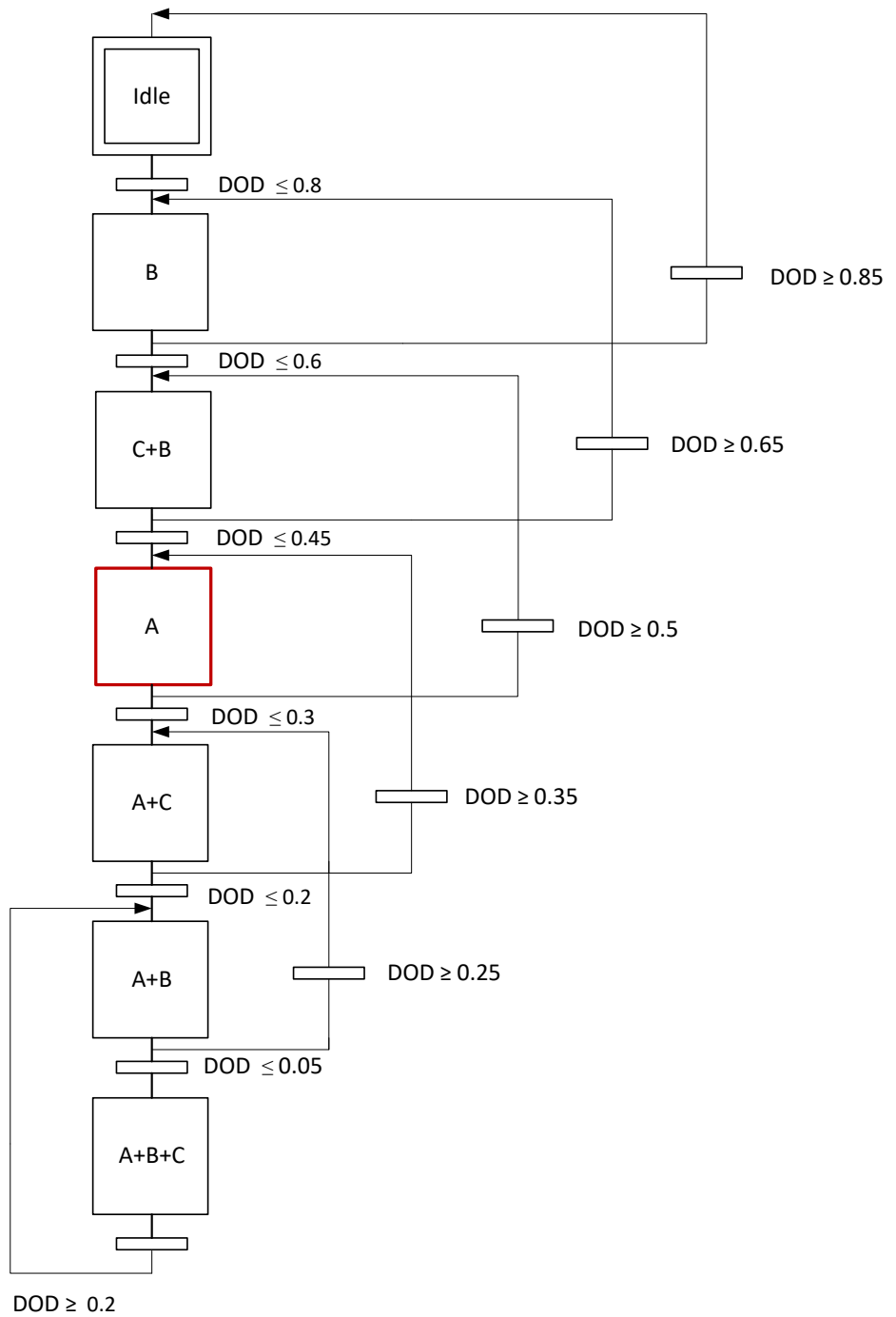

Figure 3.4 - Sequential Function Chart of the Control Logic of the RO 


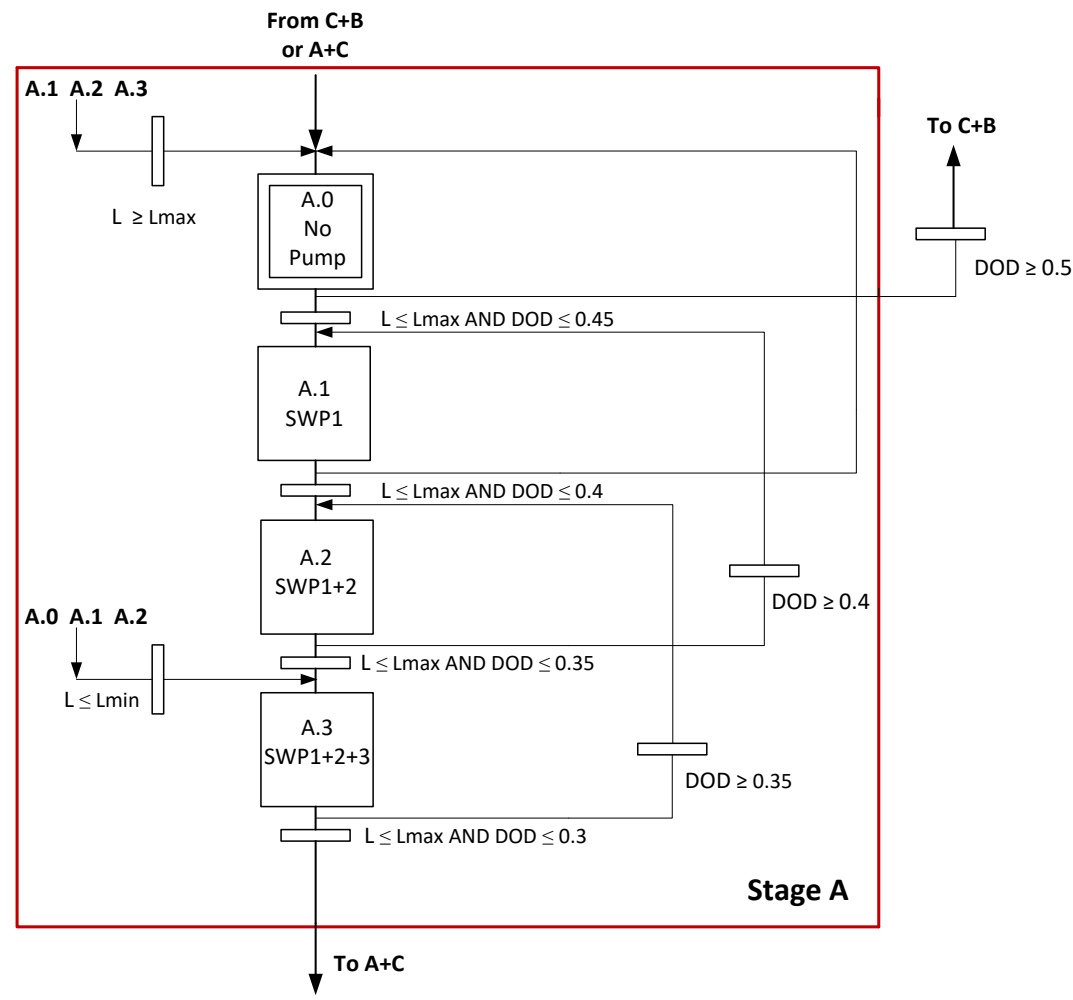

Figure 3.5 - Detail of the Sequential Function Chart (Stage A)

For this case study, a standard $\mathrm{Pb}$ battery rack system is assumed, as it has wide experience in marine applications. During charge, the electrons are provided by an external power source. The nominal voltage of the lead-acid cell is 2 volts (SZYMBORSKI, 2002). The batteries are used to provide energy to the reverse osmosis plant and the SWPs when not enough power is provided by the renewable energies.

$$
\mathrm{I}=\frac{\mathrm{P}_{\mathrm{W}}-\mathrm{P}_{\mathrm{T}}}{\mathrm{V}}
$$

where $\mathrm{I}$ is the amperage of the battery, $\mathrm{V}$ is the voltage, $\mathrm{P}_{\mathrm{w}}$ is the power supplied by renewable energies, and $\mathrm{P}_{\mathrm{T}}$ is the total power consumed by the SWP and the RO. The equation relating the capacity of the battery and the amperage is as follows (SERNA; TADEO, 2013): 


$$
\frac{\mathrm{dC}_{\mathrm{R}}}{\mathrm{dt}}=\psi \frac{\mathrm{I}^{\mathrm{k}_{\mathrm{P}}}}{3600}
$$

where $C_{R}$ is the rated capacity at that discharge rate, $t$ is the time, $k_{P}$ is Peukert's coefficient, and $\psi$ is the efficiency of the battery. The DOD is given by the expression below, where $C_{P}$ is Peukert's capacity.

$$
\mathrm{DOD}=1-\frac{\mathrm{C}_{\mathrm{R}}}{\mathrm{C}_{\mathrm{P}}}
$$

The value of the $\%$ of battery charge is given by this simple equation:

$$
\% \text { Battery charge }=(1-\text { DOD }) \cdot 100
$$

The DOD is used in more works (YAHYAOUI et al. 2014) to control different devices, such as photovoltaic panels or batteries. It is important to note the importance of the fact that the constant discharging and charging of the batteries often leads to them becoming quickly ineffective. Therefore, the battery capacity finally chosen for the simulation in Section 3.1.2.3 aims to be the least harmful to the system.

\subsubsection{Sizing of the first case study}

In the proposed facility shown in Fig. 3.2, a central aspect of the design for a specific location is the selection of the size of the components, so as to ensure the autonomous operation of the facility without excessive capital or operation costs. In particular, the following parameters should be selected:

- The maximum fresh water demand, $\mathrm{Q}_{\mathrm{F}}\left(\mathrm{m}^{3} / \mathrm{h}\right)$.

- The total rated power consumption of the process, $\overline{\mathrm{P}}_{\mathrm{T}}(\mathrm{kW})$.

- The volume of the seawater tank, $\mathrm{V}_{\mathrm{S}}\left(\mathrm{m}^{3}\right)$.

- $\quad$ The battery capacity, $\mathrm{C}_{\mathrm{P}}(\mathrm{Ah})$.

In this kind of renewable energy installations, it is important to consider the variability of the source: thus, forecasts are usually needed (LEI et al. 2009). In this case, we assume that a significant record of data measured in the location where the Wave Energy Converters (WECs) and Vertical Axis Wind Turbines (VAWTs) would be placed is 
available. The sizing of the proposed facility can be carried out on the basis of the measured data. The proposed methodology to select the plant parameters is then the following:

1) Using the measured data, the evolution of the power produced by the renewable energy devices, $\mathrm{P}_{\mathrm{W}}(\mathrm{t})$, is estimated as explained in Sections 2.1.1 and 2.1.2.

2) The total rated power consumption of the process $\bar{P}_{T}$ is selected to ensure that one or more of the different sections of the RO operate for at least some of the time. This value must always be less than $\mathrm{P}_{\mathrm{W}}$.

3) The tank size $V_{S}$ is selected to ensure autonomy at all times ( $L_{T m i n}$ $\leq \mathrm{L} \leq \mathrm{L}_{\text {Tmax }}$ ).

4) The battery capacity $C_{P}$ is selected to ensure $W_{a}$ hours of autonomy at idle of all times and that the DOD is always between given limits $\overline{\mathrm{DOD}}<$ DOD $<$ DOD.

Figure 3.6 shows inputs and outputs in the sizing scheme, taking into account the variables of the desalination installation:

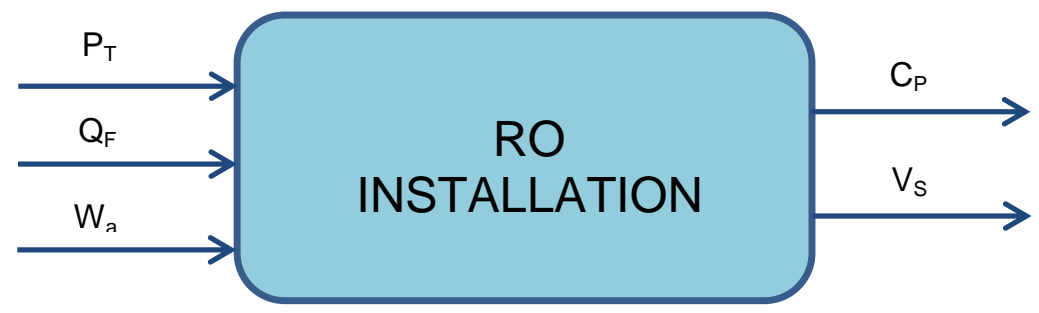

Figure 3.6 - Scheme of the sizing for the first case study

\subsubsection{Results and discussion}

The first case study proposes a desalination stage designed to operate consuming between $95 \mathrm{~kW}$ and $585 \mathrm{~kW}$ of electricity $\left(\overline{\mathrm{P}}_{\mathrm{T}}\right)$ as shown in Fig. 3.2: section $A$ is designed to produce $150 \mathrm{~m}^{3} / \mathrm{h}$ with a consumption of $340 \mathrm{~kW}$, whereas section $\mathrm{B}$ is designed to produce 70 $\mathrm{m}^{3} / \mathrm{h}$ with a consumption of $150 \mathrm{~kW}$, and $\mathrm{C}$ produces $40 \mathrm{~m}^{3} / \mathrm{h}$ consuming $95 \mathrm{~kW}$. The energy consumption of the RO units (power consumed between water produced) is about $2.4 \mathrm{kWh} / \mathrm{m}^{3}$ and the plant 
recovery ratio (water input between water output) is about $50 \%$ (SERNA; TADEO, 2013).

There are three seawater pumps (SWPs) that provide water from the seawater intake to the seawater tank. Each pump works with a power of $45 \mathrm{~kW}$ and a flow rate of $80 \mathrm{~m}^{3} / \mathrm{h}$. These pumps are on-off pumps that work (or not) while the tank level is between certain values: if the tank level is higher than a safety value, all the pumps immediately switch off. Thus, the tank level can be controlled as has been detailed in Figure 3.5.

To validate the proposed offshore platform and the sizing methodology, this case study was carried out for a specific location in the Atlantic Ocean, selected for its good wave regime. For this location, buoy data was measured for 165 days (wind speed, wave heights, wave periods, water salinity and temperature, etc.). Based on this data, an installation was designed using the proposed sizing methodology. This design was then tested assuming different platform parameters. The simulation was modelled and performed using MATLAB $^{\circledR}$ and Simulink ${ }^{\circledR}$.

Figure 3.7 shows the effect of the battery's capacity on system performance: the RO plant capacity and switch on-off times of the SWPs and sections of the RO for a tank volume $\left(\mathrm{V}_{\mathrm{S}}\right)$ of $5500 \mathrm{~m}^{3}$. It also shows that the amount of fresh water produced $\left(\mathrm{Q}_{\mathrm{F}}\right)$ increases until a battery capacity value of $C_{P}=2400 \mathrm{Ah}$, remaining constant after this value. The value of the number of times that the SWPs are switched onoff is independent of the battery capacity. The number of times that the RO is switched on-off decreases with the increase in the battery's capacity. Therefore, a battery capacity of 2400 Ah will be chosen to evaluate the effect of the seawater tank size on system performance.

Figure 3.8 shows the effect of the seawater tank volume with the same system parameters for the case of a battery capacity of $2400 \mathrm{Ah}$. It also shows that the amount of fresh water produced, $\mathrm{Q}_{\mathrm{F}}$, is independent of the seawater tank volume $\mathrm{V}_{\mathrm{S}}$. The same behaviour has been seen with the number of times that the sections of the RO are switched on-off. The value of the number of times that the SWP are switched on-off decreases in line with the tank volume $\mathrm{V}_{\mathrm{S}}$. Thus, a volume of $7700 \mathrm{~m}^{3}$ it has been chosen 


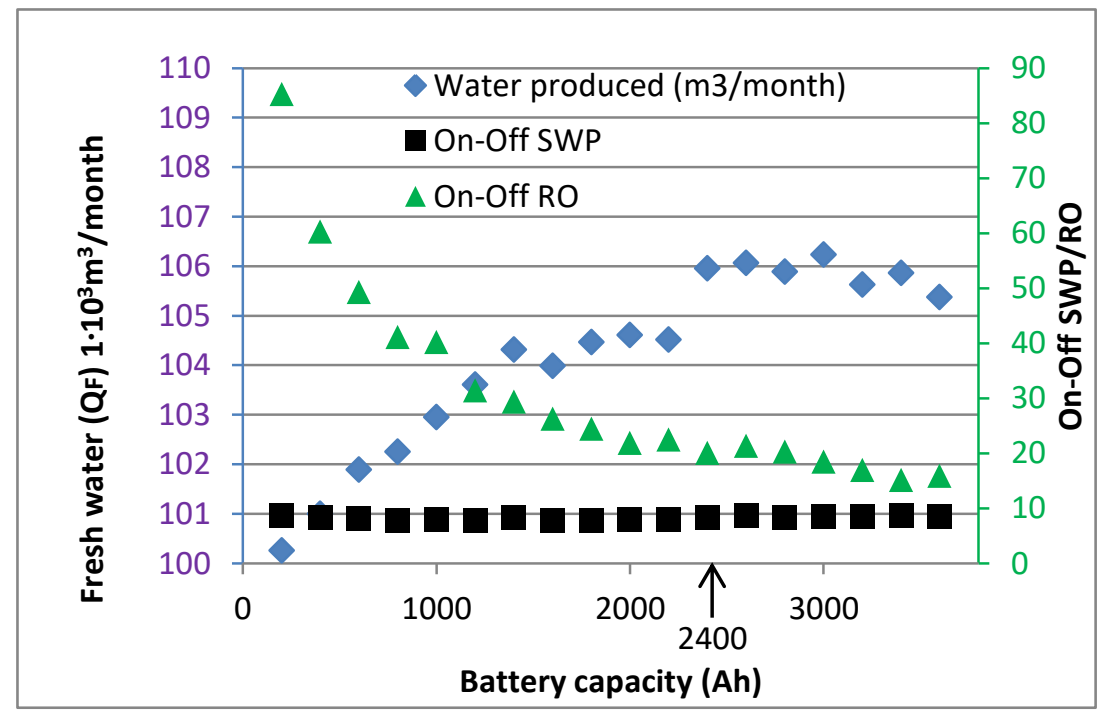

Figure 3.7 - Effect of battery capacity $\left(C_{P}\right)$ on system performance $\left(V_{S}=5500 \mathrm{~m}^{3}\right)$.

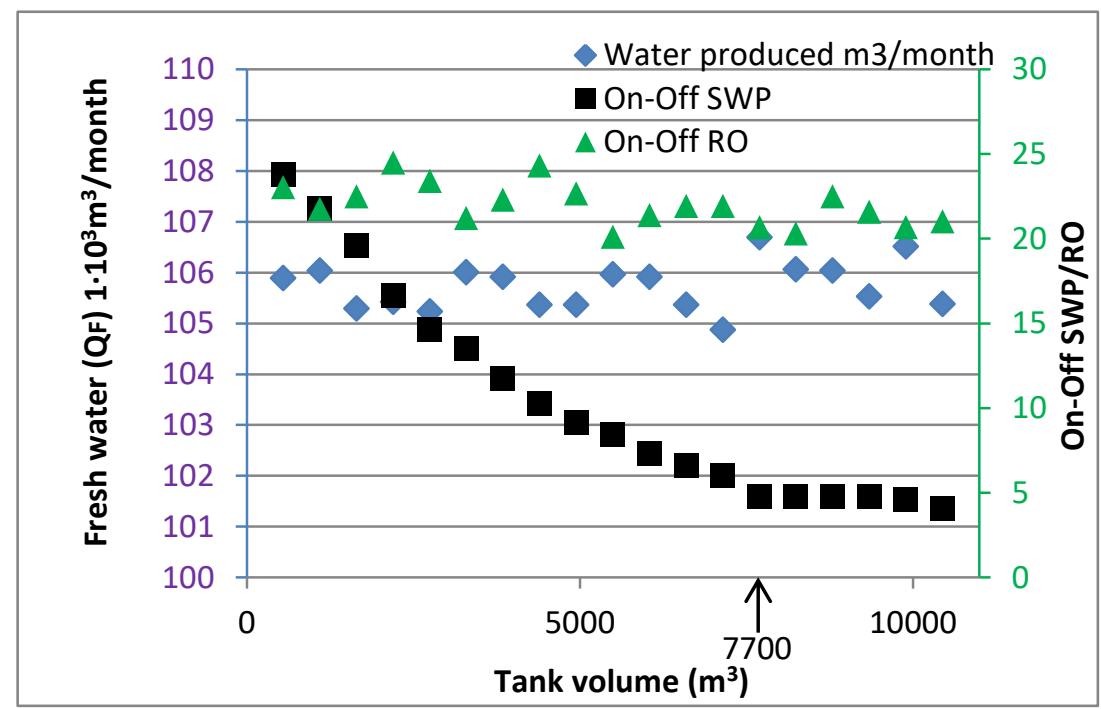

Figure 3.8 - Effect of seawater tank volume $\left(V_{S}\right)$ on system performance $\left(C_{P}=2400\right.$ $\mathrm{Ah})$. 
Finally, an operating point was selected (in bold), which is the first presented in Table 3.1.

\begin{tabular}{ccccc}
\hline $\begin{array}{c}\text { Battery } \\
\text { capacity } \\
(\text { Ah) }\end{array}$ & $\begin{array}{c}\text { Tank } \\
\text { volume } \\
\left(\mathrm{m}^{3}\right)\end{array}$ & $\begin{array}{c}\text { Fresh water } \\
\left(\mathrm{m}^{3} / \text { month) }\right.\end{array}$ & $\begin{array}{c}\text { On-Off SWP } \\
\text { (times/month) }\end{array}$ & $\begin{array}{c}\text { On-Off RO } \\
\text { (times/month) }\end{array}$ \\
\hline $\mathbf{2 4 0 0}$ & $\mathbf{7 7 0 0}$ & $\mathbf{1 0 6 6 9 3}$ & 4.8 & $\mathbf{2 0 . 6}$ \\
2400 & 5500 & 105860 & 8.2 & 19.8 \\
1000 & 5500 & 103128 & 4.8 & 16.4 \\
\hline
\end{tabular}

Table 3.1 - Selected operating point for the first case study

Figures 3.9 to 3.14 show different parameters at the operating point on 165 days with buoy measurements. It can be seen that the proposed system operates adequately:

Figure 3.9 represents the power produced by the renewable energy sources $\left(\mathrm{P}_{\mathrm{W}}\right)$. The power produced depends on the values of the wave's height and period and on the wind speed.

Figure 3.10 shows that the value of the fresh water produced in each RO section varies over time, according to the activation of the stages of the RO illustrated in Figure 3.2.

Figure 3.11 shows the total fresh water produced $\left(\mathrm{Q}_{\mathrm{F}}\right)$, which is the sum of sections A, B and C. It can be seen that this value increases if the value of the power produced (Figure 3.9) is high.

Figure 3.12 depicts the total power consumed, $\mathrm{P}_{\mathrm{T}}$. This is proportional to the total fresh water produced plus the power consumed by the SWPs.

Figure 3.13 shows the stored seawater. The value is between the minimum and maximum safety level.

Finally, Figure 3.14 depicts the value of the \% Battery charge. As expected, this value varies between $30 \%$ and $100 \%$, so it never gets discharged.

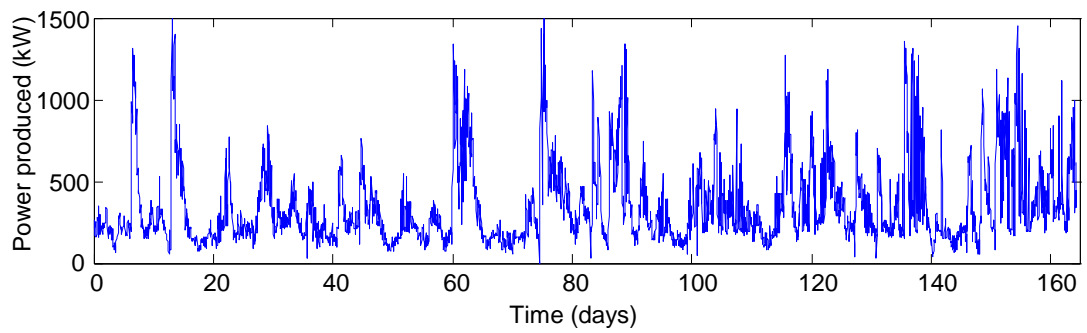

Figure 3.9 - Power produced by renewable energies $\left(\mathrm{P}_{\mathrm{w}}\right)$ 


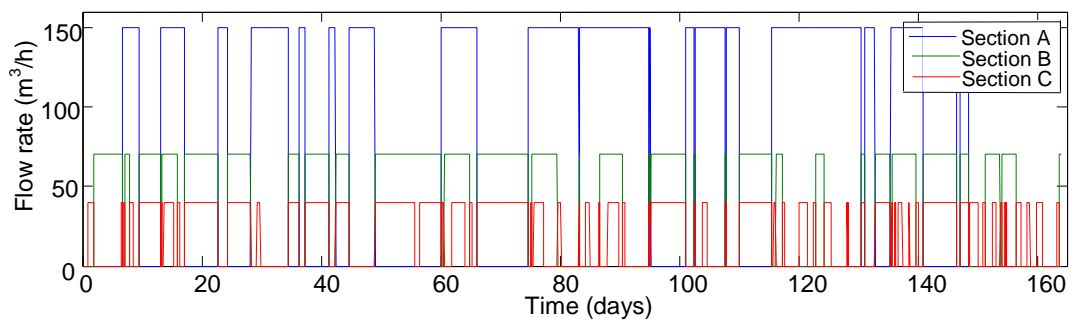

Figure 3.10- Fresh water produced $\left(\mathrm{Q}_{\mathrm{F}}\right)$ in each $\mathrm{RO}$ section

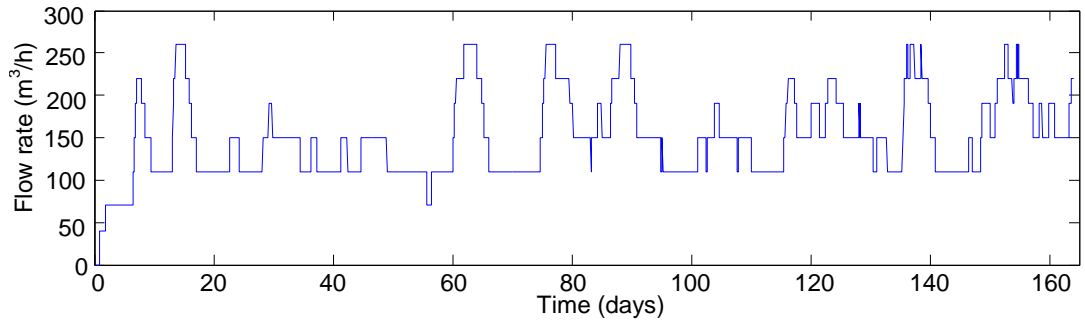

Figure 3.11- Total fresh water produced $\left(\mathrm{Q}_{\mathrm{F}}\right)$

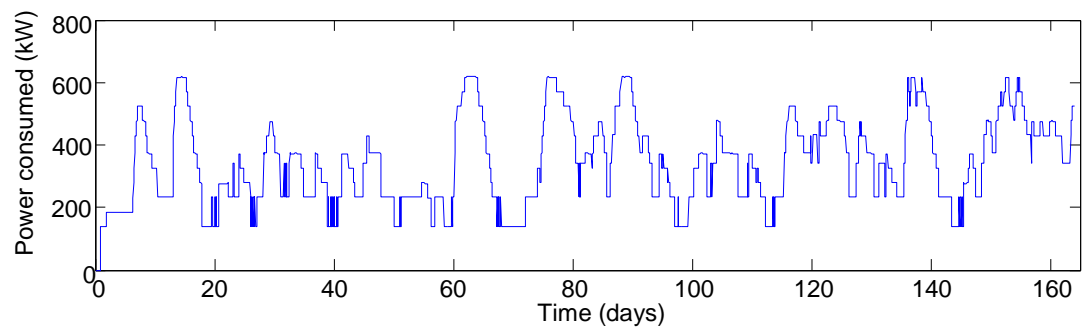

Figure 3.12 - Total power consumed $\left(\mathrm{P}_{\mathrm{T}}\right)$

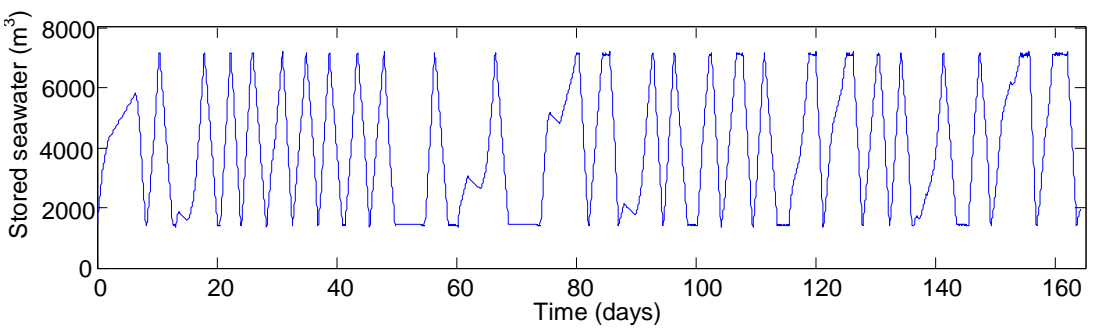

Figure 3.13 - Stored seawater 


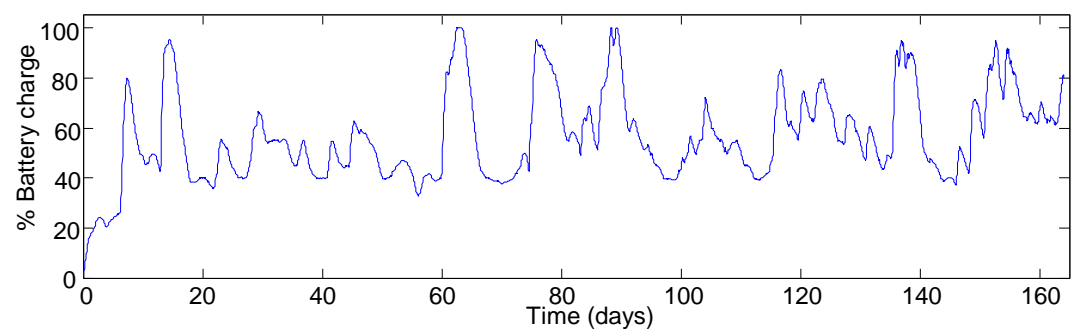

Figure 3.14 - \% Battery charge: 100\% (1-DOD).

\subsubsection{Second case study}

The approach presented in Section 3.1.2 is developed for desalination plants with few sections. However, it is not adequate when there is a significant number of units being used and complex control objectives; in particular, it is not adequate for multi-stage desalination plants operated by several lines, as the number of components with high electrical consumptions (high pressure pumps) is too big to develop and maintain a functional block diagram that accurately represents the control objectives.

In fact, water for electrolysis requires low conductivity (few $\mu \mathrm{S} / \mathrm{cm}$ ); therefore, the H2OCEAN desalination section is composed of two successive stages, solving complex control objectives.

Thus, an alternative procedure is presented in this section which combines the implementation in existing control hardware (PLCs) with the fulfilment of conflicting control objectives.

In this second case study, a ruled-based control strategy is porposed for a reverse osmosis plant powered by renewable energy which is simple to implement and, as will be shown, presents good results (SERNA et al. 2015). There are some previous works that use rule-based control strategies for energy management: JALIL et al. (1997) designed a rule-based control for a hybrid vehicle, whilst PARIS et al. (2010) developed this control strategy in the design of heating control schemes for energy management in buildings.

\subsubsection{Energy Management System for the second case study}

For the sake of simplicity, the control proposal is presented for a platform with a single seawater pump, two high pressure pumps for a first stage of RO and two high pressure pumps for a second stage, as can be seen in Figure 3.15. 
The characteristics of each of the units of consumption are as follows (SERNA; TADEO, 2015):

- A $51 \mathrm{~kW} \mathrm{SWP} \mathrm{that} \mathrm{provides} \mathrm{a} \mathrm{nominal} \mathrm{flow} \mathrm{rate} \mathrm{of} 256 \mathrm{~m}^{3} / \mathrm{h}\left(\mathrm{Q}_{\mathrm{S}}\right)$.

- The first stage of the RO plant, RO1, consists of two similar lines, each designed to produce $57 \mathrm{~m}^{3} / \mathrm{h}\left(\mathrm{Q}_{\mathrm{F}}\right)$ of fresh water when connected (with a recovery ratio of around 45\%), consuming 155 $\mathrm{kW}$ per line (corresponding to approximately $2.7 \mathrm{kWh} / \mathrm{m}^{3}$ ) when they are operating.

- The second stage, RO2, also consists of two similar lines, which, when connected, produce $34 \mathrm{~m}^{3} / \mathrm{h}\left(\mathrm{Q}_{\mathrm{DE}}\right)$ of demineralized water (recovery ratio of $75 \%$ ), in each line, consuming around $38 \mathrm{~kW}$ per line (approximately $1 \mathrm{kWh} / \mathrm{m}^{3}$ of demineralized water produced).

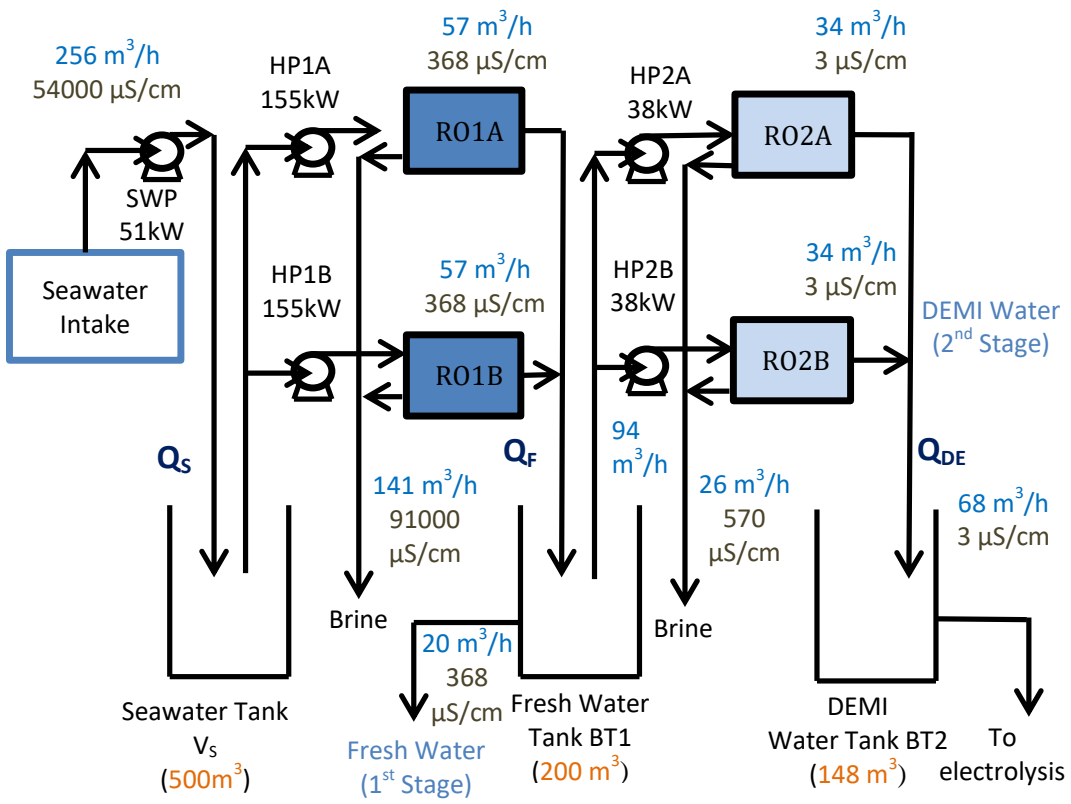

Figure 3.15 - Structure of the second case study

Parallel approaches can be easily extended for other configurations, perhaps using other components with different rated powers and configurations. The main goal to ensure the smooth operation of the facility is the control system, balancing power consumption with the available power by deciding which units of the 
plant are connected or disconnected. The units in this second case study are:

a) The seawater pump (SWP).

b) Each of the two lines and two stages of the desalination system: in the simplified structure presented in Figure 3.15, they would be denoted as sections RO1A, RO1B, RO2A and RO2B.

The control variables are then the connections of the SWP and the different sections of the RO (see Figure 3.16). The main objectives can be written in a prioritized way as follows:

1) Keep the buffer tanks $V_{S}, B T 1$ and BT2 with a water level higher than the minimum, so the next stage can operate properly.

2) Once a unit of consumption is connected, it should be kept operating at its nominal value as long as there is enough energy.

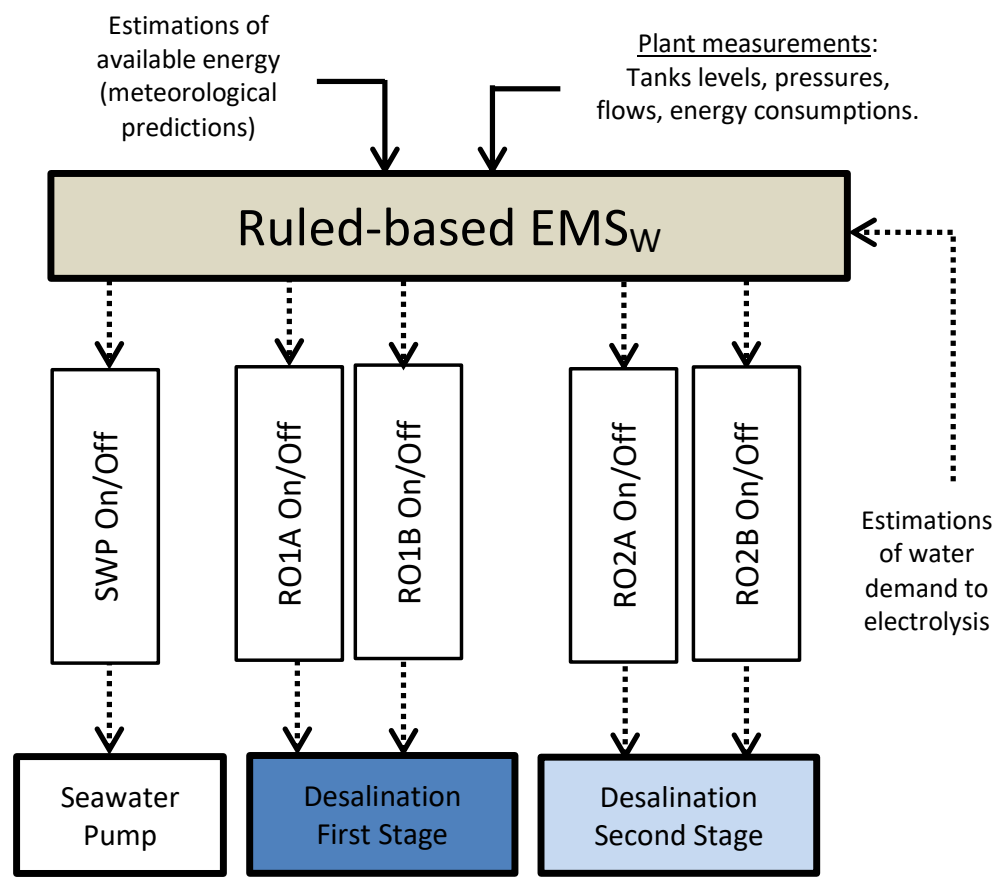

Figure 3.16 - Scheme of the proposed $\mathrm{EMS}_{\mathrm{W}}$ for the second case study 


\section{Control strategy inside the $\mathrm{EMS}_{\mathrm{W}}$}

The control strategy is based on two consecutive steps defined by different rules:

STEP 1) At each sampling time a prioritized list of units is created on the basis of the current state of the plant (i.e., the tank levels and the information of the units currently operating) and the expected water demand. This list of prioritized units is denoted as $\left\{U_{i}\right\}_{i=1}^{n}$; a list of predicted energy demands is associated, denoted as $\left\{\mathrm{E}_{\mathrm{i}}\right\}_{\mathrm{i}=1}^{\mathrm{n}}$. These lists are generated based on the knowledge of the process, so as to fulfil the requirements. For example, the following algorithm is used for this second case study, shown in Figure 3.15, to generate $\left\{U_{i}\right\}_{i=1}^{n}$ :

a) Initialize: $\left\{\mathrm{U}_{\mathrm{i}}\right\}=\{\mathrm{SWP}, \mathrm{R} 01 \mathrm{~A}, \mathrm{R} 01 \mathrm{~B}, \mathrm{R} 02 \mathrm{~A}, \mathrm{RO} 2 \mathrm{~B}\}$

b) At each sample time:

IF the level of $\mathrm{V}_{\mathrm{S}}$ is LOW THEN increase the priority of SWP decrease the priority of RO1A and RO1B

IF the level of BT1 is LOW THEN increase the priority of RO1A and RO1B decrease the priority of $\mathrm{RO} 2 \mathrm{~A}$ and $\mathrm{RO} 2 \mathrm{~B}$

IF the level of BT2 is LOW THEN increase the priority of $\mathrm{RO} 2 \mathrm{~A}$ and $\mathrm{RO} 2 \mathrm{~B}$

IF the level of $\mathrm{V}_{\mathrm{S}}$ is HIGH THEN decrease the priority of SWP increase the priority of RO1A and RO1B

IF the level of BT1 is HIGH THEN decrease the priority of RO1A and RO1B increase the priority of $\mathrm{RO} 2 \mathrm{~A}$ and $\mathrm{RO} 2 \mathrm{~B}$

IF the level of BT2 is HIGH THEN decrease the priority of $\mathrm{RO} 2 \mathrm{~A}$ and $\mathrm{RO} 2 \mathrm{~B}$ 
STEP 2) Distribute the available energy from the units, following the prioritized list $\left\{U_{i}\right\}_{i=1}^{n}$; when possible, energy is assigned to those units with a higher priority. That is, a list of units that would be operating during the next sample, denoted $\left\{\mathrm{O}_{\mathrm{j}}\right\}_{\mathrm{j}=1^{\prime}}^{\mathrm{m}}$, is generated, together with the corresponding list of predicted energy demands $\left\{\mathrm{EO}_{\mathrm{j}}\right\}_{\mathrm{j}=1}^{\mathrm{m}}$. The disconnected elements would be $\left\{D_{j}\right\}_{j=1}^{n-m}$, with the corresponding unsatisfied energy demands $\left\{E D_{j}\right\}_{j=1}^{n-m}$. The energy consumed by the connected units fulfil $\sum_{\mathrm{j}=1}^{\mathrm{m}} \mathrm{EO}_{\mathrm{j}} \leq \mathrm{P}_{\mathrm{W}}$, while all the units in the set of disconnected units fulfil $\mathrm{P}_{\mathrm{W}}-\sum_{\mathrm{j}=1}^{\mathrm{m}} \mathrm{EO}_{\mathrm{j}} \leq \mathrm{ED}_{\mathrm{k}} \forall \mathrm{k}$. These lists can be generated by examining the list of predicted energy demands, $\left\{E_{i}\right\}_{i=1}^{n}$, generated in parallel with $\left\{U_{i}\right\}_{i=1}^{n}$, as given by the following algorithm at each sample time:

a) Initialize $\mathrm{EO}=\{\} ; \mathrm{ED}=\{\} ; \mathrm{m}=0$;

b) FOR $\mathrm{i}=1: \mathrm{n}$

$$
\begin{aligned}
& \text { IF } E_{i} \leq P_{W}-\sum_{j=1}^{m} E_{j} \text { THEN } \\
& m=m+1 \\
& O_{m}=U_{i} \\
& \mathrm{EO}_{m}=E_{i}
\end{aligned}
$$

\section{OTHERWISE}

$\mathrm{D}_{\mathrm{i}-\mathrm{m}}=\mathrm{U}_{\mathrm{i}}$

$$
\mathrm{ED}_{\mathrm{i}-\mathrm{m}}=\mathrm{E}_{\mathrm{i}}
$$

\subsubsection{Results and discussion}

As a practical case study, the proposed control strategy was applied to the second case study of a desalination plant producing up to $68 \mathrm{~m}^{3} / \mathrm{h}$ of demineralized (DEMI, $\mathrm{Q}_{\mathrm{DE}}$ ) water with the requirement of low conductivity for the electrolysis process $(3 \mu \mathrm{S} / \mathrm{cm})$ and up to $20 \mathrm{~m}^{3} / \mathrm{h}$ of drinkable and service water. It consumes renewable electricity with variable production. A schematic diagram was presented in Figure 3.15. 
Meteorological data at the target location was used to validate the proposed control system, as well as previously derived production models for power and water. Some preliminary results for 20 days of operation are shown in Figures 3.17 to 3.23.

The evaluation over 20 days confirms the correct operation of the EMS proposed in Section 3.1.3.1.

As can be seen in Figure 3.17, the value of the power consumed by the system is lower than the available power.

Figure 3.18 shows the seawater level tank $\left(\mathrm{V}_{\mathrm{S}}\right)$ in percentage. Figure 3.19 shows the fresh water level tank (BT1) and Figure 3.20 the DEMI water tank BT2. In all cases, the levels are between the minimum and maximum defined to maintain them within a safety range.

Figure 3.21 depicts the operation of the SWP, whereas Figures 3.22 and 3.23 show the operation of the first and second RO stages respectively.

As in the previous figure, the performance of both stages of the RO process can be considered correct.

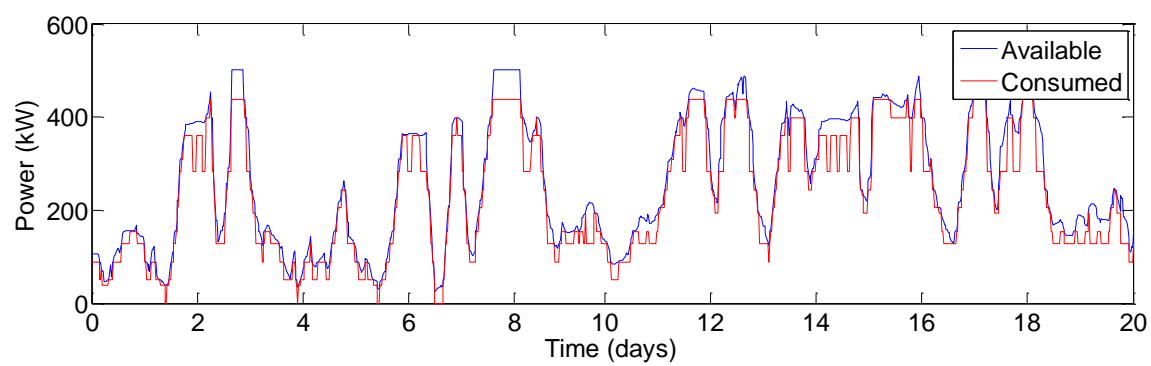

Figure 3.17 - Power available $\left(\mathrm{P}_{\mathrm{W}}\right)$ and consumed $\left(\mathrm{P}_{\mathrm{T}}\right)$ by the desalination unit

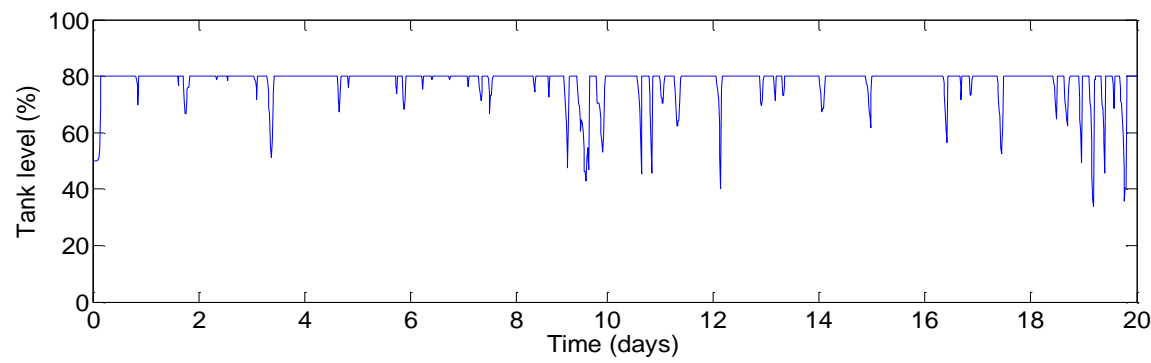

Figure 3.18 - Evaluation of the seawater tank level $\left(\mathrm{V}_{\mathrm{S}}\right)$ 


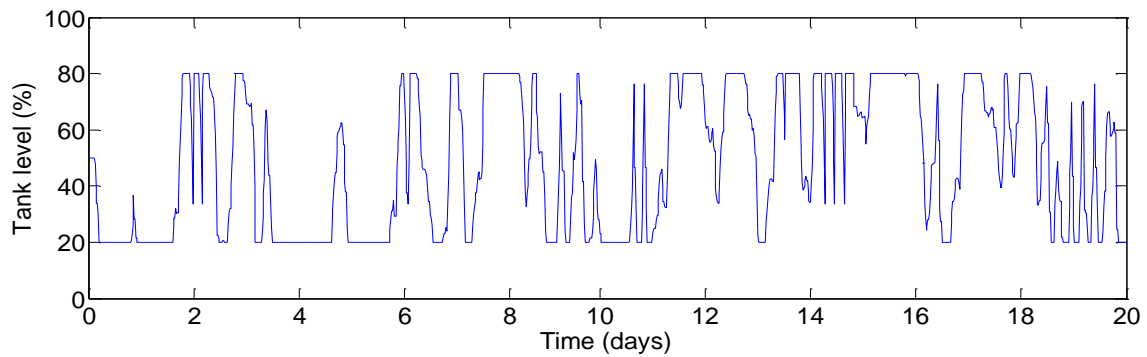

Figure 3.19 - Evaluation of the fresh water tank level (BT1)

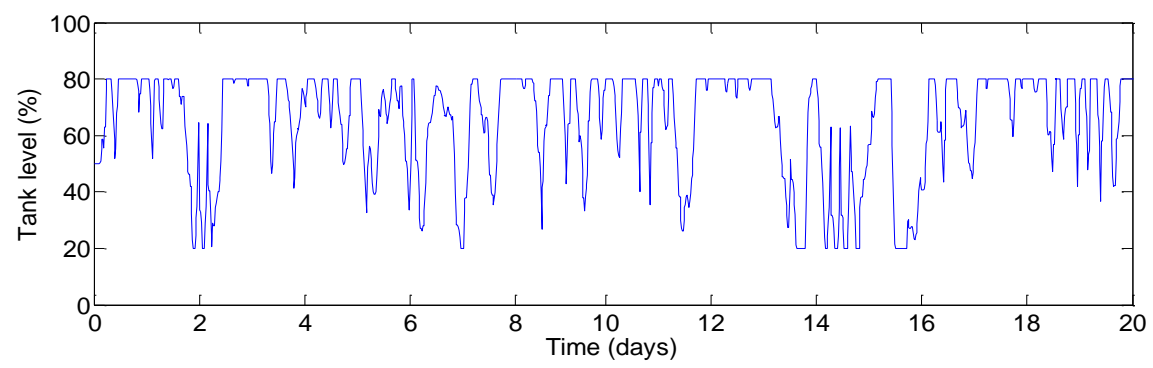

Figure 3.20 - Evaluation of the DEMI water tank level (BT2)

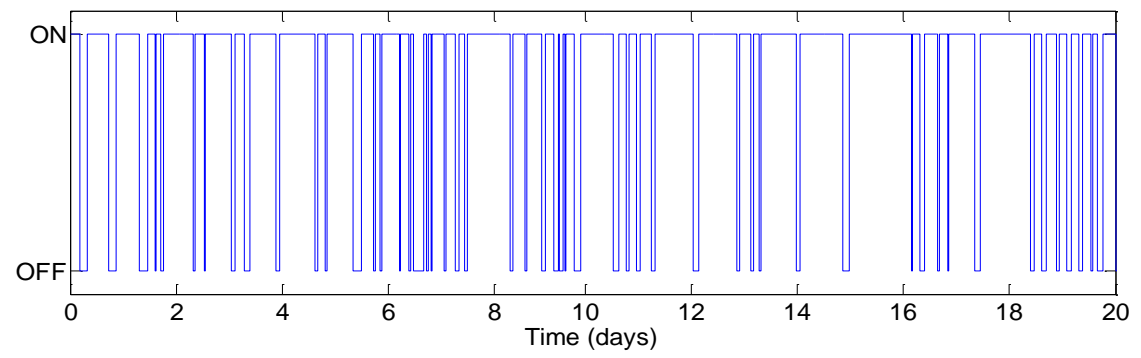

Figure 3.21 - Operation of the seawater pump (SWP)

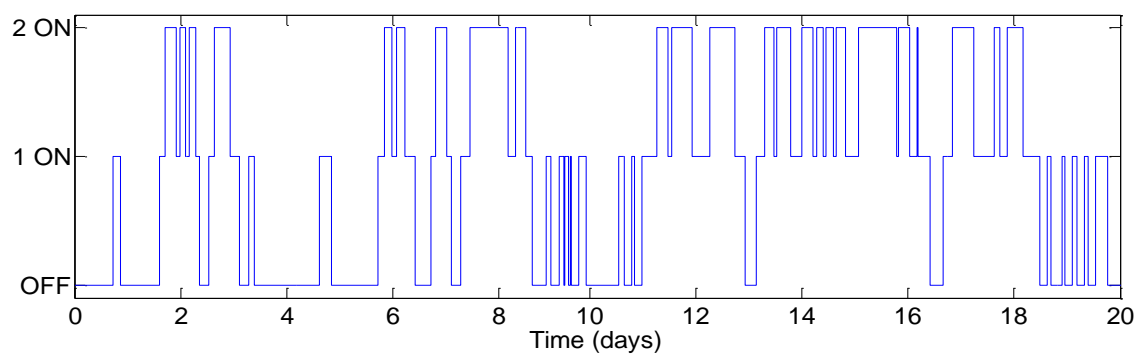

Figure 3.22 - Operation of the first stage of the desalination unit (RO1A+RO1B) 


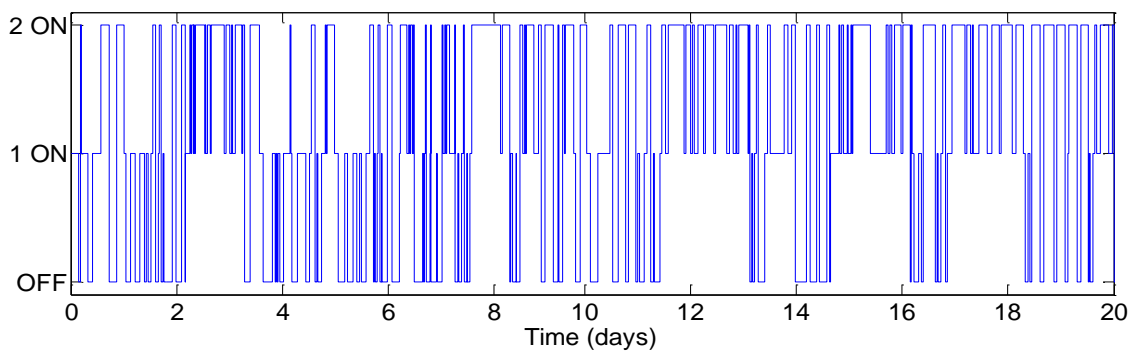

Figure 3.23 - Operation of the second stage of the desalination unit (RO2A+RO2B)

Finally, Table 3.2 summarizes the total parameters and consumption. This corresponds to a mean production of $32.39 \mathrm{~m}^{3} / \mathrm{h}$ of DEMI water for the electrolysis, consuming a mean power of $219.8 \mathrm{~kW}$.

\begin{tabular}{cccc}
\hline $\begin{array}{c}\text { Mean Power } \\
\begin{array}{c}\text { Available } \\
(\mathrm{kW})\end{array}\end{array}$ & $\begin{array}{c}\text { Mean Power } \\
\text { Consumed } \\
(\mathrm{kW})\end{array}$ & $\begin{array}{c}\text { DEMI water } \\
\left(\mathrm{m}^{3} / \mathrm{h}\right)\end{array}$ & Fresh water $\left(\mathrm{m}^{3} / \mathrm{h}\right)$ \\
\hline 271.7 & 219.8 & 32.39 & 55.71 \\
$\begin{array}{c}\text { SWP ON/OFF } \\
\text { (times/day) }\end{array}$ & $\begin{array}{c}1^{\text {nst }} \text { RO stage } \\
\text { ON/OFF } \\
\text { (times/day) } \\
5.8\end{array}$ & $\begin{array}{c}2^{\text {nd }} \text { RO stage ON/OFF } \\
\text { (times/day) }\end{array}$ \\
\hline
\end{tabular}

Table 3.2 - Parameters and consumptions of the second case study

This proposal can be considered more appropriate for the offshore water production as it does not require a significant number of batteries in the EMS $\mathrm{W}_{\mathrm{W}}$. The results summarized in Table 3.2 show the correct operation of the control system, as all the high pressure pumps work without excess switching on and off. The amount of DEMI water produced in the second stage of the RO is enough for the hydrogen production, which will be studied in Section 3.2.

\section{2 $\mathrm{H}_{2}$ PRODUCTION IN THE H2OCEAN PLATFORM}

The aim of this section is to present and evaluate a proposal for the Energy Management System for Hydrogen production $\left(\mathrm{EMS}_{\mathrm{H}}\right)$ in an off-grid off-shore electrolysis plant powered by renewable energies within the H2OCEAN project (SERNA; TADEO, 2014). The description of the plant has been presented in Section 1.1. 
To produce hydrogen, DEMI water with low conductivity is necessary in the electrolysis process, so the proposal developed in Section 3.1.3 is used. The $\mathrm{EMS}_{\mathrm{H}}$ is also composed of the electrolysis unit of a compression unit to store the hydrogen for transport. Batteries for the temporary storage of electricity for short-time balances are also developed in this section. Fig. 3.24 shows the process diagram of the hydrogen plant.

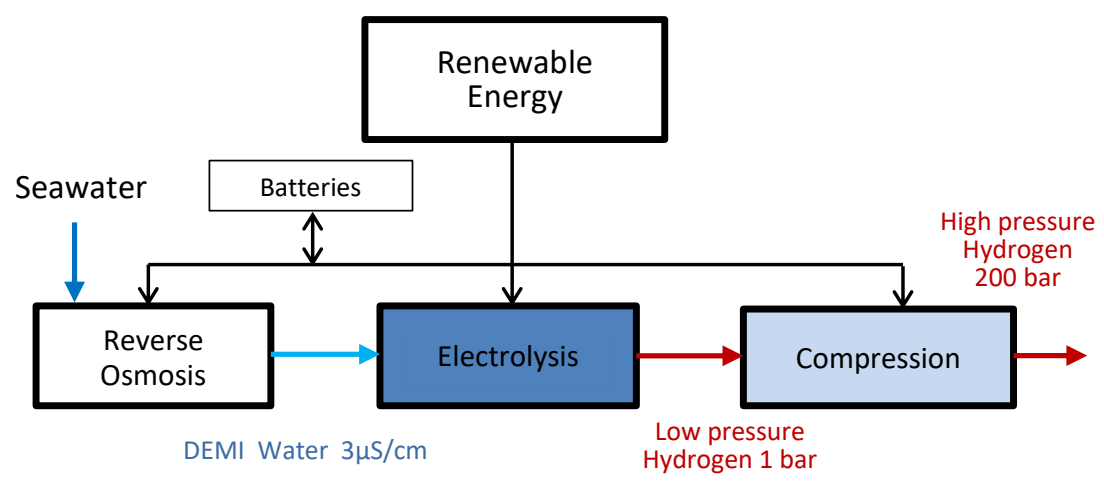

Figure 3.24 - Process diagram of the hydrogen plant

First, the subsystems that form the proposed plant are justified and described in Section 3.2.1. The proposed $\mathrm{EMS}_{\mathrm{H}}$ is developed in Section 3.2.2. Then a proposal for sizing these subsystems is evaluated in Section 3.2.3, based on simple mathematical models of the different sections of the plant. Finally, the performance of the $\mathrm{EMS}_{\mathrm{H}}$ in a specific location is tested in detail in Section 3.2.4 using measured data and studying the influence of sizing on the expected performance.

\subsubsection{Hydrogen plant operation}

The system presented here is composed of primary energy sources, wind and wave energies, which provide electricity in order to later produce hydrogen using PEM electrolyzers from DEMI water. A set of batteries which facilitate the balance of production and demand is also installed. Hydrogen is then transported to the final users by ships (barges), after compression.

The process diagram depicted in Fig. 3.24 presents the four main blocks of our proposal: the renewable energy sources, the RO unit, the electrolysis unit and the compression unit used to compress the 
hydrogen for transport.

\subsubsection{Energy Management System for hydrogen production}

A central component to ensure the smooth operation of the facility is the control system that balances electricity production and consumption, adapting the consumed loads (the RO unit, the electrolyzers and the hydrogen compression). It is assumed that the $\mathrm{EMS}_{\mathrm{H}}$ is based on the following ideas:

- When the production is higher than the consumption, the energy is stored until the temporary storage system is nearly full (DOD of the battery is near to 0 ); then sections of the electrolyzer and compression systems are switched on.

- When the storage system is almost empty (DOD of the battery is near to 1), sections of the electrolyzers and compression systems are switched off (these sections are then automatically cleaned and maintenance operations carried out).

- The desalination is just switched on/off depending on the amount of DEMI water stored in the tanks and the electrolyzation demand (see Section 3.1.3).

\subsubsection{Sizing and modelling}

In the proposed facility, a central aspect of the design for a specific location is the selection of the component sizes, in order to ensure the autonomous operation of the facility without excessive capital or operation costs. In particular the following parameters should be selected:

- The rated power consumption of the electrolyzers $\overline{\mathrm{P}}_{\mathrm{EL}}$.

- The flow of DEMI water that must be produced by the desalination plant $\mathrm{Q}_{\mathrm{DE}}$, and the corresponding flow of inlet seawater $\mathrm{Q}_{\mathrm{S}}$ (see Fig. 3.16).

- The volumes of seawater and DEMI water stored in the storage tanks ( $\mathrm{V}_{\mathrm{S}}$ and $\mathrm{BT} 2$ respectively, see Fig. 3.16).

- The total capacity of the $\mathrm{EMS}_{\mathrm{H}}$ batteries, $\mathrm{C}_{\mathrm{P}}$.

As in the case of DEMI water production, it is important to take into account the variability of the energy sources, so forecasts are needed. It is assumed that a significant record of data measured in the 
location is available.

The proposed methodology to select the plant parameters is then the following:

i) Using the measured data, the evolution of the power produced by the renewable energy devices $\mathrm{P}_{\mathrm{W}}(\mathrm{t})$ is estimated.

ii) The rated power consumption of the electrolyzers $\overline{\mathrm{P}}_{\mathrm{EL}}$ is selected to ensure that the set of electrolyzers is in full operation for at least $\lambda \%$ of the time (this parameter would be a trade-off between the cost of the electrolyzers and the cost of the WECs and VAWTs, as part of the produced energy will not be used.).

iii) The required flow of DEMI water produced by the desalination system $\left(\mathrm{Q}_{\mathrm{DE}}\right)$ can then be calculated from the water that is required by the electrolyzers when the entire set is in operation. The corresponding flow of inlet seawater $Q_{s}$ can be directly calculated from the recovery ratio.

iv) The tank sizes are selected to ensure $\mathrm{W}_{\mathrm{a}}$ hours of autonomy at all times.

v) The battery capacity $C_{P}$ is selected to ensure $W_{a}$ hours of autonomy at all times and the DOD is always between given limits $\overline{\mathrm{DOD}}<$ DOD $<$ DOD.

\subsubsection{Electrolyzers}

Nowadays, PEM technology is one of the most promising water electrolysis technologies for direct coupling with renewable electrical sources (MILLET et al. 2013). The purpose here is to use a simple PEM water electrolyzer model to predict energy and water consumptions and hydrogen production, so a simplified electrochemical sub-model will be described based on (GARCÍA-VALVERDE et al. 2011).

From a thermodynamic point of view, the minimum voltage to start the water electrolysis reaction corresponds to the sum of the reversible potential for each semi-reaction described in Section 2.3.1.3 at both electrodes.

These minimum potentials are affected by the pressure and temperature conditions of the reactions. Moreover, in real systems, a higher potential must be applied due to kinetic losses at the bipolar plates, electrodes and internal resistances in the cell. Hence, when current is flowing through the electrodes, the operating voltage for a single cell $\left(\mathrm{V}_{\text {cell }}\right)$ is given by the reversible voltage and the sum of the difference over the potentials. For PEM electrolytic cells: 


$$
\mathrm{V}_{\text {cell }}=\mathrm{U}_{\mathrm{rev}}+\eta_{\text {electrodes }}+\eta_{\Omega}
$$

\section{a) Reversible voltage}

The reversible voltage or open circuit voltage at the cell $\left(\mathrm{U}_{\text {rev }}\right)$ depends on the temperature and pressure of reaction. This dependence can be theoretically estimated from thermodynamic calculations on the change of the Gibbs free energy or, from the electrochemical point of view, using the Nernst equation for water electrolysis (16). Assuming $\mathrm{H}_{2}$ and $\mathrm{O}_{2}$ as ideal gases, water as an incompressible fluid and ideal gasliquid phase mixture, can simplify the calculations of the thermodynamic variables and activity coefficients $\left(\mathrm{ac}_{\mathrm{H}_{2} \mathrm{O}}, \mathrm{ac}_{\mathrm{H}_{2}}, \mathrm{ac}_{\mathrm{O}_{2}}\right)$.

$$
\mathrm{U}_{\mathrm{rev}}(\mathrm{T}, \mathrm{p})=\frac{\Delta \mathrm{G}(\mathrm{T})}{\mathrm{nF}}+\frac{\mathrm{RT}}{\mathrm{nF}} \cdot \ln \left[\frac{\mathrm{ac}_{\mathrm{H}_{2} \mathrm{O}}}{\mathrm{acH}_{2} \cdot\left(\mathrm{a}_{\mathrm{O}_{2}}\right)^{1 / 2}}\right]
$$

Nevertheless, for low-pressure or atmospheric applications, the effect of the pressure can be neglected to simplify the model. Reversible voltage for water electrolysis at constant atmospheric pressure is empirically given by (17):

$$
\mathrm{U}_{\mathrm{rev}}(\mathrm{T})=1.5184-1.5421 \cdot 10^{-3}+9.523 \cdot 10^{-5} \mathrm{~T} \ln \mathrm{T}+9.84 \cdot 10^{-8} \mathrm{~T}^{2}
$$

b) Electrodes over potential

Charge transfer and mass transport phenomena in the electrode must be considered when current flows through the electrolytic cell. These limitations on the semi-reactions are known as activation and concentration over potentials, respectively. On each electrode, one of the branches (oxidation at the anode and reduction at the cathode) will dominate during operation. Thus, the anodic and cathodic activation over the potentials ( $\eta_{\mathrm{a}}$ and $\eta_{\mathrm{c}}$ respectively) can be written as:

$$
\begin{aligned}
& \eta_{\mathrm{a}}=\frac{\mathrm{RT}}{\lambda_{\mathrm{a}} \mathrm{sF}} \cdot \ln \left(\frac{\mathrm{i}_{\mathrm{a}}}{\mathrm{i}_{0, \mathrm{a}}}\right) \\
& \eta_{\mathrm{c}}=\frac{\mathrm{RT}}{\lambda_{\mathrm{c}} \mathrm{sF}} \cdot \ln \left(\frac{\mathrm{i}_{\mathrm{c}}}{\mathrm{i}_{0, \mathrm{c}}}\right)
\end{aligned}
$$


where $\lambda_{\mathrm{c}}$ and $\lambda_{\mathrm{a}}$ are defined as the charge transfer coefficients for the cathode and the anode, respectively. Many reactions tend towards symmetry, so with no information available, it is usual to assume both charge transfer coefficients as 0.5 . In water electrolysis, $s=2$, while $i_{0 a}$ and $i_{0 c}$ are the exchange current densities for each electrode. The activation over potential is highly affected by these values, which depend on the electro catalyst used, the electrode morphology, the age, pressure, temperature, and other factors. A value of $\mathrm{i}_{\text {0ref }}$ at reference temperature must be chosen from the literature, from the manufacturer's information, or obtained empirically by polarization curve fitting from experimental data, so:

$$
\mathrm{i}_{0}=\mathrm{i}_{0, \mathrm{ref}} \cdot \exp ^{\left[-\frac{\mathrm{E} \operatorname{exc}}{\mathrm{R}}\left(\frac{1}{\mathrm{~T}}-\frac{1}{\mathrm{~T}_{\mathrm{ref}}}\right)\right]}
$$

where $\mathrm{E}_{\mathrm{exc}}$ can be defined as the activation energy for the electrode reaction. During the global reaction, each electrode has its own contribution to the activation over potential (i.e, $\eta_{\text {act }}=\eta_{\text {act, } \mathrm{a}}+\eta_{\text {act,c }}$ ). However, this contribution is not symmetric, the values of the exchange current density at the anode electrode are tipically much lower at the cathode side (e.g $10^{-7} \mathrm{~A} / \mathrm{cm}^{2}$ in Pt-Ir anode and $10^{-3} \mathrm{~A} / \mathrm{cm}^{2}$ in Pt cathode at $80^{\circ} \mathrm{C}$ ) (CHOI et al. 2004). In this sense, the cathode contribution to the activation over potential can be neglected. At high current densities transport limitations cannot be neglected.

c) Resistive over potential

The ohmic over potential could be expressed by:

$$
\eta_{\Omega}=\left(R E_{\text {ele }}+R E_{\text {ion }}\right) \mathrm{i}=\mathrm{RE}_{\mathrm{I}} \mathrm{i}
$$

where $R_{\text {ele }}$ and $R_{\text {ion }}$ are the electronic and ionic contribution to the resistive losses. The addition of the two contributions can be defined as the normalized interfacial resistance $\left(\operatorname{RE}_{\mathrm{i}}\left[\Omega \cdot \mathrm{cm}^{2}\right]\right)$. RE ele increases with the operation temperature; this is due to the electrical resistance of the cell components, with the exception of the electrolyte (bipolar and current collector plates, gas diffusion layers and electrode layers).

The ionic resistance of the membrane $\left(R_{i o n}\right)$ is due to the resistance to proton transport in the polymeric membrane. Thus, ionic resistance can be expressed as a function of the thickness $\left(\mathrm{t}_{\mathrm{m}}\right)$ and conductivity $(\pi)$ of the membrane. 


$$
\mathrm{RE}_{\mathrm{ion}}=\frac{\mathrm{t}_{\mathrm{m}}}{\pi}
$$

The temperature dependence of the membrane conductivity is modelled using an Arrhenius expression (NGUYEN, 1993):

$$
\pi(T)=\pi_{\text {ref }} \cdot \exp ^{\left[\frac{\text { Epro }}{R}\left(\frac{1}{T_{\text {ref }}}-\frac{1}{T}\right)\right]}
$$

where $\mathrm{E}_{\text {pro }}$ is a temperature independent parameter representing the activation energy for proton transport in the membrane.

In practice, the main contribution to the resistive losses is expected to arise from $\mathrm{R}_{\mathrm{ion}}$, since the conductivity of the membrane is usually much lower than the conductivity of the rest of the components. So, neglecting the $\mathrm{R}_{\text {ele }}$ contribution does not imply a significant error.

Finally, the power consumed by a single cell $\left(\mathrm{P}_{\mathrm{EL}}\right)$ is obtained by equation (24), where $\mathrm{I}_{\text {cell }}$ is the cell current.

$$
\mathrm{P}_{\mathrm{EL}}=\mathrm{V}_{\text {cell }} \cdot \mathrm{I}_{\text {cell }}
$$

\subsubsection{Hydrogen compression}

For real gases far above their boiling temperature, the thermodynamic process of compression can be described by the adiabatic compression given by equation (25):

$$
\mathrm{P}_{\mathrm{CO}}=\mathrm{m}_{\mathrm{H} 2} \cdot\left[\frac{\gamma}{\gamma-1}\right] \cdot \mathrm{p}_{0} \cdot \mathrm{V}_{0} \cdot\left[\left(\frac{\mathrm{p}_{1}}{\mathrm{p}_{0}}\right)^{\frac{\gamma-1}{\gamma}}-1\right]
$$

where $\mathrm{P}_{\mathrm{CO}}$ is the power consumed in the compression process, $\mathrm{p}_{0}$ the initial pressure at the outlet of the electrolyzers ( $1 \mathrm{bar}), \mathrm{p}_{1}$ the final pressure (200 bar), $V_{0}$ the initial specific volume, $\gamma$ the ratio of specific heats, and $\mathrm{m}_{\mathrm{H} 2}$ is the hydrogen production rate in $\mathrm{kg} / \mathrm{h}$ (BOSSEL, 2006). In both isothermal and adiabatic compression, the compression work is the difference between the final and initial energy states of the gas. At identical final pressures, the different compression processes yield different temperatures of the compressed medium. 


\subsubsection{Electricity storage}

The batteries are used to provide energy to the RO plant and electrolyzers when not enough power is provided by the wave converters.

$$
\mathrm{I}=\frac{\mathrm{P}_{\mathrm{W}}-\mathrm{P}_{\mathrm{OS}}-\mathrm{P}_{\mathrm{EL}}-\mathrm{P}_{\mathrm{CO}}}{\mathrm{V}}
$$

where $\mathrm{I}$ is the amperage of the battery, $\mathrm{V}$ is the voltage and $\mathrm{P}$, with different subscripts, are the power of the renewable energy devices $\left(\mathrm{P}_{\mathrm{W}}\right)$, $\mathrm{RO}$ plant $\left(\mathrm{P}_{\mathrm{OS}}\right)$, electrolysis $\left(\mathrm{P}_{\mathrm{EL}}\right)$ and compression $\left(\mathrm{P}_{\mathrm{CO}}\right)$.

The equation that relates the capacity of the battery, $\mathrm{C}_{\mathrm{P}}$, and the amperage, I, was shown previously in Equation (12). The key decision variable, the Depth of Discharge, or DOD, was given by Equation (13).

\subsubsection{Results and discussion}

To validate the proposed $\mathrm{EMS}_{\mathrm{H}}$ and the sizing methodology, a casestudy was carried out for a specific location in the Atlantic Ocean, selected for its good wave regime and proximity to potential hydrogen consumers. For this location (longitude $9.5^{\circ} \mathrm{W}$, latitude $40.0^{\circ} \mathrm{S}$ ), buoy data was measured for 5.5 months (wave heights and periods, wind speed, water salinity and temperature).

Based on this data, a platform was designed using the proposed $\mathrm{EMS}_{\mathrm{H}}$ in Section 3.2.2 for the following parameters of the models in Section 3.2.3.

- RO plant: $\mathrm{Q}_{\mathrm{s}}=11.4 \mathrm{~m}^{3} / \mathrm{h}$

- Electrolysis: $\mathrm{T}_{\text {ref }}=320 \mathrm{~K}, \mathrm{~T}=293 \mathrm{~K}, \pi_{\mathrm{ref}}=10000 \mathrm{~S} / \mathrm{m}, \mathrm{i}=$ $10000 \mathrm{~A} / \mathrm{m}^{2}, \mathrm{E}_{\mathrm{exc}}=53990.06 \mathrm{~J} / \mathrm{mol}, \mathrm{E}_{\mathrm{pro}}=18912.42 \mathrm{~J} / \mathrm{mol}, \mathrm{t}_{\mathrm{m}}=$ $0.0002 \mathrm{~m}, \mathrm{I}_{\text {cell }}=55000 \mathrm{~A}, \mathrm{R}=8.314 \mathrm{~J} / \mathrm{mol}, \mathrm{F}=96485 \mathrm{C} / \mathrm{mol}$

- Compression: $\gamma=1.41, \mathrm{~V}_{0}=11.11 \mathrm{~m}^{3} / \mathrm{kg}, \mathrm{p}_{0}=1 \mathrm{bar}, \mathrm{p}_{1}=200$ bar.

- $\quad$ Batteries: $\mathrm{V}=12 \mathrm{~V}, \mathrm{k}=1.12, \psi=0.9$.

The results of the sizing of the components following the procedure proposed in Section 3.2.3 are the following: 
Total rated power of the electrolyzers: $\mathrm{P}_{\mathrm{EL}}=440 \mathrm{~kW}$

DEMI water rated: $\mathrm{Q}_{\mathrm{DE}}=0.066 \mathrm{~m}^{3} / \mathrm{h}$

Seawater tank volume: $\mathrm{V}_{\mathrm{s}}=45 \mathrm{~m}^{3}$

DEMI water tank volume: BT2 $=1 \mathrm{~m}^{3}$

Rated battery capacity: $C_{P}=3400 A h(17 \cdot 200 A h)$

This design was then tested. Some results are presented in Figures 3.25 to 3.30. They show the expected operation of the system parameters chosen for the simulation.

It can be seen that the proposed $\mathrm{EMS}_{\mathrm{H}}$ operates adequately: as can be seen in Fig. 3.25, the value of converted power over time is between 100 and $1000 \mathrm{~kW}$, except for specific moments due to the uniqueness of the meteorological conditions.

Fig. 3.26 depicts the power used. As expected, the electrolysis process consumes most of the power (four stages of 110, 220, 330 and $440 \mathrm{~kW}$ were assumed). Compression consumes between 10 and $40 \mathrm{~kW}$, whereas RO consumes very little in comparison with the other processes (less than $20 \mathrm{~kW}$ ). Fig. 3.27 shows the power balance, which is the difference between the power generated (converted) and consumed by the components of the installation.

The battery's DOD changes along time as depicted in Fig. 3.28: it evolves between the required range ( $9 \%$ to 95\%), without fully discharging or overcharging (which is known to significantly decrease battery life). Fig. 3.29 shows the flow of hydrogen produced.

Finally, Fig. 3.30 depicts the DEMI water tank level.

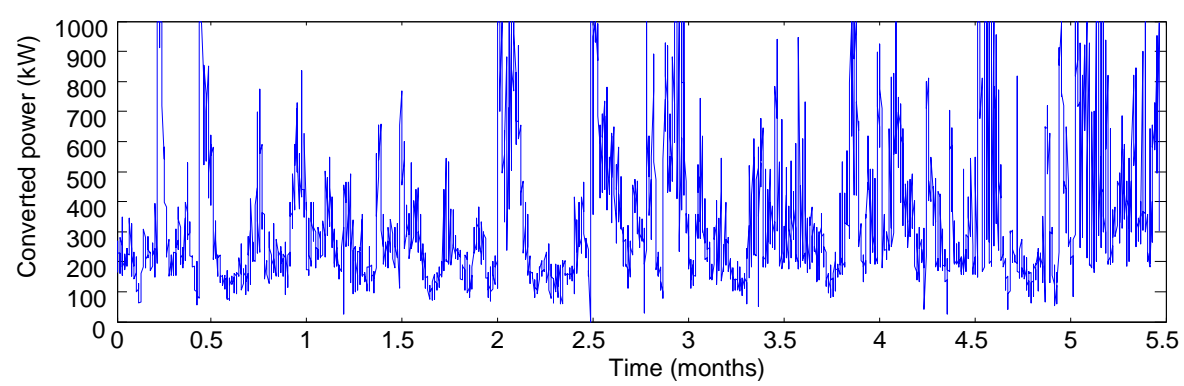

Figure 3.25 - Converted power over time 


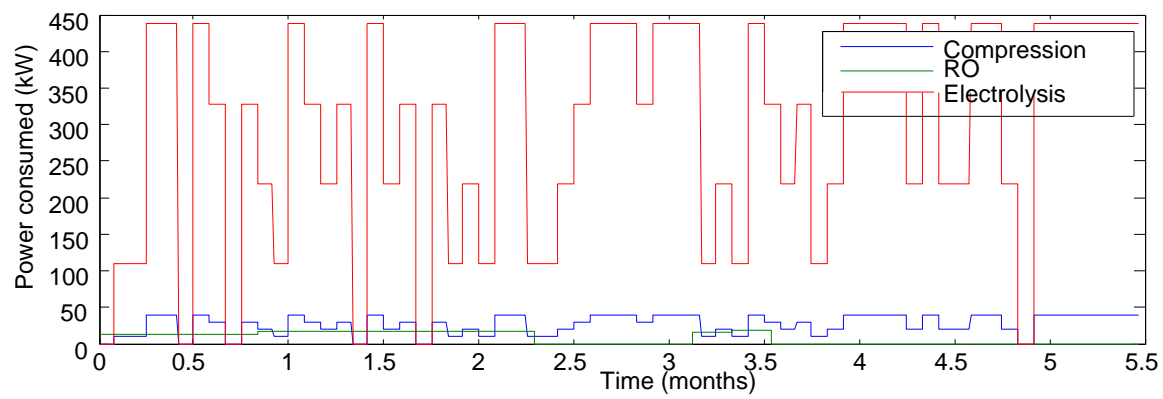

Figure 3.26 - Power consumed by the different sections in the installation.

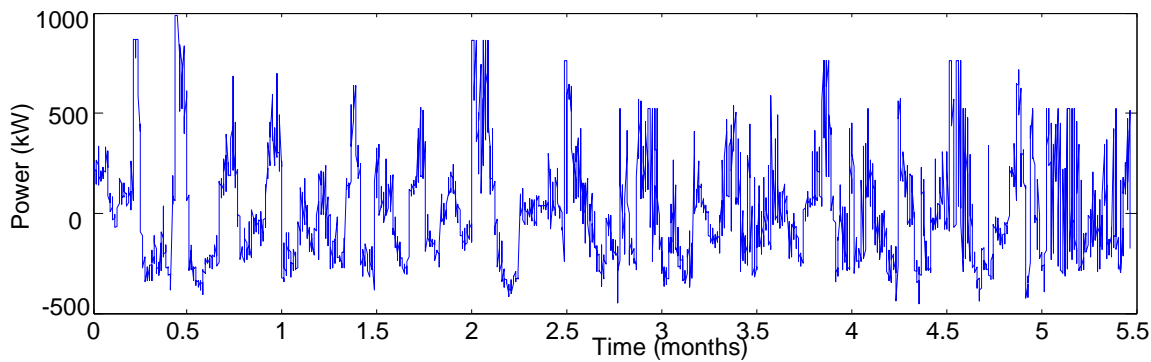

Figure 3.27 - Power balance (converted - consumed)

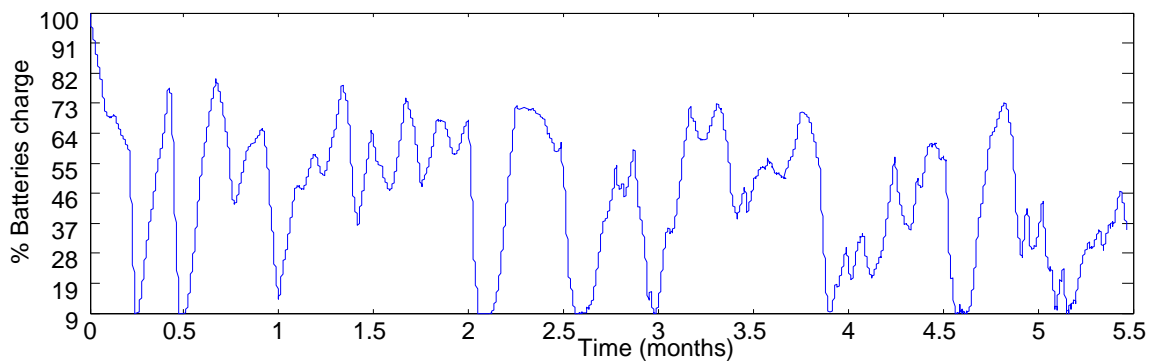

Figure 3.28 - \% Battery charge: 100\% (1-DOD)

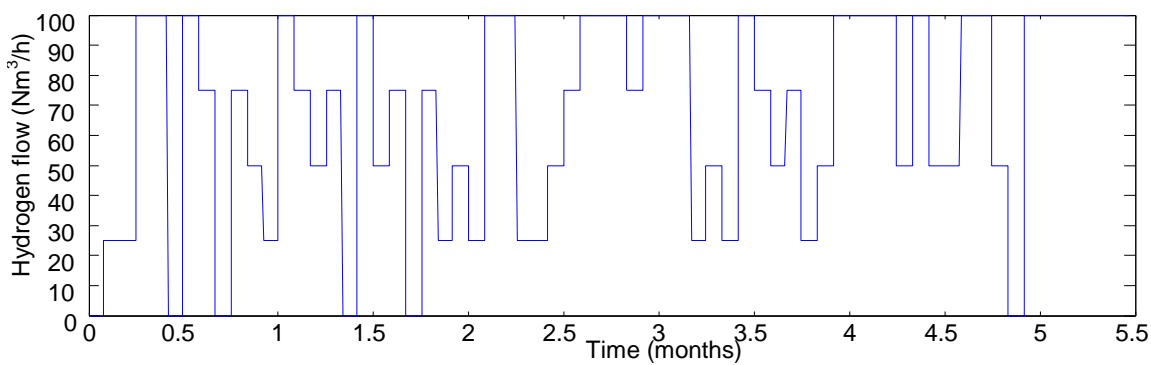

Figure 3.29 - Hydrogen production in the installation 


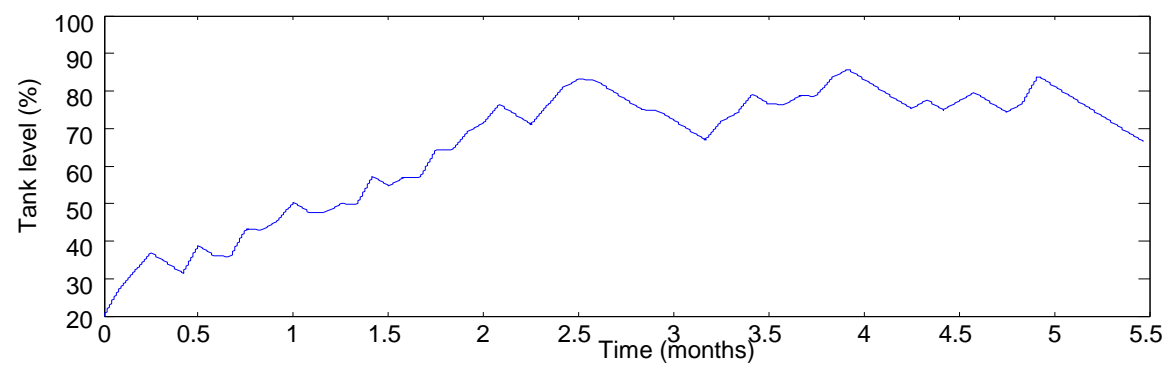

Figure 3.30 - DEMI water tank level

This proposal can then be considered suitable for off-shore hydrogen production as it does not require a significant number of batteries in the $\mathrm{EMS}_{\mathrm{H}}$. The results depicted in Figures 3.25 to 3.30 show the correct operation of the control system, as the batteries work within the proposed range and the hydrogen produced is considered sufficient for different uses (hydrogen car, chemical industry, etc).

\subsection{SUMMARY AND CONCLUSIONS}

The innovative concept of the H2OCEAN platform was developed in Chapter 1, whereas an overall introduction of the technologies developed in the thesis (renewable energies, reverse osmosis, electrolysis and Model Predictive Control) has been detailed in Chapter 2.

A proposal for the design of control strategies, more specifically Energy Management Systems, to produce fresh water $\left(E M S_{W}\right)$ and hydrogen $\left(E_{\mathrm{H}}\right)$ by electrolysis in the H2OCEAN platform is studied in this Chapter 3:

- A proposal for the design of the facility, which consists of a desalination system, a seawater supply and short-term energy storage, has been proposed.

- Some guidelines for sizing the plant for a specific location have been given. This sizing is based on using buoy data at the proposed location and a multi-component model-based simulation, which makes it possible to reproduce the effect of measured sea conditions (wave height, wave period and wind speed) on the water production. To demonstrate the feasibility of the proposed 
platform, both case studies have been evaluated for one specific location.

- The rule-based $\mathrm{EMS}_{\mathrm{W}}$ is proposed for two different case studies based on adapting power consumption to power production by connecting or disconnecting sections of the RO and using a temporary storage of electricity for short-time balances.

- The selected design was then evaluated in terms of DEMI water production and the evolution of the platform parameters, as the hydrogen section needs low conductivity water; showing how the proposed design methodology makes it possible to produce DEMI water in a sustainable way.

- Then, a presentation of the proposed design for the electrolysis unit, which consists of a PEM electrolyzer and hydrogen compression, has been developed.

- $A n E_{H}$ based on adapting power consumption to power production by connecting or disconnecting sections of the electrolyzation plant is defined. This rule-based control system has been developed with some guidelines for modelling the electrolysis plant.

- This proposal has been evaluated for a specific location in the Atlantic Ocean, using buoy-measured data for sizing the proposed platform at this location. The selected design was then evaluated in terms of hydrogen production and the evolution of the platform parameters, considering that the proposed $\mathrm{EMS}_{\mathrm{H}}$ is suitable and well-sized.

Chapter 4 will develop a numerical optimization based on advanced control (more specifically Model Predictive Control ideas) in order to obtain a better performance for hydrogen production.

This algorithm improves the state of health of the electrolyzers reducing the number of connections and disconnections of the devices. 


\section{CHAPTER 4}

\section{ENERGY MANAGEMENT SYSTEM FOR HYDROGEN PRODUCTION BASED ON MPC}




\section{ENERGY MANAGEMENT SYSTEM FOR HYDROGEN PRODUCTION BASED ON MPC}

The Energy Management System for Hydrogen production $\left(\mathrm{EMS}_{\mathrm{H}}\right)$, developed in Chapter 3, is based on heuristic and rule-based control systems. This chapter evaluates the design of the $\mathrm{EMS}_{\mathrm{H}}$ using advanced algorithms based on Model Predictive Control (MPC) ideas to balance the consumption of power by electrolysis units in an offshore platform, with the aim of maximizing hydrogen production.

This approach is more advanced than the previous $\mathrm{EMS}_{\mathrm{H}}$ defined for the H2OCEAN plant (see Section 3.2), as it takes into account a cost function which optimizes the operation of the electrolysis plant.

We focus here only on the hydrogen production section, maximizing production numerically while taking into account the reduction in the number of connection/disconnections (in order to improve the state of health of the electrolyzers). Moreover, the proposed approach enables system operators to know in advance the expected production and, therefore, schedule preventive-predictive maintenance operations on the electrolyzer units.

For simplicity, in this work, renewable hydrogen is locally generated by wind turbines and wave energy converters and it is fully used (no storage or external sources are considered). However, the results can be easily extended to the most common situation of using only the excess of energy from renewable sources (VALVERDE et al. 2016), (GUTIÉRREZ-MARTÍN et al. 2010).

The $\mathrm{EMS}_{\mathrm{H}}$ developed in this chapter follows a smart grid approach for the local micro grid (SERNA et al. 2017). In comparison with previous works developed in Chapter 3 (SERNA; TADEO, 2014), this proposal focuses on using an advanced control system to optimize hydrogen production and improve the operation of the appliances.

The energy generated at the platform by wind and waves is balanced by regulating the operating point of each electrolysis unit and its connections or disconnections using an MPC. The term MPC does not designate a specific control strategy, but a very wide range of control methods which make an explicit use of a model of the process to obtain the control signal by minimizing an objective function (see Section 2.4).

The MPC presented in this chapter is based on a Mixed-IntegerQuadratic-Programming (MIQP) algorithm, which makes it possible to 
take into account predictions of available power and power consumption, thus improving the balance and reducing the number of connections and disconnections of the devices. Furthermore, a nonlinear model with binary and continuous variables is developed in this chapter, which is then transformed in such a way that an MIQP can be used to solve the MPC optimization at each step.

Two case studies are presented in this chapter for different installations composed of wave and wind energies feeding a set of electrolyzers. The class of electrolyzers considered in this work are high-pressure and temperature alkaline electrolyzers, as they generate hydrogen with a purity better than $99.97 \%$, which is the quality used in the automotive industry (see Section 2.3.1.3), and are already available at the power levels that make the technology cost-efficient (about MW).

Validation using measured data at the target location of the platforms is presented in Section 4.3, showing the adequate operation of the proposed $\mathrm{EMS}_{\mathrm{H}}$.

This chapter is organized in the following manner: Section 4.1 presents the process description and summarizes the modelling of the components and some MPC ideas. The proposed $\mathrm{EMS}_{\mathrm{H}}$ is presented in Section 4.2, fully developing the optimization algorithm. Section 4.3 presents the two case studies and the validation using measured data from a certain location in the Atlantic Ocean. Finally, some conclusions are presented at the end of the chapter.

\subsection{MATERIALS AND METHODS}

This thesis falls within the innovative idea that consists of hydrogen offshore production using a combination of renewable energies. Besides the models of the plant described in Section 3.2, this chapter focuses on the design of an advanced control algorithm of the platform previously considered based on MPC ideas.

\subsubsection{Process description}

Fig. 4.1 depicts the components of the proposed renewable hydrogen platform: two renewable energy sources (wave and wind) supply electricity to the process (see Section 2.1). This electricity is generated in a WEC (Wave Energy Converter) coupled to a VAWT (Vertical Axes Wind Turbine) from a hybrid device, and is then used in 
the electrolyzers as scheduled by the $\mathrm{EMS}_{\mathrm{H}}$ that will be described in Section 4.2.

An electrolyzer is a piece of electrochemical apparatus (something that uses electricity and chemistry at the same time) designed to perform electrolysis: splitting a solution into the atoms from which it is made by passing electricity through it (see Section 2.3.1.3). The proposed $\mathrm{EMS}_{\mathrm{H}}$ aims to adapt the production of hydrogen to the available energy using degrees of freedom of the advanced control system, so the hydrogen produced is maximized without degrading the electrolyzers.

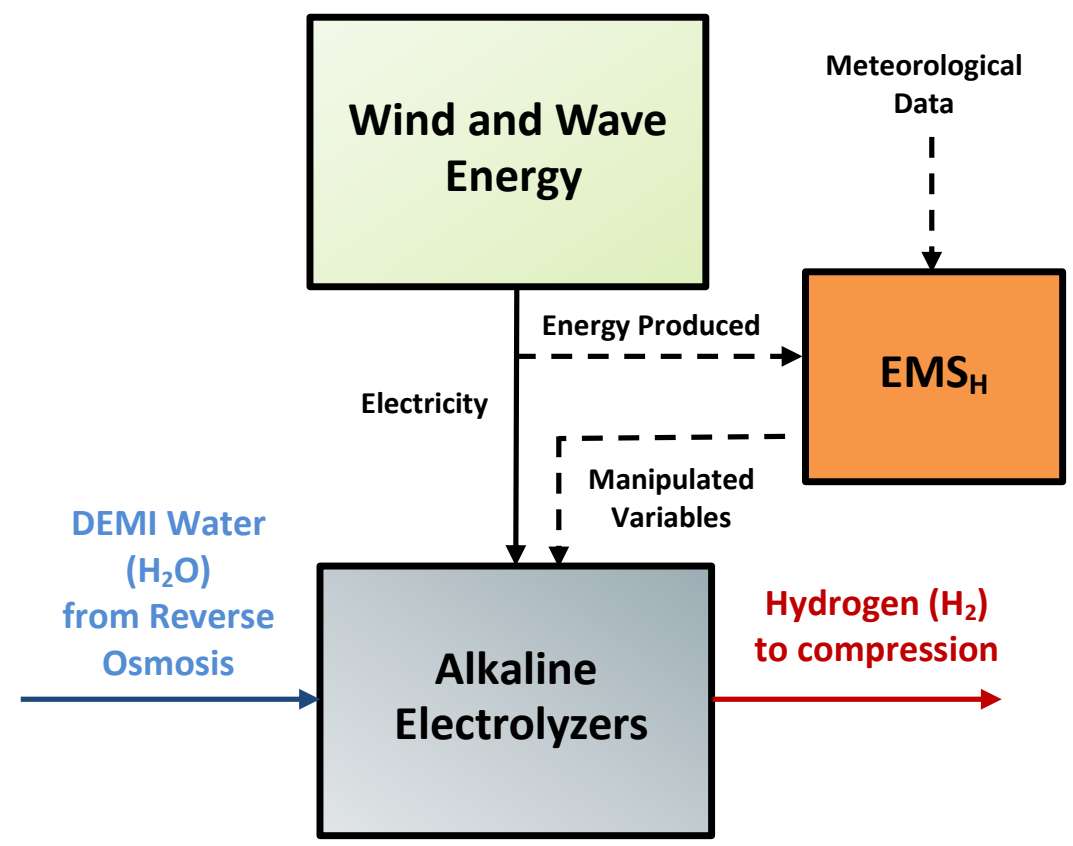

Figure 4.1 - Block structure of the renewable hydrogen platform

\subsubsection{Manipulated variables}

The manipulated variables of the proposed $\mathrm{EMS}_{\mathrm{H}}$ are the operating points for each electrolyzer, known as capacity factors. They are mathematically denoted by $\alpha_{\mathrm{i}}(\mathrm{k})$, where k represents the discrete time in samples (a sample time of 1 hour is used) and the suffix $i$ is used to identify each device. Moreover: 
$-\alpha_{\mathrm{i}}(\mathrm{k})=0$ if the electrolyzer $\mathrm{i}$ is disconnected at time $\mathrm{k}$.

$-\alpha_{\mathrm{i}}(\mathrm{k})$ is between $\left[\begin{array}{ll}\underline{\alpha}_{\mathrm{i}} & \bar{\alpha}_{\mathrm{i}}\end{array}\right]$ if the electrolyzer is connected, where $\underline{\alpha}_{\mathrm{i}}$ and $\bar{\alpha}_{i}$ are the minimum and maximum values (between 0 and $\overline{1}$ ) fixed by the manufacturer due to technological limitations.

In addition, binary variables $\delta_{\mathrm{i}}(\mathrm{k}) \in\{0,1\}$ are used where 0 corresponds to electrolyzer disconnection and 1 to electrolyzer connection (DE PRADA et al. 2008).

\subsubsection{Model and controlled variables}

The model of the electrolyzers is represented by the following equations with parameters a and b (see Equation (27)), which are obtained from the manufacturer's data and measurements from the plant (SERNA et al. 2017):

$$
\begin{aligned}
& \widehat{\mathrm{H}}_{\mathrm{i}}(\mathrm{k})=\frac{\widehat{\alpha}_{\mathrm{i}}(\mathrm{k}) \cdot \widehat{\delta}_{\mathrm{i}}(\mathrm{k})}{\mathrm{a}_{\mathrm{i}} \cdot \widehat{\alpha}_{\mathrm{i}}(\mathrm{k})+\mathrm{b}_{\mathrm{i}}} \cdot \overline{\mathrm{P}}_{\mathrm{i}} \\
& \widehat{\mathrm{P}}_{\mathrm{i}}(\mathrm{k})=\overline{\mathrm{P}}_{\mathrm{i}} \cdot \widehat{\alpha}_{\mathrm{i}}(\mathrm{k}) \cdot \widehat{\delta}_{\mathrm{i}}(\mathrm{k})
\end{aligned}
$$

Equations (27) and (28) show the controlled variables of electrolyzer $\mathrm{i}$ : $\widehat{\mathrm{P}}_{\mathrm{i}}(\mathrm{k})$ and $\widehat{\mathrm{H}}_{\mathrm{i}}(\mathrm{k})$. On the one hand, $\widehat{\mathrm{H}}_{\mathrm{i}}(\mathrm{k})$ is the predicted hydrogen production of electrolyzer $i$ at time $k$. On the other hand, $\widehat{\mathrm{P}}_{\mathrm{i}}(\mathrm{k})$ is the predicted energy consumption of device $i$, whereas $\bar{P}_{i}$ is its maximum power at the same sample time. Parameters $a_{i}, b_{i}$ and $\bar{P}_{i}$ are used to define the device operation, which gives the relationship between consumed energy and hydrogen production. Fig. 4.2 depicts the controlled and manipulated variables for the electrolysis unit.

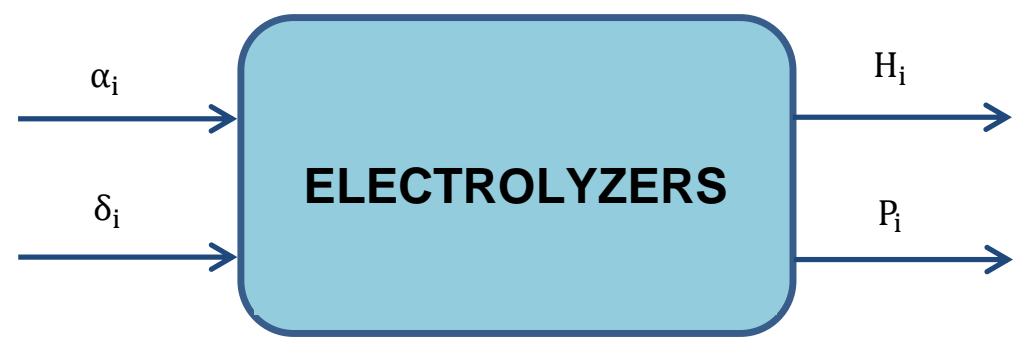

Figure 4.2 - Scheme of the controlled and manipulated variables. 
Note that the model of the electrolyzers used here is static because the time required for them to vary $\alpha$ from the minimum to the maximum value is less than a few minutes in the worst case. Thus, these dynamics can be neglected as the sampling time for the $\mathrm{EMS}_{\mathrm{H}}$ proposed here is one hour (ZHOU; FRANCOIS, 2009).

Figure 4.3 shows the ratio $\mathrm{H}_{\mathrm{i}} / \mathrm{P}_{\mathrm{i}}$ in the production of hydrogen by electrolysis as a function of the capacity factor $\left(\alpha_{i}\right)$ for the two types of electrolyzers considered, which will be explained in the two case studies of Section 4.3.

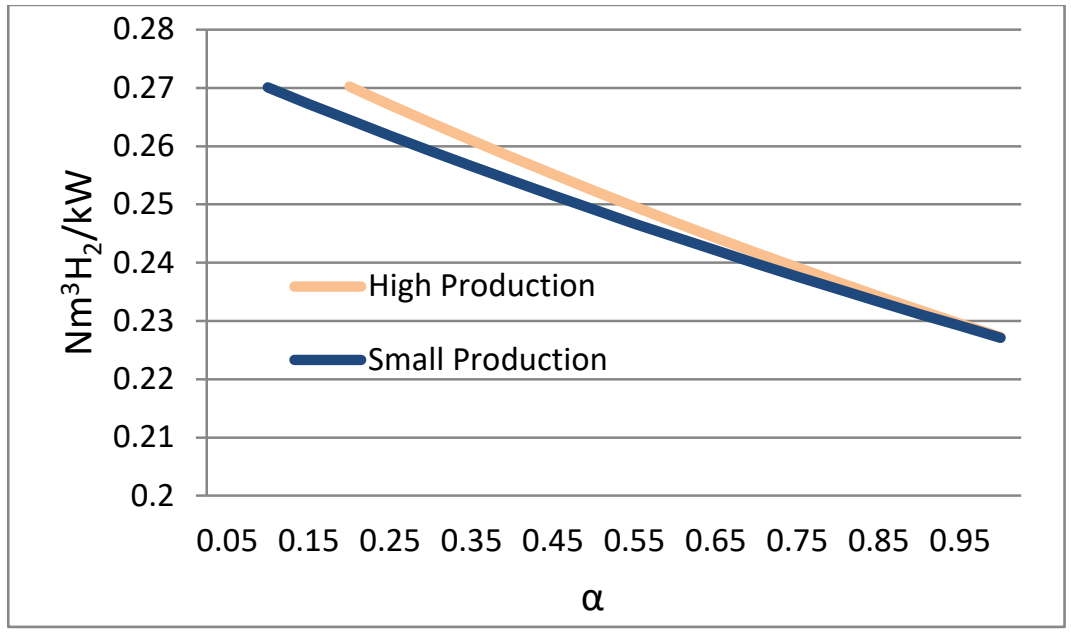

Figure $4.3-$ Ratio $\mathrm{H}_{2}$ produced/Power consumed at different $\alpha\left(\mathrm{a}_{1}=0.875\right.$ $\mathrm{kWh} / \mathrm{Nm}^{3}, \mathrm{~b}_{1}=3.525 \mathrm{kWh} / \mathrm{Nm}^{3}, \mathrm{a}_{2}=0.778 \mathrm{kWh} / \mathrm{Nm}^{3}, \mathrm{~b}_{2}=3.625 \mathrm{kWh} / \mathrm{Nm}^{3}, \overline{\mathrm{P}}_{1}=$ $2134 \mathrm{kWh}, \overline{\mathrm{P}}_{2}=220 \mathrm{kWh}$.

\subsubsection{Model Predictive Control for hydrogen production}

Comparing with other methods of process control, MPC can be used to solve the most common problems in today's industrial processes, which need to be operated under tight performance specifications where many constraints need to be satisfied. The principal elements in MPC are the objective function to be minimized, the model used to compute the predictions of the controlled variables, the definition of the process constraints and the method applied to solve the optimization problem (CAMACHO; BORDONS, 2013).

Fig. 4.4 shows the $\mathrm{EMS}_{\mathrm{H}}$ based on MPC ideas, where the optimization block receives information from the model block 
(electrolysis plant), which is responsible for computing the predictions of the plant output in a defined horizon N (see Section 2.1.4). A model (Equations (27) and (28)) is used to predict future outputs based on past and current values and on the proposed optimal future control actions. These actions are calculated by the optimizer, taking into account the cost function (where the future tracking error is considered) as well as the constraints (CAMACHO; BORDONS, 2013). This optimizer will be developed in Section 4.2

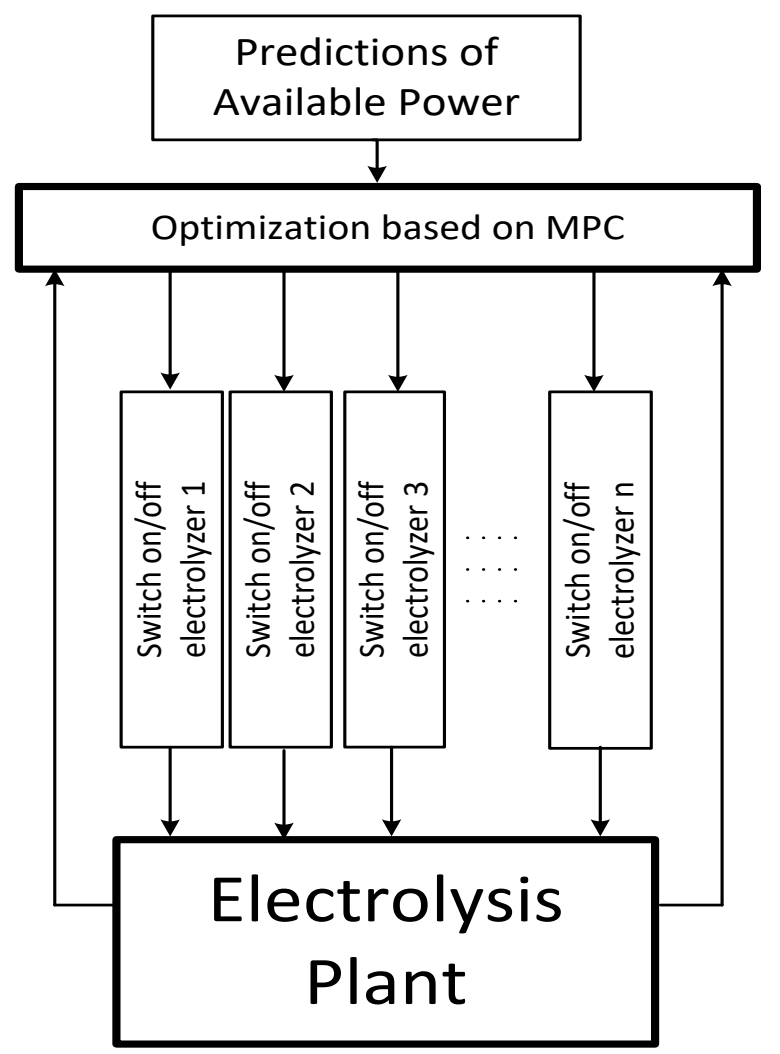

Figure 4.4 - Proposed $\mathrm{EMS}_{\mathrm{H}}$ based on MPC ideas

The MPC algorithm developed in this thesis follows the Practical Non-Linear Model Predictive Control (PNMPC) method. The PNMPC technique offers an alternative to solve the problem of linear optimization using conventional optimizers, such as QP quadratic programming or linear programming solutions (PLUCENIO, 2010). It 
only takes the $\mathrm{N}_{\mathrm{u}}$ horizon control first terms into account. Therefore, the process is assumed to be stable and without integrators. One of the characteristics of this method, which makes it very popular in industry, is the addition of constraints. Optimization (numerical because of the presence of constraints) is carried out at each sampling instant and the value of $u(t)$ is sent to the process. The inconveniences of this method are the size of the process model required and also the inability to work with unstable processes (CAMACHO; BORDONS, 2013).

\subsection{PROPOSED ENERGY MANAGEMENT SYSTEM}

In Section 4.1, we mentioned that alkaline electrolyzers had been selected to operate in the offshore platform. Two types of alkaline electrolyzers (small production and high production) are modelled in this work, as was depicted in Figure 4.2, $\mathrm{n}$ being the number of devices.

The control algorithm designed in this work aims to maximize the hydrogen produced by electrolysis considering such different aspects as the limitation in the available power and the operational constraints. The following three main objectives must be fulfilled:

\subsubsection{Control objectives}

Objective 1: To maximize the hydrogen production, the difference between the values of the prediction and its desired values for each electrolyzer is minimized for all the devices along the prediction horizon $(\mathrm{N})$.

Objective 2: To maximize the operation of the devices and avoid unnecessary connections and disconnections, the discrete variables defining the connection/disconnection condition should be, whenever possible, equal to one (connection condition) along $\mathrm{N}$.

Objective 3: The energy consumed by the devices should always be smaller than the energy supplied from the wind and waves $\left(\widehat{\mathrm{P}}_{\text {available }}(\mathrm{k})\right)$ but will try to be equal.

\subsubsection{Cost function and optimization problem}

Equation (29) shows the quadratic cost function considered in this work. It is solved in each sample time to maximize production, without excess connections/disconnections: 


$$
\begin{aligned}
J= & \sum_{i=1}^{n} \sum_{j=1}^{N}\left[\left(\widehat{H}_{i}(k+j)-\bar{H}_{i}(k+j)\right)^{2} w_{H_{i}}\right. \\
& \left.+\sum_{i=1}^{n} \sum_{j=1}^{N_{u}}\left(\widehat{\delta}_{i}(k+j)-1\right)^{2} w_{\delta_{i}}\right]
\end{aligned}
$$

This equation considers, in a prediction and control horizons of $\mathrm{N}$ and $\mathrm{N}_{\mathrm{u}}$ samples respectively, the error between the predictions of hydrogen produced $\left(\widehat{\mathrm{H}}_{\mathrm{i}}\right)$ and its desired values $\left(\overline{\mathrm{H}}_{\mathrm{i}}\right)$, while also penalizing the number of connections and disconnections. In addition, $\mathrm{w}_{\mathrm{Hi}}$ and $\mathrm{w}_{\delta \mathrm{i}}$ are the weighting factors for the error and the control action $\delta_{\mathrm{i}}$, respectively. The first term of (29) is used for Objective 1, while the second term of this equation aims to achieve Objective 2 of section 4.2.1.

To solve this problem, the predictions of the hydrogen production are expressed as a function of the future control actions $\widehat{\alpha}_{i}$ and $\widehat{\delta}_{i}$, and the past values of these inputs and the outputs $\mathrm{H}_{\mathrm{i}}$ and $\mathrm{P}_{\mathrm{i}}$. These predictions are obtained using the electrolyzer models (27) and (28) (see Sections 4.1.2 and 4.1.3). Thus, using Equation (29) with all the system constraints and the electrolyzer models, it can be shown that the optimization problem to be solved at each sample time is (30), where the last constraint aims to solve Objective 3. The vector of predictions of available power, $\widehat{\mathrm{P}}_{\text {available }}(\mathrm{k})$, is calculated over $\mathrm{N}_{\mathrm{u}}$ using real meteorological predictions: wave's height and period and wind speed.

$$
\begin{aligned}
& \min _{\left(\alpha_{\mathrm{i}}, \delta_{\mathrm{i}}\right)} \mathrm{J} \\
& \text { such that: }\left\{\begin{array}{l}
\delta_{\mathrm{i}} \in\{0,1\} \\
\underline{\alpha}_{\mathrm{i}} \leq \alpha_{\mathrm{i}} \leq \bar{\alpha}_{\mathrm{i}} \\
\widehat{\mathrm{P}}_{\mathrm{i}}(\mathrm{k})=\overline{\mathrm{P}}_{\mathrm{i}} \cdot \widehat{\alpha}_{\mathrm{i}}(\mathrm{k}) \cdot \widehat{\delta}_{\mathrm{i}}(\mathrm{k}) \\
\widehat{\mathrm{H}}_{\mathrm{i}}(\mathrm{k})=\frac{\widehat{\alpha}_{\mathrm{i}}(\mathrm{k}) \cdot \widehat{\delta}_{\mathrm{i}}(\mathrm{k})}{\mathrm{a}_{\mathrm{i}} \cdot \widehat{\alpha}_{\mathrm{i}}(\mathrm{k})+\mathrm{b}_{\mathrm{i}}} \cdot \overline{\mathrm{P}}_{\mathrm{i}} \\
\mathrm{n} \\
\sum_{\mathrm{i}=1}^{\mathrm{n}} \widehat{\mathrm{P}}_{\mathrm{i}}(\mathrm{k}) \leq \widehat{\mathrm{P}}_{\text {available }}(\mathrm{k})
\end{array}\right.
\end{aligned}
$$


Because of the non-linear model of the electrolyzer (see Equation (27)) and the use of discrete $(\delta)$ and real $(\alpha)$ decision variables, the problem to be solved by the MPC control algorithm is, at each $\mathrm{k}$, an NLMIQP (Non-Linear Mixed Integer Quadratic Problem), which is complicated to solve. Hence, a simple solution is proposed in Section 4.2.3. Having once made this approximation, the PNMPC technique can be implemented, as it uses linearized models of the system trajectory (PLUCENIO, 2010).

\subsubsection{Approximation to an MIQP}

The main goal of this section is to transform the NLMIQP problem (30) into a Mixed-Integer Quadratic Problem with linear constraints (MIQP). To do so, each electrolyzer model is first modified using the following change of variable:

$$
\mathrm{z}_{\mathrm{i}}(\mathrm{k})=\alpha_{\mathrm{i}}(\mathrm{k}) \cdot \delta_{\mathrm{i}}(\mathrm{k})
$$

where $z_{i}$ is now a real variable: $z_{i} \in \mathbb{R}$. The predictions of the hydrogen production are now given by:

$$
\begin{aligned}
& \widehat{\mathrm{H}}_{\mathrm{i}}(\mathrm{k})=\frac{\widehat{\mathrm{z}}_{\mathrm{i}}(\mathrm{k})}{\mathrm{a}_{\mathrm{i}} \cdot \widehat{\alpha}_{\mathrm{i}}(\mathrm{k})+\mathrm{b}_{\mathrm{i}}} \cdot \overline{\mathrm{P}}_{\mathrm{i}} \\
& \widehat{\mathrm{P}}_{\mathrm{i}}(\mathrm{k})=\overline{\mathrm{P}}_{\mathrm{i}} \cdot \hat{\mathrm{z}}_{\mathrm{i}}(\mathrm{k})
\end{aligned}
$$

Note that the predictions of the hydrogen produced do not depend on past values because a static model for the electrolyzers was considered. It can be seen in Equation (31) that $\mathrm{H}_{\mathrm{i}}=0$ if $\delta_{\mathrm{i}}=0$, therefore Equation (34) can be rewritten to eliminate the dependence between $\alpha_{i}$ and $\mathrm{H}_{\mathrm{i}}$ :

$$
\widehat{\mathrm{H}}_{\mathrm{i}}(\mathrm{k})=\frac{\hat{\mathrm{z}}_{\mathrm{i}}(\mathrm{k})}{\mathrm{a}_{\mathrm{i}} \hat{\mathrm{z}}_{\mathrm{i}}(\mathrm{k})+\mathrm{b}_{\mathrm{i}}} \cdot \overline{\mathrm{P}}_{\mathrm{i}}
$$

Thereby, $\mathrm{H}_{\mathrm{i}}$ is now a real function of the real variable $\mathrm{z}_{\mathrm{i}}$. As $\mathrm{z}_{\mathrm{i}}$ is in the $[0,1]$ interval, $a>0$ and $b>0, H_{i}\left(z_{i}\right)$ is differentiable and continuous in the interval $[0,1]$. In Equation $(34), \mathrm{H}_{\mathrm{i}}\left(\mathrm{z}_{\mathrm{i}}\right)$ is a nonlinear function, so the relationship between $\widehat{z}(k+j)$ and $\widehat{H}(k+j)$ will not be linear either. 
It is necessary to make another approximation in the predictions to modify the optimization problem into an MIQP which is less difficult to solve.

To linearize future predictions of the hydrogen production, an approximation using a first order truncation Taylor series has been done, where $\Delta \mathrm{z}_{\mathrm{i}}(\mathrm{k})=\mathrm{z}_{\mathrm{i}}(\mathrm{k}+1)-\mathrm{z}_{\mathrm{i}}(\mathrm{k})$ :

$$
\mathrm{H}_{\mathrm{i}}\left(\mathrm{z}_{\mathrm{i}}+\Delta \mathrm{z}_{\mathrm{i}}\right)=\mathrm{H}_{\mathrm{i}}\left(\mathrm{z}_{\mathrm{i}}\right)+\frac{\partial \mathrm{H}_{\mathrm{i}}}{\partial \mathrm{z}_{\mathrm{i}}}\left(\mathrm{z}_{\mathrm{i}}\right) \Delta \mathrm{z}_{\mathrm{i}}
$$

Hence, simplifying the notation and enforcing the same method for the $\mathrm{N}$ predictions of the hydrogen production gives Equation (36):

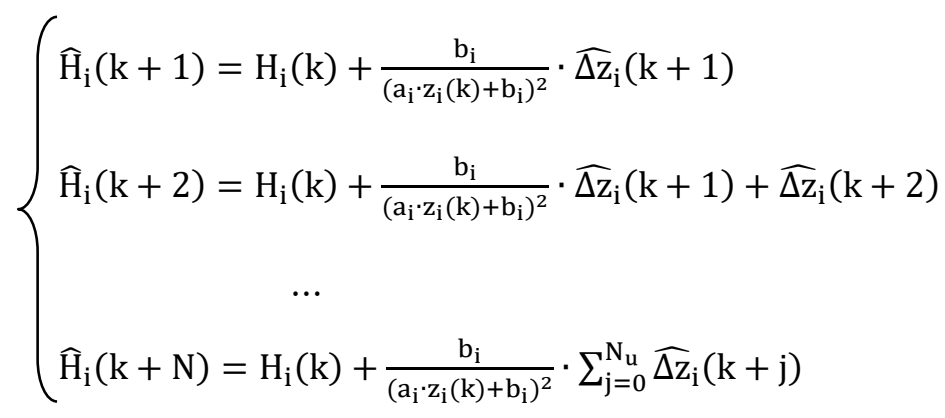

In matrix form, it is given by (37):

$$
\begin{gathered}
\widehat{\mathbf{H}}_{\mathrm{i}}:=\left[\begin{array}{c}
\widehat{\mathrm{H}}_{\mathrm{i}}(\mathrm{k}+1) \\
\widehat{\mathrm{H}}_{\mathrm{i}}(\mathrm{k}+2) \\
\cdots \\
\cdots \\
\widehat{\mathrm{H}}_{\mathrm{i}}(\mathrm{k}+\mathrm{N})
\end{array}\right]= \\
=\left[\begin{array}{c}
\mathrm{H}_{\mathrm{i}}(\mathrm{k}) \\
\mathrm{H}_{\mathrm{i}}(\mathrm{k}) \\
\cdots \\
\cdots \\
\mathrm{H}_{\mathrm{i}}(\mathrm{k})
\end{array}\right]+\frac{\mathrm{b}_{\mathrm{i}}}{\left(\mathrm{a}_{\mathrm{i}} \cdot \mathrm{z}_{\mathrm{i}}(\mathrm{k})+\mathrm{b}_{\mathrm{i}}\right)^{2}} \cdot\left[\begin{array}{ccccc}
1 & 0 & 0 & \cdots & 0 \\
1 & 1 & 0 & \cdots & 0 \\
1 & 1 & 1 & \cdots & 0 \\
1 & 1 & 1 & 1 & 0 \\
\vdots & \vdots & \vdots & \ddots & \vdots \\
1 & 1 & 1 & \cdots & 1
\end{array}\right]\left[\begin{array}{c}
{\widehat{\Delta \mathrm{z}_{\mathrm{i}}}}(\mathrm{k}+1) \\
\widehat{\Delta \mathrm{z}_{\mathrm{i}}}(\mathrm{k}+2) \\
\cdots \\
\cdots \\
\widehat{\Delta}_{\mathrm{i}}\left(\mathrm{k}+\mathrm{N}_{\mathrm{u}}\right)
\end{array}\right]
\end{gathered}
$$


We now define $g_{i}:=\frac{b_{i}}{\left(a_{i} \cdot z_{i}(k)+b_{i}\right)^{2}}$, vector $\mathbf{1}:=\left[\begin{array}{llll}1 & 1 & \ldots & 1\end{array}\right]^{T}$ (dimension $1 \times \mathrm{N}$ ) and the following matrix $\mathbf{T}$ :

$$
\mathbf{T}:=\overbrace{\left[\begin{array}{ccccc}
1 & 0 & 0 & \cdots & 0 \\
1 & 1 & 0 & \cdots & 0 \\
1 & 1 & 1 & \cdots & 0 \\
1 & 1 & 1 & 1 & 0 \\
\vdots & \vdots & \vdots & \ddots & \vdots \\
1 & 1 & 1 & \cdots & 1
\end{array}\right]}^{\mathrm{N}_{\mathrm{u}}}
$$

Predictions are then given as follows for each i:

$$
\widehat{\mathbf{H}}_{\mathbf{i}}=1 \cdot \mathrm{H}_{\mathrm{i}}(\mathrm{k})+\mathrm{g}_{\mathrm{i}} \cdot \mathrm{T} \cdot \widehat{\Delta \mathbf{z}}_{\mathbf{i}}
$$

where:

$$
\widehat{\Delta \mathbf{z}}_{\mathbf{i}}:=\left[\widehat{\Delta \mathrm{z}}_{\mathrm{i}}(\mathrm{k}+1) \ldots \widehat{\Delta \mathrm{z}}_{\mathrm{i}}\left(\mathrm{k}+\mathrm{N}_{\mathrm{u}}\right)\right]^{\mathrm{T}}
$$

and in the same way:

$$
\begin{aligned}
& \widehat{\boldsymbol{\alpha}}_{\mathrm{i}}:=\left[\widehat{\alpha}_{\mathrm{i}}(\mathrm{k}+1) \ldots \widehat{\alpha}_{\mathrm{i}}\left(\mathrm{k}+\mathrm{N}_{\mathrm{u}}\right)\right]^{\mathrm{T}} \\
& \widehat{\boldsymbol{\delta}}_{\mathrm{i}}:=\left[\widehat{\delta}_{\mathrm{i}}(\mathrm{k}+1) \ldots \widehat{\delta}_{\mathrm{i}}\left(\mathrm{k}+\mathrm{N}_{\mathrm{u}}\right)\right]^{\mathrm{T}}
\end{aligned}
$$

The vector which will be obtained at each sample time contains the manipulated variables $\alpha_{\mathrm{i}}(\mathrm{k})$ and $\delta_{\mathrm{i}}(\mathrm{k})$ and also the new variables included in this approximation, $\Delta \mathrm{z}_{\mathrm{i}}(\mathrm{k})$.

This vector, shown in Equation (43), is obtained at each sample time using receding horizon estimation, so that each instant, the horizon is displaced towards the future, which involves the application of the first control signal of the sequence calculated at each step (see Section 2.4.1 and Fig. 2.24).

Hence, the relationship between the free variables and the predictions can be rewritten by calculating the augmented vector of free variables in the following vector $\Delta \mathbf{u}_{\mathrm{i}}$ (which has dimension $3 \mathrm{~N}_{\mathrm{u}}$ × 1): 


$$
\Delta \mathbf{u}_{\mathrm{i}}:=\left[\begin{array}{c}
\widehat{\Delta \mathrm{z}}_{\mathrm{i}}(\mathrm{k}+1) \\
{\widehat{\Delta \mathrm{z}_{\mathrm{i}}}}_{\mathrm{i}}(\mathrm{k}+2) \\
\cdots \\
{\widehat{\Delta \mathrm{z}_{\mathrm{i}}}}\left(\mathrm{k}+\mathrm{N}_{\mathrm{u}}\right) \\
\widehat{\alpha}_{\mathrm{i}}(\mathrm{k}+1) \\
\widehat{\alpha}_{\mathrm{i}}(\mathrm{k}+1) \\
\cdots \\
\widehat{\alpha}_{\mathrm{i}}\left(\mathrm{k}+\mathrm{N}_{\mathrm{u}}\right) \\
\widehat{\delta}_{\mathrm{i}}(\mathrm{k}+1) \\
\widehat{\delta}_{\mathrm{i}}(\mathrm{k}+2) \\
\cdots \\
\widehat{\delta}_{\mathrm{i}}\left(\mathrm{k}+\mathrm{N}_{\mathrm{u}}\right)
\end{array}\right]:=\left[\begin{array}{c}
\widehat{\mathbf{z}}_{\mathrm{i}} \\
\widehat{\boldsymbol{\alpha}}_{\mathrm{i}} \\
\widehat{\boldsymbol{\delta}}_{\mathrm{i}}
\end{array}\right]
$$

We now define the matrix $\mathbf{G}_{\mathbf{i}}$ (dimensions $\mathrm{N} \times 3 \mathrm{~N}_{\mathrm{u}}$ ):

$$
\mathbf{G}_{\mathbf{i}}:=\left[\begin{array}{lll}
g_{\mathrm{i}} \mathbf{T} & 0 & 0
\end{array}\right]
$$

where 0 is the matrix of appropriate dimensions $\left(\mathrm{N} \times \mathrm{N}_{\mathrm{u}}\right)$ with all entries equal to zero.

Thus, Equation (45) describes the hydrogen produced by a certain device:

$$
H_{i}=f_{i}+G_{i} \cdot \Delta u_{i}
$$

$\mathrm{G}_{\mathrm{i}}$ is the system's dynamics matrix, whereas $\mathrm{H}_{\mathrm{i}}$ is a vector which contains the system predictions along the horizon, $\Delta \mathbf{u}_{\mathbf{i}}$ represents the vector of control increments and $\mathbf{f}_{\mathbf{i}}$ is the free response vector computed using the nonlinear model written in Equation (34) (CAMACHO; BORDONS, 2013).

Now, taking into account the set of $\mathrm{n}$ devices:

$$
\begin{aligned}
& \mathrm{H}:=\left[\begin{array}{llll}
\mathrm{H}_{1} & \mathrm{H}_{2} & \ldots \mathrm{H}_{\mathrm{n}}
\end{array}\right]^{\mathrm{T}} \\
& f:=\left[\begin{array}{lll}
f_{1} & f_{2} & \ldots \\
f_{n}
\end{array}\right]^{\mathrm{T}} \\
& \Delta \mathrm{U}:=\left[\Delta \mathrm{u}_{1} \Delta \mathrm{u}_{2} \ldots \Delta \mathrm{u}_{\mathrm{n}}\right]^{\mathrm{T}}
\end{aligned}
$$


where $\mathbf{H}$ and $\mathbf{f}$ are $\mathbf{N} \cdot n \times 1$ vectors and $\Delta \mathbf{U}$ is a $n \cdot 3 \mathrm{~N}_{\mathrm{u}} \times 1$ vector. It follows that:

$$
\mathbf{H}=\mathbf{f}+\mathbf{G} \cdot \Delta \mathbf{U}
$$

where:

$$
\mathbf{G}:=\overbrace{\left[\begin{array}{cccccccccccc}
\mathbf{G}_{1} & 0 & 0 & 0 & 0 & 0 & \cdots & 0 & 0 & \cdots & \cdots & 0 \\
0 & \mathbf{G}_{2} & 0 & 0 & \vdots & \vdots & \cdots & \vdots & \vdots & \vdots & \cdots & \vdots \\
0 & 0 & \ddots & 0 & \vdots & \vdots & \ddots & \vdots & \vdots & \vdots & \ddots & \vdots \\
0 & 0 & 0 & \mathbf{G}_{\mathbf{n}} & 0 & 0 & \cdots & 0 & 0 & \cdots & \cdots & 0
\end{array}\right]}^{\mathrm{n} \cdot 3 \mathrm{~N}_{\mathrm{u}}} \mathrm{N} \cdot \mathrm{n}
$$

Equation (48) relates, in a linear manner, the manipulated variables (vector $\Delta \mathbf{U}$ ) and the controlled variables (vector $\mathbf{H}$ ), thus the nonlinear problems in (30) are eliminated.

\subsubsection{Constraints}

Constraints were defined in Section 4.2.2 (see Equation (30)). They are mathematically given by:

$$
\begin{aligned}
& \alpha_{i}(k+j) \leq \bar{\alpha}_{i} \\
& \alpha_{i}(k+j) \geq \underline{\alpha}_{i}
\end{aligned}
$$

The following constraint (53) must be considered to fulfil Objective 3: At each sample (k), the total energy consumed should always be smaller than the predicted energy available from the wind and waves, $\widehat{\mathrm{P}}_{\text {available }}(\mathrm{k})$. Considering MPC ideas, the vector of predictions of available power, $\widehat{P}_{\text {available }}(\mathrm{k})$, is calculated over $\mathrm{N}_{\mathrm{u}}$ using real meteorological data such as wave height, wave period, and wind speed. Hence, the constraint in the consumed energy is:

$$
\mathrm{J}=\sum_{\mathrm{i}=1}^{\mathrm{n}} \overline{\mathrm{P}}_{\mathrm{i}} \cdot \hat{\mathrm{z}}_{\mathrm{i}}(\mathrm{k}+\mathrm{j}) \leq \widehat{\mathrm{P}}_{\text {available }}(\mathrm{k}+\mathrm{j}) \quad \mathrm{j}=1,2, \ldots, \mathrm{N}_{\mathrm{u}}
$$

Besides constraints (51)-(53), in section 4.2.3 new decision variables $\mathrm{z}$ were defined to simplify the optimization problem that had to be solved as part of the MPC strategy. The constraints presented in 
this section are modified into an MLD (Mixed Logical Dynamical System) (BEMPORAD; MORARI, 1999) to associate the performance of the platform with the discrete variable $\delta$ and the continuous variable $\alpha$, and to linearize the model (see Section 2.4.3). More specifically, the mixed product P10 was chosen from Table 2.1, where $\mathrm{m}$ and $\mathrm{M}$ represent the lower and upper bounds of the system $\left(\underline{\alpha}_{i}\right.$ and $\left.\bar{\alpha}_{i}\right)$, respectively.

\begin{tabular}{|c|c|c|c|}
\hline & Relation & Logic & MLD Inequalities \\
\hline P10 & Mixed Product & $\mathrm{z}=\delta \cdot \alpha$ & $\begin{array}{c}\mathrm{z} \leq \mathrm{M} \delta \\
\mathrm{z} \geq \mathrm{m} \delta \\
\mathrm{z} \leq \alpha-\mathrm{m}(1-\delta) \\
\mathrm{z} \geq \alpha-\mathrm{M}(1-\delta)\end{array}$ \\
\hline
\end{tabular}

Table 4.1 -MLD inequalities transformed for this approximation.

Thus, constraints (54)-(57) show this idea for all the cases where the binary variable could be 0 or 1 and $\mathrm{j}=1, \ldots, \mathrm{N}_{\mathrm{u}}$.

$$
\begin{aligned}
& \mathrm{z}_{\mathrm{i}}(\mathrm{k})+\sum_{\mathrm{l}=1}^{\mathrm{j}} \Delta \mathrm{z}_{\mathrm{i}}(\mathrm{k}+\mathrm{l}) \leq \bar{\alpha}_{\mathrm{i}} \cdot \delta_{\mathrm{i}}(\mathrm{k}+\mathrm{j}) \\
& \mathrm{z}_{\mathrm{i}}(\mathrm{k})+\sum_{\mathrm{l}=1}^{\mathrm{j}} \Delta \mathrm{z}_{\mathrm{i}}(\mathrm{k}+\mathrm{l}) \geq \underline{\alpha}_{\mathrm{i}} \cdot \delta_{\mathrm{i}}(\mathrm{k}+\mathrm{j}) \\
& \mathrm{z}_{\mathrm{i}}(\mathrm{k})+\sum_{\mathrm{l}=1}^{\mathrm{j}} \Delta \mathrm{z}_{\mathrm{i}}(\mathrm{k}+\mathrm{l}) \leq \alpha_{\mathrm{i}}(\mathrm{k}+\mathrm{j})-\underline{\alpha}_{\mathrm{i}}\left(1-\delta_{\mathrm{i}}(\mathrm{k}+\mathrm{j})\right) \\
& \mathrm{z}_{\mathrm{i}}(\mathrm{k})+\sum_{\mathrm{l}=1}^{\mathrm{j}} \Delta \mathrm{z}_{\mathrm{i}}(\mathrm{k}+\mathrm{l}) \geq \alpha_{\mathrm{i}}(\mathrm{k}+\mathrm{j})-\bar{\alpha}_{\mathrm{i}}\left(1-\delta_{\mathrm{i}}(\mathrm{k}+\mathrm{j})\right)
\end{aligned}
$$

Thus, the constraints defined in Equations (51)-(57) are linear in the decision variables $\Delta \mathrm{z}, \alpha$ and $\delta$; so the optimization problem can be solved using Mixed-Integer Quadratic Programming (MIQP).

\subsubsection{Optimization}

We propose that the MPC problem of minimizing the cost function (30), subject to (51)-(57) can be transformed into the following MIQP given by Equation 58. This equation is solved at each sample time using the receding horizon estimation:

$$
\mathbf{J}=\min _{\Delta \mathbf{U}} \frac{\mathbf{1}}{\mathbf{2}} \Delta \mathbf{U}^{\mathrm{T}} \cdot \mathbf{Q} \cdot \boldsymbol{\Delta} \mathbf{U}+\mathbf{L}^{\mathrm{T}} \cdot \boldsymbol{\Delta} \mathbf{U}
$$


$\mathbf{Q}$ and $\mathbf{L}$ can be obtained by the following Equation (58), which has been developed from Equations (49) and (42) in the cost function (29) and by operating mathematically:

$$
\begin{aligned}
& \mathbf{J}=(\mathbf{f}+\mathbf{G} \cdot \Delta \mathbf{U}-\overline{\mathbf{H}})^{\mathbf{T}} \mathbf{w}_{\mathbf{H}}(\mathbf{f}+\mathbf{G} \cdot \Delta \mathbf{U}-\overline{\mathbf{H}})+(\widehat{\boldsymbol{\delta}}-\mathbf{1})^{\mathbf{T}} \mathbf{w}_{\boldsymbol{\delta}}(\widehat{\boldsymbol{\delta}}-\mathbf{1})= \\
& =\left(\mathbf{f}^{\mathbf{T}}+\mathbf{G}^{\mathbf{T}} \cdot \Delta \mathbf{U}^{\mathbf{T}}-\overline{\mathbf{H}}^{\mathbf{T}}\right) \mathbf{w}_{\mathbf{H}}(\mathbf{f}+\mathbf{G} \cdot \Delta \mathbf{U}-\overline{\mathbf{H}})+\left(\widehat{\boldsymbol{\delta}}^{\mathbf{T}}-\mathbf{1}^{\mathbf{T}}\right) \mathbf{w}_{\boldsymbol{\delta}}(\widehat{\boldsymbol{\delta}}-\mathbf{1})= \\
& =\mathbf{f}^{\mathrm{T}} \mathbf{w}_{\mathbf{H}} \mathbf{f}+\mathbf{f}^{\mathrm{T}} \mathbf{w}_{\mathbf{H}} \mathbf{G} \cdot \Delta \mathbf{U}-\mathbf{f}^{\mathrm{T}} \mathbf{w}_{\mathbf{H}} \overline{\mathbf{H}}+\mathbf{G}^{\mathrm{T}} \Delta \mathbf{U}^{\mathrm{T}} \mathbf{w}_{\mathbf{H}} \mathbf{f}+\mathbf{G}^{\mathrm{T}} \Delta \mathbf{U}^{\mathrm{T}} \mathbf{w}_{\mathbf{H}} \mathbf{G} \cdot \Delta \mathbf{U}- \\
& \mathbf{G}^{\mathrm{T}} \Delta \mathbf{U}^{\mathrm{T}} \mathbf{W}_{\mathbf{H}} \overline{\mathbf{H}}-\overline{\mathbf{H}}^{\mathrm{T}} \mathbf{W}_{\mathbf{H}} \mathbf{f}-\overline{\mathbf{H}}^{\mathrm{T}} \mathbf{W}_{\mathbf{H}} \mathbf{G} \cdot \Delta \mathbf{U}+\overline{\mathbf{H}}^{\mathrm{T}} \mathbf{W}_{\mathbf{H}} \overline{\mathbf{H}}+ \\
& \widehat{\boldsymbol{\delta}}^{\mathrm{T}} \mathbf{w}_{\boldsymbol{\delta}} \widehat{\boldsymbol{\delta}}-\mathbf{1}^{\mathrm{T}} \mathbf{w}_{\boldsymbol{\delta}} \widehat{\boldsymbol{\delta}}-\widehat{\boldsymbol{\delta}}^{\mathrm{T}} \mathbf{w}_{\boldsymbol{\delta}} \mathbf{1}+\mathbf{1}^{\mathrm{T}} \mathbf{w}_{\boldsymbol{\delta}} \mathbf{1}= \\
& \left.=\Delta \mathbf{U}^{\mathrm{T}}\left[\mathbf{G}^{\mathrm{T}} \mathbf{w}_{\mathbf{H}} \mathbf{G}\right] \Delta \mathbf{U}+2 \mathbf{f}^{\mathrm{T}} \mathbf{w}_{\mathbf{H}} \mathbf{G}-\mathbf{2} \overline{\mathbf{H}}^{\mathrm{T}} \mathbf{w}_{\mathbf{H}} \mathbf{G}\right] \Delta \mathbf{U}+\mathbf{f}^{\mathrm{T}} \mathbf{w}_{\mathbf{H}} \mathbf{f}-\mathbf{2} \overline{\mathbf{H}}^{\mathrm{T}} \mathbf{w}_{\mathbf{H}} \mathbf{f}+ \\
& \overline{\mathbf{H}}^{\mathrm{T}} \mathbf{w}_{\mathrm{H}} \overline{\mathbf{H}}+\widehat{\boldsymbol{\delta}}^{\mathrm{T}} \mathbf{w}_{\boldsymbol{\delta}} \widehat{\delta}-\mathbf{2}\left(\mathbf{1}^{\mathrm{T}} \mathbf{w}_{\boldsymbol{\delta}} \widehat{\delta}\right)+\mathbf{1}^{\mathrm{T}} \mathbf{w}_{\boldsymbol{\delta}} \mathbf{1}
\end{aligned}
$$

Matrices $\mathbf{L}$ and $\mathbf{Q}$ are the linear and quadratic part of the quadratic optimization problem, respectively, which are obtained from Equation (59) (marked in circle).

They are given by Equations (60) and (61):

$$
\begin{gathered}
\mathbf{L}:=2 \mathbf{f}^{\mathrm{T}} \mathbf{w}_{\mathbf{H}} \mathbf{G}-2 \overline{\mathbf{H}}^{\mathrm{T}} \mathbf{w}_{\mathbf{H}} \mathbf{G} \\
\mathbf{Q}:=\mathbf{G}^{\mathrm{T}} \mathbf{w}_{\mathbf{H}} \mathbf{G}
\end{gathered}
$$

All the constraints (51)-(57) can be rewritten in the compact form $\mathbf{A} \cdot \mathbf{\Delta} \mathbf{U} \leq \mathbf{B}$.

The dimensions of matrices $\mathbf{L}, \mathbf{Q}, \mathbf{A}$ and $\mathbf{B}$ depend on the number of electrolyzers (n) and the control horizon $\mathrm{N}_{\mathrm{u}}$. These matrices have the

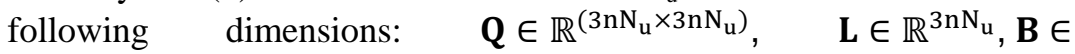
$\mathbb{R}^{\left(4 n N_{u}+N_{u}\right)}$ and $\mathbf{A} \in \mathbb{R}^{\left(\left(4 \mathrm{nN}_{\mathrm{u}}+\mathrm{N}_{\mathrm{u}}\right) \times 3 \mathrm{nN}_{\mathrm{u}}\right)}$. Matrices $\mathbf{B}$ and $\mathbf{A}$ from Equation (58) are the constraints of the problem. Matrix $\mathbf{A}$ is: 


$$
\mathbf{A}:=\overbrace{\left[\begin{array}{lll}
\mathbf{A}_{11} & \mathbf{A}_{12} & \mathbf{A}_{13} \\
\mathbf{A}_{21} & \mathbf{A}_{22} & \mathbf{A}_{23} \\
\mathbf{A}_{31} & \mathbf{A}_{32} & \mathbf{A}_{33} \\
\mathbf{A}_{41} & \mathbf{A}_{42} & \mathbf{A}_{43} \\
\mathbf{A}_{51} & \mathbf{A}_{52} & \mathbf{A}_{53}
\end{array}\right]}^{3 n \cdot \mathrm{N}_{\mathrm{u}}} 4 \mathrm{n} \cdot \mathrm{N}_{\mathrm{u}}+\mathrm{N}_{\mathrm{u}}
$$

where:

$$
\begin{aligned}
& \mathbf{A}_{11}:=\left[\begin{array}{ccccccccccccc}
\overline{\mathrm{P}}_{1} & 0 & \cdots & 0 & \overline{\mathrm{P}}_{2} & 0 & \cdots & 0 & \cdots & \overline{\mathrm{P}}_{\mathrm{n}} & 0 & \cdots & 0 \\
\overline{\mathrm{P}}_{1} & \overline{\mathrm{P}}_{1} & \cdots & 0 & \overline{\mathrm{P}}_{2} & \overline{\mathrm{P}}_{2} & \cdots & 0 & \cdots & \overline{\mathrm{P}}_{\mathrm{n}} & \overline{\mathrm{P}}_{\mathrm{n}} & \cdots & 0 \\
\vdots & \vdots & \ddots & 0 & \vdots & \vdots & \ddots & 0 & \cdots & \vdots & \vdots & \ddots & 0 \\
\overline{\mathrm{P}}_{1} & \overline{\mathrm{P}}_{1} & \cdots & \overline{\mathrm{P}}_{1} & \overline{\mathrm{P}}_{2} & \overline{\mathrm{P}}_{2} & \cdots & \overline{\mathrm{P}}_{2} & \cdots & \overline{\mathrm{P}}_{\mathrm{n}} & \overline{\mathrm{P}}_{\mathrm{n}} & \cdots & \overline{\mathrm{P}}_{\mathrm{n}}
\end{array}\right] \\
& \mathbf{A}_{12}=\mathbf{A}_{22}=\mathbf{A}_{32}=\mathbf{A}_{13}:=\left[\begin{array}{cccc}
0 & 0 & \cdots & 0 \\
0 & 0 & \cdots & 0 \\
\vdots & \vdots & \ddots & \vdots \\
0 & 0 & \cdots & 0
\end{array}\right] \\
& \mathbf{A}_{21}=\mathbf{A}_{41}:=\left[\begin{array}{cccccccccc}
1 & 0 & \cdots & 0 & & & 0 & 0 & \cdots & 0 \\
1 & 1 & \cdots & 0 & & & \vdots & \vdots & \cdots & 0 \\
\vdots & \vdots & \ddots & 0 & & & \vdots & \vdots & \ddots & \vdots \\
1 & 1 & \cdots & 1 & & & 0 & 0 & \cdots & 0 \\
& & & & \ddots & & & & & \\
& & & & & \ddots & & & & \vdots \\
0 & 0 & \cdots & 0 & & & 1 & 0 & \cdots & 0 \\
\vdots & \vdots & \cdots & 0 & & & 1 & 1 & \cdots & 0 \\
\vdots & \vdots & \ddots & \vdots & & & \vdots & \vdots & \ddots & 0 \\
0 & 0 & \cdots & 0 & & & 1 & 1 & \cdots & 1
\end{array}\right]
\end{aligned}
$$




$$
\begin{aligned}
& \mathbf{A}_{\mathbf{3 1}}=\mathbf{A}_{\mathbf{5 1}}:=\left[\begin{array}{cccccccccc}
-1 & 0 & \cdots & 0 & & & 0 & 0 & \cdots & 0 \\
-1 & -1 & \cdots & 0 & & & \vdots & \vdots & \cdots & 0 \\
\vdots & \vdots & \ddots & 0 & & & \vdots & \vdots & \ddots & \vdots \\
-1 & -1 & \cdots & -1 & & & 0 & 0 & \cdots & 0 \\
& & & & \ddots & & & & & \\
0 & 0 & \cdots & 0 & & & -1 & 0 & \cdots & 0 \\
\vdots & \vdots & \cdots & 0 & & & -1 & -1 & \cdots & 0 \\
\vdots & \vdots & \ddots & \vdots & & & \vdots & \vdots & \ddots & 0 \\
0 & 0 & \cdots & 0 & & -1 & -1 & \cdots & -1
\end{array}\right] \\
& \mathbf{A}_{42}:=\left[\begin{array}{cccc}
-1 & 0 & \cdots & 0 \\
0 & -1 & \cdots & 0 \\
\vdots & \vdots & \ddots & \vdots \\
0 & 0 & \cdots & -1
\end{array}\right] \quad \mathbf{A}_{52}:=\left[\begin{array}{cccc}
1 & 0 & \cdots & 0 \\
0 & 1 & \cdots & 0 \\
\vdots & \vdots & \ddots & \vdots \\
0 & 0 & \cdots & 1
\end{array}\right] \\
& \mathbf{A}_{32}:=\left[\begin{array}{cccc}
-\bar{\alpha}_{1}(1) & 0 & \cdots & 0 \\
0 & -\bar{\alpha}_{1}(2) & \cdots & 0 \\
\vdots & \vdots & \ddots & \vdots \\
0 & 0 & \cdots & -\bar{\alpha}_{\mathrm{n}}\left(\mathrm{N}_{\mathrm{u}}\right)
\end{array}\right] \\
& \mathbf{A}_{33}:=\left[\begin{array}{cccc}
\underline{\alpha}_{1}(1) & 0 & \cdots & 0 \\
0 & \underline{\alpha}_{1}(2) & \cdots & 0 \\
\vdots & \vdots & \ddots & \vdots \\
0 & 0 & \cdots & \underline{\alpha}_{\mathrm{n}}\left(\mathrm{N}_{\mathrm{u}}\right)
\end{array}\right] \\
& \mathbf{A}_{43}:=\left[\begin{array}{cccc}
-\underline{\alpha}_{1}(1) & 0 & \cdots & 0 \\
0 & -\underline{\alpha}_{1}(2) & \cdots & 0 \\
\vdots & \vdots & \ddots & \vdots \\
0 & 0 & \cdots & -\underline{\alpha}_{\mathrm{n}}\left(\mathrm{N}_{\mathrm{u}}\right)
\end{array}\right] \\
& \mathbf{A}_{53}:=\left[\begin{array}{cccc}
\bar{\alpha}_{1}(1) & 0 & \cdots & 0 \\
0 & \bar{\alpha}_{1}(2) & \cdots & 0 \\
\vdots & \vdots & \ddots & \vdots \\
0 & 0 & \cdots & \bar{\alpha}_{\mathrm{n}}\left(\mathrm{N}_{\mathrm{u}}\right)
\end{array}\right]
\end{aligned}
$$

Matrix B is given by Equation (63): 


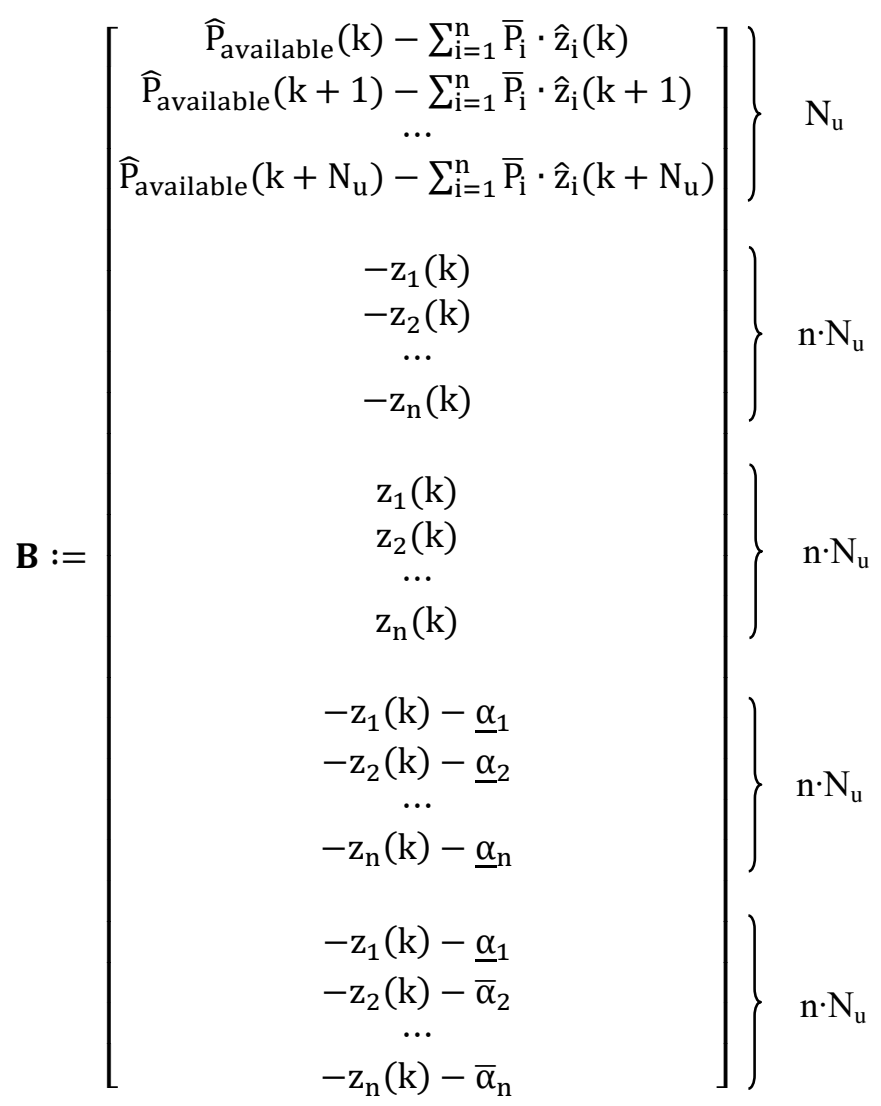

\subsubsection{MPC strategy}

As seen in Section 4.1.4, the MPC based on PNMPC ideas used in this advanced control algorithm includes a quadratic cost function $\mathbf{J}$ (see Equation (58)) which considers, in a horizon of $\mathrm{N}$ samples, the error between the produced hydrogen $\left(\widehat{\mathrm{H}}_{\mathrm{i}}\right)$ and its desired values $\left(\overline{\mathrm{H}}_{\mathrm{i}}\right)$ and also the number of electrolyzers in operation $\left(\delta_{\mathrm{i}}\right)$. $\mathbf{J}$ is solved at each sample time using receding horizon estimation (see Section 2.4.1 and Fig. 2.24).

With this, the optimization problem solved each sample time aims to optimize hydrogen production, $\left(\widehat{\mathrm{H}}_{\mathrm{i}}\right)$, and minimize de consumption, $\left(\widehat{P}_{\mathrm{i}}\right)$, (see the objectives in Section 4.2.1).

For the H2OCEAN platform presented in Section 1.1, the predictions are wave height $\left(\mathrm{H}_{\mathrm{S}}\right)$, wave period $\left(\mathrm{T}_{\mathrm{P}}\right)$ and wind speed $\left(\mathrm{W}_{\mathrm{S}}\right)$, but other different sources can be used for different proposals. The 
available power, $\widehat{\mathrm{P}}_{\mathrm{available}}$, over the control horizon, $\mathrm{N}_{\mathrm{u}}$, is given by meteorological predictions. They are then transformed into predicted available power by the WEC power matrix given in Figure 2.8 and the VAWT power profile given in Figure 2.12, depicted in Section 2.1 for the specific case of the H2OCEAN platform.

Then, the future predictions of the output (hydrogen production, vector $\widehat{\mathrm{H}}_{\mathrm{i}}$ ) are expressed as a function of the future control actions (vectors $\widehat{\alpha}_{\mathrm{i}}$ and $\widehat{\delta}_{\mathrm{i}}$ ) and the past values of the input and outputs. In the case of the electrolyzers modelled in this chapter, only a static model is considered. Thus a structure of the $\mathrm{EMS}_{\mathrm{H}}$ control algorithm proposed in this Chapter is depicted in Figure 4.5.

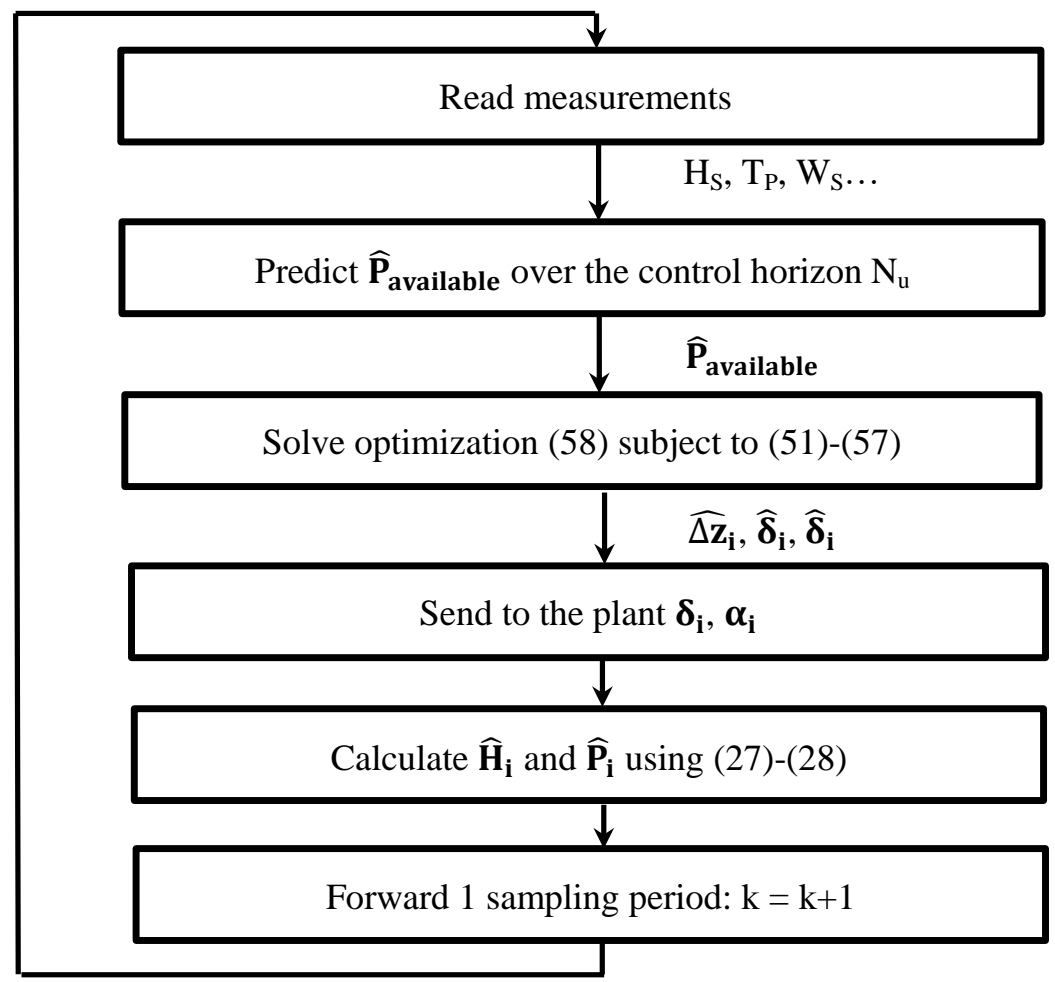

Figure 4.5 - Structure of the $\mathrm{EMS}_{\mathrm{H}}$ control algorithm

This strategy can easily be implemented using such computer software as MATLAB ${ }^{\circledR}$ and its optimization tool TOMLAB ${ }^{\circledR}$, which has an MIQP optimization solver. This optimization solver has been used 
for predictive control in different works: (YELCHURU et al. 2010), (NANDOLA; RIVERA, 2013), (MENDES, 2016b).

\subsection{CASE STUDIES}

We now present two case studies: first a simulation of the platform with a perfect knowledge is carried out; whereas in the second case study, some variations in the simulation parameters will be considered. As detailed in Section 4.1 (see Figure 4.1), the platform is made up of two different parts: one is the energy source and the other consumes the energy to generate hydrogen. To produce the energy for the renewable hydrogen plant, two sources (wind and wave) have been considered in both case studies. Wind energy was chosen as it is a mature technology (GONZÁLEZ; LACAL-ARÁNTEGUI, 2016) and wave energy as it provides lower variability in energy production (ZURKINDEN et al. 2014). A co-located hybrid device of 1 vertical axis wind turbine (VAWT) of 5.0 MW peak power and 1 wave energy converter (WEC) of 1.6 MW peak power were chosen according to the studies developed in the project H2OCEAN (BORG; COLLU, 2014) (see Section 2.1).

This hybrid VAWT-WEC device (shown in Figure 4.6) provides the energy: it consists of a platform with a hull (where the VAWT is located) and a cross bridge where four pitching wave energy converters are placed. The wave energy converters also reduce the motion of the platform and passively rotate it to face the waves.

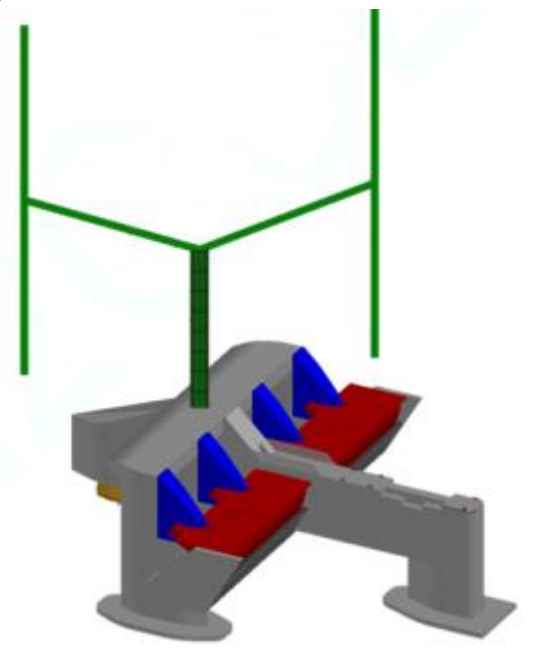

Figure 4.6 - A co-located hybrid VAWT-WEC device (BORG; COLLU, 2014) 
To produce hydrogen, different NEL A485 electrolyzers (NELHydrogen, 2014) were chosen. The main gas storage containers are located on two other floating units, well separated from both the hydrogen production and each other. The alkaline electrolyzers operate slightly above ambient pressure and are further equipped with pressure relief equipment, to prevent overpressure operation. Electrochemical reactions of these alkaline electrolyzers were shown in Section 2.3.1.3.

\subsubsection{First case study}

A simulation was carried out using one hybrid device of $5.0+1.6$ MW for the energy production. Meteorological data provided by Agencia Estatal de Meteorología (AEMET) from a certain location in the Atlantic Ocean were used. Figure 4.7 shows wave period predictions, whereas Figure 4.8 shows wave height predictions.

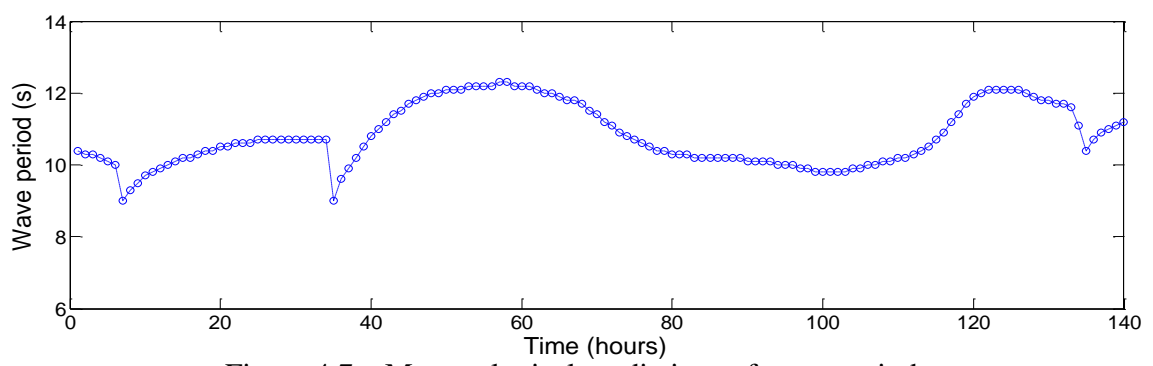

Figure 4.7 - Meteorological predictions of wave period.

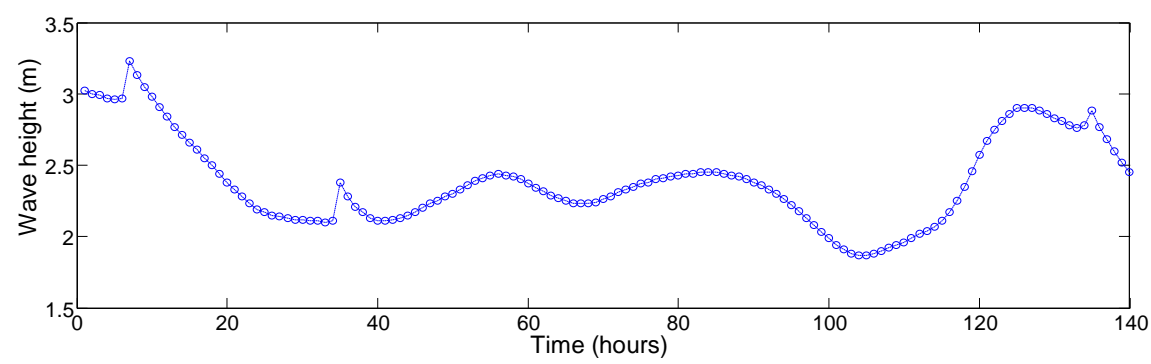

Figure 4.8 - Meteorological predictions of wave height.

Figure 4.9 depicts wind speed predictions for the same location in the Atlantic Ocean. 


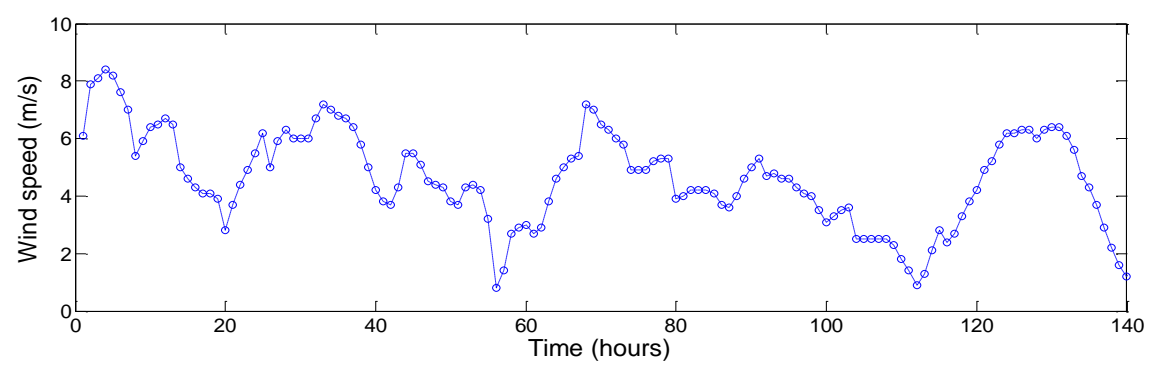

Figure 4.9 - Meteorological predictions of wind speed.

Three NEL electrolyzers (two high production of 2.134 MW rated and one small production of $0.220 \mathrm{MW}$ rated) were chosen for this first case study. The model of the electrolyzers was shown in Section 4.1.3 (see Figure 4.3).

To implement the $\mathrm{EMS}_{\mathrm{H}}$ developed in Section 4.2, a control horizon of 3 hours, a prediction horizon of 3 hours and a sampling time of 1 hour were selected to validate the proposal. Thus, $\mathrm{n}=3, \mathrm{~N}_{\mathrm{u}}=3$ and $\mathrm{N}=3$.

The parameters of the platform analyzed in this case study were obtained from the manufacturer's data:

$$
\begin{gathered}
\overline{\mathrm{P}}=\left[\begin{array}{lll}
2134 & 2134 & 220
\end{array}\right]^{\mathrm{T}} \\
\overline{\mathrm{a}}=\left[\begin{array}{lll}
0.875 & 0.875 & 0.778
\end{array}\right]^{\mathrm{T}} \\
\overline{\mathrm{b}}=\left[\begin{array}{lll}
3.525 & 3.525 & 3.625
\end{array}\right]^{\mathrm{T}} \\
\overline{\mathrm{H}}=\left[\begin{array}{lll}
485 & 485 & 485
\end{array}\right]^{\mathrm{T}} \\
\bar{\alpha}=\left[\begin{array}{lll}
1 & 1 & 1
\end{array}\right]^{\mathrm{T}} \\
\underline{\alpha}=\left[\begin{array}{lll}
0.2 & 0.2 & 0.1
\end{array}\right]^{\mathrm{T}}
\end{gathered}
$$

The weighting factors given in (65) were selected:

$$
\left.\begin{array}{l}
\mathrm{w}_{\mathrm{H}}=\left[\begin{array}{lll}
1 & 1 & 50
\end{array}\right]^{\mathrm{T}} \\
\mathrm{w}_{\delta}=\left[\begin{array}{lll}
1 & 10 & 1
\end{array}\right]^{\mathrm{T}}
\end{array}\right\}
$$

To optimize, an MIQP solver in the MATLAB ${ }^{\circledR}$ TOMLAB $^{\circledR}$ was used (58). The available energy at each time $\mathrm{k}$ is different from the one predicted in the previous step. 
For this first case study of the $\mathrm{EMS}_{\mathrm{H}}$ presented in Section 4.2, some results for 140 hours of operation are shown in Figures 4.10 to 4.14. These results confirm the correct operation of the advanced control system designed in this chapter for the parameters considered.

Figure 4.10 shows the power provided by the renewable energy sources (black line) and the power consumed (red line) by the electrolyzers.

As can be seen in the simulations, the controller maintains the consumed power very close to the available one. As a consequence, the hydrogen produced is near the achievable maximum. This happens because, in this first case study, the parameters chosen for the electrolyzers suppose an ideal operation.

It must be pointed out that perfect knowledge of the electrolyzers parameters are assumed and correspond to the manufacturer's data. In practice, there are some tolerances and variations in parameters, which will be taken into account in the second case study.

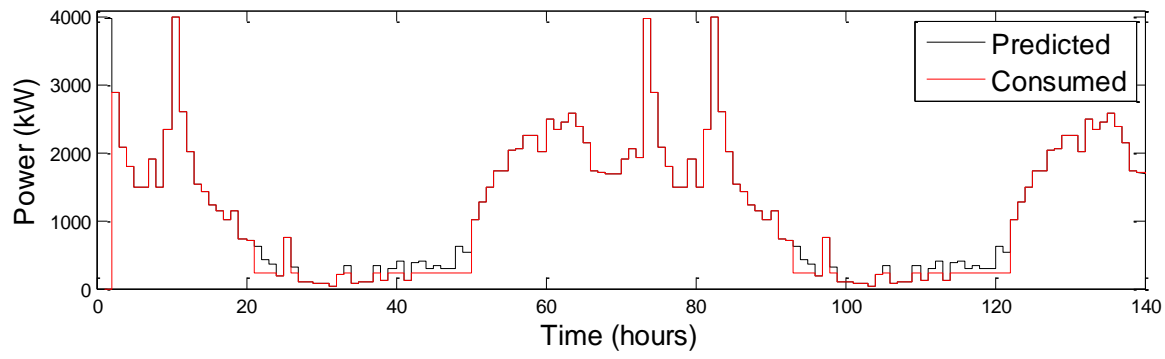

Figure 4.10 - Power available and consumed for the first case study

Figure 4.11 shows the operation of the electrolyzer $\mathrm{i}=1$ (high production). As expected, this device is not connected/disconnected very often by the proposed $\mathrm{EMS}_{\mathrm{H}}$ and $\alpha_{1}$ is always between the requested bounds $\bar{\alpha}_{1}$ and $\underline{\alpha}_{1}$.

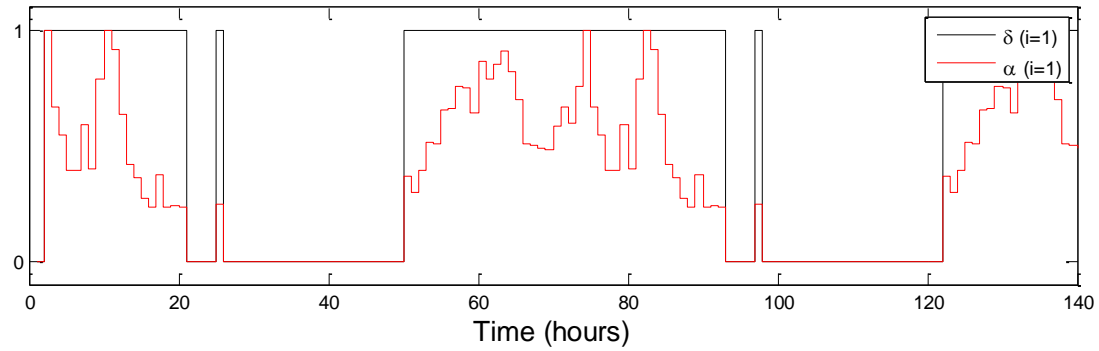

Figure 4.11 - Operation of electrolyzer $\mathrm{i}=1$ for the first case study 
Figure 4.12 shows the operation of the second high production electrolyzer $(i=2)$. This operation is different from the electrolyzer $i=1$ because they have different weighting factors (see Equation (64)).

Thus, here the capacity factor $\alpha_{2}$ is almost always at the lower bound $\underline{\alpha}_{2}=0.2$. As it is not disconnected frequently, the control algorithm can be considered to be well designed and tuned.

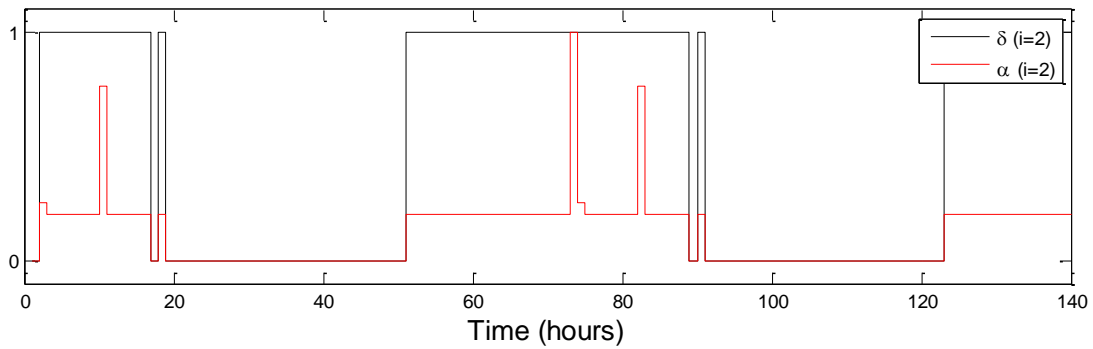

Figure 4.12 - Operation of electrolyzer $i=2$ for the first case study

Electrolyzer $\mathrm{i}=3$ (Figure 4.13 ) is more closely connected because it has different model parameters ( $a$ and $b$ ) from the high production electrolyzers (see Figure 4.3). Therefore, the operation of this device can also be considered correct. As in the other electrolyzers, the values of the manipulated variables are always between the defined bounds.

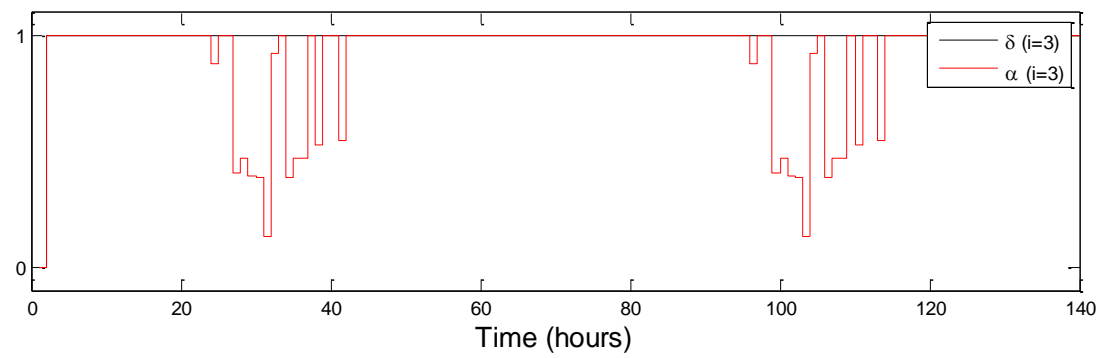

Figure 4.13 - Operation of electrolyzer $i=3$ for the first case study

The last figure of this case study (Figure 4.14) depicts the hydrogen produced by the three devices. As expected, it depends on the power consumed (Figure 4.10), following the model depicted in Figure 4.3 . 


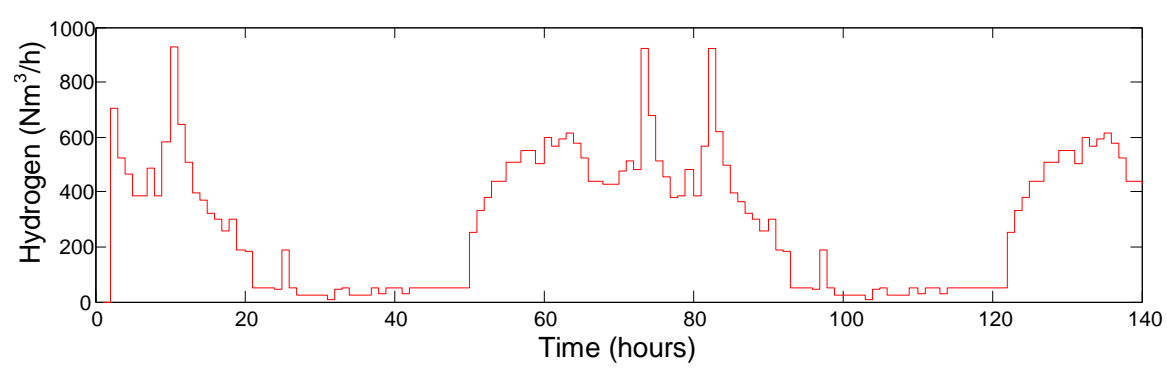

Figure 4.14 - Hydrogen production for the first case study

Some operation indices and consumptions are presented in Table 4.2. These results confirm the correct design of the $\mathrm{EMS}_{\mathrm{H}}$ proposed in this chapter: $97.3 \%$ of the available energy is used to produce hydrogen with a reduced number of ON/OFF cycles.

\begin{tabular}{|c|c|c|}
\hline $\begin{array}{c}\text { Energy available } \\
\text { (kWh/day) }\end{array}$ & $\begin{array}{c}\text { Energy consumed } \\
\text { (kWh/day) }\end{array}$ & $\mathrm{H}_{2}$ produced $\left(\mathrm{Nm}^{3} / \mathrm{h}\right)$ \\
\hline 14363 & 13986 (97.3\%) & 389.6 \\
\hline Electrolyzer i = 1 & Electrolyzer i = 2 & Electrolyzer i = 3 \\
\hline ON/OFF cycles/day & ON/OFF cycles/day & ON/OFF cycles/day \\
\hline 2.91 & 0.85 & 2.74 \\
\hline
\end{tabular}

Table 4.2- Operation indices and consumption of scenario 1.

\subsubsection{Second case study}

A different simulation was carried out using a platform with three hybrid devices), so total rated power is 19.8 MW (15.0 MW of VAWTs + 4.8 MW of WECs). Six electrolyzers (three high production and three small production) were chosen for this second case study (see Figure 4.3).

This second proposal aims to be more realistic than the first case study, as the rated power of the electrolyzers is not the maximum value: a loss-of-performance factor is added for each device. The parameters and weighting factors of the platform in this second case study are: 


$$
\begin{gathered}
\overline{\mathrm{P}}=\left[\begin{array}{lllllll}
2066.7 & 2025.6 & 2014.6 & 201.2 & 208.5 & 200.6
\end{array}\right]^{\mathrm{T}} \\
\overline{\mathrm{a}}=\left[\begin{array}{lllllll}
0.8706 & 0.8697 & 0.8670 & 0.8089 & 0.7882 & 0.7731
\end{array}\right]^{\mathrm{T}} \\
\overline{\mathrm{b}}=\left[\begin{array}{lllllll}
3.5271 & 3.5301 & 3.6124 & 3.6809 & 3.6406 & 3.5101
\end{array}\right]^{\mathrm{T}} \\
\overline{\mathrm{H}}=\left[\begin{array}{lllllll}
485 & 485 & 485 & 485 & 485 & 485
\end{array}\right]^{\mathrm{T}} \\
\bar{\alpha}=\left[\begin{array}{lllllll}
1 & 1 & 1 & 1 & 1 & 1
\end{array}\right]^{\mathrm{T}} \\
\underline{\alpha}=\left[\begin{array}{lllllll}
0.2 & 0.2 & 0.2 & 0.1 & 0.1 & 0.1
\end{array}\right]^{\mathrm{T}} \\
\mathrm{w}_{\mathrm{H}}=\left[\begin{array}{lllllll}
1 & 1 & 1 & 500 & 500 & 500
\end{array}\right]^{\mathrm{T}}
\end{gathered}
$$

The same optimization toolbox $\left(\right.$ TOMLAB $^{\circledR}$ ) was used to carry out the simulation and optimization. A simulation has been done with a prediction and control horizon of 3 hours $\left(n=6, N=3\right.$ and $\left.N_{u}=3\right)$ and taking a sample time of 1 hour.

For the second case study, some results for 140 hours of operation are shown in Figures 4.15-4.21. The results confirm the correct operation of the advanced control system for this case, where the current available power at each time is different from the one predicted in the previous step.

Fig. 4.15 shows the power available for the electrolysis. The maximum power that the six electrolyzers can consume in this case study is $6717 \mathrm{~kW}$ (see Equation (66)). Effectively, the available power is always slightly bigger than the power consumed by the electrolyzers. Unlike the previous case study, where the available power was more similar to the consumed power; in this second case study, the difference is bigger because the electrolyzer parameters are not ideal. In spite of that, a good robustness response of the model can be seen. 


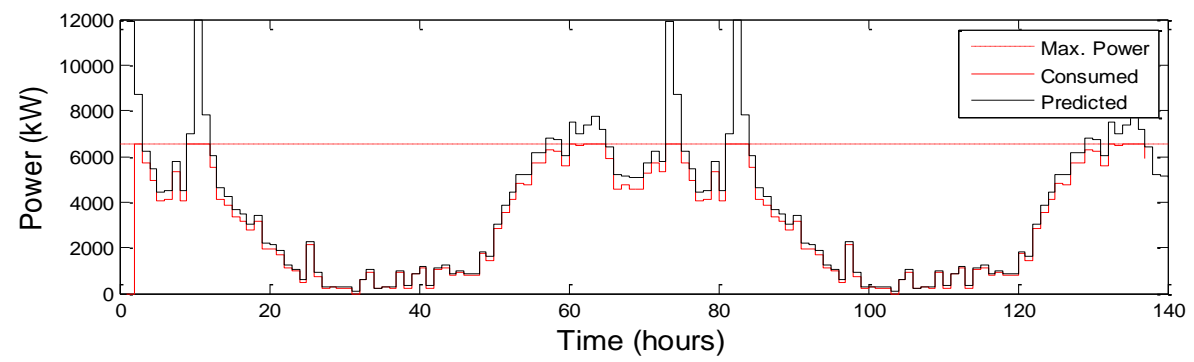

Figure 4.15 - Power available and consumed for the second case study

Figures 4.16 to 4.18 show the operation of the three high production electrolyzers $(i=1,2,3)$. As expected, they are not switched on/off very frequently. In comparison with the case study presented in Section 4.3.1, it can be seen that the power was shared between all the electrolyzers, so the more electrolyzers there are installed, the fewer disturbances the system has, because $\alpha$ tries to remain in the nominal capacity factor.

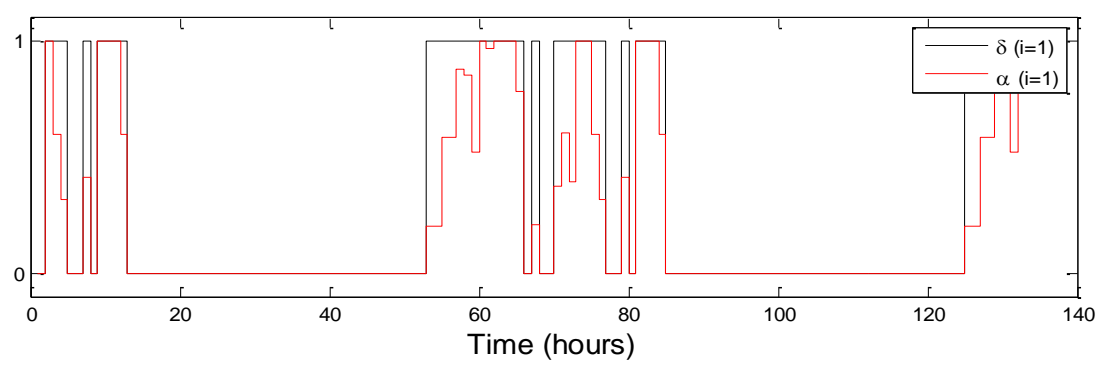

Figure 4.16 - Operation of electrolyzer $\mathrm{i}=1$ for the second case study

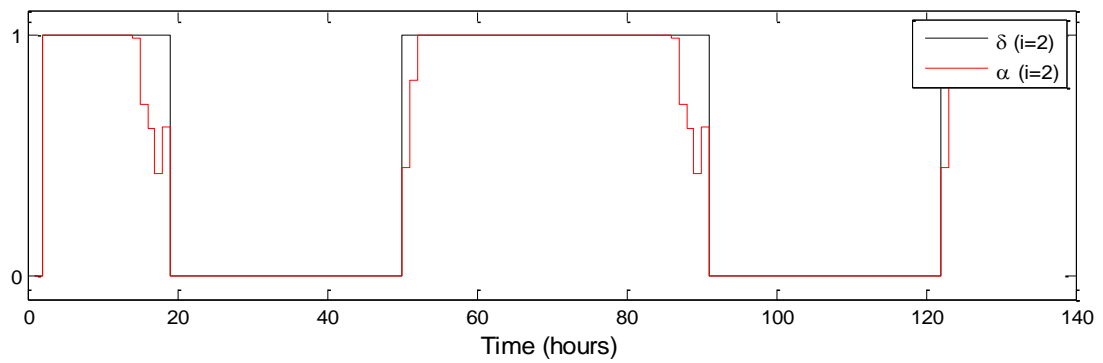

Figure 4.17 - Operation of electrolyzer $\mathrm{i}=2$ for the second case study 


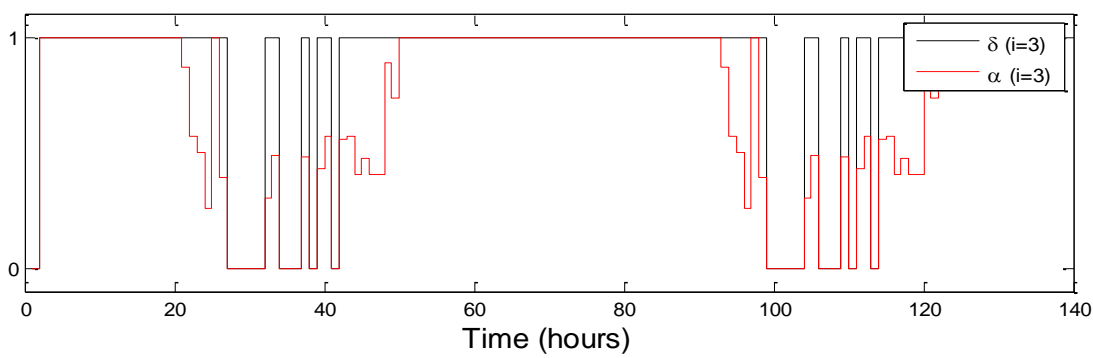

Figure 4.18 - Operation of electrolyzer $i=3$ for the second case study

Figures 4.19 to 4.21 depict the results for the three small production electrolyzers $(i=4,5,6)$. The operation of these electrolyzers can be considered correct, as they operate between the constraints designed in this case study and they are also used more, as they have a better operation record.

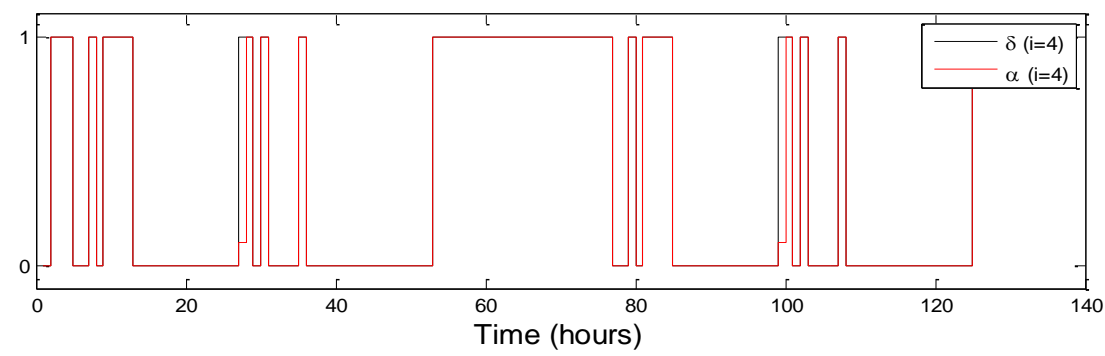

Figure 4.19 - Operation of electrolyzer $i=4$ for the second case study

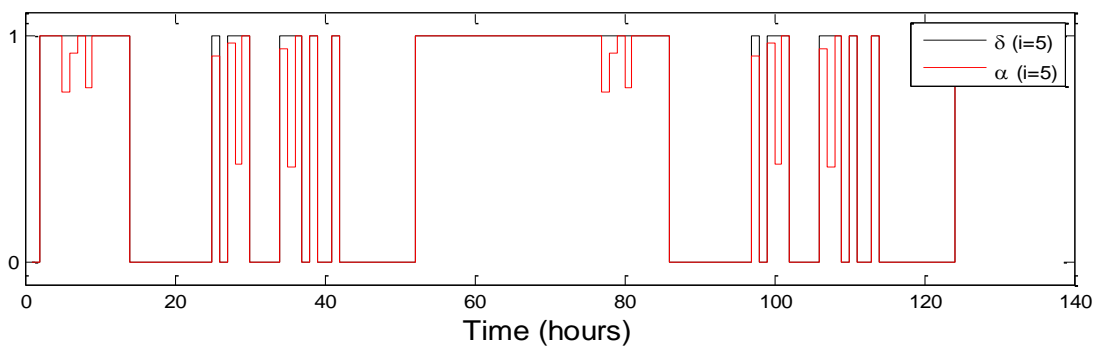

Figure 4.20 - Operation of electrolyzer $\mathrm{i}=5$ for the second case study 


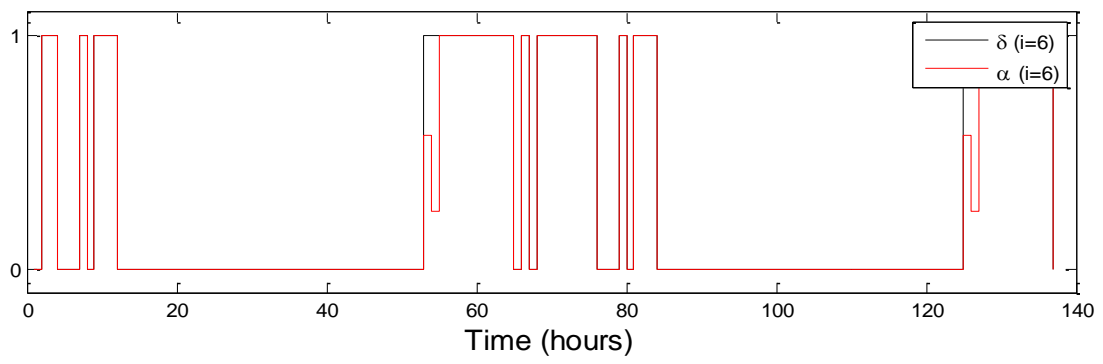

Figure 4.21 - Operation of electrolyzer $i=6$ for the second case study

The last figure (4.22) shows the production of hydrogen for all the 6 electrolyzers in this second scenario. The devices produce the maximum amount of hydrogen they can, so the design of the control algorithm can be considered efficient.

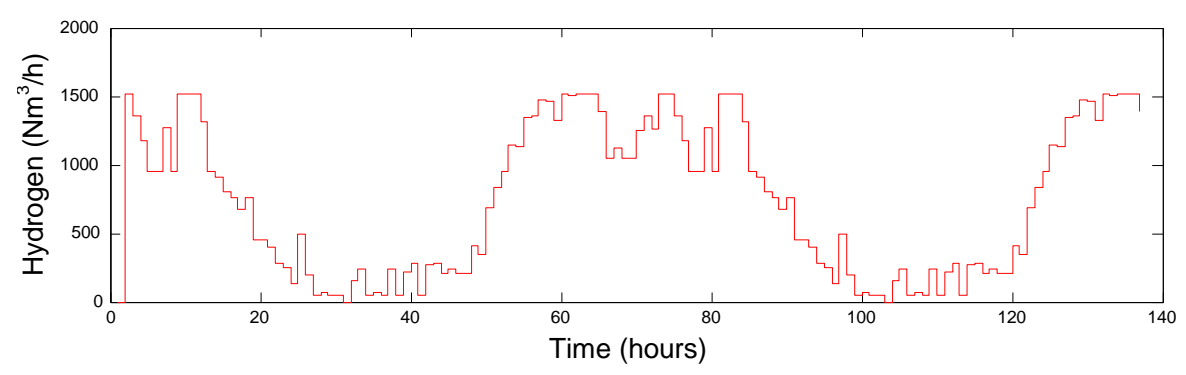

Figure 4.22 - Hydrogen production for the second case study

Finally, to summarize this second scenario, some operation indices and consumptions are presented in Table 4.2. These results confirm the high mean hydrogen production obtained from the available power and also the small number of ON/OFF cycles. It can be seen that $88.6 \%$ of the available energy is consumed to produce hydrogen. This value is smaller than in the first case study $(97.3 \%)$ because this second study case proposes a more realistic scenario.

Nevertheless, it can be considered as a good operation. The rest of the parameters also show a good operation of the electrolyzers. 


\begin{tabular}{|c|c|c|}
\hline $\begin{array}{c}\text { Energy available } \\
\text { (kWh/day) }\end{array}$ & $\begin{array}{c}\text { Energy consumed } \\
(\mathrm{kWh} / \text { day })\end{array}$ & $\mathrm{H}_{2}$ produced $\left(\mathrm{Nm}^{3} / \mathrm{h}\right)$ \\
\hline 27047 & $24250(88.6 \%)$ & 726.9 \\
\hline Electrolyzer $\mathrm{i}=1$ & Electrolyzer i = 2 & Electrolyzer $\mathrm{i}=\mathbf{3}$ \\
\hline ON/OFF cycles/day & ON/OFF cycles/day & ON/OFF cycles/day \\
\hline 2.91 & 0.85 & 2.91 \\
\hline $\begin{array}{c}\text { Electrolyzer } \mathrm{i}=4 \\
\text { ON/OFF cycles/day }\end{array}$ & $\begin{array}{c}\text { Electrolyzer } \mathrm{i}=5 \\
\text { oN/OFF cycles/day }\end{array}$ & $\begin{array}{c}\text { Electrolyzer i = } 6 \\
\text { ON/OFF cycles/day }\end{array}$ \\
\hline 4.45 & 3.94 & 3.08 \\
\hline
\end{tabular}

Table 4.3 - Operation indices and consumptions of scenario 2.

If compared to the ideal scenario of case 1 , the real operation of scenario 2 can be considered very good. Note that, only when the available power was very low did the controller not find a proper solution and the consumed power was under the desired value. This result is expected because of the constraints imposed on the minimum values of the capacity factors. In terms of power distribution between electrolyzers and switching ON/OFF of the equipment, both scenarios had expected results confirming the good operation of the control strategy.

\subsection{SUMMARY AND CONCLUSIONS}

An $\mathrm{EMS}_{\mathrm{H}}$ algorithm based on a Model Predictive Control is proposed and tested to optimize and balance the hydrogen production for an offshore plant, which includes a set of electrolysis units, following the power provided by variable renewable energy sources (wind and waves). Using the Smart Grid concept, the characteristics of each electrolyzer are considered to improve the state-of-health of the units. The proposed approach has been validated using real data measured from a certain location in the north Atlantic Ocean, which is used to verify the correct operation of the platform with the designed controller.

The main conclusions of this study are the following:

- $\quad$ The Mixed-Integer-Quadratic-Programming for the MPC allows the capacity factor of each electrolysis unit and its connections or disconnections to be regulated. 
- In the two cases studies, the error between the predicted and the desired powers consumed by each electrolyzer is minimized for all the devices along the prediction horizon $\mathrm{N}$.

- The operation of the electrolysis set is maximized, since the discrete variables defining the connection/ disconnection condition of the electrolysis is enacted along the prediction horizon, as much as possible.

- $\quad$ The MPC control strategy ensures the continuity of the hydrogen production, since the energy consumed by the electrolysis is almost equal to the energy supplied from the wind and waves during the prediction horizon.

- The electrolyzers' state of health is ensured, thanks to the minimization of switching between the states of connection/ disconnection. 


\section{CHAPTER 5}

COUPLING OF A LOW LEVEL SYSTEM WITH A HIGH LEVEL SYSTEM IN A $\mathrm{H}_{2}$ MICROGRID 


\section{COUPLING OF A LOW LEVEL SYSTEM WITH A HIGH LEVEL SYSTEM IN A HYDROGEN MICROGRID}

In Chapter 4, an Energy Management System for Hydrogen production $\left(E M S_{H}\right)$ was developed in a microgrid which took into account meteorological predictions in the long term (the prediction horizon was 24 hours and the sample time was one hour, so it can be considered that it was a Long Term System (LTS)).

Here, in this chapter, a coupling of the Long Term System (LTS) proposed in Chapter 4 with a Short Term System (STS) in a hydrogenbased microgrid is proposed, as the STS developed in this chapter has a prediction horizon of $15 \mathrm{~s}$. Thus, the operation of a set of electrolyzers that produce hydrogen from renewable energies (wind and waves) can be managed in a more accurate way.

The combination of high-level control (LTS) and low-level control (STS) published in (SERNA et al. 2017) and (GARCÍA-TORRES et al. 2016), respectively, is the main contribution of the chapter. Both systems are based on Model Predictive Control (MPC) ideas. Figure 5.1 shows the main blocks of the control proposal presented in Chapter 5:

\section{Controller}

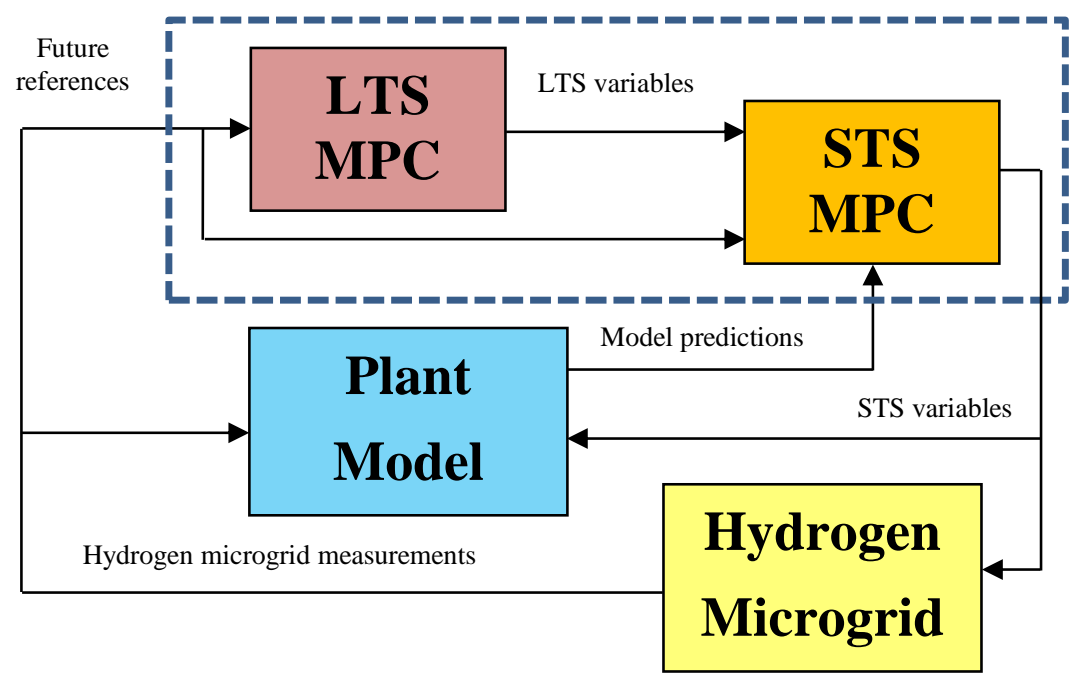

Figure 5.1 - Coupling of the Long Term System with the Short Term System for the hydrogen-based microgrid. 
The LTS manages the on/off conditions of the electrolyzers, taking into account control and prediction horizons in terms of hours (high level control) and regulating the operation point of the devices using meteorological predictions. On the other hand, the STS, in a low-level control (sample time seconds), adapts the behaviour of the electrolyzers to the rest of the components of the microgrid (battery and ultracapacitor), reducing the degradation of the microgrid's devices.

The plant is modelled in the Mixed Logic Dynamic (MLD) framework (see Section 2.4.3), due to the presence of logical states such as the start-up/shut down of the electrolyzers and charge/discharge states in the battery and ultracapacitor. The start-up sequences of the electrolyzers are also considered and controlled with the use of logical variables. The performance of the hydrogen-based microgrid is developed, solved and experimentally validated in a simulation.

The chapter is organized as follows: Section 5.1 describes hydrogen-based microgrid ideas, focusing on the components, models and variables of the microgrid chosen for this chapter. Sections 5.2 presents the LTS proposed as a high-level control (taking into account the variables and parameters of Chapter 4); while Section 5.3 proposes the STS as the low-level control (GARCÍA-TORRES et al. 2016). Section 5.4 presents and discusses the results of the coupling of both MPC controllers in a case study. Finally, Section 5.5 outlines the conclusions.

\subsection{HYDROGEN-BASED MICROGRIDS}

Hydrogen-based microgrids can be a useful alternative for isolated locations as they provide energy without the need for fuel cells and electricity grid (WANG et al. 2016). The high energy density of hydrogen as an energy carrier will play an important role in this new energy paradigm (GARCÍA-TORRES et al. 2016), especially because fuel cells can operate in houses as generators with the advantage of not having $\mathrm{CO}_{2}$ emissions.

Advanced control of microgrids has been developed over the last few years (GUERRERO et al. 2013) and (LIN; ZHENG, 2011), with the proposal of a strategy based on adaptive control using neural networks. Different studies associated with the management of microgrids with hybrid storage propose the hysteresis method (ARCE et al. 2009). In 
(ULLEBERG, 2004) the electrolyzers are activated depending on the state of charge (SOC) of the batteries and ultracapacitors. More specifically, MPC has been used (GARCÍA-TORRES, 2015) to solve the problem of connections and disconnections of the electrolyzers and their integration with such storage devices as batteries, ultracapacitors or fuel cells.

MPC controllers have been applied with satisfactory results in the hybridization of this type of microgrid in several papers, such as that carried out by (VAHIDI; GREENWELL, 2007). (PATTERSON et al. 2015) explore solutions for microgrids with electrical and hybrid vehicles. The optimal use of the microgrid requires the development of a controller which takes into account all the constraints, limitations and degradation issues, as well as the economic cost of each component of the microgrid.

In comparison with previous work (GARCÍA-TORRES et al. 2016), this chapter proposes a solution which takes into account wind and waves as energy sources, so the energy profile is more stable because wave energy is more continuous (see Section 2.1.1). As the energy sources proposed in this work are wind and waves, microgrids similar to the one proposed here can be installed in isolated coastal locations (PALMA-BEHNKE, et al. 2013).

Different electrolyzers are defined in the case study proposed here (alkaline and PEM, see Section 2.3.1.3), unlike in the case of (GARCÍATORRES et al. 2016), where the microgrid proposed was composed of one electrolyzer and one fuel cell.

Another difference with (GARCÍA-TORRES et al. 2016) is that the high level control here is based on the production and consumption of the electrolyzers and not on an economic dispatch. Electrolyzers depend solely on certain constant model parameters, so the case study can be modified simply by adjusting these parameters.

\subsubsection{Components of the hydrogen-based microgrid}

The hydrogen-based microgrid proposed in this chapter follows the scheme depicted in Figure 5.2. Energy sources (wind and wave) are renewable and can easily be obtained in coastal locations. Electricity produced is supplied to a set of electrolyzers that transform demineralized water into hydrogen. 


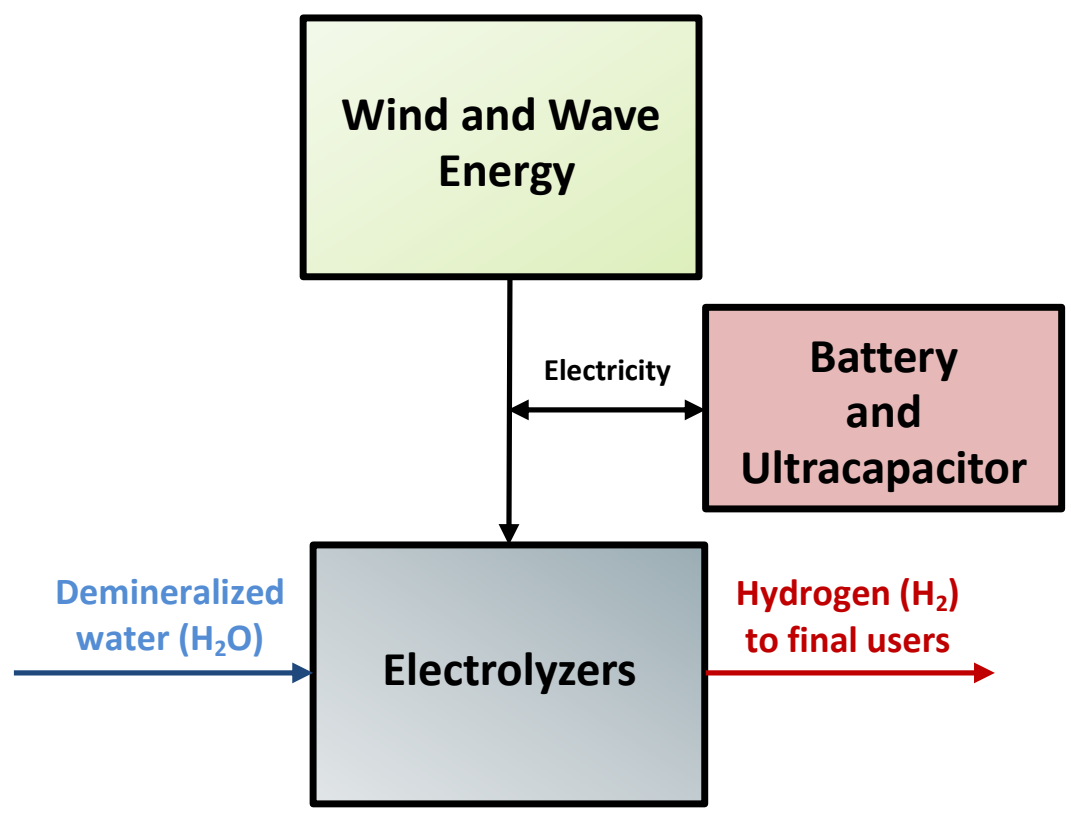

Figure 5.2 - Components of the hydrogen-based microgrid.

The microgrid proposed in this chapter has three electrolyzers (two alkaline high production and one small production PEM for residual power values). Moreover, for certain times when available renewable power is not enough for the operation of the electrolyzers, a battery and an ultracapacitor are included to supply energy to the electrolyzers. Finally, the hydrogen produced is sent to users, so it can be used as input in fuel cells or for different needs (VERGRAGT; BROWN, 2007).

\subsubsection{Electrolyzers}

As detailed in Section 2.3.1.3, an electrolyzer is an electrochemical device. This means that it uses electricity and chemistry at the same time to perform electrolysis. Different types of electrolyzers have been developed over the last few years for microgrids, alkaline and PEM electrolyzers being the most easily available on the market (MUELLERLANGER et al. 2007). In section 4.1.2, a model based on MPC ideas for the electrolyzer operation was developed. This model has been chosen for the microgrid proposed in this chapter. Two types of variables were defined for the electrolyzers: the first are the operating points for each 
electrolyzer, known as capacity factors. They are mathematically denoted by $\left.\alpha_{\mathrm{i}}(\mathrm{k})\right|_{\mathrm{i}=\text { ele }}$, where $\mathrm{k}$ represents the discrete time in samples, the suffix ele refers to the electrolyzers, and the suffix $\mathrm{i}$ is used to identify each electrolyzer. Moreover:

- $\left.\alpha_{\mathrm{i}}(\mathrm{k})\right|_{\mathrm{i}=\mathrm{ele}}=0$ if the device $\mathrm{i}$ is disconnected at time $\mathrm{k}$.

- $\left.\alpha_{\mathrm{i}}(\mathrm{k})\right|_{\mathrm{i}=\text { ele }}$ is between $\left[\underline{\alpha}_{\mathrm{i}} \bar{\alpha}_{\mathrm{i}}\right]$ if the electrolyzer is connected, where $\underline{\alpha}_{i}$ and $\bar{\alpha}_{i}$ are minimum and maximum values (between 0 and 1) fixed by the manufacturer due to technological limitations.

Other variables are the binary variables $\left.\delta_{\mathrm{i}}(\mathrm{k})\right|_{\mathrm{i}=\mathrm{ele}} \in\{0,1\}$, where 0 corresponds to electrolyzer disconnection and 1 to electrolyzer connection (SERNA et al. 2017).

\subsubsection{Batteries and ultracapacitor}

Batteries are one of the storage devices chosen for this microgrid. They have degradation issues that must be avoided, such as the formation of permanent oxides during the charging of the battery pack at a high state of charge (SOC). The shorter the discharge (low depth of discharge DOD), the longer the battery will last. Since these processes are diffusion controlled and slow, a low charging rate must be used (GARCÍA-TORRES et al. 2016). The rate capability loss is proportional to the value of the average current used (SHIKA et al. 2003).

Ultracapacitors are the other type of energy storage selected for this proposal. They have low energy density and behave as a short circuit when exposed to low levels of the state of charge (OROPEZA, 2004). High SOC can also damage this technology (RAJANI et al. 2016). The ultracapacitor model has complex equations to be linearized as detailed in (GLAVIN et al. 2008), but the voltage dynamic is slower than for the current, for the selected sample time $T_{\mathrm{s}}=1 \mathrm{~s}$. Therefore, the approximation considered in Equation (68) is valid for the selected sampling time, and it will be included in the MPC controller, where the suffixes uc and bat refer to the ultracapacitor and battery, respectively; whereas the suffix $i$ is used to identify each device. The same assumption can be made for the case of the voltage of the batteries (GARCÍA-TORRES et al. 2016).

$$
\left.\widehat{\mathrm{V}}_{\mathrm{i}}(\mathrm{k}+1)\right|_{\mathrm{i}=\mathrm{uc}, \text { bat }}=\mathrm{V}_{\mathrm{i}}(\mathrm{k})
$$


The discharge and charge power of the batteries and the ultracapacitor can be expressed as shown in Equations (69) and (70):

$$
\begin{aligned}
& \left.P_{i}^{\text {dis }}(k)\right|_{i=u c, b a t}=\left\{\begin{array}{cc}
P_{i}(k) & P_{i}(k) \geq 0 \\
0 & P_{i}(k)<0
\end{array}\right\} \\
& \left.P_{i}^{\text {ch }}(k)\right|_{i=u c, b a t}=\left\{\begin{array}{cc}
0 & P_{i}(k)>0 \\
P_{i}(k) & P_{i}(k) \leq 0
\end{array}\right\}
\end{aligned}
$$

Both devices also have the logical charge and discharge states $\left(\left.\delta_{\mathrm{i}}^{\text {ch }}\right|_{\mathrm{i}=\text { uc,bat }}\right)$ and $\left(\left.\delta_{\mathrm{i}}^{\text {dis }}\right|_{\mathrm{i}=\mathrm{uc}, \mathrm{bat}}\right)$, respectively, for the batteries and ultracapacitor. The capacity of the ultracapacitor and the batteries can be modelled with Equation (71), where $\mathrm{C}$ is the capacity and I the current.

$$
\widehat{\mathrm{C}}_{\mathrm{i}}(\mathrm{k}+1)=\mathrm{C}_{\mathrm{i}}(\mathrm{k})+\left.\left(\hat{\mathrm{I}}_{\mathrm{i}}^{\mathrm{ch}}(\mathrm{k}+1)-\hat{\mathrm{I}}_{\mathrm{i}}^{\mathrm{dis}}(\mathrm{k}+1)\right) \cdot \mathrm{T}_{\mathrm{s}}\right|_{\mathrm{i}=\mathrm{uc}, \text { bat }}
$$

The relationship between the charging and discharging current and the corresponding charging and discharging power are given by Equations (72) and (73) (GARCÍA-TORRES et al. 2016), where $\psi_{\mathrm{i}}^{\text {ch }}$ and $\psi_{\mathrm{i}}^{\text {dis }}$ are the charge and discharge performances:

$$
\begin{aligned}
& \hat{\mathrm{I}}_{\mathrm{i}}^{\mathrm{ch}}(\mathrm{k}+1)=\left.\frac{\widehat{\mathrm{P}}_{\mathrm{i}}^{\mathrm{ch}}(\mathrm{k}+1) \cdot \psi_{\mathrm{i}}^{\mathrm{ch}}}{\mathrm{V}_{\mathrm{i}}(\mathrm{k})}\right|_{\mathrm{i}=\mathrm{uc}, \mathrm{bat}} \\
& \hat{\mathrm{I}}_{\mathrm{i}}^{\mathrm{dis}}(\mathrm{k}+1)=\left.\frac{\widehat{\mathrm{P}}_{\mathrm{i}}^{\mathrm{dis}}(\mathrm{k}+1)}{\mathrm{V}_{\mathrm{i}}(\mathrm{k}) \cdot \psi_{\mathrm{i}}^{\text {dis }}}\right|_{\mathrm{i}=\mathrm{uc}, \mathrm{bat}}
\end{aligned}
$$

Finally, the state of charge of the storage devices is given by the next expression, where $C_{i}^{\max }$ is the maximum capacity:

$$
\widehat{\mathrm{SOC}_{\mathrm{i}}}(\mathrm{k}+1)=\left.\frac{\widehat{\mathrm{C}}_{\mathrm{i}}(\mathrm{k}+1)}{\mathrm{C}_{\mathrm{i}}^{\max }}\right|_{\mathrm{i}=\mathrm{uc}, \text { bat }}
$$

\subsection{LONG TERM SYSTEM}

This control system follows the $\mathrm{EMS}_{\mathrm{H}}$ depicted in Chapter 4. This control algorithm aims to maximize the hydrogen produced, considering such different aspects as the limitation in the available renewable power and the operational constraints. The available power is obtained by meteorological predictions such as wind speed, wave height and wave 
period, taking into account a sample time of one hour. Predictions of the hydrogen production and the power consumed were defined by Equations (27) and (28) (see Section 4.1.3) respectively:

$$
\begin{aligned}
& \widehat{\mathrm{H}}_{\mathrm{i}}(\mathrm{k})=\left.\frac{\widehat{\alpha}_{\mathrm{i}}(\mathrm{k}) \cdot \widehat{\delta}_{\mathrm{i}}(\mathrm{k})}{\mathrm{a}_{\mathrm{i}} \cdot \widehat{\alpha}_{\mathrm{i}}(\mathrm{k})+\mathrm{b}_{\mathrm{i}}} \cdot \overline{\mathrm{P}}_{\mathrm{i}}\right|_{\mathrm{i}=\operatorname{ele}(\mathrm{LTS})} \\
& \widehat{\mathrm{P}}_{\mathrm{i}}(\mathrm{k})=\overline{\mathrm{P}}_{\mathrm{i}} \cdot \widehat{\alpha}_{\mathrm{i}}(\mathrm{k}) \cdot \widehat{\delta}_{\mathrm{i}}(\mathrm{k})
\end{aligned}
$$

Parameters $a_{i}, b_{i}$ are used to define the device performance, whilst $\overline{\mathrm{P}}_{\mathrm{i}}$ is the maximum power consumption of the electrolyzer. As mentioned in Section 4.1.3, the model of the electrolyzers is static because the time required for them to vary the capacity factor $\alpha$ from the minimum to the maximum value is less than a few minutes in the worst case. Thus, these dynamics can be neglected, as the sampling time for the LTS proposed here is one hour.

\subsubsection{Long Term MPC design}

The quadratic cost function considered for the LTS is the one proposed for the $\mathrm{EMS}_{\mathrm{H}}$ in Section 4.2.2 of Chapter 4. This cost function was depicted in Equation (29): it is minimized at each sample time to find the optimal control action. This equation, in prediction and control horizons of $\mathrm{N}$ and $\mathrm{N}_{\mathrm{u}}$ samples respectively, considers the error between the predictions of hydrogen produced $\left(\widehat{\mathrm{H}}_{\mathrm{i}}\right)$ and the desired values $\left(\overline{\mathrm{H}}_{\mathrm{i}}\right)$, while also penalizing the number of connections and disconnections. Besides, $\mathrm{w}_{\mathrm{Hi}}$ and $\mathrm{w}_{\delta \mathrm{i}}$ are the weighting factors for the error and the control action, respectively (SERNA et al. 2017).

$$
\begin{aligned}
J= & \sum_{i=1}^{n} \sum_{j=1}^{N}\left[\left(\widehat{H}_{i}(k+j)-\bar{H}_{i}(k+j)\right)^{2} w_{H_{i}}\right. \\
& \left.+\sum_{i=1}^{n} \sum_{j=1}^{N_{u}}\left(\widehat{\delta}_{i}(k+j)-1\right)^{2} w_{\delta_{i}}\right]
\end{aligned}
$$

\subsubsection{Control objectives of the LTS}

The control objectives of the LTS proposed in this chapter are the same as those defined for the $\mathrm{EMS}_{\mathrm{H}}$ in Section 4.2.1: two main 
objectives must be fulfilled to maximize hydrogen production, considering the limitation of the available power and operational constraints (SERNA et al. 2017):

- To maximize hydrogen production, the difference between the values of the prediction $\left(\widehat{\mathrm{H}}_{\mathrm{i}}\right)$ and its desired values $\left(\overline{\mathrm{H}}_{\mathrm{i}}\right)$ is minimized for all the electrolyzers in the prediction horizon $(\mathrm{N})$.

- To maximize the operation of the electrolyzers $(\alpha)$, the discrete variables defining the connection/disconnection condition $(\delta)$ should be, whenever possible, equal to one along N. Energy consumed by the electrolyzers should always be smaller than the energy supplied from the renewable sources, but will try to be equal.

Thus, using equation (29) with all the system constraints and the electrolyzer models, it can be shown that the optimization problem to be solved at each sample time in the Long Term System $(\mathrm{N}=1$ hour $)$ is (30).

$$
\begin{aligned}
& \min _{\left(\alpha_{\mathrm{i}}, \delta_{\mathrm{i}}\right)} J \\
& \text { such that: }\left\{\begin{array}{l}
\left.\delta_{\mathrm{i}} \in\{0,1\}\right|_{\mathrm{i}=\operatorname{ele}(\mathrm{LTS})} \\
\underline{\alpha}_{\mathrm{i}} \leq \alpha_{\mathrm{i}} \leq\left.\bar{\alpha}_{\mathrm{i}}\right|_{\mathrm{i}=\operatorname{ele}(\mathrm{LTS})} \\
\widehat{\mathrm{P}}_{\mathrm{i}}(\mathrm{k})=\left.\overline{\mathrm{P}}_{\mathrm{i}} \cdot \widehat{\alpha}_{\mathrm{i}}(\mathrm{k}) \cdot \widehat{\delta}_{\mathrm{i}}(\mathrm{k})\right|_{\mathrm{i}=\operatorname{ele}(\mathrm{LTS})} \\
\widehat{\mathrm{H}}_{\mathrm{i}}(\mathrm{k})=\left.\frac{\widehat{\alpha}_{\mathrm{i}}(\mathrm{k}) \cdot \widehat{\delta}_{\mathrm{i}}(\mathrm{k})}{\mathrm{a}_{\mathrm{i}} \widehat{\alpha}_{\mathrm{i}}(\mathrm{k})+\mathrm{b}_{\mathrm{i}}} \cdot \overline{\mathrm{P}}_{\mathrm{i}}\right|_{\mathrm{i}=\operatorname{ele}(\mathrm{LTS})} \\
\mathrm{n} \\
\sum_{\mathrm{i}=1} \widehat{\mathrm{P}}_{\mathrm{i}}(\mathrm{k}) \leq\left.\widehat{\mathrm{P}}_{\mathrm{available}}(\mathrm{k})\right|_{\mathrm{i}=\text { ele }(\mathrm{LTS})}
\end{array}\right.
\end{aligned}
$$

This high-level control (LTS) provides continuous $\left(\alpha_{i}\right)$ and discrete $\left(\delta_{\mathrm{i}}\right)$ values of the electrolyzers (SERNA et al. 2017). The approximation to an MIQP, proposed in Section 4.2.3, has also been done here. Each electrolyzer model is first modified using the following change of variable: 


$$
\left.\hat{\mathrm{z}}_{\text {ele }}^{\mathrm{LTS}}(\mathrm{k})\right|_{\mathrm{i}=\text { ele(LTS })}=\left.\overline{\mathrm{P}}_{\mathrm{i}}(\mathrm{k}) \cdot \widehat{\alpha}_{\mathrm{i}}(\mathrm{k}) \cdot \widehat{\delta}_{\mathrm{i}}(\mathrm{k})\right|_{\mathrm{i}=\mathrm{ele}(\mathrm{LTS})}
$$

The parameters obtained, $\hat{z}_{\text {ele }}^{\mathrm{LTS}}$, are then used as inputs in the lowlevel control system for the electrolyzers, which will be explained in Section 5.3.

\subsection{SHORT TERM SYSTEM}

This control system aims to eliminate fluctuations in the current applied to the electrolyzers, which produce several degradation mechanisms (MILEWSKI et al. 2014). The different degradation issues associated with each energy storage system, concerning load fluctuation or start-up/shut-down cycles, are analyzed and minimized with this control system. The start-up sequence of the electrolyzer is also considered and controlled.

The electrolyzer management system (ELMS) is designed to feed the stack with enough water to produce the electrolysis reaction (GARCÍA-TORRES et al. 2016). The procedure of the start-up sequence takes the ELMS a starting time of $15 \mathrm{~s}$ for the electrolyzers before it can absorb energy from the microgrid. As there are logical states in the electrolyzers, it is necessary to introduce logical, dynamic and mixed variables. The first variable to be introduced must be the energized state of each electrolyzer for this Short Term System (STS). It

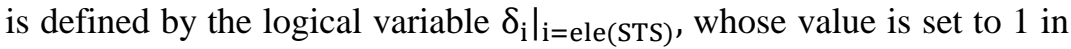
this state and 0 in the rest of the states of the electrolyzers (note the equivalence with the LTS).

Due to the start-up sequence, the logical variable $\left.\delta_{\mathrm{i}}(\mathrm{k})\right|_{\mathrm{i}=\mathrm{ele}(\mathrm{STS})}$ must be expressed as a function of the logical control signal to switch on/off the electrolyzers $\left(\left.\Lambda_{\mathrm{i}}(\mathrm{k})\right|_{\mathrm{i}=\mathrm{ele}(\mathrm{STS})}\right)$. The devices only reach the energized state, $\left.\varphi_{\mathrm{i}}(\mathrm{k})\right|_{\mathrm{i}=\text { ele(STS)}}$, if $\left.\Lambda_{\mathrm{i}}(\mathrm{k})\right|_{\mathrm{i}=\mathrm{ele}(\mathrm{STS})}$ is active in all the instants of the required time $\left.\varphi_{\mathrm{i}}(\mathrm{k})\right|_{\mathrm{i}=\mathrm{ele}(\mathrm{STS})}$ for the starting sequence (GARCÍA-TORRES et al. 2016). Figure 5.3 shows the relationship between the variables $\varphi, \delta$, and $\Lambda$. The activation time $(\varphi)$ between the activation of the logical command to start up the electrolyzer $(\Lambda)$ and the beginning of the process to absorb electrical power of the electrolyzer $(\delta)$ can be seen. 


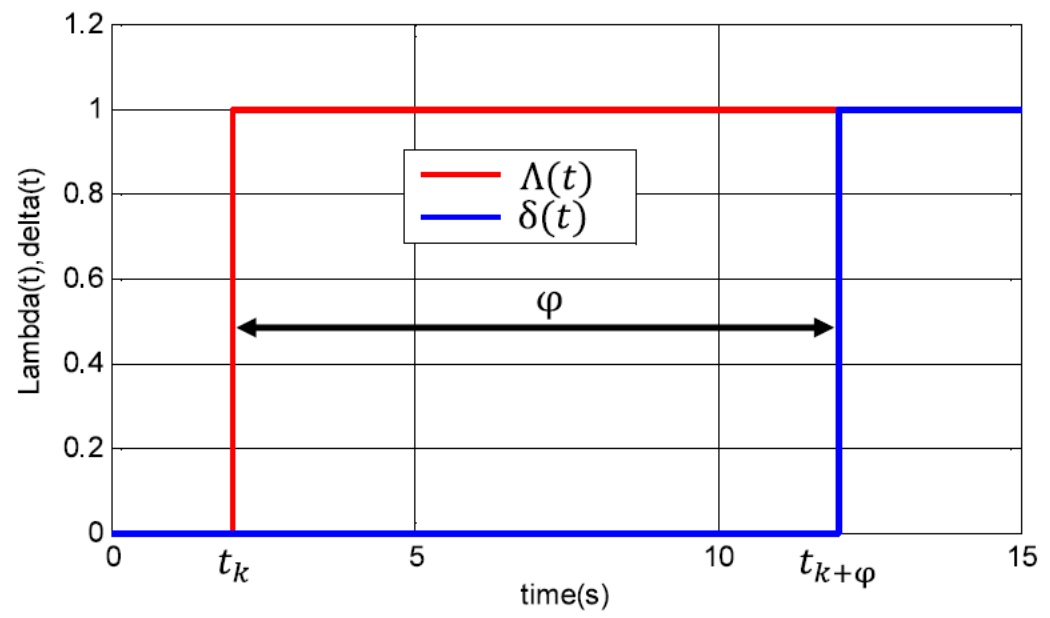

Figure 5.3 - Activation time $(\varphi)$ between the on/off state $(\delta)$ and the logical order signal to start-up $(\Lambda)$ (GARCÍA-TORRES et al. 2016).

This relationship between $\left.\delta_{\mathrm{i}}(\mathrm{k})\right|_{\mathrm{i}=\mathrm{ele}(\mathrm{STS})}$ and $\left.\Lambda_{\mathrm{i}}(\mathrm{k})\right|_{\mathrm{i}=\mathrm{ele}(\mathrm{STS})}$ is defined by Equation (76):

$$
\delta_{\mathrm{i}}(\mathrm{k})=1 \leftrightarrow \varphi_{\mathrm{i}}-\left.\sum_{\mathrm{s}_{\mathrm{j}}=0}^{\mathrm{s}_{\mathrm{j}}=\varphi_{\mathrm{i}}}\left(\Lambda_{\mathrm{i}}\left(\mathrm{k}-\mathrm{s}_{\mathrm{j}}\right)\right)\right|_{\mathrm{i}=\mathrm{ele}(\mathrm{STS})} \leq 0
$$

Using the conversions defined in (BEMPORAD; MORARI, 1999) (see Section 2.4.3), this equation can be transformed into the constraints expressed in inequalities (77) and (78), where coefficients $\mathrm{m}, \mathrm{M}$ and $\varepsilon$ follow the notation given in Table 1.1, shown in Section 2.4.3.

$$
\begin{aligned}
& \varphi_{\mathrm{i}}-\sum_{\mathrm{s}_{\mathrm{j}}=0}^{\mathrm{s}_{\mathrm{j}}=\varphi_{\mathrm{i}}}\left(\Lambda_{\mathrm{i}}\left(\mathrm{k}-\mathrm{s}_{\mathrm{j}}\right)\right) \leq \mathrm{M}-\left.\mathrm{M} \delta_{\mathrm{i}}\right|_{\mathrm{i}=\operatorname{ele}(\mathrm{STS})} \leq 0 \\
& \varphi_{\mathrm{i}}-\sum_{\mathrm{s}_{\mathrm{j}}=0}^{\mathrm{s}_{\mathrm{j}}=\varphi_{\mathrm{i}}}\left(\Lambda_{\mathrm{i}}\left(\mathrm{k}-\mathrm{s}_{\mathrm{j}}\right)\right) \geq \varepsilon+\left.(\mathrm{m}-\varepsilon) \delta_{\mathrm{i}}\right|_{\mathrm{i}=\operatorname{ele}(\mathrm{STS})} \leq 0
\end{aligned}
$$

The start-up $\left(\sigma_{\mathrm{i}}^{\text {on }}(\mathrm{k})\right)$ and shut-down $\left(\sigma_{\mathrm{i}}^{\text {off }}(\mathrm{k})\right)$ states for the electrolyzers are defined in Equations (79) and (80) (GARCÍATORRES et al. 2016).

$$
\begin{aligned}
& \widehat{\sigma}_{\mathrm{i}}^{\text {on }}(\mathrm{k}+1)=\left.\max \left(\widehat{\Lambda}_{\mathrm{i}}(\mathrm{k}+1)-\Lambda_{\mathrm{i}}(\mathrm{k}), 0\right)\right|_{\mathrm{i}=\operatorname{ele}(\mathrm{STS})} \\
& {\widehat{\sigma}_{\mathrm{i}}^{\text {off }}}^{\mathrm{k}}(\mathrm{k}+1)=\left.\max \left(\Lambda_{\mathrm{i}}(\mathrm{k})-\widehat{\Lambda}_{\mathrm{i}}(\mathrm{k}+1), 0\right)\right|_{\mathrm{i}=\operatorname{ele}(\mathrm{STS})}
\end{aligned}
$$


The electrolyzers would only be able to consume the energy in the microgrid in the energized state. So the logical power $\mathrm{z}_{\text {ele }}^{\mathrm{STS}}$ is defined by Equation (81) as the product of the maximum power of the electrolyzers, the capacity factor and the logical on/off state, giving as a result the introduction of MLD constraints in the controller, in the same way as Equation (75).

$$
\left.\widehat{\mathrm{Z}}_{\text {ele }}^{\mathrm{STS}}(\mathrm{k})\right|_{\mathrm{i}=\mathrm{ele}(\mathrm{STS})}=\left.\overline{\mathrm{P}}_{\mathrm{i}}(\mathrm{k}) \cdot \widehat{\alpha}_{\mathrm{i}}(\mathrm{k}) \cdot \widehat{\delta}_{\mathrm{i}}(\mathrm{k})\right|_{\mathrm{i}=\mathrm{ele}(\mathrm{STS})}
$$

When the energized state is reached, the controller must provide a reference as a function of the schedule. The remaining power in the microgrid must be maintained later on in order to minimize the power fluctuations of the electrolyzers, which can lead to degradation conditions in these devices. Thus, the logical power variation $\vartheta_{\mathrm{i}}$ (see Equation (82) is defined as the power variation in all the instants except those when the device passes from the start-up state to the energized state. This term is introduced in the MLD constraints of the STS (GARCÍA-TORRES et al. 2016).

$$
\widehat{\vartheta}_{\mathrm{i}}(\mathrm{k}+1)=\left.\widehat{\Delta \mathrm{z}}_{\mathrm{ele}}^{\mathrm{STS}}(\mathrm{k}) \cdot\left(\widehat{\delta}_{\mathrm{i}}(\mathrm{k}+1) \wedge \delta_{\mathrm{i}}(\mathrm{k})\right)\right|_{\mathrm{i}=\mathrm{ele}(\mathrm{STS})}
$$

The energy source in the microgrid is the power available $\left(\widehat{\mathrm{P}}_{\mathrm{available}}\right)$ from the hybrid wind and wave device. The sample time established for the controller is $1 \mathrm{~s}$. In this time-order, the dynamic of the generators, for all the sample instants of the control horizon $\mathrm{N}_{\mathrm{u}}(\mathrm{j}=1$, $2, \ldots 15)$, can be assumed constant and equal to the sampled value. The following power prediction is introduced in the controller.

$$
\widehat{\mathrm{P}}_{\text {available }}(\mathrm{k}+\mathrm{j})=\widehat{\mathrm{P}}_{\text {available }}(\mathrm{k})
$$

\subsubsection{Short term MPC design}

Figure 5.4 depicts the block diagram for the system that couples the LTS seen in Section 5.2 with the STS proposed here. The STS receives the operation points, binary variables and power consumptions of the devices of the microgrid as reference, and also the model parameters which were seen in Section 5.3.

While the high level control (LTS) explained in Section 5.2 has a control horizon $\mathrm{N}_{\mathrm{u}}$ of 1 hour, the STS MPC controller has a control 
horizon $\mathrm{N}_{\mathrm{u}}$ of $15 \mathrm{~s}$ (value taken due to the start sequence of the electrolyzers) and the sample time is 1 second.

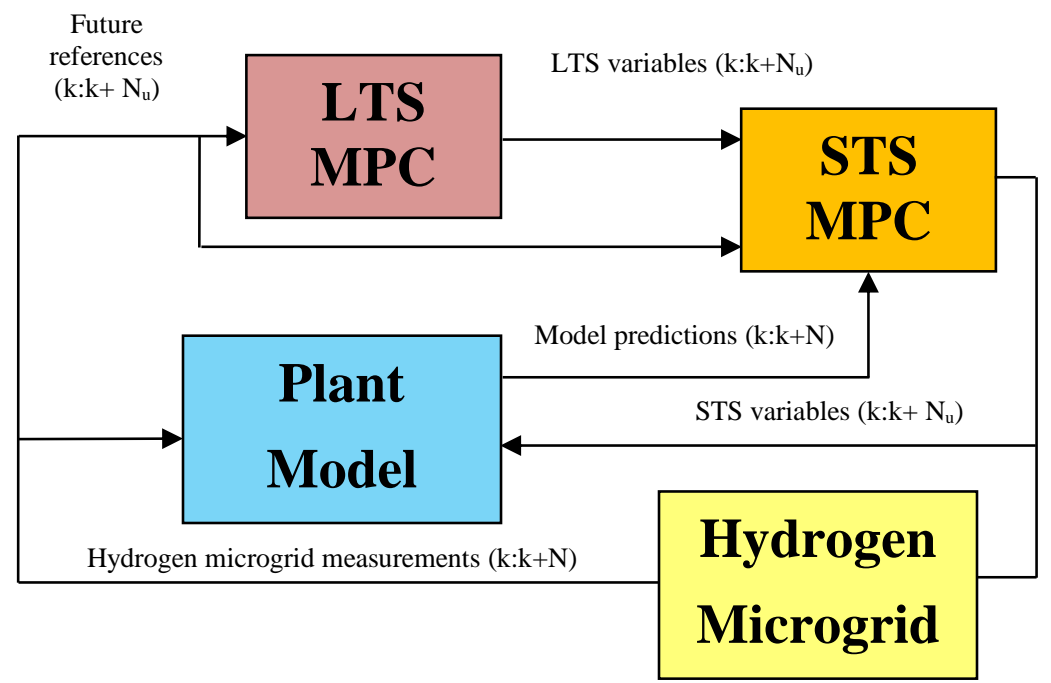

Figure 5.4 - Block diagram coupling the LTS and STS

MLD conversion makes it possible to include binary and auxiliary variables into a discrete-time dynamic system in order to describe the evolution of the continuous and logic signals of the system in a unified model (GARCÍA-TORRES et al. 2016). Tables 5.1 to 5.5 summarize the list of variables of the MPC systems.

\begin{tabular}{|c|c|c|}
\hline \multirow{4}{*}{ Future references } & Predictions of power available & $\widehat{\mathrm{P}}_{\text {available }}$ \\
\cline { 2 - 3 } & State of Charge of the battery & SOC $_{\text {bat }}^{\text {LTS }}$ \\
\cline { 2 - 3 } & $\begin{array}{c}\text { State of Charge of the } \\
\text { ultracapacitor }\end{array}$ & SOC $_{\text {uc }}^{\text {LTS }}$ \\
\hline
\end{tabular}

Table 5.1 - List of the future references

\begin{tabular}{|c|c|c|}
\hline \multirow{2}{*}{$\begin{array}{c}\text { Hydrogen } \\
\text { microgrid }\end{array}$} & State of Charge of the battery & SOC $_{\text {bat }}^{\text {STS }}$ \\
\cline { 2 - 3 } measurements & $\begin{array}{c}\text { State of Charge of the } \\
\text { ultracapacitor }\end{array}$ & $\mathrm{SOC}_{\mathrm{uc}}^{\mathrm{STS}}$ \\
\cline { 2 - 3 } \begin{tabular}{c} 
Power consumed by the battery \\
\cline { 2 - 3 }
\end{tabular} & $\begin{array}{c}\text { Power consumed by the } \\
\text { ultracapacitor }\end{array}$ & $\mathrm{P}_{\mathrm{uc}}^{\text {STS }}$ \\
\hline
\end{tabular}

Table 5.2 - List of the hydrogen microgrid measurements 


\begin{tabular}{|l|c|c|}
\hline \multirow{4}{*}{ LTS variables } & ON/OFF state of the electrolyzer & $\delta_{\text {ele }}^{\mathrm{LTS}}$ \\
\cline { 2 - 3 } & Capacity factor of the electrolyzer & $\alpha_{\text {ele }}^{\mathrm{LTS}}$ \\
\cline { 2 - 3 } & Power consumed by the battery & $\mathrm{P}_{\mathrm{bat}}^{\mathrm{LTS}}$ \\
\cline { 2 - 3 } & $\begin{array}{c}\text { Power consumed by the } \\
\text { ultracapacitor }\end{array}$ & $\mathrm{P}_{\mathrm{uc}}^{\mathrm{LTS}}$ \\
\cline { 2 - 3 } & Power formulated as MLD variable & $\mathrm{z}_{\text {ele }}^{\mathrm{LTS}}$ \\
\cline { 2 - 3 } & ON/OFF state of the battery & $\delta_{\mathrm{bat}}^{\mathrm{LTS}}$ \\
\cline { 2 - 3 } & ON/OFF state of the ultracapacitor & $\delta_{\mathrm{uc}}^{\mathrm{LTS}}$ \\
\hline
\end{tabular}

Table 5.3 - List of the LTS variables

\begin{tabular}{|c|c|c|}
\hline \multirow{4}{*}{ STS variables } & ON/OFF state of the electrolyzer & $\delta_{\text {ele }}^{\text {STS }}$ \\
\cline { 2 - 3 } & Capacity factor of the electrolyzer & $\alpha_{\text {ele }}^{\text {STS }}$ \\
\cline { 2 - 3 } & Power formulated as MLD variable & $\mathrm{z}_{\text {ele }}^{\text {STS }}$ \\
\cline { 2 - 3 } & Charge of the battery & $\delta_{\text {bat }}^{\text {ch }}$ \\
\cline { 2 - 3 } & Discharge of the battery & $\delta_{\text {bat }}^{\text {dis }}$ \\
\cline { 2 - 3 } & Charge of the ultracapacitor & $\delta_{\mathrm{uc}}^{\text {ch }}$ \\
\cline { 2 - 3 } & Discharge of the ultracapacitor & $\delta_{\mathrm{uc}}^{\text {dis }}$ \\
\hline
\end{tabular}

Table 5.4 - List of the STS variables

\begin{tabular}{|c|c|c|}
\hline \multirow{4}{*}{ Model predictions } & Start-up state of the electrolyzer & $\sigma_{\text {ele }}^{\text {on }}$ \\
\cline { 2 - 3 } & Start-down state of the electrolyzer & $\sigma_{\text {ele }}^{\text {off }}$ \\
\cline { 2 - 3 } & $\begin{array}{c}\text { Logical order signal to start up the } \\
\text { electrolyzer }\end{array}$ & $\Lambda_{\text {ele }}$ \\
\cline { 2 - 3 } & $\begin{array}{c}\text { MLD power variation in } \\
\text { degradation state }\end{array}$ & $\vartheta_{\text {ele }}$ \\
\cline { 2 - 3 } & $\begin{array}{c}\text { Activation time to start up the } \\
\text { electrolyzer }\end{array}$ & $\varphi_{\text {ele }}$ \\
\hline
\end{tabular}

Table 5.5 - List of the model predictions

Different weighting factors $\left(\mathrm{w}_{\mathrm{i}}\right)$ and constraint limits for the components of the hydrogen microgrid have been defined in this STS. The weighting factor assignment criterion has been the same as for the LTS in order to couple both MPC controllers in the most accurate way. Physical constraints are given by the upper and lower power limit that the system can absorb.

\subsubsection{Control objectives of the STS}

The main cost function in this control level consists of the sum of the devices of the microgrid (see Equation (84)). The cost function of 
each device is based on the deviation from the power references between the LTS and the STS controllers.

In the cost functions applied to each component, degradation or anomalous working conditions are avoided, introducing these terms in the objective function of the controller, as will be explained in the next sections (GARCÍA-TORRES et al. 2016).

$$
\min J=\min \left(J_{\mathrm{uc}}+\mathrm{J}_{\mathrm{bat}}+\mathrm{J}_{\mathrm{ele}}\right)
$$

\subsubsection{Ultracapacitor cost function}

Equation (85) depicts the cost function of the ultracapacitor. The ultracapacitor is kept in an intermediate SOC in order to be always available if required to compensate the rest of the components of the microgrid. This provides protection from undercharging or overcharging. The second term of the cost function is added to avoid instability points in the ultracapacitor giving a low weighting factor, but zero as power reference value for the ultracapacitor (GARCÍA-TORRES et al. 2016). If this term had not been included, sub-optimal problem solutions would have been found when the power calculated by the solver is close to zero.

$$
\begin{gathered}
\mathrm{J}_{\mathrm{uc}}=\sum_{\mathrm{j}=1}^{15}\left(\mathrm{w}_{\mathrm{uc}}^{\mathrm{SOC}}\left(\widehat{\mathrm{SOC}}_{\mathrm{uc}}^{\mathrm{STS}}(\mathrm{k}+\mathrm{j})-\widehat{\mathrm{SOC}}_{\mathrm{uc}}^{\mathrm{ref}}(\mathrm{k}+\mathrm{j})\right)^{2}\right. \\
+\left(\mathrm{w}_{\mathrm{uc}}^{\mathrm{P}} \cdot\left(\widehat{\mathrm{P}}_{\mathrm{uc}}^{\mathrm{STS}}(\mathrm{k}+\mathrm{j})-0\right)^{2}\right)
\end{gathered}
$$

\subsubsection{Battery cost function}

Equation (86) shows the battery cost function. Batteries are more flexible than other devices due to the fact that start-up and shut-down cycles do not affect this technology. The last term of the cost function penalizes the AC current in the batteries.

$$
\begin{gathered}
\mathrm{J}_{\text {bat }}=\sum_{\mathrm{j}=1}^{15}\left(\mathrm{w}_{\text {bat }}^{\mathrm{P}}\left(\widehat{\mathrm{P}}_{\text {bat }}^{\mathrm{STS}}(\mathrm{k}+\mathrm{j})-\widehat{\mathrm{P}}_{\text {bat }}^{\mathrm{LTS}}(\mathrm{k}+\mathrm{j})\right)^{2}+\right. \\
\mathrm{w}_{\text {bat }}^{\mathrm{SOC}}\left(\widehat{S O C}_{\text {bat }}^{\text {STS }}(\mathrm{k}+\mathrm{j})-\widehat{S O C}_{\text {bat }}^{\mathrm{LTS}}(\mathrm{k}+\mathrm{j})\right)^{2} \\
\left.\left.+\mathrm{w}_{\text {bat }}^{\text {ripple }}\left({\widehat{\Delta \mathrm{P}_{\text {bat }}^{\mathrm{STS}}}}^{\mathrm{ST}}+\mathrm{j}\right)\right)^{2}\right)
\end{gathered}
$$




\subsubsection{Electrolyzer cost function}

Equation (87) defines the electrolyzer cost function. As in the case of the battery, the output of the high level control of the microgrid gives the power reference at each instant. In order to protect it from the main causes of degradation, the start-up and shut-down states are penalized in the controller.

$$
\begin{gathered}
\mathrm{J}_{\text {ele }}=\sum_{\mathrm{j}=1}^{15}\left(\mathrm{w}_{\text {ele }}^{\mathrm{P}}\left(\hat{\mathrm{z}}_{\text {ele }}^{\mathrm{STS}}(\mathrm{k}+\mathrm{j})-\hat{\mathrm{z}}_{\text {ele }}^{\mathrm{LTS}}(\mathrm{k}+\mathrm{j})\right)^{2}+\right. \\
\mathrm{w}_{\text {ele }}^{\text {ripple }}\left(\widehat{\vartheta}_{\text {ele }}(\mathrm{k}+\mathrm{j})\right)^{2}+\mathrm{w}_{\text {ele }}^{\text {startup }} \cdot \widehat{\sigma}_{\text {ele }}^{\text {on }}(\mathrm{k}+\mathrm{j}) \\
\left.\quad+\mathrm{w}_{\text {ele }}^{\text {shutdown }} \cdot \widehat{\sigma}_{\text {ele }}^{\text {off }}(\mathrm{k}+\mathrm{j})\right)
\end{gathered}
$$

\subsection{CASE STUDY}

The installation proposed for this case study is presented in Figure 5.5. To produce the energy, two sources (wind and wave) have been considered. A hybrid device (shown in Figure 4.6) of 1 vertical axis wind turbine (VAWT) and 1 wave energy converter (WEC) are assumed to provide the energy, following the project H2OCEAN (see Section 1.1), but scaled down to $10.0 \mathrm{~kW}$ peak power for the WEC and $3.2 \mathrm{~kW}$ peak power for the VAWT, giving a total peak power of $13.2 \mathrm{~kW}$.

The electrolyzers and storage devices used in this case study are based on a real microgrid installed in the $\mathrm{CNH} 2$ (National Hydrogen Centre), located in Puertollano, Spain. To produce hydrogen, two $4 \mathrm{kWp}$ Nitidor alkaline electrolyzers and one small production $1 \mathrm{kWp}$ Hydrogen Works PEM electrolyzer were chosen (BEN-MOHATAR et al. 2013). The electrolyzers operate slightly above ambient pressure and are further equipped with pressure relief equipment, to prevent overpressure operation. 


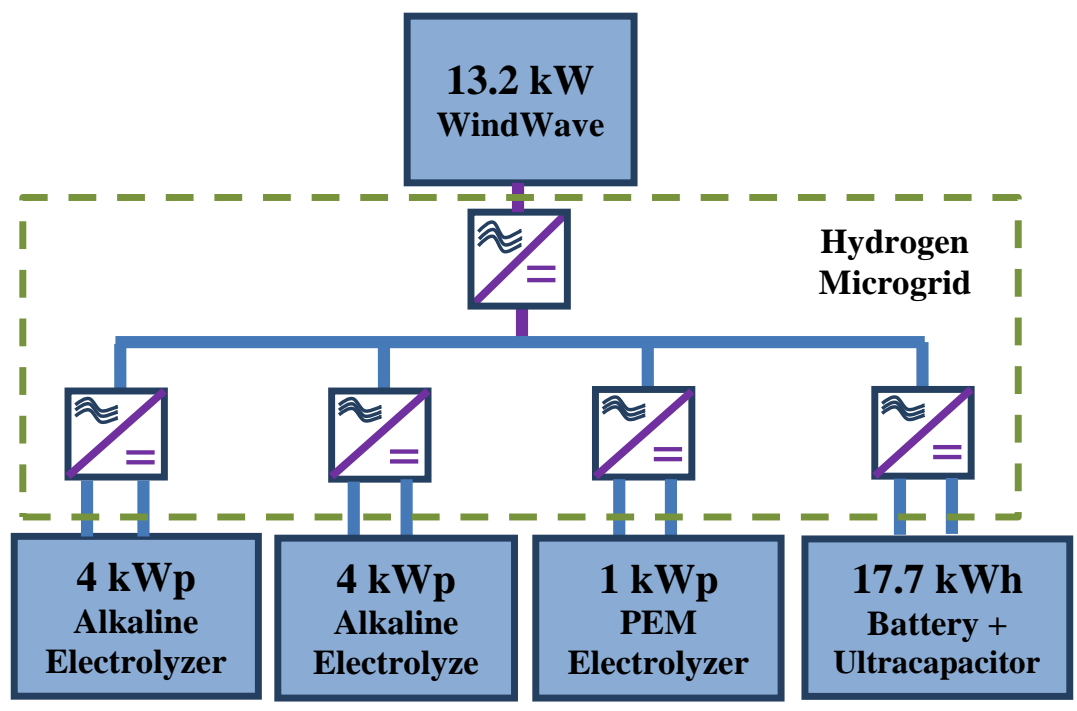

Figure 5.5 - Hydrogen-based microgrid proposed in this case study

The parameters of the electrolyzers are as follows:

$$
\left.\begin{array}{c}
\overline{\mathrm{P}}=\left[\begin{array}{lll}
4 & 4 & 1
\end{array}\right]^{\mathrm{T}} \\
\overline{\mathrm{a}}=\left[\begin{array}{lll}
0.875 & 0.875 & 0.778
\end{array}\right]^{\mathrm{T}} \\
\overline{\mathrm{b}}=\left[\begin{array}{lll}
3.525 & 3.525 & 3.625
\end{array}\right]^{\mathrm{T}} \\
\overline{\mathrm{H}}=\left[\begin{array}{lll}
0.85 & 0.85 & 0.22
\end{array}\right]^{\mathrm{T}} \\
\bar{\alpha}=\left[\begin{array}{lll}
1 & 1 & 1
\end{array}\right]^{\mathrm{T}} \\
\underline{\alpha}=\left[\begin{array}{lll}
0.1 & 0.1 & 0.1
\end{array}\right]^{\mathrm{T}}
\end{array}\right\}
$$

The weighting factors for the cost function of the LTS are given by Equation (89):

$$
\left.\begin{array}{l}
\mathrm{w}_{\mathrm{H}}=\left[\begin{array}{lll}
1 & 1 & 50
\end{array}\right]^{\mathrm{T}} \\
\mathrm{w}_{\delta}=\left[\begin{array}{lll}
1 & 10 & 1
\end{array}\right]^{\mathrm{T}}
\end{array}\right\}
$$

Figure 5.6 depicts the Nitidor electrolyzers located in the $\mathrm{CNH} 2$ laboratory: 


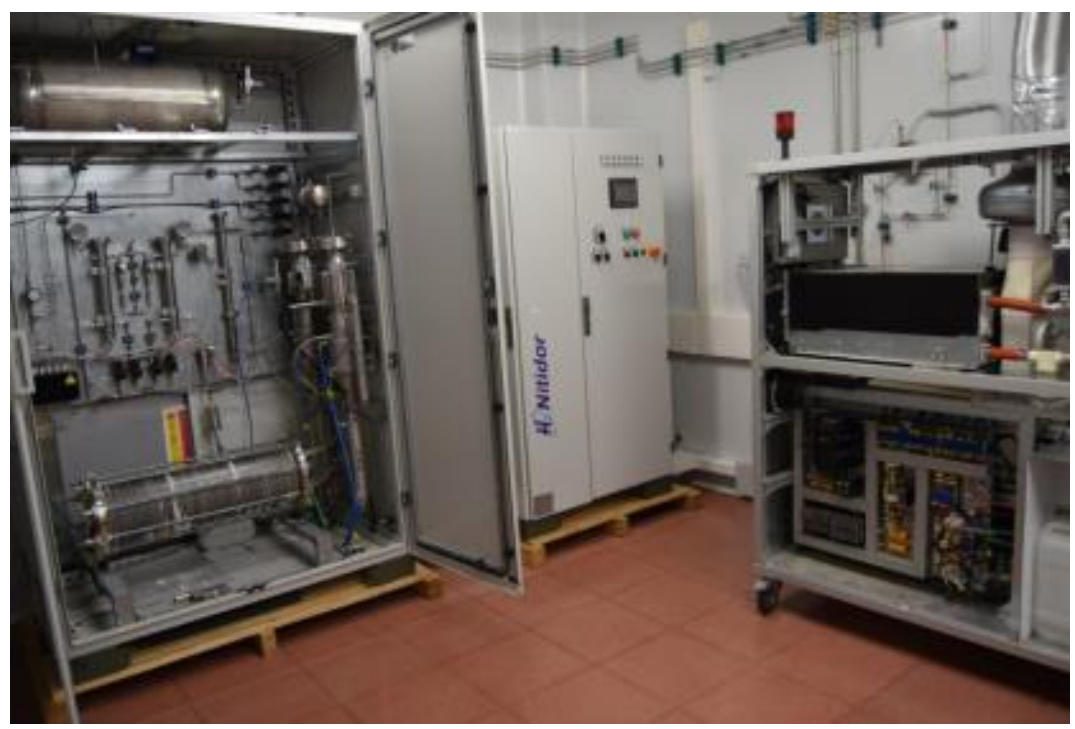

Figure 5.6 - Nitidor electrolyzer in the $\mathrm{CNH} 2$ (http://cnh2.es/docs/tripticos/IV.\%20Triptico_Lab.Microrredes_CNH2.pdf)

The battery and the ultracapacitor have a rated capacity of 367 and 14.68 Ah respectively. They are shown in Figure 5.7:

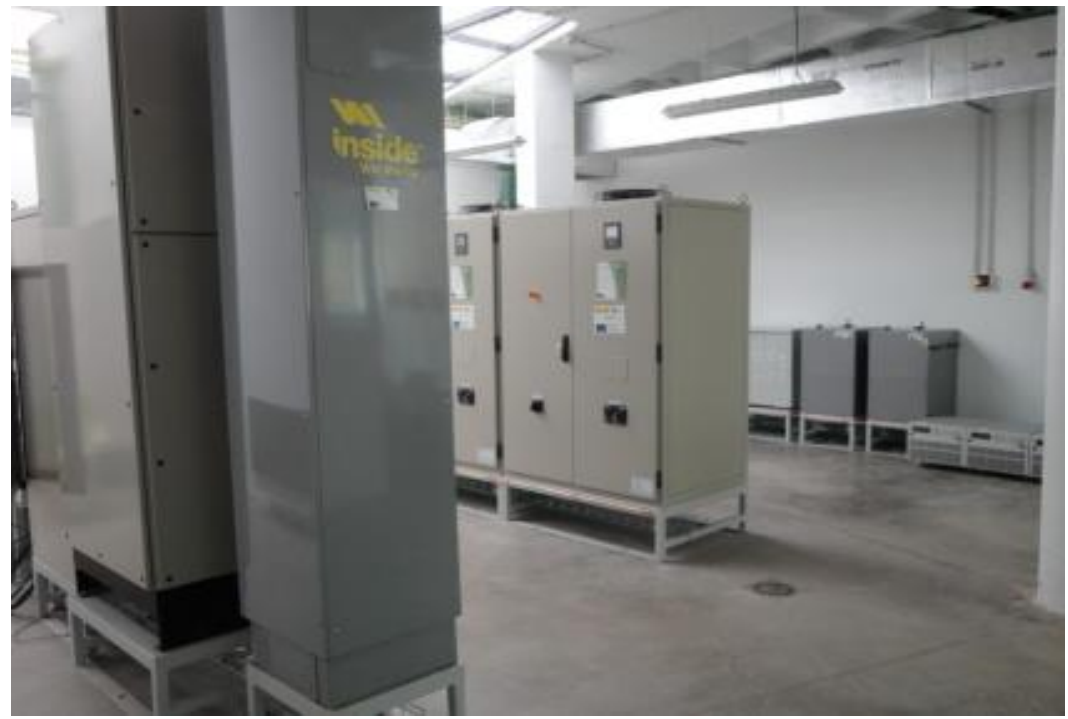

Figure 5.7 - Battery and ultracapacitor in the $\mathrm{CNH} 2$ (http://cnh2.es/docs/tripticos/IV.\%20Triptico_Lab.Microrredes_CNH2.pdf) 


\subsubsection{Controller implementation}

As shown in Figure 5.1, the outputs of the LTS controller are the inputs of the STS controller along with the variables of the model of the plant and the future predictions. The LTS gives the references of the capacity factors of the electrolyzers, whereas the hydrogen microgrid measurements give the battery and ultracapacitor SOCs.

Available power is obtained by meteorological data from a certain location in the north of the Atlantic Ocean. Then, the STS calculate the control parameters defined in Section 5.3 and return to the model plant.

A simulation of the coupling proposed in Section 5.3.1 has been done for a sample time of $1 \mathrm{~s}$ using MATLAB ${ }^{\circledR}$. The LTS optimization strategy was developed in Section 4.2.6, whereas the STS optimization strategy was developed in (GARCÍA-TORRES et al. 2016). Both algorithms were solved with the optimization tool TOMLAB ${ }^{\circledR}$, which has an MIQP optimization solver.

\subsubsection{Results and discussion}

For this case study, some results for 8 hours $(28,800$ samples) can be observed in Figures 5.8 to 5.11 and Table 5.6.

Figure 5.8 shows the power profile used for the simulation. It can be seen that the power provided by the hybrid device, at all times, is less than the peak power that it could provide $(13.2 \mathrm{~kW})$.

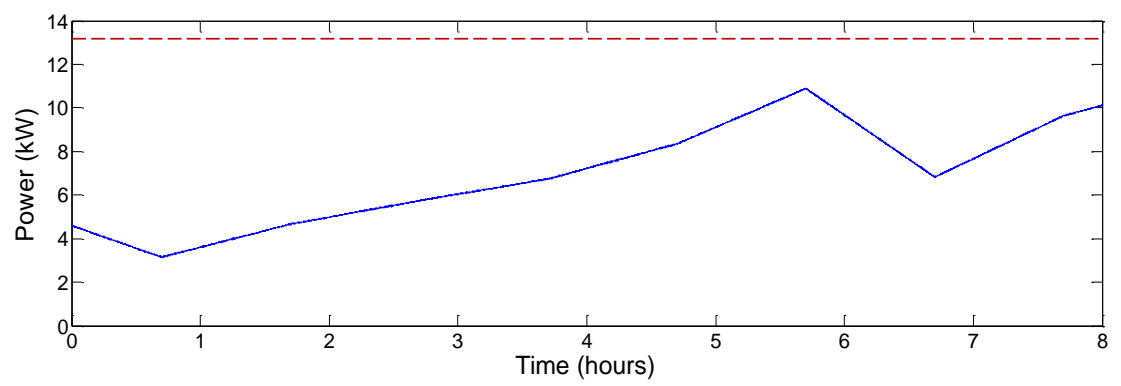

Figure 5.8 - Available renewable power profile

Figure 5.9 depicts the performance of the three electrolyzers that produce hydrogen. As can be observed, they do not switch on/off frequently, so the control system can be considered appropriate 
(ULLEBERG, 2004). The different behaviour of the electrolyzers is because each one has its own weighting $(w)$.

Electrolyzer $\mathrm{i}=1$ and $\mathrm{i}=2$ are the $4 \mathrm{kWp}$ electrolyzers, while $\mathrm{i}=3$ is the $1 \mathrm{kWp}$ production device, which supplies power for residual values.

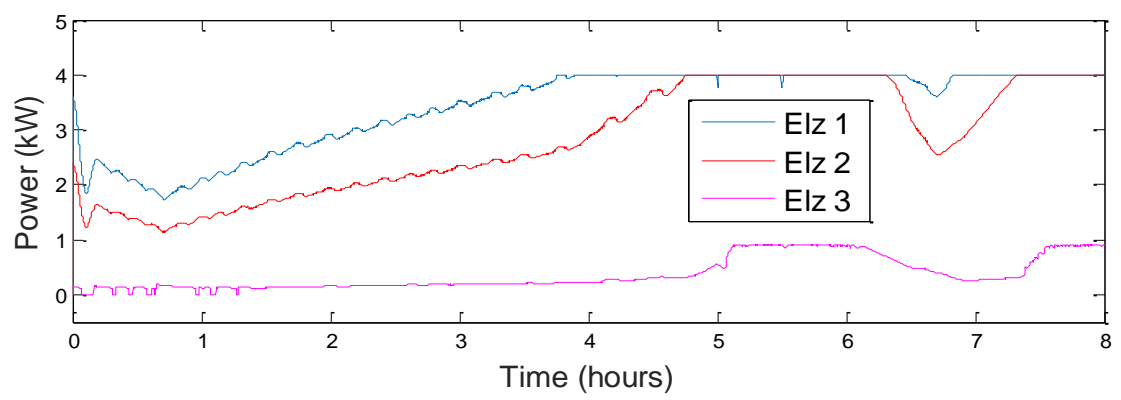

Figure $5.9-$ Operation of the electrolyzers $($ Elz $1=4 \mathrm{kWp}$, Elz $2=4 \mathrm{kWp}$, Elz $3=$ $1 \mathrm{kWp})$

Figure 5.10 shows the power exchanged with the storage devices (battery and ultracapacitor). They receive power when there is an excess of available energy because the electrolyzers are operating at $100 \%$ performance (between $5^{\text {th }}$ and $6^{\text {th }}$ hours in the case study). On the other hand, they provide power to produce hydrogen when there is a lack of renewable energy.

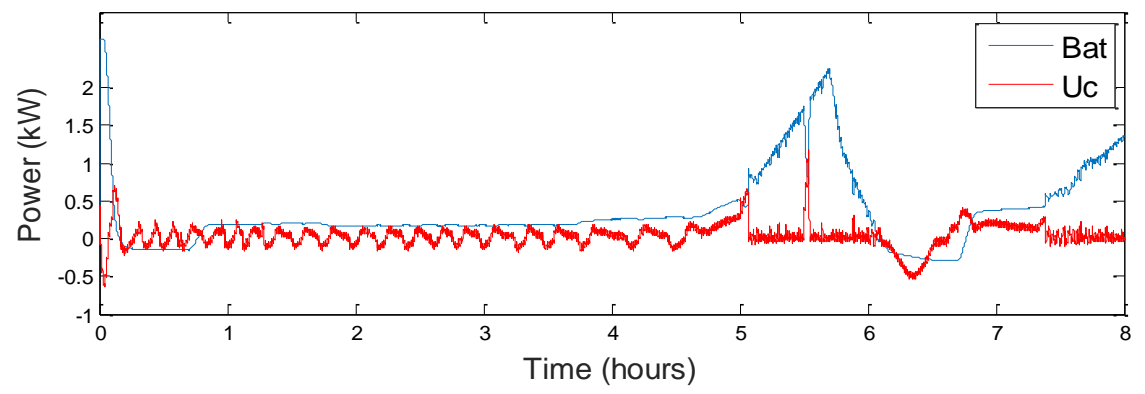

Figure 5.10 - Power exchange of the battery and ultracapacitor

Finally, Figure 5.11 depicts the state of charge (SOC) values of the same storage devices. They meet minimum and maximum constraints, so it can be considered as well designed. Moreover, it can be seen that the variation of the SOC is very smooth, so the lifetime of these devices 
is certain to be improved in comparison with other heuristic control systems.

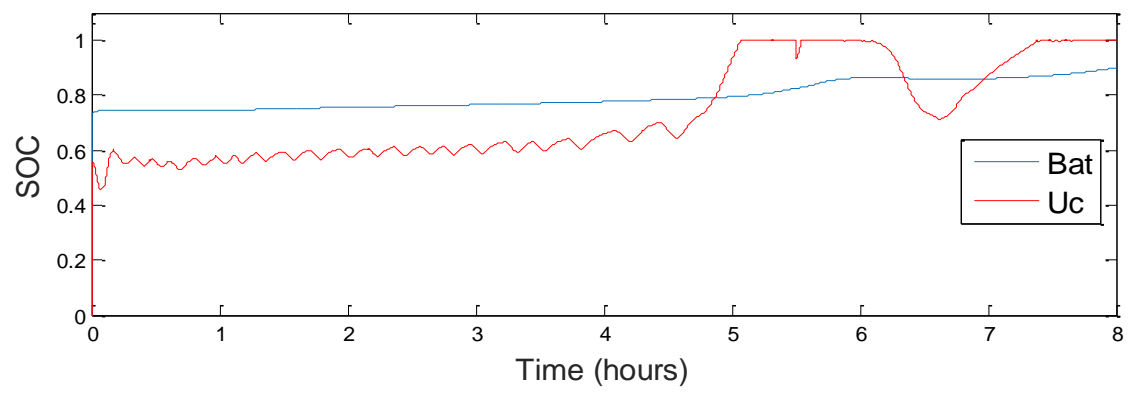

Figure 5.11 - Battery and ultracapacitor SOC

Finally, some operation indices and consumptions are presented in Table 5.6. It can be seen that the energy used by the electrolyzers is about $98 \%$, being much better than the case studies depicted in Chapter 4. These results confirm the correct design of the LTS and the STS proposed in this chapter.

\begin{tabular}{ccc}
\hline $\begin{array}{c}\text { Energy available } \\
\text { (kWh/day) }\end{array}$ & $\begin{array}{c}\text { Energy used by the } \\
\text { electrolyzers (kWh/day) }\end{array}$ & $\begin{array}{c}\text { Energy lost in the } \\
\text { converters } \\
\text { (kWh/day) }\end{array}$ \\
\hline 75.1 & $73.9(98.1 \%)$ & $0.3(0.5 \%)$ \\
\hline $\begin{array}{c}\text { Energy lost in the } \\
\text { battery }(\mathrm{kWh} / \text { day) }\end{array}$ & $\begin{array}{c}\text { Energy lost in the } \\
\text { ultracapacitor }(\mathrm{kWh} / \text { day) }\end{array}$ & $\begin{array}{c}\text { Energy not used } \\
(\mathrm{kWh} / \text { day) }\end{array}$ \\
\hline $0.3(0.5 \%)$ & $0.6(0.9 \%)$ & 0 \\
\hline
\end{tabular}

Table 5.6 - Operation indices and consumptions of the case study.

\subsection{SUMMARY AND CONCLUSIONS}

A coupling of control systems based on Model Predictive Control ideas is proposed and tested to optimize and balance the hydrogen production for a hydrogen-based microgrid. The microgrid includes renewable energy sources such as wind and wave energy, a set of electrolyzers (alkaline and PEM), a battery and an ultracapacitor. The proposed approach has been validated using real data measured from a certain location in the north of the Atlantic Ocean, which is used to verify the correct operation of the microgrid with the designed controller. 
The main conclusions of this study are the following:

- In this chapter, the long term MPC controller developed in Chapter 4 and a short term controller from the literature of a hydrogenbased microgrid have been coupled and validated in a simulation.

- The integration of the two systems allows a better performance and a better use of the energy. This formulation considers the penalties of degradation situations for all the components of the microgrid (electrolyzers, battery and ultracapacitor).

- The proposal has been validated for a case study in which the state of health of the electrolyzers, battery and ultracapacitor are ensured thanks to the minimization of the switching. 


\section{CHAPTER 6}

\section{CONCLUSIONS}




\section{CONCLUSIONS}

Section 6.1 summarizes the final conclusions and completed tasks concerning this thesis. Finally section 6.2 gives general ideas for future work and open issues.

\subsection{FINAL CONCLUSIONS}

This thesis named "Control systems of offshore hydrogen production by renewable energies" has presented several contributions on the modelling, sizing and control of an offshore plant powered by renewable energies which produces hydrogen.

The main objective of the thesis was to develop Energy Management Systems (EMS) based on Model Predictive Control (MPC) ideas to balance energy consumption with the renewable energy supplied in stand-alone installations. The feasibility of the approaches has been shown. The most significant results of this study are summarized below, according to different topics.

\section{$\underline{\text { H2OCEAN platform }}$}

1.a) A model-based simulation has been developed to reproduce the effect of measured sea conditions (wave height, wave period and wind speed) on energy production of the hybrid wind-wave H2OCEAN device. [Section 2.1]

1.b) A model-based simulation has been developed for the energy consuming units in the H2OCEAN platform: desalination, seawater supply and short-term energy storage, electrolysis, and hydrogen compression. This simulation was integrated with the one of energy sources given by 1.a). [Chapter 3]

1.c) A methodology for sizing the H2OCEAN desalination unit was proposed and applied at a certain location in the Atlantic Ocean based on buoy data. [Section 3.1]

1.d) A rule-based Energy Management System for water production $\left(\mathrm{EMS}_{\mathrm{W}}\right)$ was proposed, based on adapting power consumption to power production by connecting or disconnecting sections of the desalination unit and using a temporary storage of electricity for 
short-time balances. The methodology was validated in two different case studies, concentrating on the one that produced water with less conductivity (DEMI water). [Section 3.1]

1.e) A proposal was presented for modelling and simulating the electrolysis unit in order to design and test the control system. [Section 3.2]

1.f) An Energy Management System for Hydrogen production $\left(\mathrm{EMS}_{\mathrm{H}}\right)$ was developed based on a rule-based control system. It was then evaluated in terms of hydrogen production and the evolution of the platform parameters, showing that the proposed $\mathrm{EMS}_{\mathrm{H}}$ was suitable. [Section 3.2]

\section{$\underline{\text { Advanced control system for electrolysis }}$}

2.a) An Energy Management System for hydrogen production $\left(\mathrm{EMS}_{\mathrm{H}}\right)$ based on Model Predictive Control (MPC) ideas has been proposed to balance energy consumption with the renewable energy supplied in stand-alone installations. The $\mathrm{EMS}_{\mathrm{H}}$ proposed uses a MixedInteger-Quadratic-Programming to manipulate the capacity factor and connections/disconnections of the units, minimizing the error between the predicted and the desired powers consumed by each electrolyzer for all the devices along the prediction horizon $\mathrm{N}$. [Section 4.2]

2.b) The proposal in 2.a) has been validated for two cases studies using measured data at the location in 1.a), showing that the operation of the electrolysis units was maximized, that the hydrogen production was maintained, that the energy consumed was almost equal to the energy supplied by the wind-wave hybrid devices, and the electrolyzers' state of health was ensured thanks to the minimization of the switching. [Section 4.3]

\section{Coupling of controllers}

3.a) The $\mathrm{EMS}_{\mathrm{H}}$ based on MPC developed in 2.a) was coupled with a short term controller from the literature (see Section 5.3) for a hydrogen-based microgrid. The $\mathrm{EMS}_{\mathrm{H}}$ proposed integrates the penalties of degradations situations, considering all the components of the microgrid (electrolyzers, batteries, ultracapacitor) using a 
Mixed-Integer-Quadratic-Programming algorithm to optimize microgrid. The discrete variables define the switching conditions of the electrolyzers and the storage devices along the prediction horizon N. [Chapter 5].

3.b) The proposal in 3.a) has been validated for a case study in which the state of health of the electrolyzers, battery and ultracapacitor was ensured thanks to the minimization of the switching. [Section 5.4].

\subsection{FUTURE WORK}

The work presented in this dissertation is an open research line and inspires several interesting problems in the field of advanced control in hydrogen production. As future work, several ideas should be investigated with the general aim of improving the performance of hydrogen production by electrolysis:

- Scheduling of the cleanings and maintenance of the components of the microgrid.

- Implementation of the control algorithms in a SCADA to evaluate the performance in a real case study.

- Integration with different renewable energy sources such as photovoltaic or hydropower.

- Study of new findings of electrolyzers.

- Coupling of a fuel cell with the electrolyzers in the hydrogen-based microgrid.

- Possibility of using stochastic programming to solve the variability of meteorological predictions, especially wind speed. 


\section{ACKNOWLEDGEMENTS}

This work was partly supported by MiCInn DPI2010-21589-c0505, DPI2014-5430-R and the European Commission (7th Framework Programme, grant agreement 288145, Ocean of Tomorrow Joint Call 2011). The author thanks the financial support given by the Junta de Castilla y León (EDU/1083/2013). This PhD was partially carried out in the context of the international laboratory HyRES (https://www.lsis.org/mgef2015/HyRESLab.htm). Also thanks to AEMET for providing meteorological data

Part of this work was carried out financed by a mobility grant given by the University of Valladolid (Call 2015 and 2016). Prof. Normey-Rico thanks CNPq-Brazil for the financial support under projects 305785/2015-0 and 401126/2014-5. 


\section{REFERENCES}

ACAR, C., DINCER, I. (2014). Comparative assessment of hydrogen production methods from renewable and non-renewable sources. International Journal of Hydrogen Energy, 39(1), 1-12.

AGERSTED, K. (2014). Report on expected marinised hydrogen generator performance. WP5 Deliverable 5.1. H2OCEAN project, 1-3. http://h2oceanproject.eu/_content/dissemination/attachments/H2Ocean_ D5-1_Final_PUBLIC.pdf

AMBASHTA, R. D.; SILLANPÄ̈̈, M. E. (2012). Membrane purification in radioactive waste management: a short review. Journal of environmental radioactivity, 105, 76-84.

ANTONIA, O.; SAUR, G. (2012). Wind to hydrogen in California: case study. National Renewable Energy Laboratory, Technical Report, 303, 275-3000.

ANTONIO, F. D. O. (2010). Wave energy utilization: A review of the technologies. Renewable and sustainable energy reviews, 14(3), 899918.

ARCE, A.; ALEJANDRO, J.; BORDONS, C. (2009). MPC for battery/fuel cell hybrid vehicles including fuel cell dynamics and battery performance improvement. Journal of process control, 19(8), 12891304.

ASTARIZ, S.; IGLESIAS, G. (2015). The economics of wave energy: A review. Renewable and Sustainable Energy Reviews, 45, 397-408.

BABARIT, A.; HALS J, MULIAWAN, MJ.; KURNIAWAN, A.; MOAN, T:, KROKSTAD, J. (2012). Numerical benchmarking study of a selection of wave energy converters. Renewable Energy 45 44-63.

BAHAJ, A. S. (2011). Generating electricity from oceans. Renewable and Sustainable Energy Reviews, 15(7), 3399-3416.

BALOG, I.; RUTI, P. M.; TOBIN, I.; ARMENIO, V.; VAUTARD, R. (2016). A numerical approach for planning offshore wind farms from 
regional to local scales over the Mediterranean. Renewable Energy, 85, 395-405.

BARBIR, F. (2005). PEM electrolysis for production of hydrogen from renewable energy sources. Solar energy, 78(5), 661-669.

BARNES, E. A..; FIORE, A. M.; HOROWITZ, L. W. (2016). Detection of trends in surface ozone in the presence of climate variability. Journal of Geophysical Research: Atmospheres, 121(10), 6112-6129.

BARQUET, A. P. B.; CUNHA, V. P.; OLIVEIRA, M. G.; ROZENFELD, H. (2011). Business model elements for product-service system. Functional Thinking for Value Creation, 332-337. Springer Berlin Heidelberg.

BARRETO, L.; MAKIHIRA, A.; RIAHI, K. (2003). The hydrogen economy in the 21st century: a sustainable development scenario. International Journal of Hydrogen Energy, 28(3), 267-284.

BASAK, P.; CHOWDHURY, S.; NEE DEY, S. H.; CHOWDHURY, S.P. (2012). A literature review on integration of distributed energy resources in the perspective of control, protection and stability of microgrid. Renewable and Sustainable Energy Reviews, 16(8), 55455556.

BAUER, J.; LYSGAARD, J. (2015). The offshore wind farm array cable layout problem: a planar open vehicle routing problem. Journal of the Operational Research Society, 66(3), 360-368.

BEMPORAD, A,; MORARI, M. (1999). Control of systems integrating logic, dynamics, and constraints. Automatica, 35(3), 407-427.

BEN-MOHATAR, R.; PÉREZ-DELGADO, J. J.; RODADO, G. M.; RUIZ, B.; SÁNCHEZ-MOLINA, M. (2011). Experimentation of a system based on hydrogen and renewable energy to supply energy to an off-grid installation. In Proceedings $3^{\text {rd }}$ Iberian Symposium on Hydrogen, Fuel Cells and Advanced Batteries (HYCELTEC 25-30 June 2011, Zaragoza, Spain).

BIANCHI, F. D.; MANTZ, R. J.; De BATTISTA, H. (2007). The Wind and Wind Turbines (pp. 7-28). Springer London. 
BORG, M.; COLLU, M. (2015). Offshore floating vertical axis wind turbines, dynamics modelling state of the art. Part III: Hydrodynamics and coupled modelling approaches. Renewable and Sustainable Energy Reviews, 46, 296-310.

BORG, M.; COLLU, M. (2014). A comparison on the dynamics of a floating vertical axis wind turbine on three different floating support structures. Energy Procedia, 53, 268-279.

BOSSE, U. (2006). Does a hydrogen economy make sense? Proceedings of the IEEE, 94; (10): 3-4. 2006.

BURTON, T.; SHARPE, D.; JENKINS, N.; BOSSANYI, E. (2001). Wind energy handbook. John Wiley \& Sons.

CAMACHO, E.F.; BORDONS, C. Model predictive control. Springer, 2013.

CARMO, M.; FRITZ, D. L.; MERGEL, J.; STOLTEN, D. (2013). A comprehensive review on PEM water electrolysis. International Journal of Hydrogen Energy, 38(12), 4901-4934.

CHEN, W. M.; KIM, H.; YAMAGUCHI, H. (2014). Renewable energy in eastern Asia: Renewable energy policy review and comparative SWOT analysis for promoting renewable energy in Japan, South Korea, and Taiwan. Energy Policy, 74, 319-329.

CHOI, P.; BESSARABOVB, D. G.; DATTA, R. (2004). A simple model for solid polymer electrolyte (SPE) water electrolysis. Solid State Ionics; (175):535-539.

CHRISTOFIDES, P. D.; SCATTOLINI, R.; DE LA PENA, D. M.; LIU, J. (2013). Distributed model predictive control: A tutorial review and future research directions. Computers \& Chemical Engineering, 51, 2141.

CHUNG, T-S.; LI, X.; ONG, R.C.; GE, Q.; WANG, H.; HAN, G. (2012). Emerging forward osmosis (FO) technologies and challenges ahead for clean water and clean energy applications. Current Opinion in Chemical Engineering 1:246-57. 
CLÉMENT, A.; McCULLEN, P.; FALCÃO, A.; FIORENTINO, A.; GARDNER, F.; HAMMARLUND, K.; PONTES, M. T. (2002). Wave energy in Europe: current status and perspectives. Renewable and sustainable energy reviews, 6(5), 405-431.

DAVIDS, M. W.; TOLJ, I.; JAO, T. C.; LOTOTSKYY, M.; PASUPATHI, S.; SITA, C. (2016). Development of a Portable Polymer Electrolyte Membrane Fuel Cell System Using Metal Hydride as the Hydrogen Storage Medium. ECS Transactions, 75(14), 553-562.

DAVIES, P. A. (2005). Wave-powered desalination: resource assessment and review of technology. Desalination, 186 97-109.

DE MATOS, J. G.; E SILVA, F. S.; RIBEIRO, L. A. D. S. (2015). Power control in ac isolated microgrids with renewable energy sources and energy storage systems. IEEE Transactions on Industrial Electronics, 62(6), 3490-3498.

DE PRADA, C.; SARABIA, D.; CRISTEA, S.; MAZAEDA, R. (2008). Plant-wide control of a hybrid process. International Journal of Adaptative Control and Signal Processing, 22(2), 124-141.

DI BLASI, A.; ANDALORO, L.; SIRACUSANO, S.; BRIGUGLIO, N.; BRUNACCINI, G.; STASSI, A.; ANTONUCCI, V. (2013). Evaluation of materials and components degradation of a PEM electrolyzer for marine applications. International Journal of Hydrogen Energy, 38(18), 7612-7615.

DONG, Z., ZHANG, X.; HUANG, Q.; ZHANG, J.; ZUO, X.; LI, W.; LI, X. (2015). Synthesis and pyrolysis behavior of a soluble polymer precursor for ultra-fine zirconium carbide powders. Ceramics International, 41(6), 7359-7365.

DÖNITZ, W.; ERDLE, E. (1985). High-temperature electrolysis of water vapor-status of development and perspectives for application. International Journal of Hydrogen Energy, 10(5), 291-295.

DOS SANTOS, K. G.; ECKERT, C. T.; DE ROSSI, E.; BARICCATTI, R. A.; FRIGO, E. P.; LINDINO, C. A.; ALVES, H. J. (2017). Hydrogen production in the electrolysis of water in Brazil, a review. Renewable and Sustainable Energy Reviews, 68, 563-571. 
ELLABBAN, O.; ABU-RUB, H.; BLAABJERG, F. (2014). Renewable energy resources: Current status, future prospects and their enabling technology. Renewable and Sustainable Energy Reviews 39:748-64.

ERIKSSON, M. (2007). Modelling and experimental verification of direct drive wave energy conversion -Buoy- generator dynamics, $\mathrm{PhD}$ thesis, Uppsala Universitet.

ESTEBAN, M. D.; DIEZ, J. J.; LOPEZ J. S.; NEGRO, V. (2011). Why offshore wind energy?. Renewable Energy, 36(2), 444-450.

FOLLEY, M. (2016). Numerical Modelling of Wave Energy Converters: State-of-the-art Techniques for Single Devices and Arrays. Academic Press, Print.

GANLEY, J. C. (2009). High temperature and pressure alkaline electrolysis. International Journal of Hydrogen Energy, 34(9), 36043611 .

GARCIA CLUA, J.G. (2013). "Sistemas de control híbrido. Aplicación a sistemas de generación de hidrógeno a partir de recursos energéticos renovables". Thesis presented at National University of La Plata, Argentina.

GARCIA-RODRIGUEZ, L. (2003). Renewable energy applications in desalination: state of the art. Solar energy, 75(5), 381-393.

GARCÍA-TORRES, F.; VALVERDE, L.; BORDONS, C. (2016). Optimal Load Sharing of Hydrogen-Based Microgrids With Hybrid Storage Using Model-Predictive Control. IEEE Transactions on Industrial Electronics, 63(8), 4919-4928.

GARCÍA-TORRES, F. (2015). "Advanced Control of Renewable Energy Microgrids with Hybrid Energy Storage". Thesis presented at University of Sevilla, Spain.

GARCÍA-VALVERDE, A.; ESPINOSA, N.; URBINA, A. (2011). Optimized method for photovoltaic-water electrolyser direct coupling. International Journal of Hydrogen Energy; 36:10574-10586. 
GARRETT, C.; MUNK, W. (1975). Space-time scales of internal waves: A progress report. Journal of Geophysical Research, 80(3), 291297.

GLAVIN, M. E.; CHAN, P. K.; ARMSTRONG, S.; HURLEY, W. G.; A stand-alone photovoltaic supercapacitor battery energy storage system. In IEEE Proceedings $13^{\text {th }}$ Power Electronics and Motion Control Conference, EPE-PEMC 2008. (pp. 1688-1695).

GOMEZ PALACIN, L. (2014). "Modelling, simulation and advanced control of small-scale reverse osmosis desalination plants". Thesis presented at University of Valladolid, Spain.

GONZÁLEZ, J. S.; LACAL-ARÁNTEGUI, R. (2016). A review of regulatory framework for wind energy in European Union countries: current state and expected developments. Renewable and Sustainable Energy Reviews, 56, 588-602.

GUDE, V. G. (2016). Desalination and sustainability-an appraisal and current perspective. Water research, 89, 87-106.

GUERRERO, J. M.; CHANDORKAR, M.; LEE, T. L.; LOH, P. C. (2013). Advanced control architectures for intelligent microgrids-Part I: Decentralized and hierarchical control. IEEE Transactions on Industrial Electronics, 60(4), 1254-1262.

GUTIÉRREZ-MARTÍN, F.; CONFENTE, D.; GUERRA, I. (2010). Management of variable electricity loads in wind-hydrogen systems: the case of a Spanish wind farm. International Journal of Hydrogen Energy, 35(14), 7329-7336.

HAMACHER, T. (2016). Hydrogen as a Strategic Secondary Energy Carrier. In Hydrogen and Fuel Cell (pp. 1-20). Springer Berlin Heidelberg.

HENDERSON, R. Design, simulation and testing of a novel hydraulic power take-off system for the pelamis wave energy converter. Renewable Energy 31 (2), 271-83, 2006.

HOU, P.; ENEVOLDSEN, P.; EICHMAN, J.; HU, W.; JACOBSON, M. Z; CHEN, Z. (2017). Optimizing investments in coupled offshore 
wind-electrolytic hydrogen storage systems in Denmark. Journal of Power Sources, 359, 186-197.

IBRAHIM, H.; ILINCA, A.; PERRON, J. (2008). Energy storage systems-characteristics and comparisons. Renewable and sustainable energy reviews, 12(5), 1221-1250.

IGLESIAS, G.; LOPEZ, M.; CARBALLO, R.; CASTRO, A.; FRAGUELA, J. A.; FRIGAARD, P. (2009). Wave energy potential in Galicia (NW Spain). Renewable Energy, 34(11), 2323-2333.

JACOBSON, M. Z.; DELUCCHI, M. A. (2011). Providing all global energy with wind, water, and solar power, Part I: Technologies, energy resources, quantities and areas of infrastructure, and materials. Energy Policy, 39(3), 1154-1169.

JALIL, N.; KHEIR, N. A.; SALMAN, M. A rule-based energy management strategy for a series hybrid vehicle. In IEEE Proceedings of American Control Conference, June 1997. (Vol. 1, pp. 689-693).

KHO, E. T.; LOVELL, E.; WONG, R. J.; SCOTT, J.; AMAL, R. (2017). Manipulating ceria-titania binary oxide features and their impact as nickel catalyst supports for low temperature steam reforming of methane. Applied Catalysis A: General, 530, 111-124.

KIM, M.; KIM, J. (2017). An integrated decision support model for design and operation of a wind-based hydrogen supply system. International Journal of Hydrogen Energy, 42(7), 3899-3915.

KROPOSKI, B.; SEN, P. K.; HARRISON, K.; LEVENE, J.; NOVACHEK, F. (2006). Electrolysis: information and opportunities for electric power utilities. United States. Department of Energy.

KRUYT, B.; van VUUREN, D. P.; de VRIES, H .G. M.; GROENENBERG, H. (2009). Indicators for energy security. Energy Policy 37(6):2166-81.

LEE, J. H. (2011). Model predictive control: Review of the three decades of development. International Journal of Control, Automation and Systems, 9(3), 415. 
LEI, M.; SHIYAN, L.; CHUANWEN, J.; HONGLING, L.; YAN, Z. (2009). A review on the forecasting of wind speed and generated power. Renewable and Sustainable Energy Reviews, 13(4), 915-920.

LENEE-BLUHM, P.; PAASCH, R.; ÖZKAN-HALLER, H. T. (2011). Characterizing the wave energy resource of the US Pacific Northwest. Renewable Energy, 36(8), 2106-2119.

LEWIS, A.; ESTEFEN, S.; HUCKERBY, J.; MUSIAL, W.; PONTES, T.; TORRES-MARTINEZ, J. (2011). IPCC Special Report on Renewable Energy Sources and Climate Change Mitigation. Prepared by Working Group of the Intergovernmental Panel of Climate Change. Cambridge University Press, Cambridge and New York.

LI, D.; WANG, H. (2010). Recent developments in reverse osmosis desalination membranes. Journal of Materials Chemistry, 20(22), 45514566.

LIN, W. S.; ZHENG, C. H. (2011). Energy management of a fuel cell/ultracapacitor hybrid power system using an adaptive optimalcontrol method. Journal of Power Sources, 196(6), 3280-3289.

LIBERTI, L.; CARILLO, A.; SANNINO, G. (2013). Wave energy resource assessment in the Mediterranean, the Italian perspective. Renewable Energy, 50, 938-949.

MANSILlA, C.; LOUYRETTE, J.; ALBOU, S.; BOURASSEAU, C.; DAUTREMONT, S. (2013). Economic competitiveness of off-peak hydrogen production today-A European comparison. Energy, 55, 9961001.

MELANIA, M. W.; EICHMAN, J. (2015), Hydrogen Energy Storage: Grid and Transportation Services. National Renewable Energy Laboratory. Technical Report. NREL/TP-5400-62518

MELO, D. F. R.; CHANG-CHIEN, L. R. (2014). Synergistic control between hydrogen storage system and offshore wind farm for grid operation. IEEE Transactions on Sustainable Energy, 5(1), 18-27. 
MENDES, P. R.; ISORNA, L. V.; BORDONS, C.; NORMEY-RICO, J. E. (2016). Energy management of an experimental microgrid coupled to a V2G system. Journal of Power Sources, 327, 702-713.

MENDES, P. R. (2016b). "Predictive control for energy management of renewable energy based microgrids". Thesis presented at Federal University of Santa Catarina, Brazil.

MILEWSKI, J.; GUANDALINI, G.; CAMPANARI, S. (2014). Modeling an alkaline electrolysis cell through reduced-order and lossestimate approaches. Journal of Power Sources, 269, 203-211.

MILLET, P.; MBEMBA, N.; GRIGORIEV, S.; FATEEV, V.; AUKAULOO, A.; ETIÉVANT, C. (2011). Electrochemical performances of PEM water electrolysis cells and perspectives. International Journal Hydrogen Energy; 36:4134-4142.

MOMIRLAN, M.; VEZIROGLU, T. N.; (2005). The properties of hydrogen as fuel tomorrow in sustainable energy system for a cleaner planet. International Journal of Hydrogen Energy, 30(7), 795-802.

MORARI, M.; LEE, J. H. (1999). Model predictive control: past, present and future. Computers \& Chemical Engineering, 23(4), 667-682.

MORGAN, E. R.; MANWELL, J. F.; McGOWAN, J. G. (2013). Opportunities for economies of scale with alkaline electrolyzers. International Journal of Hydrogen Energy, 38(36), 15903-15909.

MUELLER-LANGER, F.; TZIMAS, E.; KALTSCHMITT, M.; PETEVES, S. (2007). Techno-economic assessment of hydrogen production for the hydrogen economy for the short and medium term. International Journal of Hydrogen Energy, 32(16), 3797-3810.

NANDOLA, N. N.; RIVERA, D. E. (2013). An improved formulation of hybrid model predictive control with application to productioninventory systems. IEEE Transactions on Control Systems Technology, 21(1), 121-135.

NG, C.; RAN, L. (2016). Offshore wind farms: technologies, design and operation. Woodhead Publishing, Print. 
NGUYEN, T.V. (1993). A water and heat management model for proton-exchange-membrane fuel cells. Journal of Electrochemical Society, 140(8):2178-2186.

NI, M.; LEUNG, D. Y.; LEUNG, M. K.; SUMATHY, K. (2006). An overview of hydrogen production from biomass. Fuel processing technology, 87(5), 461-472.

OPPENHEIMER, M.; ANTTILA-HUGHES, J. K. (2016). The Science of Climate Change. The Future of Children, 26(1), 11-30.

OROPEZA, L. A. F. (2004). "Estudio y análisis de soluciones topológicas de convertidores CC-CC bidireccionales para su aplicación en vehículos híbridos". Thesis presented at Universidad Politécnica de Madrid, Spain.

OSTERWALDER, A.; PIGNEUR, Y. (2010). Business model generation: a handbook for visionaries, game changers, and challengers. John Wiley \& Sons.

OSTERWALDER, A. (2004). The business model ontology: A proposition in a design science approach.

PALMA-BEHNKE, R.; BENAVIDES, C.; LANAS, F.; SEVERINO, B.; REYES, L., LLANOS, J.; SAEZ, D. (2013). A microgrid energy management system based on the Rolling horizon strategy. IEEE Transactions on Smart Grid, 4(2), 996-1006.

PANWAR, N. L.; KAUSHIK, S. C.; KOTHARI, S. (2011). Role of renewable energy sources in environmental protection: a review. Renewable and Sustainable Energy Reviews, 15(3), 1513-1524.

PARASCHIV, B.; BAIESU, A.; STAMATESCU, G. (2009). Using an advanced control technique for controlling a distillation column. In IEEE Proceedings of Control and Automation, September 2009. (Vol. 1, pp. 581-584).

PARIS, B.; EYNARD, J.; GRIEU, S.; TALBERT, T.; POLIT, M. (2010). Heating control schemes for energy management in buildings. Energy and Buildings, 42(10), 1908-1917. 
PATTERSON, M.; MACIA, N. F.; KANNAN, A. M.; (2015). Hybrid microgrid model based on solar photovoltaic battery fuel cell system for intermittent load applications. IEEE Transactions on Energy Conversion, 30(1), 359-366.

PEPERMANS, G.; DRIESEN, J.; HAESELDONCKX, D.; BELMANS, R.; D'HAESELEER, W. (2005). Distributed generation: definition, benefits and issues. Energy policy, 33(6), 787-798.

PÉREZ-COLLAZO, C.; GREAVES, D.; IGLESIAS, G. (2015). A review of combined wave and offshore wind energy. Renewable and Sustainable Energy Reviews, 42, 141-153.

PETERSEN, H. N. (2012). Note on the targeted hydrogen quality produced from electrolyser units. Review of the Department of Energy Conversion and Storage, Technical University of Denmark.

PLUCENIO, A. (2010). "Desenvolvimento de técnicas de controle não linear para elevação de fluidos multifásicos". Thesis presented at Federal University of Santa Catarina, Brazil.

POST, J.W.; VEERMAN, J.; HAMELERS, H- V.M.; EUVERINK, GJ.W.; METZB, S.J.; NTMEIJERC, K.; BUISMAN, J.N.C. (2007). Salinity-gradient power: Evaluation of pressure-retarded osmosis and reverse electrodialysis. Journal of Membrane Science 288:218-30.

QUADRELLI. R.; PETERSON, S. (2007). The energy-climate challenge: recent trends in $\mathrm{CO} 2$ emissions from fuel combustion. Energy policy, 35(11), 5938-5952.

RAJANI, S. V.; PANDYA, V. J.; SHAH, V. A. (2016). Experimental validation of the ultracapacitor parameters using the method of averaging for photovoltaic applications. Journal of Energy Storage, 5, 120-126.

RASHID, M. M.; Al MESFER, M. K.; NASEEM, H.; DANISH, M. (2015). Hydrogen production by water electrolysis: a review of alkaline water electrolysis, PEM water electrolysis and high temperature water electrolysis. Int J Eng Adv Technol, 4(3), 80-93. 
REITER, G. (2016). Power-to-Gas. Fuel Cells: Data, Facts, and Figures.

RINGWOOD, J. V.; BACELLI, G.; FUSCO, F. (2014). Energymaximizing control of wave-energy converters: The development of control system technology to optimize their operation. IEEE Control Systems, 34(5), 30-55.

ROC, T.; BAWN, G.; MONFORT, E.; VIDAL, J. (2014). H2OCEAN 3.2 Database of resources conditions. WP3 Deliverable 3.2. H2OCEAN project, 1-16.

http://h2oceanproject.eu/_content/dissemination/attachments/H2Ocean \%20D3.2\%20Database\%20of\%20Resource\%20Conditions_v3.0.pdf

RODRIGUEZ, J.; KAZMIERKOWSKI, M. P.; ESPINOZA, J. R.; ZANCHETTA, P.; ABU-RUB, H., YOUNG, H. A.; ROJAS, C. A. (2013). State of the art of finite control set model predictive control in power electronics. IEEE Transactions on Industrial Informatics, 9(2), 1003-1016.

ROSER, M. (2016) - 'Energy Production \& Changing Energy Sources'. Published online at OurWorldInData.org. Retrieved from: https://ourworldindata.org/energy-production-and-changing-energysources/ [Online Resource]

ROZAIN, C.; MAYOUSSE, E.; GUILLET, N.; MILLET, P. (2016). Influence of iridium oxide loadings on the performance of PEM water electrolysis cells: Part I-Pure IrO 2-based anodes. Applied Catalysis B: Environmental, 182, 153-160.

RUDDY, J.; MEERE, R.; O’DONNELL, T. (2016). Low Frequency AC transmission for offshore wind power: A review. Renewable and Sustainable Energy Reviews, 56, 75-86.

RUELLAN, M.; Ben AHMED, H.; MULTON, B.; JOSSET, C.; BABARIT A.; CLÉMENT A.H. (2010). Design methodology for a SEAREV wave energy converter. IEEE Transactions on Energy Conversion 25 (3), 760-7.

SCHILlER, G.; ANSAR, A.; LANG, M.; PATZ, O. (2009). High temperature water electrolysis using metal supported solid oxide 
electrolyser cells (SOEC). Journal of Applied Electrochemistry, 39(2), 293-301.

SCHOENUNG. S. M; KELLER, J. O. (2017). Commercial potential for reneable hydrogen in California. International Journal of Hydrogen Energy, 42 (19), 13321-13328.

SERNA, A.; YAHYAOUI, I.; NORMEY-RICO, J. E.; DE PRADA, C.; TADEO, F. (2017). Predictive control for hydrogen production by electrolysis in an offshore platform using renewable energies. International Journal of Hydrogen Energy, 42(17), 12865-12876.

SERNA, A.; TADEO, F.; TORRIJOS, D. (2015). Ruled-based control of off-grid desalination powered by renewable energies. Renewable Energy and Sustainable Development, 1(1), 205-213.

SERNA, A.; TADEO, F. (2014). Offshore hydrogen production from wave energy. International Journal of Hydrogen Energy, 39(3), 15491557.

SERNA, A.; TADEO, F. (2013). Offshore desalination using wave energy. Advances in Mechanical Engineering, 5, 539857.

SHAFIEI, E.; DAVIDSDOTTIR, B.; LEAVER, J.; STEFANSSON, H.; ASGEIRSSON, E. I. (2017). Energy, economic, and mitigation cost implications of transition toward a carbon-neutral transport sector: A simulation-based comparison between hydrogen and electricity, Journal of Cleaner Production, 141, 237-247.

SHIKA, G.; RAMADASS, P.; HARAN, B. S.; WHITE, R. E.; POPOV, B. N. (2003). Comparison of the capacity fade of Sony US 18650 cells charged with different protocols. Journal of Power Sources, 122(1), 6776.

SHOKO, E.; McLELLAN, B.; DICKS, A. L.; Da COSTA, J. D. (2006). Hydrogen from coal: production and utilisation technologies. International Journal of Coal Geology, 65(3), 213-222.

SIRNIVAS, S.; YU, Y. H.; HALL, M.; BOSMA, B. (2016, June). Coupled Mooring Analyses for the WEC-Sim Wave Energy Converter Design Tool. In ASME 2016 35th International Conference on Ocean, 
Offshore and Arctic Engineering (pp. V006T09A023-V006T09A023). American Society of Mechanical Engineers.

SUBRAMANI, A.; BASILE, A.; VEZIROGLU, T. N. (2016). Compendium of Hydrogen Energy. Volume 1: Hydrogen Production and Purification. Woodhead Publishing, Print.

SUBRAMANI, A.; JACANGELO, J. G. (2014). Treatment technologies for reverse osmosis concentrate volume minimization: a review. Separation and Purification Technology, 122, 472-489.

SULAIMAN, N.; HANNAN, M. A.; MOHAMED, A.; MAJLAN, E. H.; DAUD, W. W. (2015). A review on energy management system for fuel cell hybrid electric vehicle: Issues and challenges. Renewable and Sustainable Energy Reviews, 52, 802-814.

SZYMBORSKI, J. (2002). Lead-acid batteries for use in submarine applications. In Proceedings of the IEEE Autonomous Underwater Vehicles, Workshop 2002 on (pp. 11-17).

THORPE, T.W. (1999). A Brief Review of Wave Energy. A report produced for the UK Department of Trade and Industry, ETSUR120:24-25. Harwell, UK.

TORRIJOS, D. (2012). Sea water treatment reverse osmosis. Report in WP5 of H2OCEAN project, Ref No 3099. pp 1-19.

TOUATI, K. (2015). "Energy generation and recovery by Pressure Retarded Osmosis (PRO): Modelling and experiments". Thesis presented at University of Valladolid, Spain.

TSUBOI, Y.; ITO, S.; TAKAFUJI, M.; OHARA, H.; FUJIMORI, T. (2017). Development of a regenerative reformer for tar-free syngas production in a steam gasification process. Applied Energy, 185, 12171224.

ULLEBERG, Ø.; (2004). The importance of control strategies in PVhydrogen systems. Solar energy, 76(1), 323-329.

VAHIDI, A.; GREENWELL, W. (2007). A decentralized model predictive control approach to power management of a fuel cell- 
ultracapacitor hybrid. In IEEE Proceedings of American Control Conference ACC'07, July 2007. (pp. 5431-5437).

VALVERDE, L.; PINO, F. J.; GUERRA, J.; ROSA, F. (2016). Definition, analysis and experimental investigation of operation modes in hydrogen-renewable-based power plants incorporating hybrid energy storage. Energy Conversion and Management, 113, 290-311.

VARKARAKI, E.; LYMBEROPOULOS, N.; ZOULIAS, E.; GUICHARDOT, D.; POLI, G. (2007). Hydrogen-based uninterruptible power supply. International Journal of Hydrogen Energy, 32(10), 15891596.

VAZQUEZ, S.; LEON, J. I.; FRANQUELO, L. G.; RODRIGUEZ, J.; YOUNG, H. A.; MARQUEZ, A.; ZANCHETTA, P. (2014). Model predictive control: A review of its applications in power electronics. IEEE Industrial Electronics Magazine, 8(1), 16-31.

VERGRAGT, P. J.; BROWN, H. S. (2007). Sustainable mobility: from technological innovation to societal learning. Journal of Cleaner Production, 15(11), 1104-1115.

WANG, C.; YANG, X.; WU, Z.; CHE, Y.; GUO, L.; ZHANG, S.; LIU, Y. (2016). A highly integrated and reconfigurable microgrid tested with hybrid distributed energy sources. IEEE Transactions on Smart Grid, 7(1), 451-459.

WONG, M. C.; MARTINEZ, K.; RAMON, G. Z.; HOEK, E. M. (2012). Impacts of operating conditions and solution chemistry on osmotic membrane structure and performance. Desalination, 287, 340-349.

XIANG, C.; PAPADANTONAKIS, K. M.; LEWIS, N. S. (2016). Principles and implementations of electrolysis systems for water splitting. Materials Horizons, 3(3), 169-173.

YAHYAOUI, I. (2015). "Sizing and energy management for photovoltaic pumping". Thesis presented at University of Valladolid, Spain.

YAHYAOUI, I.; SALLEM, S.; KAMOUN, M. B. A.; TADEO, F. (2014). A proposal for off-grid photovoltaic systems with non- 
controllable loads using fuzzy logic. Energy Conversion and Management, 78, 835-842.

YELCHURU, R.; SKOGERSTAD, S.; MANUM, H. (2010). MIQP formulation for controlled variable selection in self optimization control. In IFAC Proceedings Volumes. 43(5), 61-66.

ZHOU, T.; FRANCOIS, B. (2009). Modeling and control design of hydrogen production process for an active hydrogen/wind power system. International Journal of Hydrogen Energy, 34(1), 21-30.

ZURKINDEN, A. S.; FERRI, F.; BEATTY, S.; KOFOED, J. P.; KRAMER, M. M. (2014). Non-linear numerical modeling and experimental testing of a point absorber wave energy converter. Ocean Engineering, 78, 11-21. 
ANNEX 


\section{ANNEX}

An economic study is developed here for a marketable hydrogenbased micro-grid powered by a mix of renewable energies shown in Chapter 5. This micro-grid was designed to be installed in an isolated location. It produces hydrogen which can then be consumed in a fuel cell when energy is required or used in a fuel cell electric vehicle (FCEV). An advanced control system based on Model Predictive Control was developed in Chapter 5, which provides an optimal control strategy to decide the electrolyzer's operating point, taking into account the availability of power and the state of the plant.

The economic study is divided into three sections: first, a brief introduction of the marketing of hydrogen-based microgrids is given. Then an evaluation of the components of the Business Model Canvas (BMC) is done for the case of this marketable microgrid. Finally, a business plan is done to summarize the economic study of the microgrid and the possibilities of marketing it. This annex ends with some conclusions.

\section{MARKETING OF HYDROGEN-BASED MICROGRIDS}

The modern concept of microgrid is highly promising as a solution to the problem due to the future scarcity of fossil fuels in conventional power generation. It is also effective against environmental impacts of existing generating systems (BASAK et al. 2012). Among the possible energy storage systems, those based on hydrogen production by electrolysis and subsequent utilization in fuel cells offer an attractive alternative to conventional systems (water pumping, compressed air, batteries, etc. (VALVERDE et al. 2016)).

The use of hydrogen energy storage systems for grid support can be more accurately conceptualized as enabling the appropriate allocation of electrical resources to high-end markets, while improving overall system sustainability and resiliency and lowering supply costs. Electrolysis units can provide ancillary grid services (PEPERMANS et al. 2015); renewable hydrogen can be stored and it can be used in multiple transportation and industrial end-use markets. When hydrogen is supplied to zero-emission fuel cell electric vehicles (FCEVs), the resulting revenue is higher than that from supplying grid electricity 
because of the higher market price per unit of energy for transportation fuels (MELANIA; EICHMAN, 2015).

The proposal presented here consists in the evaluation of the possible commercialization of a hydrogen based microgrid, (as depicted in Figure 5.5). For the case of the one proposed in Figure 5.5, the energy sources were wind and wave. They are renewable and can easily be obtained in coastal locations (BAHAJ, 2011). The electricity produced is sent to a set of electrolyzers that transform water $\left(\mathrm{H}_{2} \mathrm{O}\right)$ into hydrogen $\left(\mathrm{H}_{2}\right)$.

Moreover, for certain times when available renewable power is not enough to operate the electrolyzers, a battery and an ultracapacitor are included to supply energy to the electrolyzers.

Finally, the hydrogen produced can be given to users to be used as input in fuel cells or for different needs (BARRETO et al. 2003).

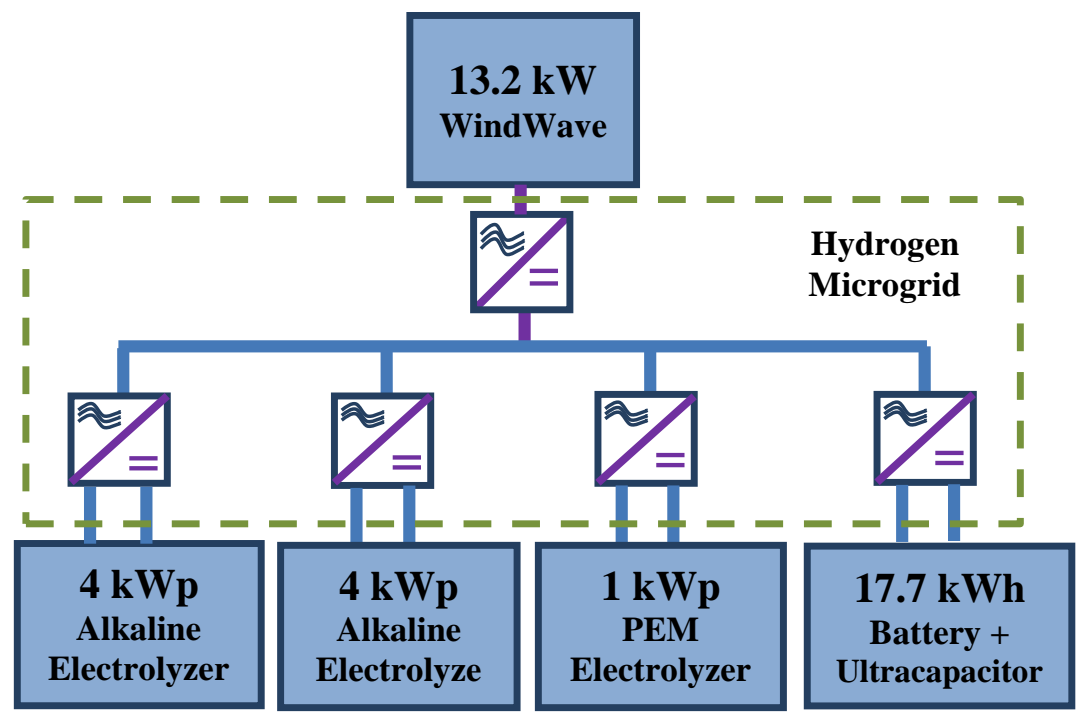

Figure 5.5 - Hydrogen-based microgrid proposed in this case study

In this annex, the commercialization possibility of the control system designed in Chapter 5 for the hydrogen-based microgrid is considered. The goal is to create a company and design a business plan for it. The proposed company would have the sale of the hydrogenbased microgrid controllers as its business model. The name of the proposed company is HyRenCon (Hydrogen Renewable Control). 


\section{BUSINESS MODEL CANVAS}

The purpose of this section is the evaluation of the Business Model Canvas (BMC) in the case of marketing this smart micro-grid. This BMC reflects systematically on the business model and comprises different aspects, such as selecting the key partners, the key activities, the value proposition, the customer relationship, the customer segment, the key resource, the distribution channel, the cost structure and the revenue stream.

The Business Model Canvas is a strategic management and lean start-up template for developing new or documenting existing business models (BARQUET et al. 2011). It is a visual chart with elements describing a firm or product's value proposition, infrastructure, customers, and finances (OSTERWALDER; PIGNEUR, 2010). It assists firms in aligning their activities by illustrating potential tradeoffs. The Business Model Canvas was initially proposed by Alexander Osterwalder, based on his earlier book on Business Model Ontology. Since the release of Osterwalder's work in 2008, new canvases for specific niches have appeared.

Formal descriptions of the business become the building blocks for its activities. Many different business conceptualizations exist; Osterwalder's work and thesis (OSTERWALDER, 2004) propose a single reference model based on the similarities of a wide range of business model conceptualizations. With his business model design template, an enterprise can easily describe the business model.

The components of a canvas assessment for the proposed HyRenCon company are as follows:

- Offering:

1) Value Propositions: These are the collection of products and services a business offers to meet the needs of its customers. According to Osterwalder (OSTERWALDER, 2004), a company's value proposition is what distinguishes it from its competitors. The value proposition provides value through various elements such as newness, performance, customization, "getting the job done", design, brand/status, price, cost reduction, risk reduction, accessibility and convenience/usability. The value propositions of HyRenCon are the design of a controller of a hydrogen-based 
microgrid, which improves equipment life by up to $30 \%$. This type of microgrid allows energy self-sufficiency without dependence on connections and disconnections to the electricity grid or from diesel or other fuels, since it works with renewable energies. Moreover, it is adaptable to many types of renewable energies (wind, solar, marine...).

- Customers:

2) Customers Segments: To build an effective business model, a company must identify which customers it tries to serve. Various sets of customers can be segmented based on the different needs and attributes to ensure the appropriate implementation of corporate strategy that meets the characteristics of the selected group of clients. In the case of HyRenCon, the customers can be companies that manufacture electrolyzers or fuel cells, R\&D companies, universities and technology centres. Examples of these customers can be: Abengoa, Tecnalia, Ariema, Repsol, Iberdrola, Panasonic, Vaillant, Viessmann, Elcore, etc. 99\% of the market is outside Spain, especially in countries such as the USA, Japan, Sweden, Denmark or Germany.

3) Channels: A company can deliver its value proposition to its targeted customers through different channels. Effective channels will distribute a company's value proposition in ways that are fast, efficient and cost effective. The channels of our proposal can be fairs (Construmat, Expoquimia, WHEC...), business visits and public announcements (H2020).

4) Customer Relationships. To ensure the survival and success of any business, companies must identify the type of relationship they want to create with their customer segments. The relationship between HyRenCon and its customers can be personal assistance (assistance in a form of employee-customer interaction) via Skype in order to check the controller for a certain period of time (initially 3 months). 
- Infrastructure:

5) Key Activities: These are the most important activities in executing a company`s value proposition. In the case of HyRenCon, it would be the recruitment of a technician, hiring a courier company, the coupling of the meteorological predictions with the PLC and contact with customers via Skype, phone, etc.

6) Key Resources: These are the resources needed to create value for the costumer. They are considered an asset to a company, as they are needed to sustain and support the business. In the case of HyRenCon, they are the control algorithm patent and human resources such as PLC programming.

7) Partner Network: In order to optimize operations and reduce the risks of a business model, organizations usually cultivate buyersupplier relationships so they can focus on their core activity. In the case of HyRenCon, these partners could be the University of Valladolid, the $\mathrm{CNH} 2$, or Technological centres such as CARTIF or CIDAUT. The controller can be tested and checked in these institutions, which receive feedback and apply the knowledge.

- Finances

8) Cost Structure: This section describes the most important monetary consequences while operating under different business models. The expenses of HyRenCon are mainly the purchase of PLCs, the staff (technical installer), the local rent, web domain, packaging, transportation and shipping.

- Characteristics of Cost Structures: Fixed Costs (costs are unchanged across different applications), Variable Costs (depending on the amount of production of goods or services), Economy of Scale (costs go down as the amount of goods are ordered or produced) and Economies of Scope (Costs go down due to incorporating other businesses which have a direct relation to the original product). HyRenCon follows a type of economy of Scope. A study of the costs is developed in the Business Plan. 
9) Revenue Streams: This is the way a company makes income from the customers. In the case of HyRenCon, the way to generate a revenue stream is to sell assets, which is the most common way (selling ownership rights to a physical good). HyRenCon sells controllers programmed and installed in a PLC. After-sales service and patent income would also be considered.

A visual chart with the elements described in the canvas is depicted on the next page: 


\section{HYRENCON BUSINESS PLAN}

\section{Project identification}

Description of the idea and value proposition

HyRenCon proposes the commercialization of an advanced controller for an autonomous energy system based on an electrolyzer and fuel cell. It makes the life of the components last up to $30 \%$ more, being a completely innovative product.

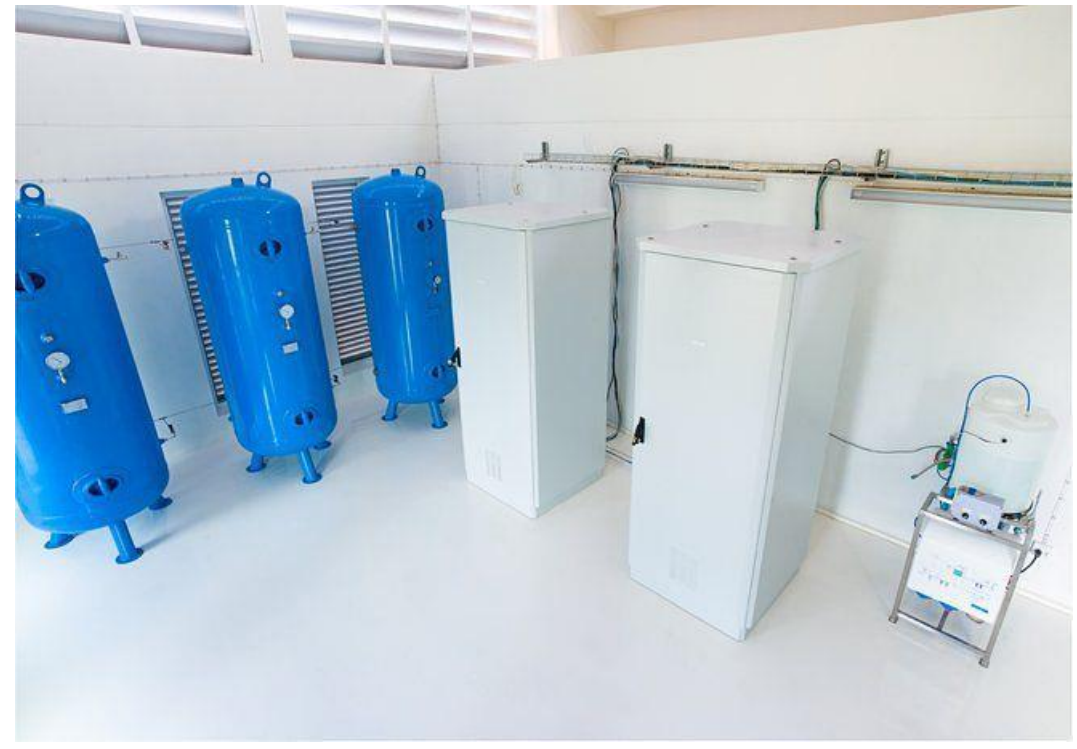

Figure A.1 - Example of a hydrogen-based microgrid (https://www.curbed.com/2016/1/22/10844376/solar-powered-hydrogen-homethailand)

This microgrid allows energy self-sufficiency without relying on electrical connections, diesel or other fossil fuels as the energy comes from renewable sources. Moreover, the controller can be adapted to any type of renewable energy, whether wind, hydraulic, solar, marine...

Figure A.2 shows a smart house powered by renewable energies and a hydrogen-based microgrid, located in the $\mathrm{CNH} 2$ in Puertollano, Spain. 


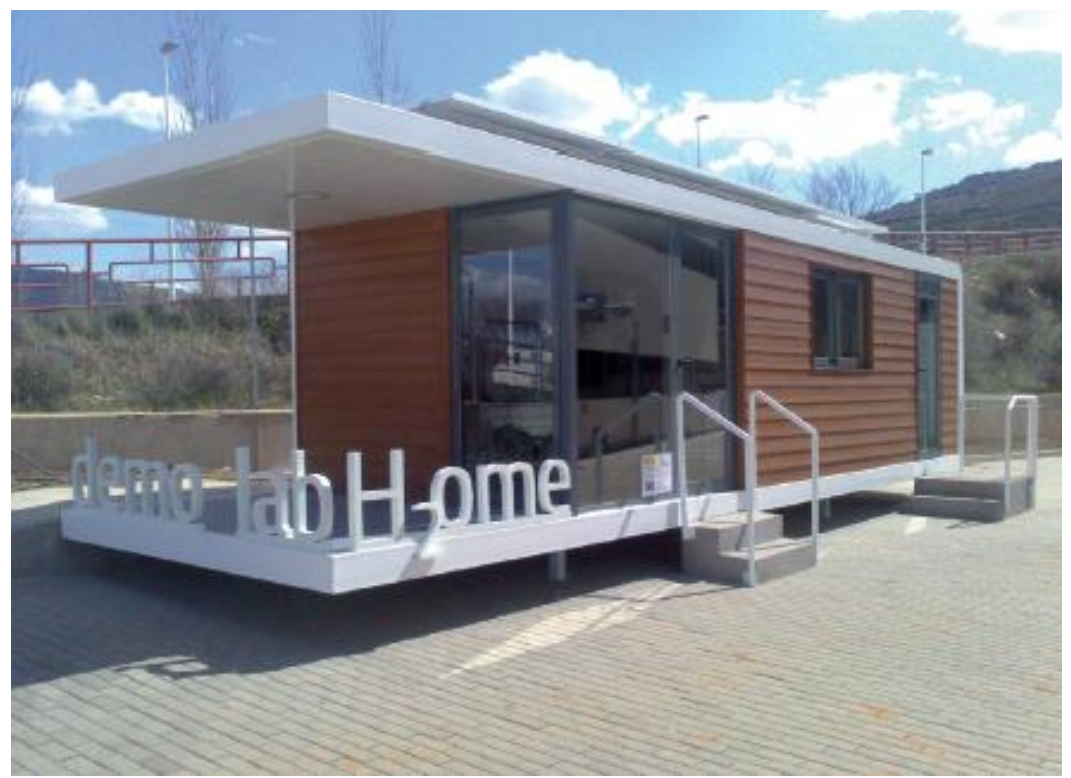

Figure A.2 - Smart house powered by renewable energies and a hydrogenbased microgrid in the $\mathrm{CNH} 2$, Spain.

Description of the business model

The business model of HyRenCon is based on selling advanced controllers for hydrogen-based microgrids. These controllers are programmed in a PLC which is coupled to the microgrid. The revenues are generated by the sales of the PLCs. In addition, there is an intellectual property registry on the design of the software algorithm of the controller (see Section 2.5.4).

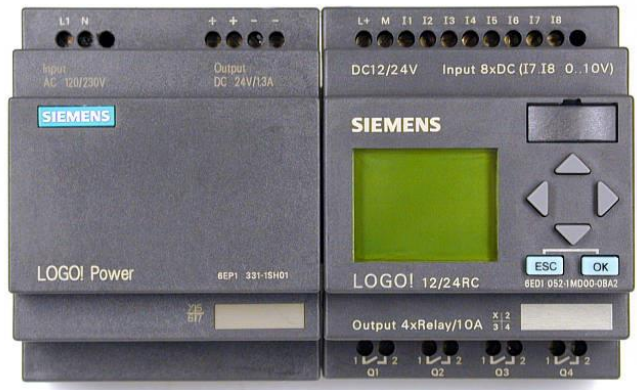

Figure A.3 - Example of a Siemens PLC controller 
The possible customers are the companies that manufacture and produce the components of the hydrogen-based microgrid (electrolyzer and fuel cell). In addition, potential clients may be technology centres, energy companies and academic institutions such as universities and institutes. The market is currently $99 \%$ outside Spain: Europe, the USA, Japan, Canada, Australia, Israel, etc. Some of these companies are depicted in Figure A.4:

Figure A.4 - Possible customers of HyRenCon

\section{Description of the promoting team}

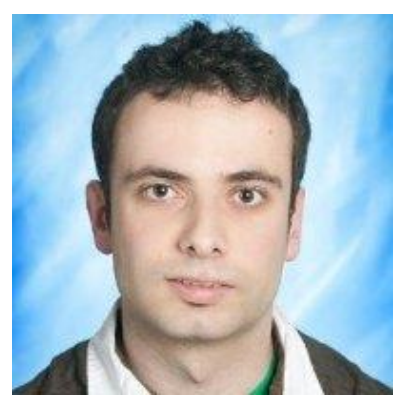

\section{Álvaro Serna Cantero}

Chemical Engineer and Master in Research in Processes and Systems from the University of Valladolid. PhD candidate in Industrial Engineering with the thesis titled "Control systems of hydrogen production by renewable energies". He has experience in modelling, simulation and control of hydrogen microgrids and renewable energies such as wind and marine. He holds business finance studies by the Yuzz Entrepreneurship Course of the Banco Santander. 


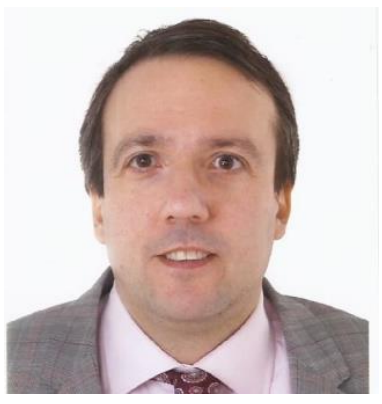

Fernando Tadeo Rico

Degree in Physics and Doctor of Electronic Engineering from the University of Valladolid. He has extensive experience in the field of electronics, control and modeling and optimization of processes. He has participated in regional, national and European projects, obtaining success in calls such as FP7 or H2020. He is currently a professor of the department of systems engineering and automatic by the University of Valladolid. He has directed several doctoral theses in the control of renewable energies and reverse osmosis.

\section{Julio Elías Normey-Rico}

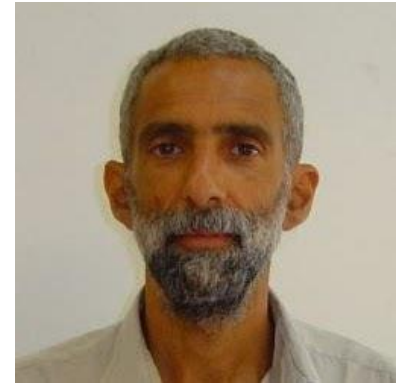

Electronic Engineer from the National University of La Plata in Argentina, Master in Electrical Engineering from the Federal University of Santa Catarina in Brazil and $\mathrm{PhD}$ in Automatic and Electronic Robotics from the University of Seville in Spain. He has experience in the use and integration of renewable energies for chemical processes. He has published several books on the subject, combining it with his teaching work at the Federal University of Santa Catarina in Brazil. He has directed research projects with energy companies, among which Petrobras stands out among others in Latin America.

The idea of HyRenCon is to set up a company to implement controllers in marketable hydrogen-based microgrids. There is a great potential in the use of hydrogen as an energy vector (there are already prototypes of hydrogen-based microgrids implemented in houses). On the other hand, there are still no marketable controllers for the components of this type of microgrid, so it is considered that there is a market available, as these components are highly expensive. This 
controller can extend the life of the microgrid components by up to $30 \%$.

\section{Marketing plan}

\section{Market description}

The value proposition would consist of the sales of an advanced controller programmed in a PLC that manages the connections and disconnections of the components of the hydrogen-based microgrid, taking into account meteorological predictions and the control algorithm developed in Chapter 5. These predictions give the amount of green energy predicted in advance that can be supplied to the hydrogen-based microgrid.

This product would be sold to the possible customers that manufacture the components of the hydrogen-based microgrid (some have been detailed in the description of the business model). The components of the microgrid currently cost around 2,000 $\$ / \mathrm{kW}$ (SCHOENUNG, KELLER, 2017). The final user would be energy selfsupplied by installing this type of microgrid at home; therefore, it would not be necessary to be connected to the electricity grid. The costs of the electrolyzers and fuel cells are expected to decrease over the years (DOS SANTOS et al. 2017).

\section{$\underline{\text { Hydrogen market situation }}$}

Hydrogen is considered the main energy vector in the future. The principal reason is because it constitutes $75 \%$ of the visible matter of the universe (MOMIRLAN; VEZIROGLU, 2005), and most of all because it depends on clean and sustainable energy consumption. It can also be used in fuel cell electric vehicles which are already marketable (Toyota Mirai, BMW i8, etc).

One of the main problems of this type of clean technologies is that if the demand is low, the electrical surplus is lost as there are no real solutions to storing this energy. There are three main options to store the energy: water elevation, air compression, and chemical storage such as hydrogen and methane. Hydrogen is considered the best option when energy requirements are high (IBRAHIM et al. 2008).

Nowadays, many industries produce hydrogen, especially petrochemicals and refineries, but these types of technologies are not green and they emit greenhouse gases such as $\mathrm{CO}_{2}, \mathrm{SO}_{2}$ or $\mathrm{NO}_{2}$. The 
problem is due to the steam reforming process (see Section 2.3.1.1). Thus, the hydrogen produced by these techniques may contain impurities. Therefore, electrolysis has been chosen as the technology to produce hydrogen in a sustainable way. Hydrogen has different commercial uses. In this business plan, we focus on the use of hydrogen in a fuel cell to supply energy requirements in an isolated house.

There are two main customer markets for hydrogen production: one is renewable energy plants and the other is fuel cell electric vehicles. Hydrogen with pure hydrogen is required to minimize the risk of explosion (see Section 2.3). Hydrogen produced by renewable energies fits perfectly with the industry's effort to reduce greenhouse gas emissions. There is a tendency in Europe that focuses on the research and development of the electric vehicle, whereas in Asia there is more interest in the hydrogen car. Batteries of electric cars take a long time to charge and their autonomy is not very high. On the other hand, the operation of hydrogen cars is equal to a gasoline or diesel car (SULAIMAN ET AL. 2015).

\section{Internal analysis of HyRenCon}

The idea of designing an advanced control in a hydrogen-based micro-grid began in 2013. Over the years, the original microgrid developed in the H2OCEAN project changed into a domestic device because it was considered that an autonomous microgrid supplied by renewable energies could be useful at a household level with the aim that any final user could self-supply with clean energy.

A draft version of the control algorithm was registered on the intellectual property registration in 2013 as the author of this thesis won a prize from the University of Valladolid (see Section 2.5.4). Much great research work is being done on the validation and analysis of the control algorithms, shown in many scientific contributions (see Sections 2.5.1 and 2.5.2). In addition, the functionality of the controller has been checked in the microgrid laboratory at the National Hydrogen Center $(\mathrm{CNH} 2)$ in Puertollano, Spain.

On the other hand, there are several handicaps that HyRenCon must confront. The most important is a lack of its own resources to be financed. Another handicap is the limited financial knowledge that the promoter team has and the uncertainty of the hydrogen-based economy in the long term. Many studies say that 2050 is considered as the date in 
which hydrogen will be used mostly in the world instead of fossil fuels, but they are still hypotheses (SHAFIEI et al. 2017).

\section{$\underline{\text { SWOT analysis }}$}

SWOT analysis is a structured planning method that evaluates some elements for an organization, project or business venture (CHEN et al. 2014). It is the acronym of strengths, weaknesses, opportunities, and threats. The SWOT analysis for the case of HyRenCon is as follows:

$>$ Strengths

High theoretical and technical knowledge. Experience of the hydrogen sector (especially national as the promoter team of HyRenCon has participated in congresses, meetings and fairs with related companies in the sector).

$>$ Weaknesses

Lack of initial resources (economic, logistic, etc). Difficulties to contact with companies that may be interested in the product as they are located mostly outside Spain and the way they work. Lack of contacts with these companies.

$>$ Opportunities

Although there is some uncertainty about the future of the hydrogen economy, we have studied its evolution over the last few years and it has been proven to be a promising market, especially in Scandinavian countries, Japan and the USA. Local governments are motivated from the European Union to restrict fossil fuels in the coming years (regulating the circulation of fossil fuel cars in cities such as Madrid, Paris or London).

\section{$>$ Threats}

The main problem could be the lack of costumers due to the fact that hydrogen-based microgrids are not common in the short and medium term. In addition, the possible customers could develop analogous controllers in their own R\&D departments, or they could 
be interested in the proposal of HyRenCon and integrate it into their manufacturing process.

$\underline{\text { Goals }}$

The main objective of HyRenCon is to be a leading company in the control of hydrogen-based microgrids. For this, the promoter team has extensive theoretical knowledge and has been working to complete this thesis manuscript which deals with the design of the advanced control system. In addition, the controller has been tested in a microgrid laboratory (CNH2 in Spain).

\section{Operational marketing plan}

The company will create a website in which the products and services that will be provided by HyRenCon will be described, as well as the email addresses of each of the members of the promoting team to solve any doubt or request.

As it is an innovative product, the controller will be shown in international congresses and industry-specific fairs such as the World Hydrogen Energy Congress (where the theoretical algorithm was presented in 2016) or in national congresses with the support of $\mathrm{AeH} 2$ (Spain's Hydrogen Association).

Most of the possible customers are companies/technological centers/research institutions located outside Spain, so the whole marketing strategy (website, demo videos, portfolio, etc) will be developed in English.

\section{HyRenCon description}

HyRenCon is a company that designs advanced controllers to be installed in a PLC to optimize the connections and disconnections of a hydrogen-based microgrid. These components are specified in Figure A.5.

The energy which supplies the house comes from renewable sources (sun, water, wind...). This energy is used to split the atoms of water (hydrogen and oxygen). Hydrogen has a high calorific value, so it can be stored in liquid form at high pressure. When energy is required in the house (e.g. for cooking, heating the water, turning on the lights, etc), 
this hydrogen will be used by a hydrogen cell which provides clean energy as it does not emit greenhouse gases (the only residue it emits is water).

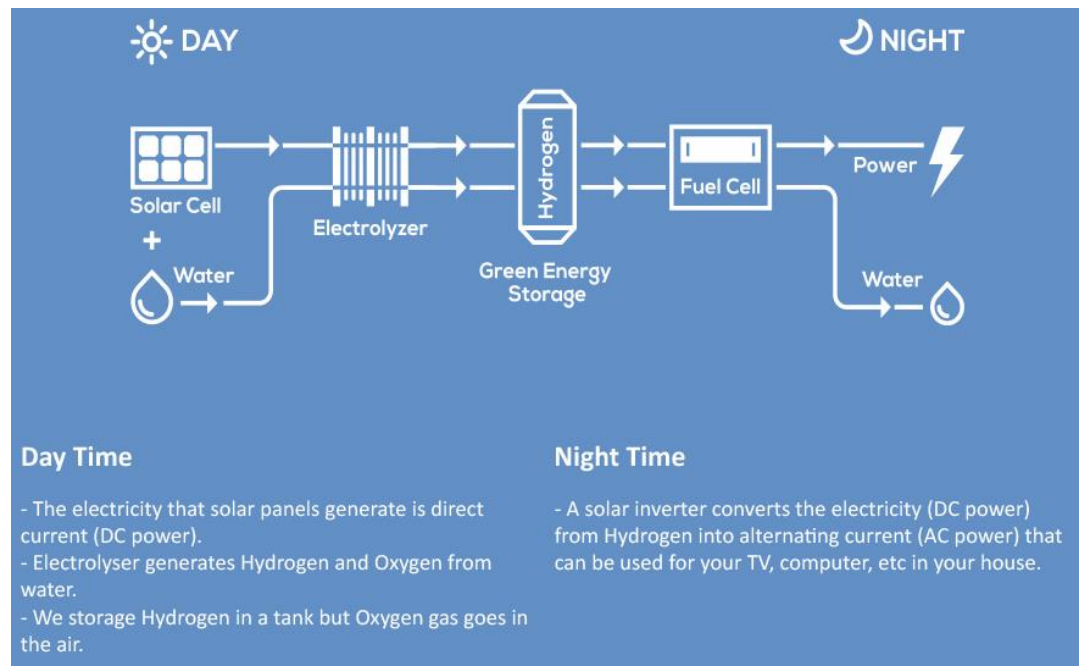

Figure A.5 - Scheme of a hydrogen-based microgrid for the case of the Phi Suea House in Thailand (http://www.phisueahouse.com/technology.php)

HyRenCon would sell the controller of this type of microgrid; more specifically, it regulates the connections and disconnections of the electrolyzer and the fuel cell that provides electricity to the house. The value proposition is based on a control algorithm that uses meteorological predictions. This algorithm manages the operation of the microgrid (when renewable energy is available, the components of the microgrid will be connected in advance). This means that the controller can extend the life of the microgrid components by up to $30 \%$.

The control algorithm would be programmed in industrial PLCs. The cables that link the PLC controller to the microgrid would also be supplied. A PLC has been chosen as the controller as it is the most common industrial controller and because it is easy to adapt and to program in any system.

The use of hydrogen-based microgrids produces benefits for the environment as they do not emit greenhouse gases and they are fully compatible with the environment, so their implementation is ideal in 
certain locations such as houses in the mountains, on or near the coast, as the installation of the connection to the electricity grid is not necessary.

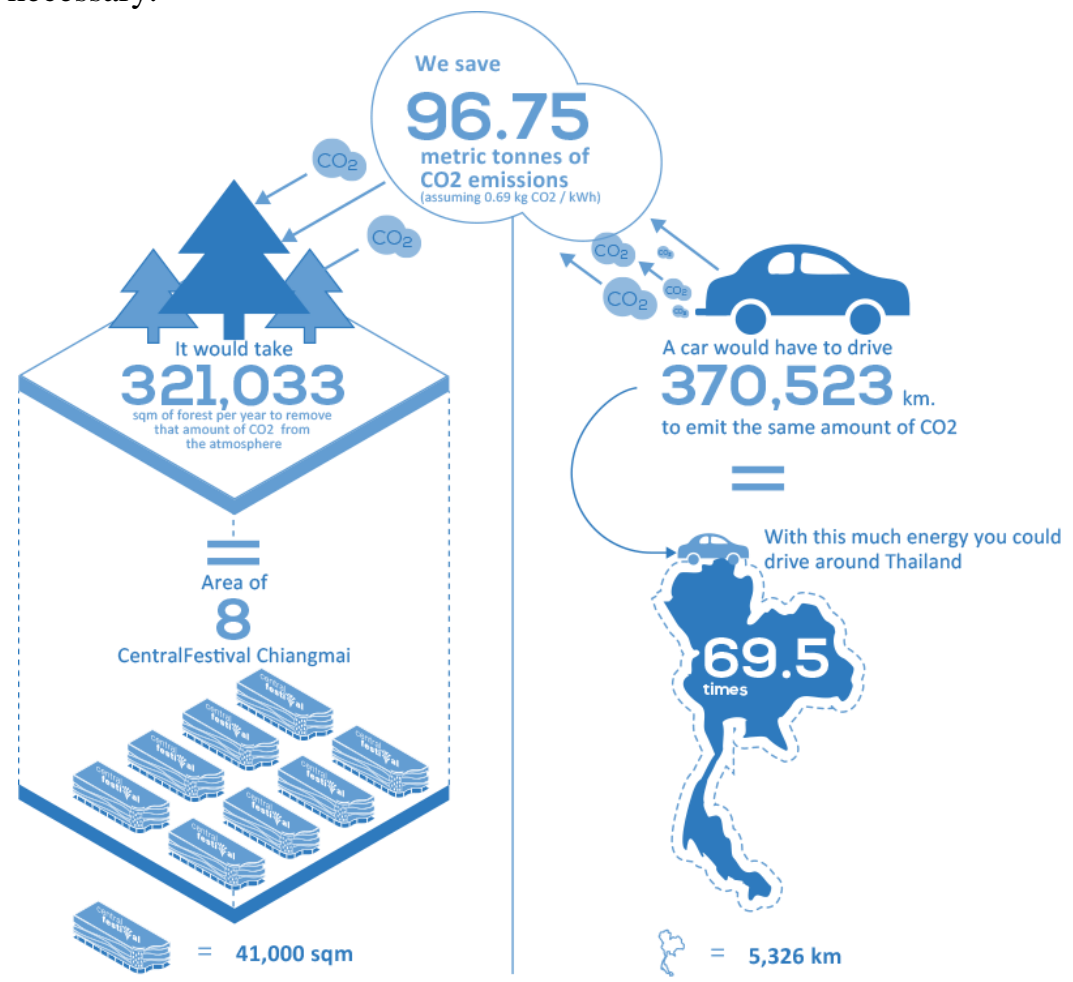

Figure A.6 - Benefits to the environment of a hydrogen-based microgrid for the case of the Phi Suea House in Thailand (http://www.phisueahouse.com/technology.php)

Nowadays, there is no competitor company that could develop an advanced controller system for hydrogen-based microgrids as HyRenCon does.

Figure A.7 shows a hydrogen-based microgrid for the real case of the Phi Suea House located in Thailand. On the left of the figure is the section that generates/consumes hydrogen (hydrogen power system). The PLC would be connected to these devices and it would control the performance of the system. There are also hydrogen tanks which store hydrogen to use in the fuel cell. The system has auxiliary batteries for certain cases in which renewable energy supplies an insufficient amount of energy. Energy sources can be different (e.g. photovoltaic panels, 
small wind turbines, hydraulic turbines, etc.). These types of microgrid have the great advantage that they do not need to be connected to the electrical network.

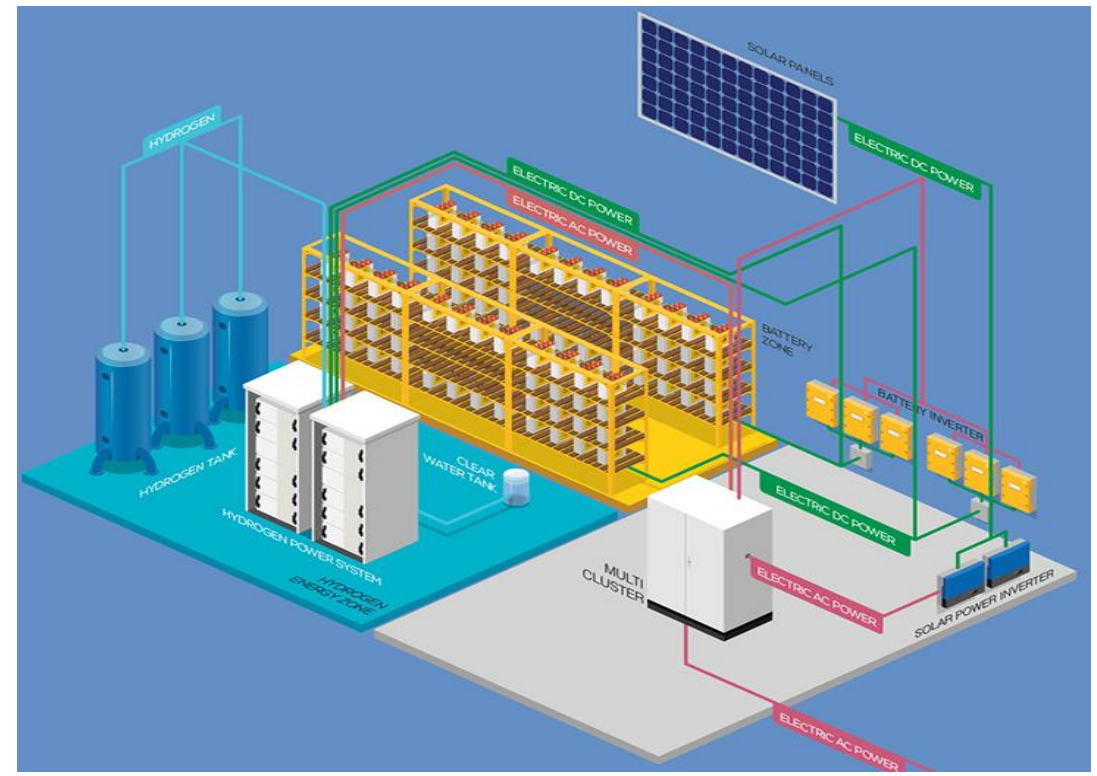

Figure A.7 - Scheme of the components of the hydrogen-based microgrid. (http://www.phisueahouse.com/technology.php)

\section{Manufacturing}

As HyRenCon produces an exclusive product, for the early years until the hydrogen economy becomes more popular, the controllers will be manufactured in a "handmade" way. That is, the PLCs will be programmed one by one, taking into account the special conditions of each client (what type of renewable energy will be used, size and capacity of the house, required power, etc.). The PLCs will be purchased from a company supplier (Siemens, Rockwell, Yokogawa, Honeywell...). Then it will be programmed and the cables will be attached so that the customer can connect the PLC to the microgrid. The PLC will be packaged and shipped via courier. 


\section{Business plan}

In this section, the business plan for HyRenCon has been estimated for the first 5 years of the company's existence using $€$ as currency. The average VAT rate of $21 \%$ has been chosen, as well as 30 days of collection and payment. Figure A.8 depicts the investment needed to create the company. In the fifth year, a purchase of land will be made to build a small industrial warehouse. An investment for machinery and transport from the second year on will be made, as in that year sales of the PLC controllers will begin to take place. A rental car will also be used. During the first year there will be an expense to create the final patent. There will also be investments each year in computer applications because the company will need computers, printers, electronic wiring, etc.

\begin{tabular}{|c|c|c|c|c|c|c|}
\hline INVESTMENTS & \begin{tabular}{l|}
$\%$ average \\
Amortiza
\end{tabular} & Year 1 & Year 2 & Year 3 & Year 4 & Year 5 \\
\hline \multicolumn{7}{|l|}{ Tangible assets } \\
\hline \multicolumn{2}{|l|}{ Land } & 0.00 & 0.00 & 0.00 & 0.00 & $10,000.00$ \\
\hline Constructions & $10 \%$ & 0.00 & 0.00 & 0.00 & 0.00 & $20,000.00$ \\
\hline Machinery & $10 \%$ & 0.00 & $2,000.00$ & $5,000.00$ & $5,000.00$ & $5,000.00$ \\
\hline Transpont & $10 \%$ & 0.00 & 500.00 & $1,000.00$ & $2,000.00$ & $4,000.00$ \\
\hline \multicolumn{2}{|l|}{ Total tangible assets } & 0.00 & $2,500.00$ & $6,000.00$ & $7,000.00$ & $39,000.00$ \\
\hline \multicolumn{7}{|l|}{ Intangible assets } \\
\hline Research and derelopment & $20 \%$ & $3,000.00$ & $1,000.00$ & $1,000.00$ & $1,000.00$ & $1,000.00$ \\
\hline Patents & $10 \%$ & $2,500.00$ & 0.00 & 0.00 & 0.00 & 0.00 \\
\hline IT tools & $10 \%$ & $1,000.00$ & $1,200.00$ & $1,200.00$ & $1,200.00$ & $1,200.00$ \\
\hline \multicolumn{2}{|l|}{ Total intangible assets } & $6,500.00$ & $2,200.00$ & $2,200.00$ & $2,200.00$ & $2,200.00$ \\
\hline Tangible assets amortianations & & 0.00 & 250.00 & 850.00 & $1,550.00$ & $4,450.00$ \\
\hline Intangible assets amortizations & & 950.00 & $1,270.00$ & $1,590.00$ & $1,910.00$ & $2,230.00$ \\
\hline
\end{tabular}

Figure A.8 - Investments for the HyRenCon company in the first five years.

Figure A.9 shows the possible funding that HyRenCon would have. It can be seen that, during the first and second years, the promoting team will provide funding to begin with the commercialization of the equipment. There will also be subsidies every year given by the Junta de Castilla y León (the regional government), county councils and young entrepreneur's prizes. A long-term loan will be contracted in the second $(50,000 €)$ and fifth year $(5,000 €)$ to finance the cost of building the industrial warehouse (to be returned in 4 and 2 years with 5\% interest respectively). 


\begin{tabular}{|c|c|c|c|c|c|}
\hline$F I N A N C I N G$ & Year 1 & Year 2 & Year 3 & Year 4 & Year 5 \\
\hline \multicolumn{6}{|l|}{ OWN FINANCING } \\
\hline Monetary contributions & $1,000.00$ & $2,000.00$ & 0.00 & 0.00 & 0.00 \\
\hline Non-refundable subsidies & $5,000.00$ & $5,000.00$ & $1,000.00$ & $1,000.00$ & $1,000.00$ \\
\hline Investment subsidies & $2,000.00$ & 500.00 & 500.00 & 500.00 & 500.00 \\
\hline
\end{tabular}

\begin{tabular}{|l|r|r|r|r|r|}
\hline EXTERNAL FINANCING & \multicolumn{1}{|l|}{} \\
\hline Long Term Bank Loans & \multicolumn{1}{|l|}{} \\
\hline Amount $(\ell)$ & 0.00 & $50,000.00$ & 0.00 & 0.00 & $5,000.00$ \\
\hline Rate of interest \% & $0.00 \%$ & $5.00 \%$ & $0.00 \%$ & $0.00 \%$ & $5.00 \%$ \\
\hline Term in years & 0.00 & 4.00 & 0.00 & 0.00 & 2.00 \\
\hline Short Term Bank Loans & & & & & \\
\hline Amount $(€)$ & 0.00 & 0.00 & 0.00 & 0.00 & 0.00 \\
\hline Rate of interest \% & $0.00 \%$ & $0.00 \%$ & $0.00 \%$ & $0.00 \%$ & $0.00 \%$ \\
\hline Term in montbs & 0.00 & 0.00 & 0.00 & 0.00 & 0.00 \\
\hline & & & & & \\
\hline Financial expenses & 0.00 & $2,500.00$ & $1,919.97$ & 0.00 & 250.00 \\
\hline
\end{tabular}

Figure A.9 - Financing for the HyRenCon company in the first five years.

Figure A.10 depicts sales and revenue. It is considered that the controllers start selling in the second year. The price of each unit will be $1,000 €$, so it is estimated that 7 units are sold the second year, 25 units the third, 50 units the fourth and 95 units the fifth year.

\begin{tabular}{|c|c|c|c|c|c|}
\hline$S A L E S-R E V E N U E$ & Year 1 & Year 2 & Year 3 & Year 4 & Year 5 \\
\hline Controllers & 0.00 & $7,000.00$ & $25,000.00$ & $50,000.00$ & $95,000.00$ \\
\hline & 0.00 & 0.00 & 0.00 & 0.00 & 0.00 \\
\hline & 0.00 & 0.00 & 0.00 & 0.00 & 0.00 \\
\hline & & 0.00 & 0.00 & 0.00 & 0.00 \\
\hline & 0.00 & 0.00 & 0.00 & 0.00 & 0.00 \\
\hline Total sales & 0.00 & $7,000.00$ & $25,000.00$ & $50,000.00$ & $95,000.00$ \\
\hline
\end{tabular}

\begin{tabular}{|c|c|c|c|c|c|}
\hline Other revenues & & & & & \\
\hline Other operating income & 0.00 & 0.00 & 0.00 & $1,000.00$ & $1,000.00$ \\
\hline Exceptional income & 0.00 & 0.00 & 0.00 & 500.00 & 800.00 \\
\hline Investment subsidies receired & 292.31 & 352.95 & 409.04 & 464.48 & 503.56 \\
\hline TOTAL REVENUES & 292.31 & $7,352.95$ & $25,409.04$ & $51,964.48$ & $97,303.56$ \\
\hline
\end{tabular}

Figure A.10 - Sales for the HyRenCon company in the first five years. 
Purchases and expenses are shown in Figure A.11. They basically consist of the PLCs and cable purchases.

It has been considered that over the years the price per unit of each PLC will decrease, as they would be purchased wholesale. There would be shipping costs, which would be proportional to the PLC purchases. There would also be bank charges as well as marketing and start-up expenses. These expenses are associated with the registration of fairs, printing of brochures, maintenance of the web, etc.

\begin{tabular}{|c|c|c|c|c|c|}
\hline PURCHASES & Year 1 & Year 2 & Year 3 & Year 4 & Year 5 \\
\hline \multirow[t]{5}{*}{ PLCs } & 0.00 & $1,000.00$ & $3,600.00$ & $6,000.00$ & $10,000.00$ \\
\hline & 0.00 & 0.00 & 0.00 & 0.00 & 0.00 \\
\hline & 0.00 & 0.00 & 0.00 & 0.00 & 0.00 \\
\hline & 0.00 & 0.00 & 0.00 & 0.00 & 0.00 \\
\hline & 0.00 & 0.00 & 0.00 & 0.00 & 0.00 \\
\hline Total purchases & 0.00 & $1,000.00$ & $3,600.00$ & $6,000.00$ & $10,000.00$ \\
\hline
\end{tabular}

\begin{tabular}{|l|r|r|r|r|r|}
\hline External services & \multicolumn{2}{|l|}{} \\
\hline Shipping & 0.00 & 300.00 & 600.00 & $1,200.00$ & $3,000.00$ \\
\hline Bank services & 100.00 & 120.00 & 120.00 & 120.00 & 120.00 \\
\hline Marketing & 0.00 & $2,000.00$ & $1,500.00$ & $2,500.00$ & $2,500.00$ \\
\hline Travel expenses & 500.00 & $2,500.00$ & $2,500.00$ & $3,000.00$ & $3,500.00$ \\
\hline Start-up expenses & 300.00 & 500.00 & 500.00 & 500.00 & 500.00 \\
\hline Total external services & $\mathbf{9 0 0 . 0 0}$ & $\mathbf{5 , 4 2 0 . 0 0}$ & $\mathbf{5 , 2 2 0 . 0 0}$ & $\mathbf{7 , 3 2 0 . 0 0}$ & $\mathbf{9 , 6 2 0 . 0 0}$ \\
\hline
\end{tabular}

Figure A.11 - Purchases for the HyRenCon company in the first five years.

The staff costs are shown in Figure A.12. Álvaro Serna would be the only one of the 3 members of HyRenCon that would work full time. His salary would be 17,000 €/year. Each of the other two partners would charge 1,500 €/year. There would be social security costs, which are estimated at 5,000 €/year. 


\section{HYRENCON}

\begin{tabular}{|l|r|r|r|r|r|}
\hline STAFF COSTS & Year 1 & Year 2 & Year 3 & Year 4 & \multicolumn{1}{c|}{ Year 5 } \\
\hline \begin{tabular}{|l|r|r|r|r|r|}
\hline W ages and salaries & $20,000.00$ & $20,000.00$ & $20,000.00$ & $20,000.00$ & $20,000.00$ \\
\hline Social security & $5,000.00$ & $5,000.00$ & $5,000.00$ & $5,000.00$ & $5,000.00$ \\
\hline \multicolumn{1}{|l|}{} & & & \\
\hline Staff costs & $25,000.00$ & $25,000.00$ & $25,000.00$ & $25,000.00$ & $25,000.00$ \\
\hline
\end{tabular}
\end{tabular}

Figure A.12 - Staff costs for the HyRenCon company in the first five years.

Gains and losses over 5 years are shown in Figures A.13 and A.14. It can be seen that, from the third year, the company starts producing profits. This makes sense as the hydrogen economy will become more common over the years and therefore final users would install hydrogenbased microgrids in their houses.

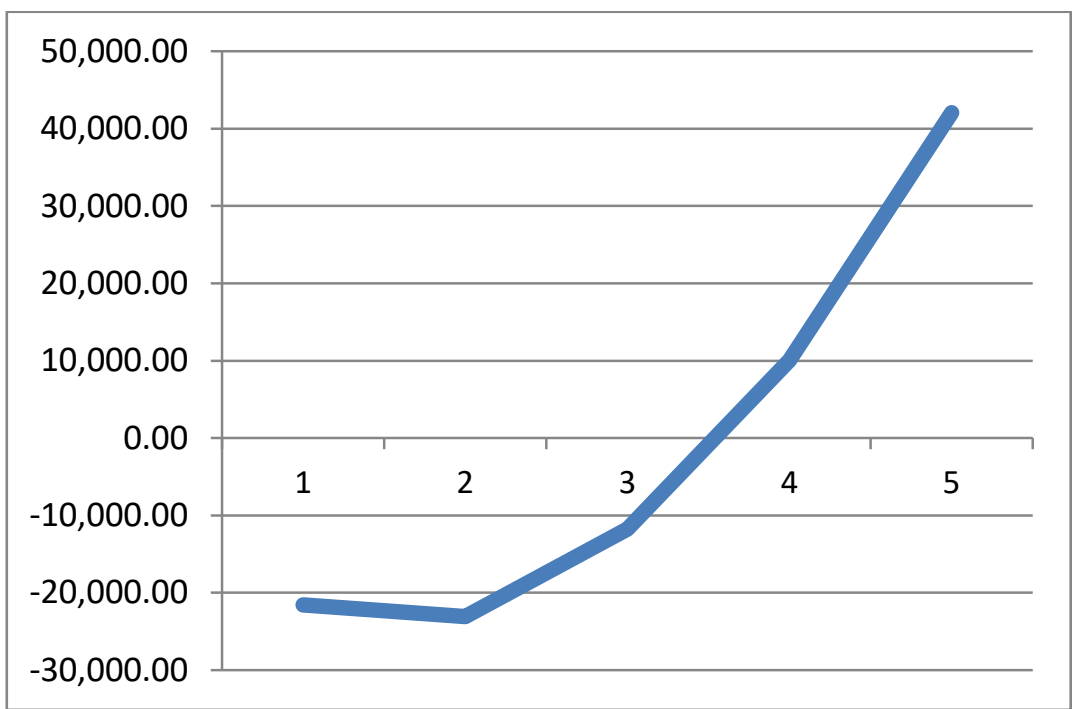

Figure A.13 - Gains and losses over the first five years 
Gains and Losses

\begin{tabular}{|c|c|c|c|c|c|c|}
\hline & \multicolumn{2}{|l|}{ HYRENCON } & \multirow[b]{2}{*}{ Year 2} & \multirow[b]{2}{*}{ Year 3} & \multirow[b]{2}{*}{ Year 4} & \multirow[b]{2}{*}{ Year 5} \\
\hline & & Year 1 & & & & \\
\hline \multirow[t]{2}{*}{ Benefits } & & & & & & \\
\hline & Sales & 0.00 & $7,000.00$ & $25,000.00$ & $50,000.00$ & $95,000.00$ \\
\hline \multirow[t]{2}{*}{ Supplies } & & & & & & \\
\hline & Purchases & 0.00 & $-1,000.00$ & $-3,600.00$ & $-6,000.00$ & $-10,000.00$ \\
\hline \multirow[t]{3}{*}{ Other incomes } & & & & & & \\
\hline & Other operating income & 0.00 & 0.00 & 0.00 & $1,000.00$ & $1,000.00$ \\
\hline & Non-refundable subsidies & $5,000.00$ & $5,000.00$ & $1,000.00$ & $1,000.00$ & $1,000.00$ \\
\hline \multirow[t]{2}{*}{ Staff costs } & & & & & & \\
\hline & Staff costs & $-25,000.00$ & $-25,000.00$ & $-25,000.00$ & $-25,000,00$ & $-25,000.00$ \\
\hline \multirow[t]{6}{*}{ External services } & & & & & & \\
\hline & Shipping & 0.00 & -300.00 & -600.00 & $-1,200.00$ & $-3,000.00$ \\
\hline & Bank services & -100.00 & -120.00 & -120.00 & -120.00 & -120.00 \\
\hline & Marketing & 0.00 & $-2,000.00$ & $-1,500.00$ & $-2,500.00$ & $-2,500.00$ \\
\hline & Travel expenses & -500.00 & $-2,500.00$ & $-2,500.00$ & $-3,000.00$ & $-3,500.00$ \\
\hline & Start-up expenses & -300.00 & -500.00 & -500.00 & -500.00 & -500.00 \\
\hline \multicolumn{7}{|c|}{ Amortization of property, plant, equipment } \\
\hline & Depreciation and amortization & -950.00 & $-1,520.00$ & $-2,440.00$ & $-3,460.00$ & $-6,680.00$ \\
\hline \multicolumn{7}{|c|}{ Non-financial fixed subsidies } \\
\hline \multirow{3}{*}{ Other resulsts } & Investment subsidies & 292.31 & 352.95 & 409.04 & 464.48 & 503.56 \\
\hline & & & & & & \\
\hline & Exceptional income & 0.00 & 0.00 & 0.00 & 500.00 & 800.00 \\
\hline \multicolumn{2}{|c|}{ OPERATING PROFIT } & $-21,557.69$ & $-20,587.05$ & $-9,850.96$ & $11,184.48$ & $47,003.56$ \\
\hline & Financial expenses & 0.00 & $-2,500.00$ & $-1,919.97$ & 0.00 & -250.00 \\
\hline \multirow{2}{*}{\multicolumn{2}{|c|}{$\begin{array}{l}\text { FINANCIAL RESULTS } \\
\text { RESULT BEFORE TAXES }\end{array}$}} & 0.00 & $-2,500.00$ & $-\mathbf{1 , 9 1 9 . 9 7}$ & 0.00 & -250.00 \\
\hline & & \begin{tabular}{|l|}
$-21,557.69$ \\
\end{tabular} & $-23,087.05$ & $-11,770.96$ & $11,184.48$ & $46,753.56$ \\
\hline & Income tax & 0.00 & 0.00 & 0.00 & $-1,118.45$ & $-4,676.36$ \\
\hline GAINS OR LOSS & SES AFTER TAXES & $-21,557.69$ & $-23,087.05$ & $-11,770.96$ & $10,066.03$ & $42,078.20$ \\
\hline
\end{tabular}

Figure A.14 - Detailed gains and losses for the HyRenCon company in the first five years.

\section{CONCLUSIONS}

In this annex an economic study for a marketable self-supplied hydrogen-based microgrid powered by renewable energies has been detailed. The main conclusions of this study are the following:

- The study of the market of this type of microgrids gives a great potential for implementation in autonomous isolated houses as different renewable sources can be integrated with the microgrid.

- The Business Model Canvas developed in the annex depicts in a visual manner the most important ideas which should be considered 
before creating a company (the value proposal, customers, financing and infrastructure).

- $\quad$ The marketing plan of the proposed company HyRenCon shows the internal analysis of the company with the drawbacks that must be overcome before starting to manufacture the product.

- The business plan shows monetary gains from the third year of the company's creation, so it can be considered as profitable. 